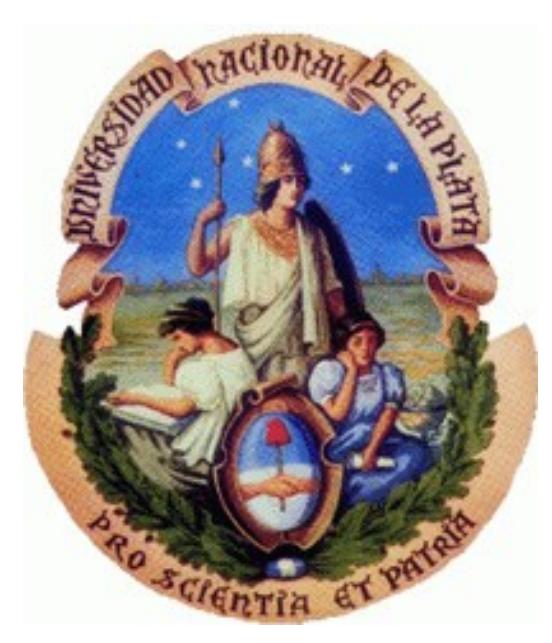

\title{
Evaluación de la Calidad de Gobierno de Tecnologías y Sistemas de Información Basada en Valor
}

\author{
AUTOR (UFA-ESPE): Vicente Merchán Rodríguez \\ DIRECTORA (UNLP): Dra. Claudia Pons \\ CO-DIRECTORA (UNLaM): Dra. Rocío Andrea Rodríguez
}

Tesis presentada para obtener el grado de

Doctor en Ciencias Informáticas

Facultad de Informática

Universidad Nacional de La Plata

Septiembre 2017 



\section{RESUMEN}

La calidad es una aspiración y al mismo tiempo una preocupación constante, más aún cuando de por medio se encuentra la procura de la satisfacción y la entrega de valor. Es una aspiración, un reconocimiento, un objetivo muy complejo y al mismo instante muy sencillo de cumplir. Pues, ¿A quién no le gusta que le cumplan los compromisos?.

La calidad es un grado de excelencia, y lo excelente es eternamente nuevo. Para un gobierno corporativo, en sentido general, sus objetivos de calidad siempre estarán enfocados en alcanzar eficiencia y eficacia en todos sus niveles de administración y áreas funcionales. Lograr la calidad para un gobierno que se enfoca en las Tecnologías y los Sistemas de Información (TSI) es un reto, porque los líderes organizacionales cada vez más esperan que los líderes de TSI innoven y entreguen valor en toda la organización y, al mismo tiempo, apoyen con la operación al máximo nivel; es decir, buscando el balance perfecto.

La calidad se ha constituido en una meta de muchos países. En Ecuador, la Constitución establece que la administración pública se rige por principios, entre otros: el de calidad. Esto involucra la participación conjunta de las personas que aseguren el accionar en el contexto organizacional. La calidad incide sobre las personas, las actividades, los procesos y los resultados; todo orientado hacia la excelencia.

Tomando en cuenta que las TSI se han constituido en el aliado estratégico de las instituciones públicas, entonces es vital propiciar que el equipo que las gobierna actúe con calidad. Al respecto el estándar ISO/IEC 38500 de Gobierno de la Tecnología de la Información propone un conjunto de principios orientadores para los administradores de las organizaciones en cuanto al uso eficiente y eficaz de la tecnología en sus organizaciones, pero entendiéndose como un aporte a la mejora de la calidad. Por ello es oportuno identificar con adecuado criterio las relaciones entre estándares de gobierno y modelos de excelencia, los criterios y sub-criterios que derivarían y como formarían parte de un modelo de calidad.

La presente tesis doctoral aborda la calidad como un medio de investigación en el contexto del Gobierno de Tecnologías y Sistemas de Información (GoTSI) basada en valor, desde un punto de vista específico y exhaustivo, con perspectiva de dirección estratégica organizacional. Este abordaje se siente corroborado por un estudio comparativo y una revisión sistemática de la literatura llevados a cabo al inicio de la investigación doctoral.

Entonces se propone un Modelo de Calidad de GoTSI Basada en Valor, denominado por sus siglas en inglés VBISTGQM (Valued-Based Information System Technology Governance Quality Model). El modelo incluye contenidos de trabajos previos, del modelo iberoamericano de excelencia y el estándar ISO/IEC 38500. Este modelo puede ser utilizado como un instrumento de medición y valoración de uso flexible y adaptable a los nuevos criterios que emergen de la dinámica del entorno, de igual manera adaptable a cada organización de TSI. El modelo define seis criterios, nueve sub-criterios y treinta y cuatro dimensiones; estas se valoran mediante cinco componentes catalogados como evidencias en la era del conocimiento, los mismos que en su conjunto inciden en la toma de decisiones de un Gobierno de Valor de TSI. Luego, cada uno de los sub-criterios y criterios de evaluación son analizados mediante tres niveles jerárquicos ponderados que permiten cuantificar la medida de sub-criterio, criterio y del GoTSI. 
En líneas generales se acompaña al modelo varias fases para realizar la autoevaluación, en donde el producto final es un informe que reporta los aspectos fuertes y débiles, así como, los aspectos que necesitan mejorar.

Para la operacionalización y afianzamiento del modelo, se llevaron a cabo varios análisis estadísticos que han permitido contrastar hipótesis, verificar errores y la consistencia de las respuestas que expresaron 62 líderes y directivos ecuatorianos con experiencia en el desarrollo de estrategias relacionadas con el uso de las TSI. Los resultados demuestran un modelo conceptual confiable.

Finalmente, con diez supuestos participantes se presenta la funcionalidad del modelo de calidad.

PALABRAS CLAVES: Gobierno de Tecnologías y Sistemas de Información, ISO/IEC 38500, Calidad, Liderazgo, Estrategias, Personas, Recursos, Procesos, Proyectos, Valor, Excelencia. 



\section{DEDICATORIA}

Dedicado a mi amada esposa Mirian, a mis hijos: Rolando y Sofía;

A mi madre, abuela y suegra;

Los amo mucho. 


\section{AGRADECIMIENTOS}

Antes que nada, quiero expresar mi sincero agradecimiento a la Secretaria de Educación Superior, Ciencia, Tecnología e Innovación SENESCYT de Ecuador por la oportunidad brindada a través de la financiación entregada con el programa de becas docentes, sin la cual indudablemente habría sido imposible enfrentar este reto académico y de investigación.

Este trabajo doctoral resume el esfuerzo, compromiso y responsabilidad de cuatro años de trabajo, que pasaron a buen ritmo, y siento que no habría sido así sin la interacción con muchas personas que de manera directa e indirecta me apoyaron y soportaron. A ellos y ellas de manera individual.

A mi esposa e hijos, quienes han sido el apoyo y compañía en todo momento. Además, a mi madre y (en memoria) a mi padre.

A la Universidad Nacional de La Plata, a través de sus autoridades, quienes resolvieron por unanimidad aceptar esta propuesta de trabajo; $y$, al personal administrativo, por su magnífica labor y filosofía de servicio.

A la Dra. Rocío Rodríguez, excelente catedrática e investigadora, quién de manera amable y siempre con sentido de agilidad atendió mis avances; quién motivó mi trabajo capítulo a capítulo; quién brindó las pautas y su buen criterio para empezar y estructurar todo el documento. Además, por haberme hecho parte de su equipo de investigación como investigador externo de la Universidad Nacional de La Matanza.

A la Dra. Claudia Pons, quién desde el primer momento analizó mi requerimiento de investigación y no dudó en apoyarlo; quién brindó las facilidades académicas y de investigación en la UNLP para que la meta de investigación se cumpliera. Además, quién a pesar de sus múltiples actividades de cátedra e investigación se preocupó por mi avance académico.

A todos mis profesores de los cursos doctorales, en especial a Elsa Estévez, Luis Olsina, Alejandro Fernández y Claudia Pons, quienes me compartieron su conocimiento más allá del aula.

Al grupo de expertos en ISO/IEC 38500, en especial al Dr. Carlos Juiz y Prof. Mark Toomey, quienes brindaron las pautas precisas para entender la naturaleza abstracta de este tema y en ofrecer su potencial conocimiento para desplegar cursos y/o conferencias de interés común.

Al Ing. Jaime Hernández, experto en temas de arquitectura empresarial y $\mathrm{TI}$, quién brindó su conocimiento y aporte en el desarrollo de un trabajo de investigación que se publicó en un journal de alto impacto.

Al Ing. Juan Ortiz, experto certificado en gobierno de TI, quién brindó su soporte incondicional en el desarrollo de esta investigación. Y a quién hipoteco mi apoyo cuando se decida emprender su formación doctoral.

Al Ing. Andrés Moya, quién mediante su equipo de investigación apoyó en la obtención de datos reales de las entidades colaboradoras y que fueron vitales para la validación operativa del modelo propuesto. 
A la Universidad de la Fuerzas Armadas ESPE, a través de las autoridades del Departamento de Ciencias de la Computación, quienes facilitaron mi movilidad para asistir a congresos y/o cursos doctorales.

A los contactos de las instituciones públicas de Ecuador que se crearon con motivo de este trabajo doctoral, quienes compartieron puntos de vista y reflexiones como aporte.

A mi compañero de doctorado, Alberto Belalcázar. Alberto comprendió la importancia de desarrollar sinergias de trabajo a fin de sortear obstáculos que se iban presentando en el camino. Comprendió, además, que toda idea es útil cuando se utiliza para resolver un problema real en nuestra formación doctoral.

A todas aquellas personas que de alguna manera estuvieron a mi lado con palabras de aliento y apoyo incondicional; les entrego mi gratitud. Muchas gracias!!. 


\section{INDICE DE CONTENIDOS}

\section{CAPÍTULO 1 - INTRODUCCIÓN}

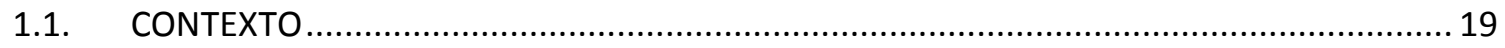

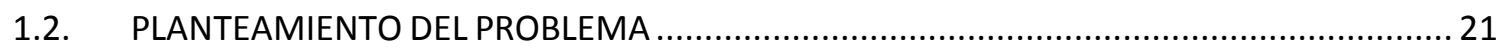

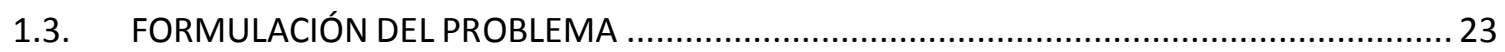

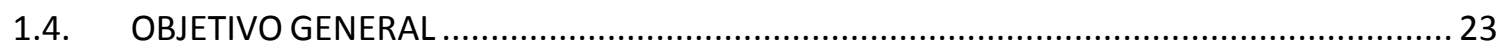

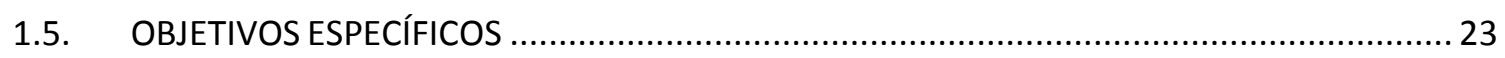

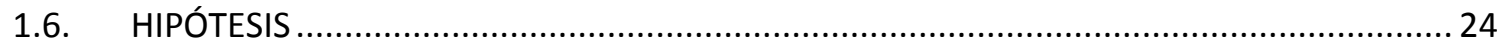

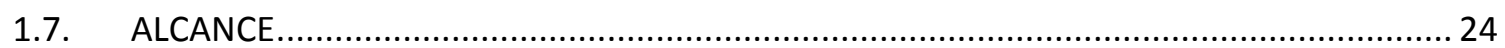

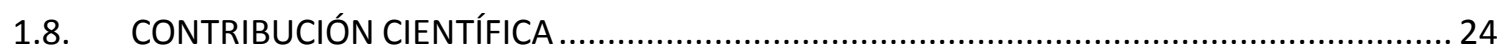

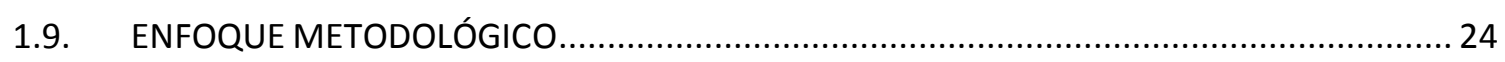

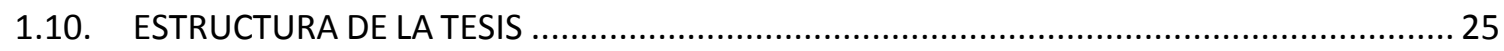

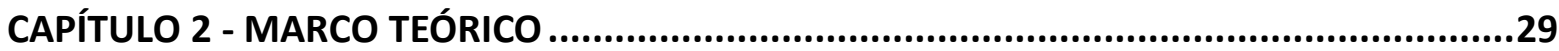

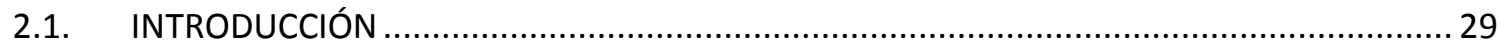

2.2. LA CALIDAD

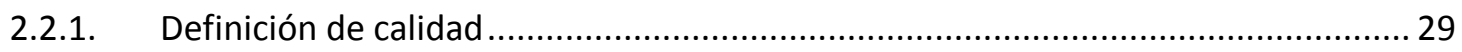

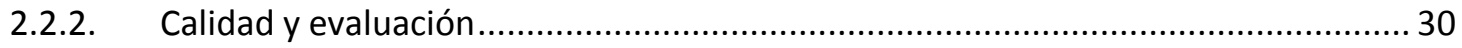

2.2.3. La calidad en el ámbito empresarial de las TSI ....................................................... 31

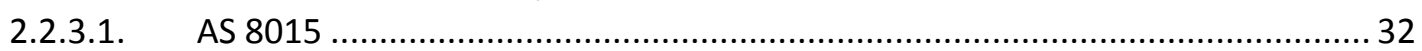

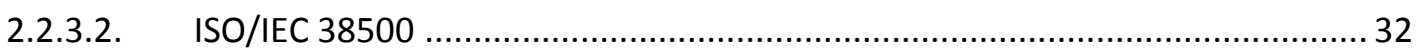

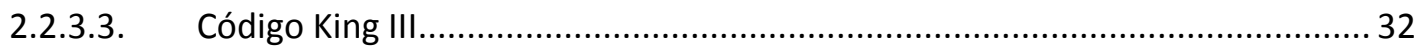

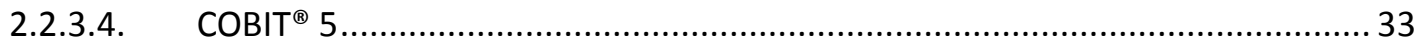

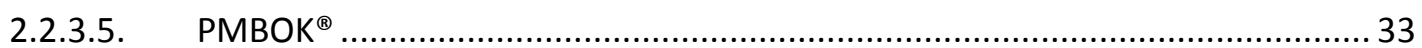

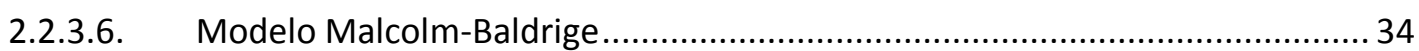

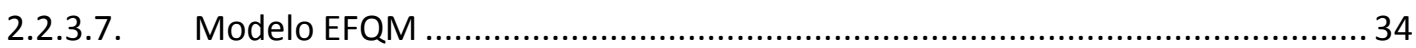

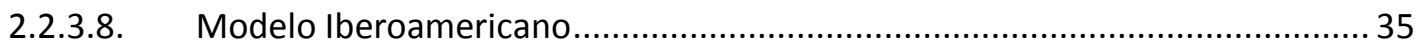

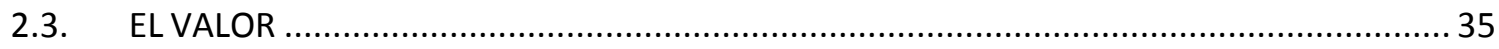

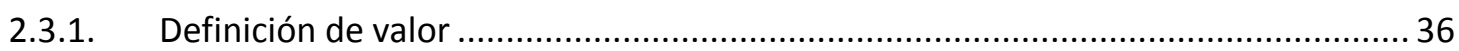

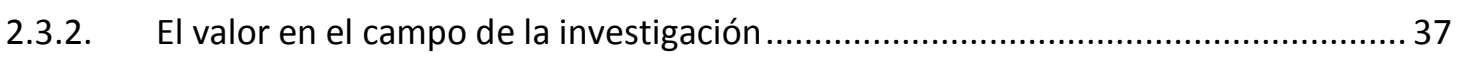

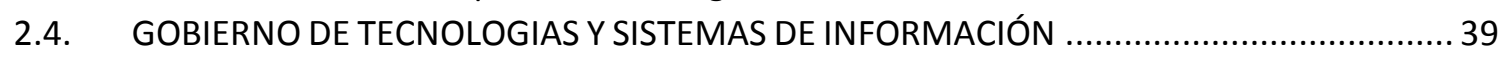

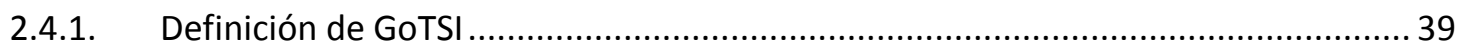

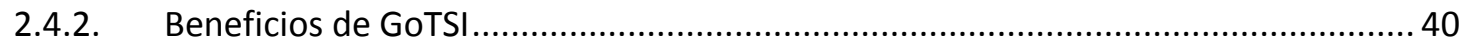

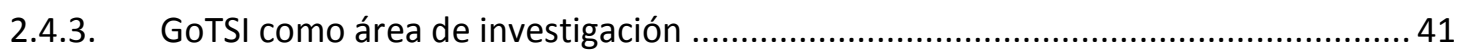

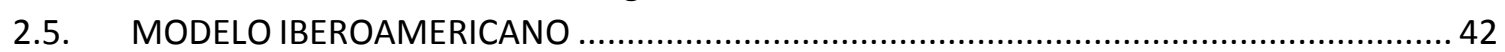

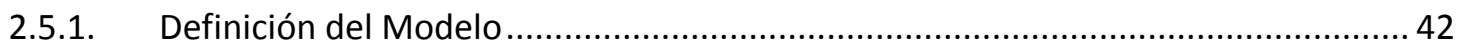

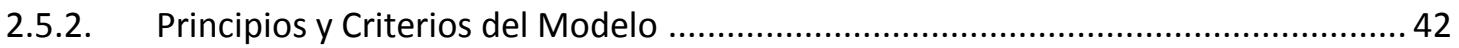

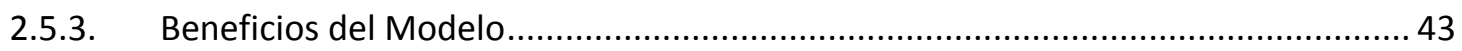

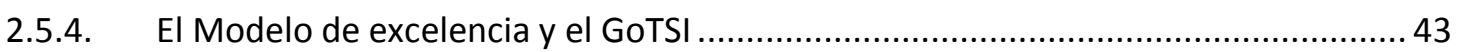

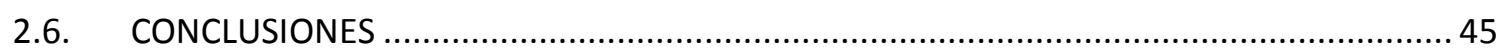

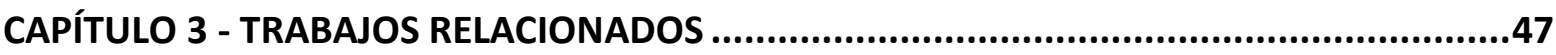

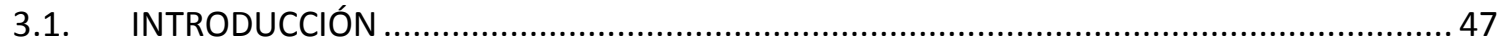

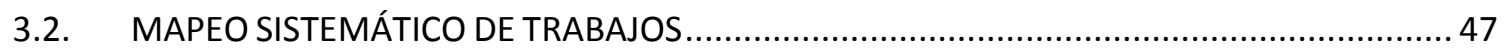

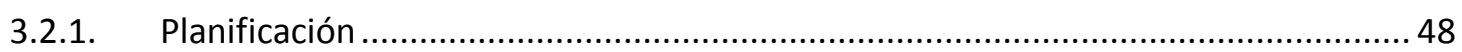




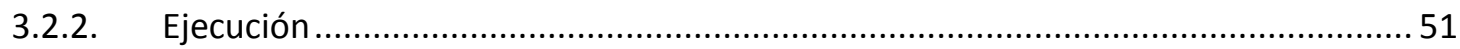

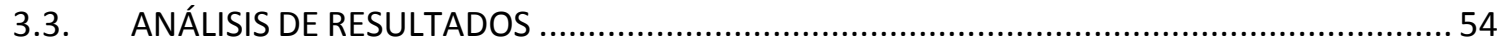

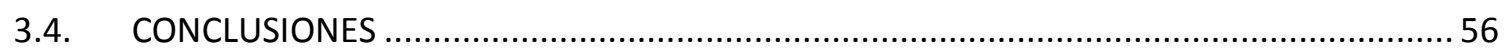

CAPÍTULO 4 - ELABORACIÓN DEL MODELO DE EVALUACIÓN (VBISTGQM) ........................57

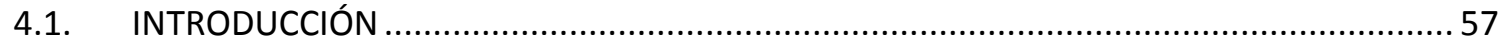

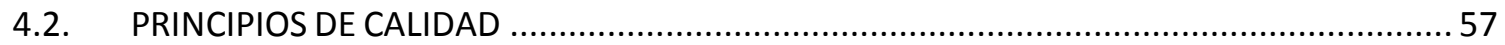

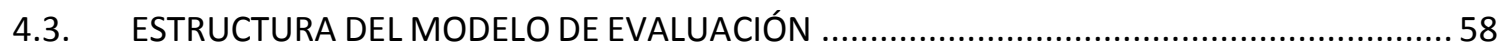

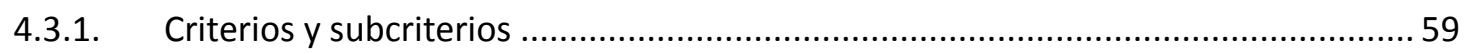

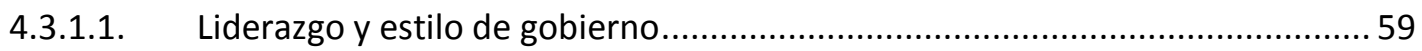

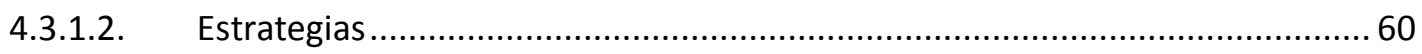

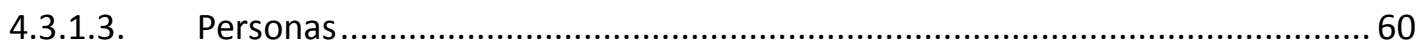

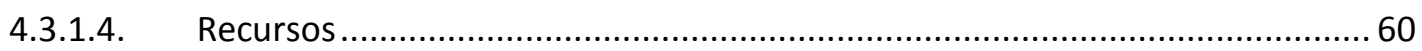

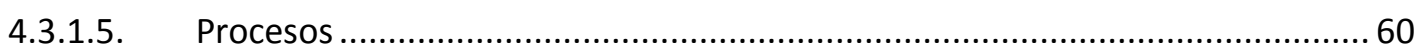

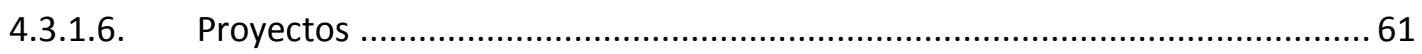

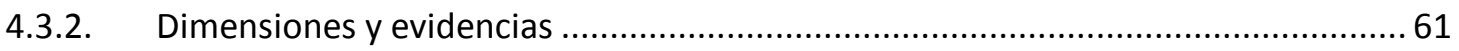

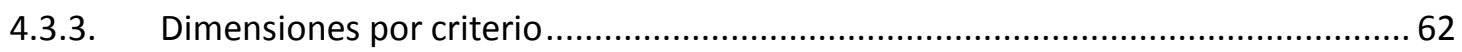

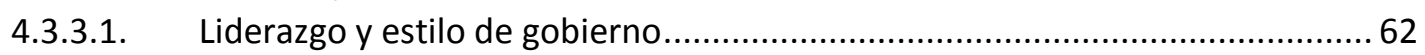

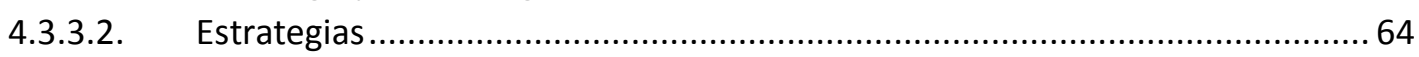

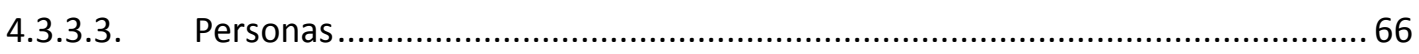

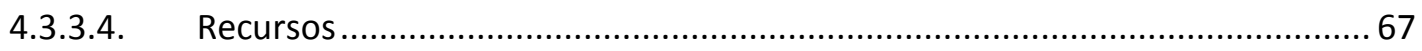

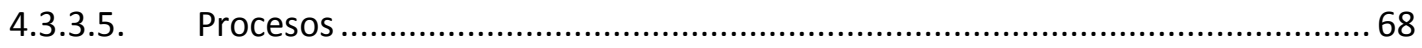

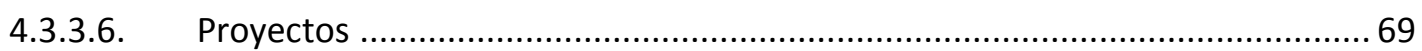

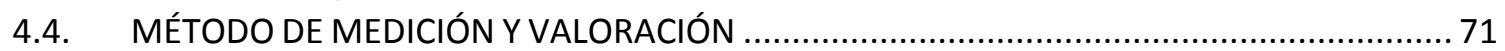

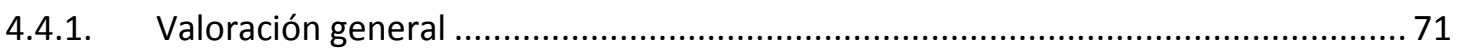

4.4.2. Valoración de las dimensiones, sub-criterios y criterios ....................................... 72

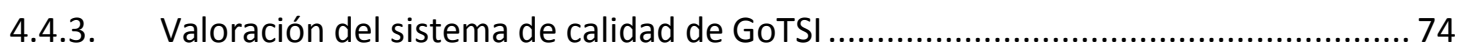

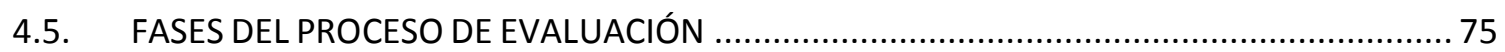

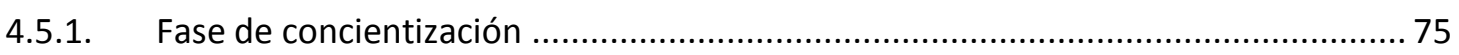

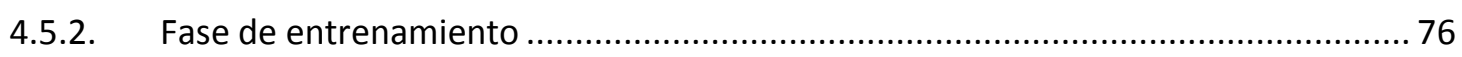

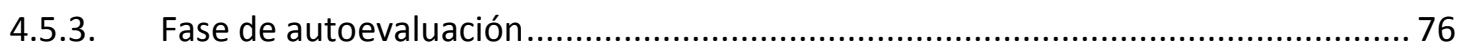

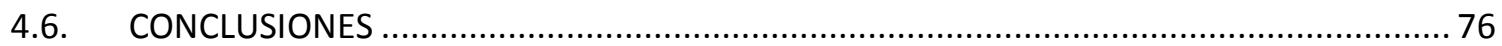

CAPÍTULO 5 - VALIDACIÓN EMPÍRICA DEL MODELO DE CALIDAD (VBISTGQM) ...............79

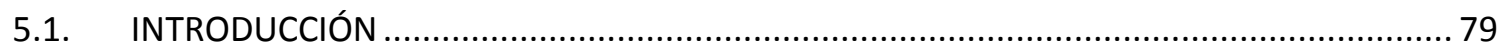

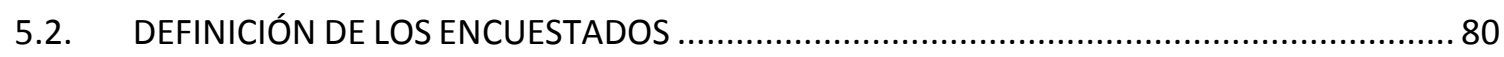

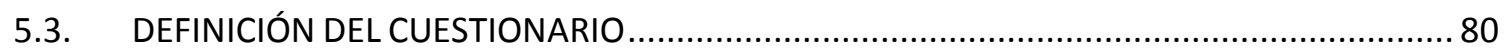

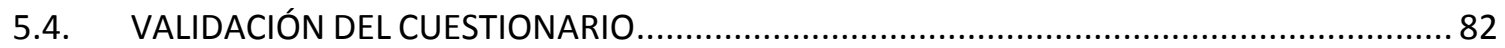

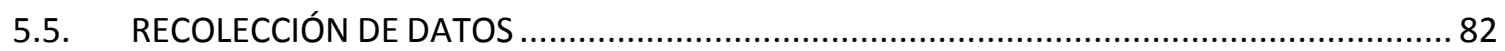

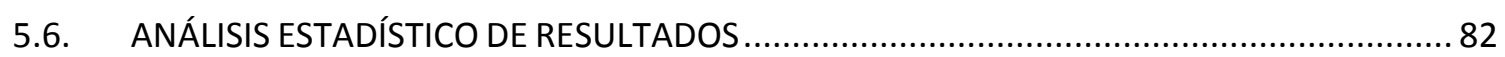

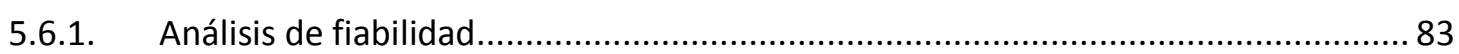

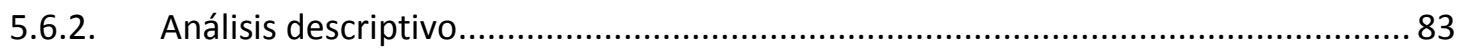

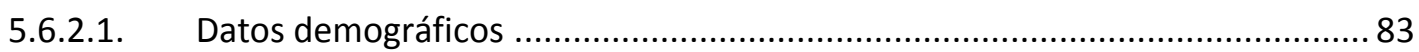

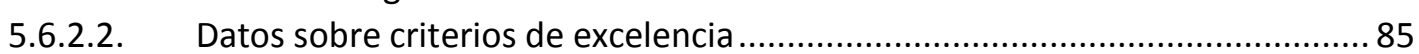

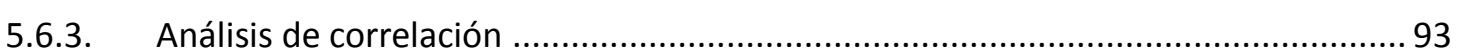

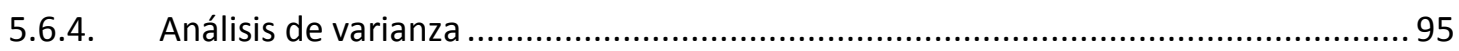

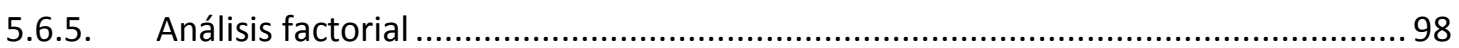

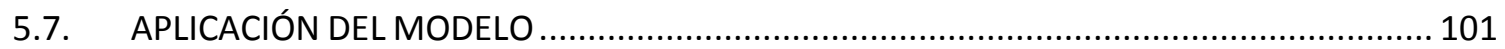

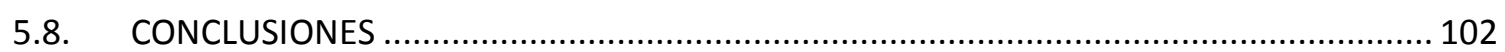


CAPÍTULO 6 - CONCLUSIONES Y TRABAJOS FUTUROS

105

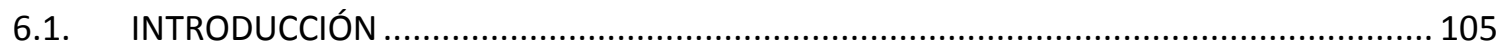

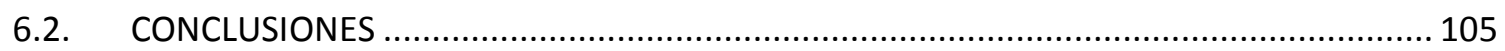

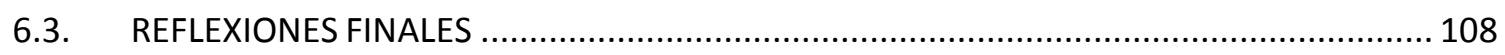

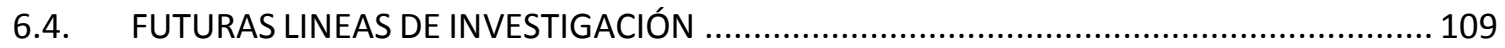

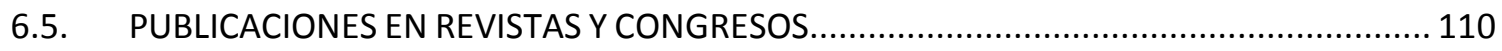

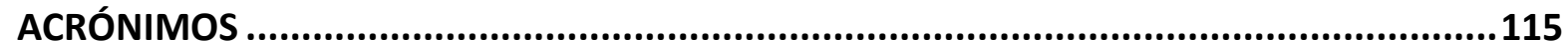

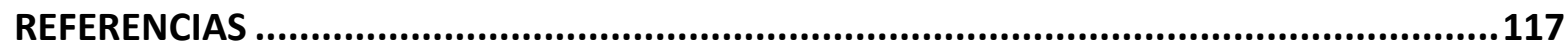

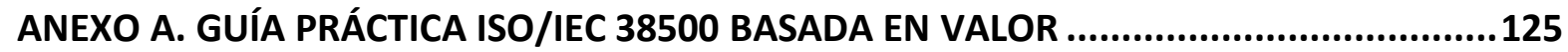

ANEXO B. ESTUDIOS SELECCIONADOS..............................................................129

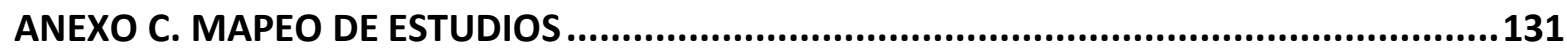

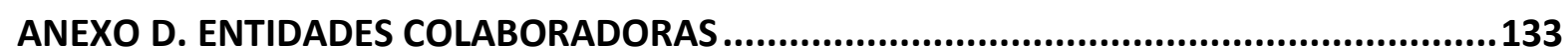

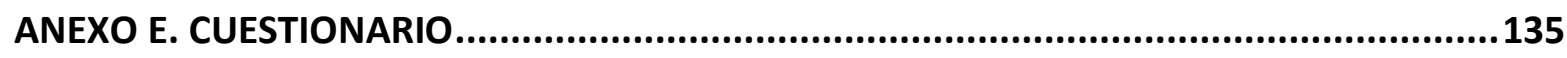

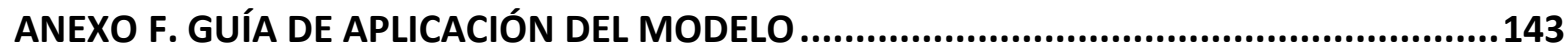





\section{INDICE DE FIGURAS}

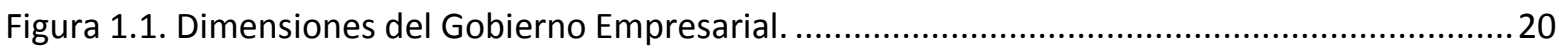

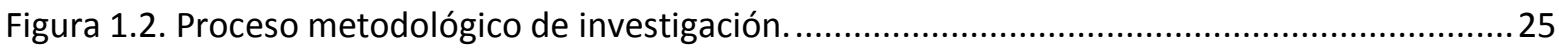

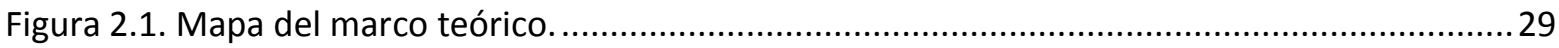

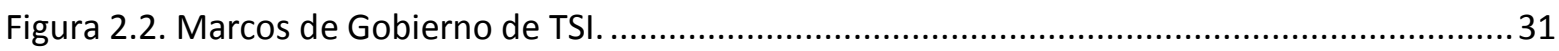

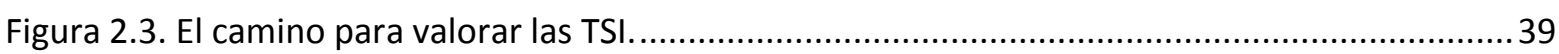

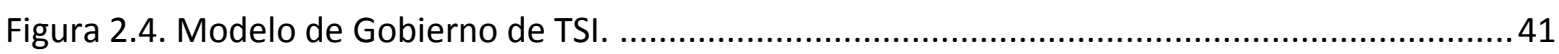

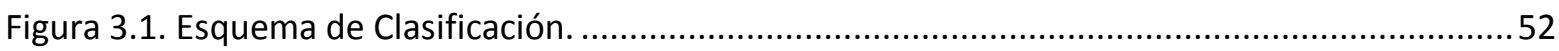

Figura 3.2. Diagrama de Burbuja. Mapeo sistemático de resultados obtenidos...............................53

Figura 3.3. Diagrama Circular. a) Ámbito de aplicación. b) Tipo de estudio......................................53

Figura 3.4. Frecuencia de trabajos seleccionados, por año de publicación. .........................................54

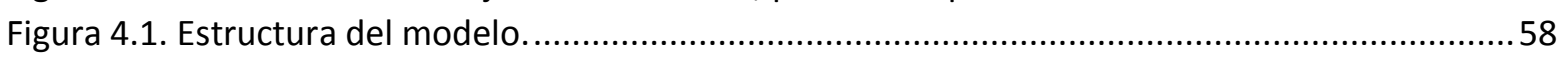

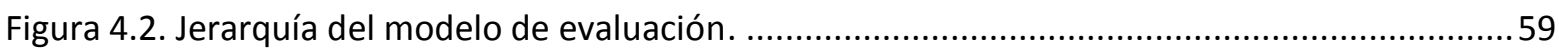

Figura 4.3. Estructura del criterio de Liderazgo y estilo de gobierno. ............................................62

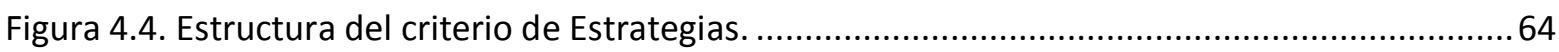

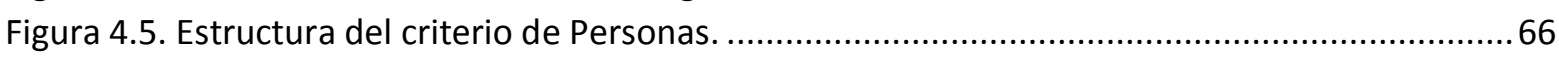

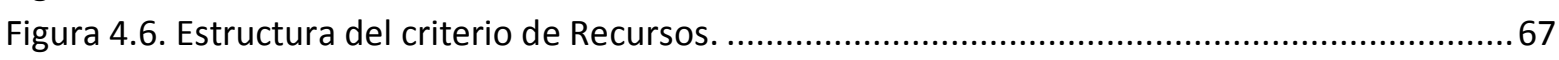

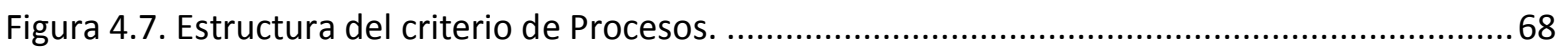

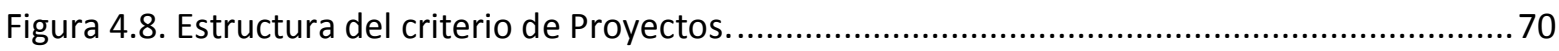

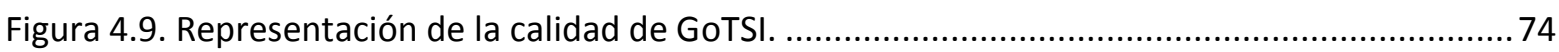

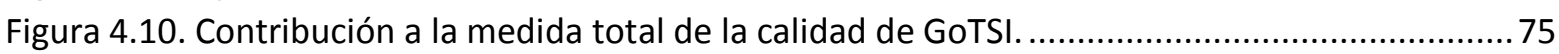

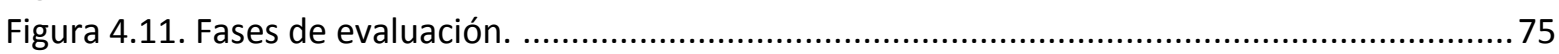

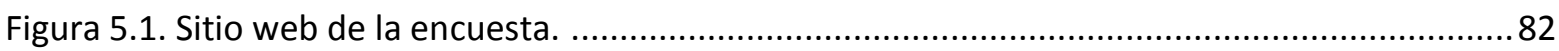

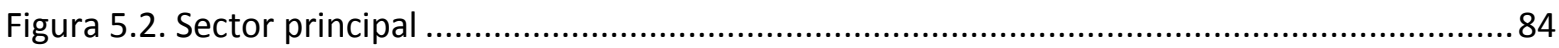

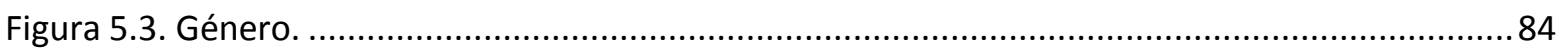

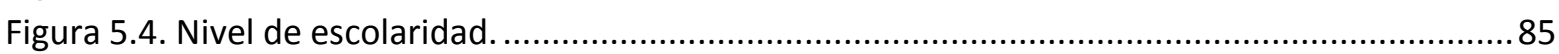

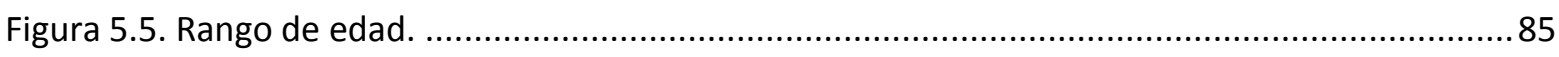

Figura 5.6. Liderazgo y estilo de gobierno. a) Cultura de Excelencia. b) Arquitectura Empresarial-

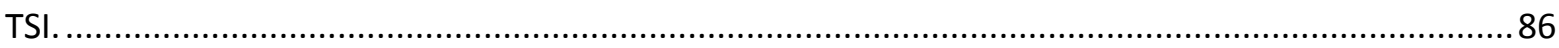

Figura 5.7. Estrategias. a) Dirección de estrategias. b) Evaluación de estrategias. ..............................87

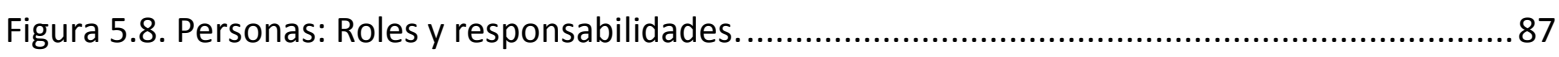

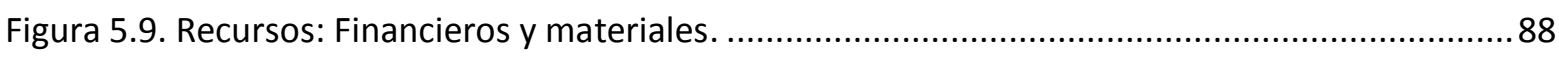

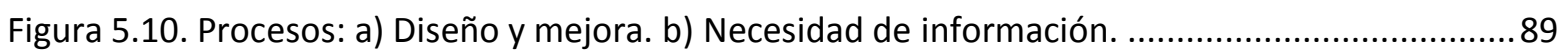

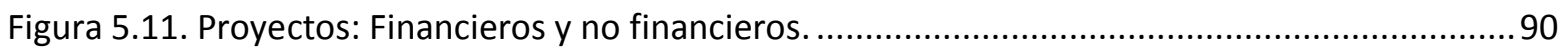

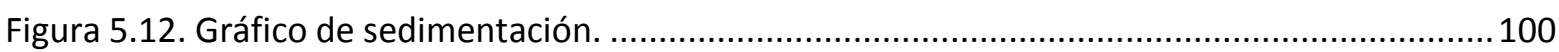





\section{INDICE DE TABLAS}

Tabla 2.1. Comparativa entre los Modelos de Gobierno de TSI ....................................................... 44

Tabla 2.2. Modelo Iberoamericano - Criterios de Calidad que promueven la Entrega de Valor .........44

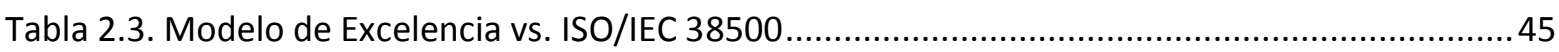

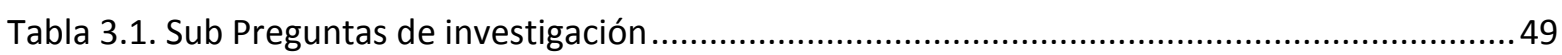

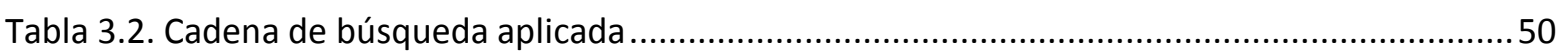

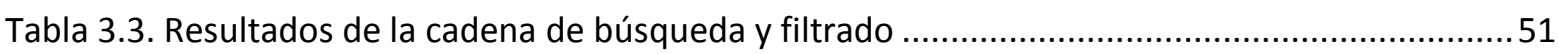

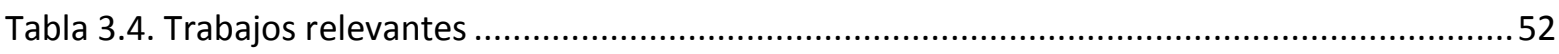

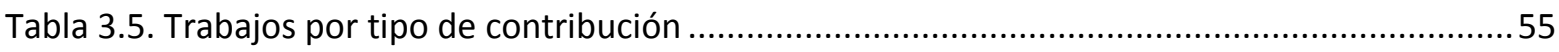

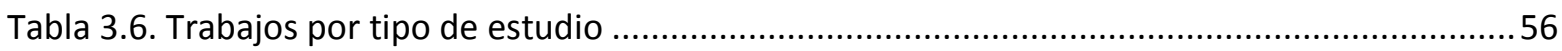

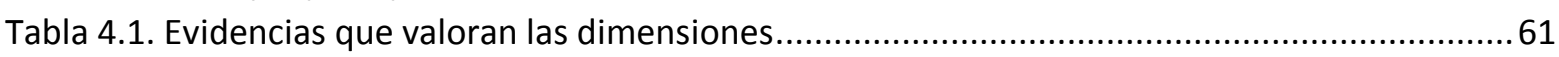

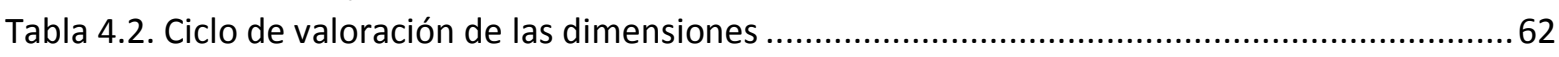

Tabla 4.3. Dimensiones de calidad por sub-criterio del criterio Liderazgo y estilo de gobierno .........63

Tabla 4.4. Valor percibido del efecto de Liderazgo y estilo de gobierno ..........................................64

Tabla 4.5. Dimensiones de calidad por sub-criterio del criterio Estrategias ........................................65

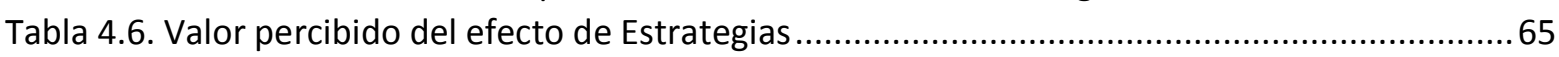

Tabla 4.7. Dimensiones de calidad por sub-criterio del criterio Personas ...........................................66

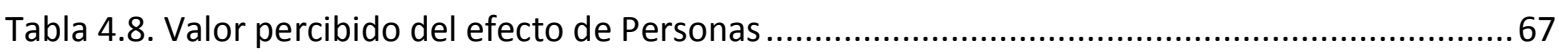

Tabla 4.9. Dimensiones de calidad por sub-criterio del criterio Recursos ......................................67

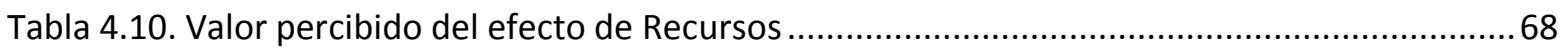

Tabla 4.11. Dimensiones de calidad por sub-criterio del criterio Procesos..........................................68

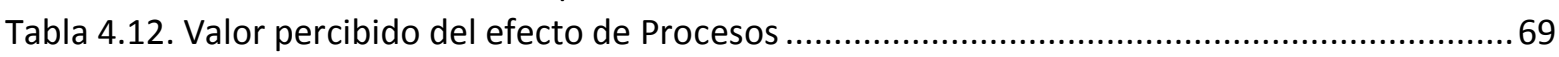

Tabla 4.13. Dimensiones de calidad por sub-criterio del criterio de proyectos ..................................70

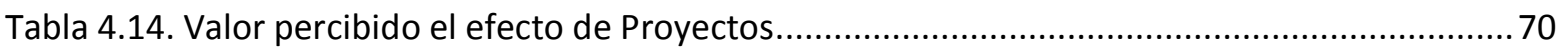

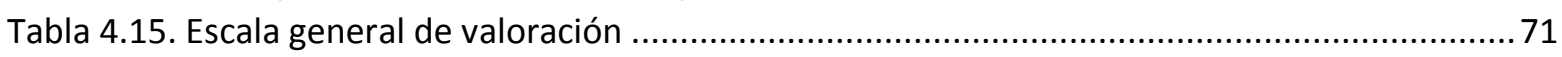

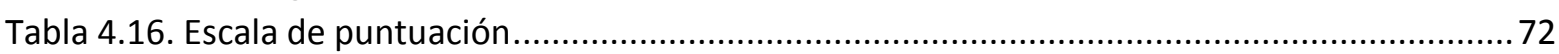

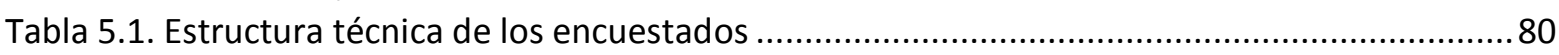

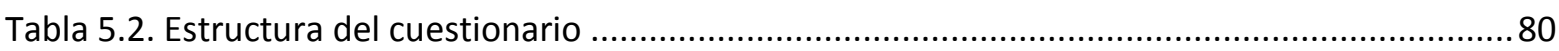

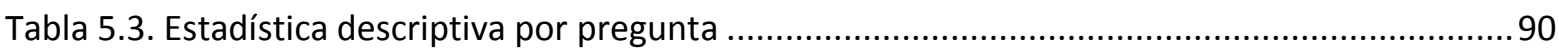

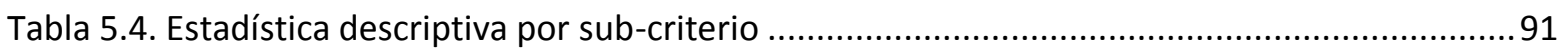

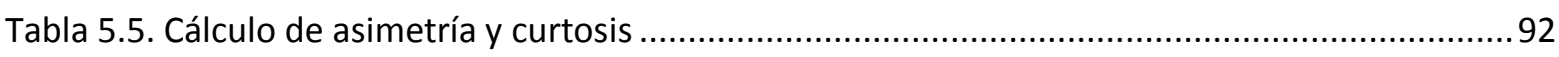

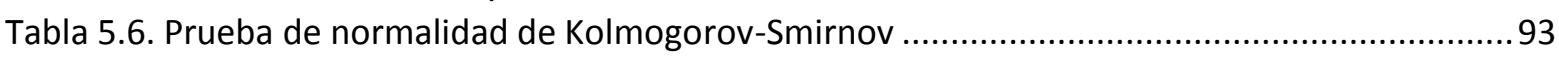

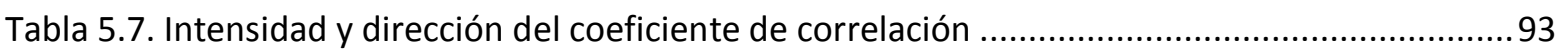

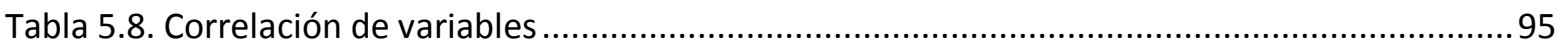

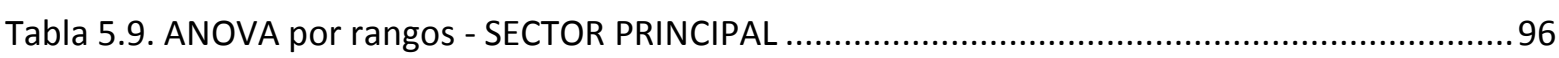

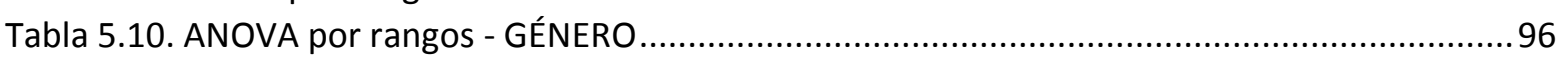

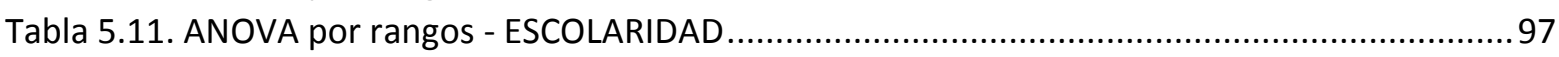

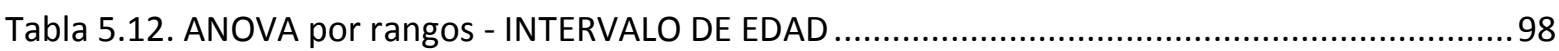

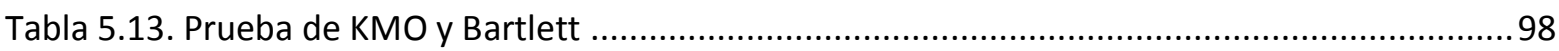

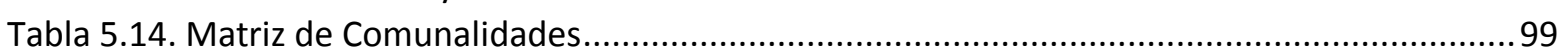

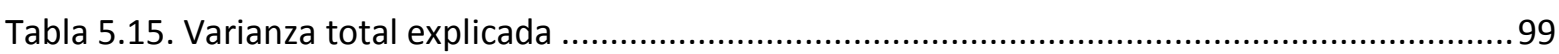

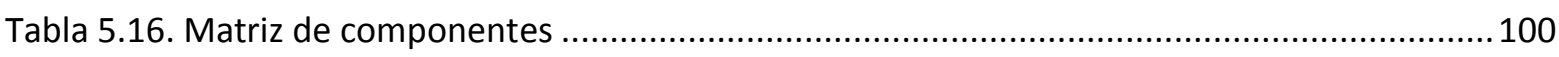

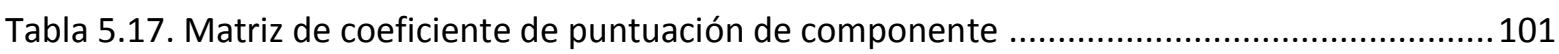

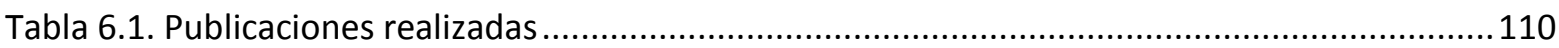





\section{INDICE DE FÓRMULAS}

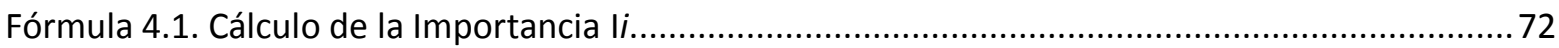

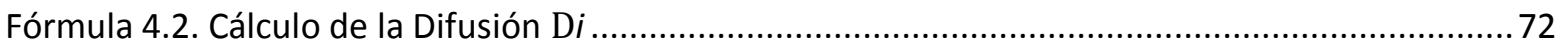

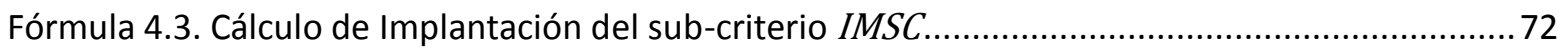

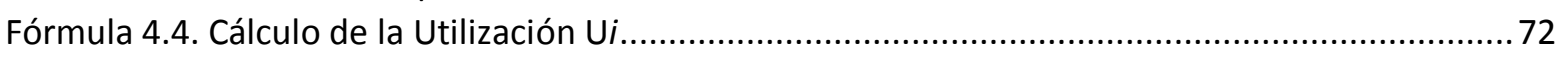

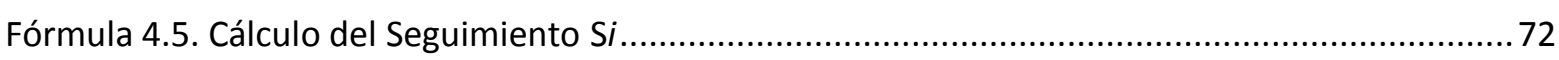

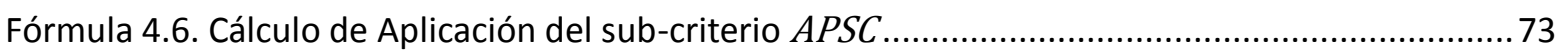

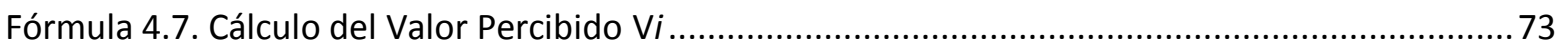

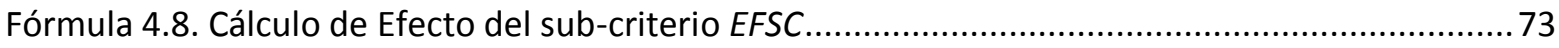

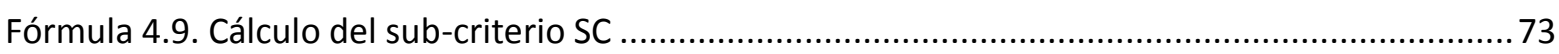

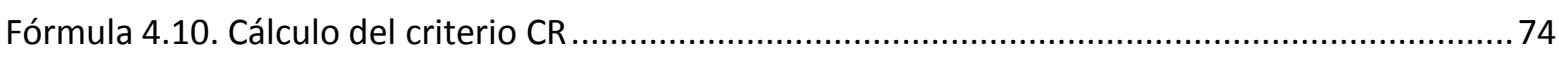

Fórmula 4.11. Cálculo de la medida total del sistema de calidad de GoTSI ....................................74

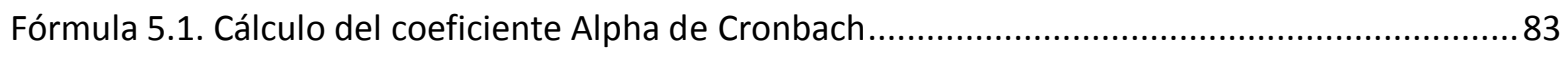

Fórmula 5.2. Cálculo del coeficiente de correlación de rangos de Spearman ..................................93

Fórmula 5.3. Cálculo del factor $t$ para correlación de rangos ......................................................94

Fórmula 5.4. Representación analítica del modelo de calidad GoTSI ............................................. 101 



\section{CAPÍTULO 1 - INTRODUCCIÓN}

En los últimos años, la mayoría de países en América Latina están experimentando un cambio de época, un cambio que afecta profundamente a las organizaciones que usan las Tecnologías y los Sistemas de Información (TSI) como componente clave, tanto para la gobernabilidad como para el desarrollo de estrategias de calidad. Al respecto, es oportuno el aporte de un sistema de evaluación de la calidad diferente que responda a las expectativas del momento, brindando soluciones ajustadas a esas características.

Este capítulo tiene como objetivo exponer el tema introductorio al Gobierno de las Tecnologías y Sistemas de Información (GoTSI), explicando los motivos de su realización. En primer lugar, analizar algunos de los aspectos más característicos del contexto en el que se desenvuelven los GoTSI. En segundo lugar, el planteamiento y formulación del problema. En tercer lugar, los objetivos a alcanzar, las interrogantes de investigación que guiarán la ejecución del trabajo, la hipótesis, la contribución esperada y el enfoque metodológico de la investigación. Finalmente, la estructura de la tesis doctoral.

\subsection{CONTEXTO}

Antes que nada, no es objetivo de este trabajo abordar profundos temas de análisis entorno a las teorías de las organizaciones públicas, no obstante, la temática demanda la descripción de algunos conceptos relacionados para clarificar las TSI en el contexto de ellas, con el objeto de facilitar el marco de evaluación propuesto. En este sentido se parte considerando a la organización como una asociación compuesta por y para las personas, regulada por normas en función de determinados fines (Real Academia Española, 2012). La cooperación entre las personas constituye un aspecto esencial para la existencia organizacional (Fernández Vicente, 2009), además, apoya en el sustento de su GoTSI.

Otros conceptos de interés son los recursos humanos y materiales, procesos, proyectos y arquitectura empresarial, esto último abarca la estructura organizacional. Estos conceptos son importantes a la hora de diseñar un sistema de evaluación.

Muchas han sido las conceptualizaciones que se han dado entorno a las TSI, desde el conjunto de elementos que forman parte de las mismas hasta las aproximaciones de interés actual, pasando por la inclusión de las telecomunicaciones (Andreu, 1996) (Fernández Vicente, 2009) (Laudon, et al., 2012). Por lo tanto, y en este trabajo en particular, se utiliza el término TSI por constituirse en un aspecto de estrategia de negocio que combina los sistemas de información con la definición de las tecnologías de la información y comunicación.

Cada vez más, las TSI pasan por estados cruciales que las vuelven críticas a la hora de exigir cambios importantes en las organizaciones, consecuencia de una sociedad que ha traspasado el umbral de la llamada sociedad basada en el conocimiento hacia la primacía de la inteligencia y del saber, como principal factor de progreso económico. Es que no es para menos cuando el gobierno empresarial vuelca sus ojos en demanda de ayuda de aquellas unidades departamentales que le pueda generar valor para el cumplimiento de su función.

En tales circunstancias, el GoTSI valoriza su condición de elemento jerárquico de carácter estratégico, y la mejora de la calidad de gobierno se convierte en un objetivo fundamental de 
muchas organizaciones a nivel mundial, no siendo la excepción en aquellos países en progreso de desarrollo.

La valorización del GoTSI como mecanismo de progreso organizacional, tecnológico y, principalmente económico, alcanza, así mismo, a las áreas departamentales, originando como efecto inducido un aumento de sus expectativas con respecto al buen funcionamiento de la organización soportada por las TSI.

En este sentido, los gobiernos empresariales son los llamados a velar por el cumplimiento de su razón de ser, siendo los GoTSI los brazos estratégicos encargados de alinear con los objetivos del negocio, principalmente, y en la misma medida con los objetivos corporativos, como se ilustra en la figura 1.1, basada en (Weill, et al., 2004). Sin embargo, esta alineación se cumple, poco o nada, ya que los ritmos de desarrollo tanto de las TSI como del negocio son diferentes (Ross, et al., 2002). No obstante, en caso de no cumplirse se vería impactada la entrega de valor de las TSI en la organización.

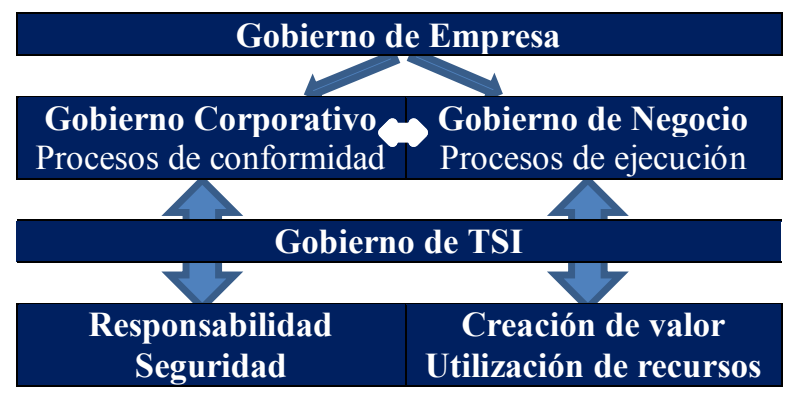

Figura 1.1. Dimensiones del Gobierno Empresarial.

Respecto al término: "gobierno" o "gobernanza" de las TSI, que son sinónimos a nivel de la segunda acepción del diccionario de (Real Academia Española, 2012), existen varias definiciones que relacionan este concepto (Van Grembergen, et al., 2004) (ITGI, 2005) (Webb, et al., 2006) (Dahlberg, et al., 2006) (Fernández Vicente, 2009) (OGC, 2011) (Fernández Martínez, et al., 2012); no obstante, una de las definiciones formales, que ha recibido gran aceptación, es la que ha dado lugar la norma ISO/IEC 38500 (ISO, 2008) para el GoTSI.

Beneficiosamente, existen muchas fuentes que definen al GoTSI, debido a que se ha constituido en una disciplina muy investigada (Pereira, et al., 2012), principalmente porque la brecha que separa al gobierno corporativo del gobierno de las TSI es muy delgada e incluso llegándose a entender, esta última, como parte integral del gobierno corporativo. Por ejemplo, la Organización para la Cooperación y el Desarrollo Económico (OCDE), la International Finance Corporation y el World Bank, poseen una creciente biblioteca de orientación acerca de la Gobernanza Corporativa, cuya piedra angular constituyen los "Principios de Gobernanza Corporativa" de las Naciones Unidas (Toomey, 2009).

En cuanto a la comprensión del rol y propósito de la gobernanza, (Barger, 2004) proporciona un buen entendimiento del tema, aunque no explica realmente cómo se ejecuta la gobernanza. Para una explicación del particular, existe un trabajo de gran autoridad: "International Corporate Governance" (Tricker, 1994), el cual explica que el gobierno corporativo opera sobre una base sólida que se relaciona con la gestión de las TSI a través del Gerente General, denominado CEO por sus siglas en inglés, o Director Ejecutivo.

EI GoTSI opera como un sistema en el cual el grupo de gobierno y de gestión tienen roles y responsabilidades claras y diferentes, con el CEO o Director Ejecutivo actuando como punto focal 
para la interacción entre el Consejo y los gerentes (Toomey, 2009). En este sentido, se toma en cuenta la definición básica del GoTSI como el liderazgo, los procesos y las estructuras que aseguran que las TSI de la organización apoyan los objetivos y estrategias de la misma (Fernández Vicente, 2009).

Desde el punto de vista de la evaluación, la norma ISO/IEC 38500 (ISO, 2008), inicia la discusión diciendo que los Consejeros deberían "examinar y juzgar el uso actual y futuro de la $\mathrm{Tl}^{\prime}$ " como claro compromiso con la mejora, a través de la evaluación del GoTSI. Sin embargo, la pregunta que muchos se hacen es: ¿Cuándo deberían los consejeros exigir una evaluación del sistema de GoTSI?. La respuesta varía de una organización a otra, y en función de sus propias circunstancias. El sistema de gobierno debe brindar a los consejeros e interesados la confianza sobre la correcta toma de decisiones y que están produciendo los resultados correctos. Aunque esta posición de evaluación es propia de la norma, no deja de aportar a la mejora de la calidad del gobierno que persigue este trabajo doctoral.

En cuanto a la calidad, ésta es un grado de excelencia, y lo excelente es eternamente nuevo. Las evaluaciones de la calidad de las organizaciones, departamentos, áreas funcionales, actividades, productos y servicios han sido reconocidas por la bondad de sus resultados comenzando a ser obligatorias y de aplicación cada vez más estricta en la búsqueda del cumplimiento de sus fines.

Durante los últimos años, tanto las instituciones públicas como los ciudadanos han sido actores de la creciente incursión que ha experimentado las TSI, impulsada por el incremento en la tasa de adopción, lo que nos lleva a confirmar que el papel que juegan las TSI en la administración pública es relevante.

Una evaluación específica y exhaustiva del GoTSI, como la propuesta en este trabajo doctoral, implica una evaluación del sistema de gobierno, usando un adecuado conjunto de componentes, partiendo de principios básicos de calidad. Esta especificidad y exhaustividad involucra el valor generado por las TSI al negocio de la organización. En términos generales, la organización percibirá este valor en el compromiso de los líderes con los objetivos estratégicos, recursos, personas, procesos y proyectos.

Para asegurar un tratamiento específico y exhaustivo de la calidad, se utiliza un sistema de evaluación basado en la experiencia que brindan los modelos de excelencia y calidad. Diversas organizaciones a nivel internacional han desarrollado modelos de excelencia y calidad, tal como indican los estudios de (Torres Fragoso, 2011) (Sánchez Peña, 2013) (Municio, 1998) (Pastor Tejedor, et al., 2012): "MBNQA: Malcolm Baldrige National Quality Award" (BNQP - Baldrige National Quality Program, 2015), "EFQM: European Foundation for Quality Management" (European Foundation for Quality Management [EFQM], 2013) y, el "Modelo Iberoamericano de Excelencia en la Gestión" (FUNDIBEQ, 2014).

En el caso de Ecuador, los modelos que mayormente se han dado a conocer son el sistema de gestión de la calidad ISO/IEC 9001, el Marco Común de Evaluación (CAF) y ahora, el Modelo Iberoamericano de Excelencia en la Gestión, como parte de la Norma Técnica de Certificación de la Calidad del Servicio Público, impulsado por la Secretaria Nacional de la Administración Pública (Secretaria Nacional de la Administración Pública, 2014). En este sentido, este trabajo constituye un aporte a nivel funcional del área de TSI, para las organizaciones que deseen evaluar el GoTSI basado en valor, con criterios de excelencia y una perspectiva de dirección.

\subsection{PLANTEAMIENTO DEL PROBLEMA}


La organización ha dado un salto cualitativo en los últimos 30 años en todos los países. Ha cambiado su arquitectura empresarial y tecnológica, se ha especializado su personal, se ha intensificado el número de proyectos y se ha vuelto más sostenible con fondos públicos y privados. Muchas organizaciones crean y se soportan en sistemas de información de última tecnología en clara competencia con organizaciones tradicionales. Esta situación presenta un claro problema que es necesario corregir desde dentro de la propia organización. Los accionistas, los consejeros, los administradores y los funcionarios de la organización participan de este deseo de mejora. Para el equipo del gobierno corporativo, en sentido general, sus objetivos de calidad siempre estarán enfocados en alcanzar eficiencia y eficacia en todos los niveles de la administración. Lograr la calidad para un gobierno empresarial que se enfoca en las Tecnologías y los Sistemas de Información es un reto, porque los líderes organizacionales cada vez más esperan que los líderes de TSI innoven y entreguen valor en toda la organización y, al mismo tiempo, apoyen con la operación al máximo nivel, es decir, buscando el balance perfecto entre el negocio y la operación.

La calidad se ha constituido en una meta de muchos países. En Ecuador, la Constitución establece que la administración pública se rige por principios, entre otros: el de calidad. Esto involucra la participación conjunta de las personas que aseguren el accionar en el contexto organizacional. La calidad incide sobre las personas, las actividades, los procesos y los resultados; todo orientado hacia la excelencia. Una intención que se persigue de calidad (no excluyente desde el punto de vista del análisis de otros modelos) y al mismo tiempo del GoTSI es la aplicación de buenas prácticas del modelo iberoamericano y el estándar ISO/IEC 38500, respectivamente.

El Ecuador, a través de los Planes de Desarrollo 2009 - 2013 y 2013 - 2017, plasma las estrategias de diversificación de la matriz productiva y reducción de la pobreza; para soportar y viabilizar estos dos grandes intereses nacionales, el Estado debe mejorar su gestión y la calidad en la prestación de sus servicios, por lo cual, el uso de las TSI se convierten en un factor clave (Secretaria Nacional de la Administración Pública, 2014). Al respecto, el seguimiento que se ha tenido mediante el Ministerio de Telecomunicaciones y Sociedad de la Información ${ }^{1}$ a los criterios para implementar o mejorar el GoTSI en las instituciones públicas no ha estado al nivel de las expectativas generadas. Es decir, no registra institución alguna que haya cumplido con los seis principios de buena o efectiva praxis de buen GoTSI de manera formal. De todas maneras, tarde o temprano la praxis de GoTSI demandará una adecuada evaluación de calidad si se pretende garantizar un nuevo paradigma cultural en las instituciones públicas.

Partiendo del contexto de la sección anterior, cuyo tema principal es la evaluación de la calidad del GoTSI basada en valor, se procedió con revisiones preliminares de la literatura (Sánchez Peña, 2013) (Aguilera, 2010) detectando que existen desafíos en el marco de la calidad de GoTSI usando contenidos de otros modelos de calidad basados en el valor generado por las TSI en la organización e incorporando componentes propios y generales de GoTSI.

Lo anterior precisa la necesidad de aportar con un modelo de calidad de GoTSI basada en valor que provea de una serie de componentes (Criterios, Subcriterios, Dimensiones y Evidencias), adaptados a la realidad del ámbito público ecuatoriano y porque no un referente a nivel general.

El enfoque y el desafío principal que tiene el modelo de calidad para su uso es que los componentes propuestos recojan la propuesta de valor dentro de un conjunto de criterios facilitadores que el GoTSI deberá evidenciar para alcanzar resultados deseados.

\footnotetext{
${ }^{1}$ EI MINTEL formó parte del equipo técnico que elaboró la NTE ISO/IEC 38500:2008.
} 
En esta tesis se considera la opinión de expertos y directivos de TSI, quienes permitirán valorar esta propuesta, a través de su participación brindando información que permita determinar la correlación entre el modelo de excelencia y el estándar de trabajo.

\subsection{FORMULACIÓN DEL PROBLEMA}

El presente trabajo de investigación no experimental transversal, busca responder el siguiente cuestionamiento: ¿Cómo evaluar la calidad de GoTSI basada en valor a través de un conjunto de componentes que respondan a principios de un buen gobierno de TSI en el ámbito público ecuatoriano?

\subsection{OBJETIVO GENERAL}

El objetivo general de la Tesis es "Proponer un Modelo de Calidad de Gobierno de Tecnologías y Sistemas de Información (GoTSI) basada en Valor, con el fin de ayudar a comprender el sistema de gobierno y mejorar procedimientos internos, a través de un conjunto de componentes que respondan a principios de un buen gobierno de TSI en el ámbito público ecuatoriano".

\subsection{OBJETIVOS ESPECÍFICOS}

Para poder alcanzar el objetivo general, se detallan a continuación los objetivos específicos:

1. Estudiar propuestas existentes de evaluación de calidad de GoTSI basadas en valor.

Para el cumplimiento de este objetivo se realizará un balance de los conceptos, modelos de excelencia, estándares y trabajos relacionados que contextualizan el alcance de este trabajo.

2. Establecer las características y principios de calidad que funcionan como componentes del sistema de evaluación de la calidad de GoTSI basada en valor.

Para el cumplimiento de este objetivo se planea analizar el modelo de calidad pertinente y los principios que responden a la caracterización de ese modelo.

3. Proponer una estructura de modelo que permita cumplir los principios de calidad establecidos.

Para cumplir con este objetivo se identificarán y describirán los criterios, sub-criterios dimensiones y evidencias que caracterizan el modelo de evaluación de calidad en función de las directrices de modelos de excelencia y el estándar de trabajo utilizado.

4. Proponer un proceso de autoevaluación que facilite la mejora del accionar del equipo rector de gobierno.

Para cumplir con este objetivo se tomarán en cuenta los pasos necesarios para cumplir con un proceso de autoevaluación como parte del proceso de mejora continua.

5. Analizar la importancia que le brindan expertos de gobierno a los diferentes criterios de excelencia.

Para cumplir con este objetivo se procederá con la estructuración de un cuestionario validado por expertos y fundamentado en teorías existentes, que permita tomar datos de los líderes de TSI con el fin de encontrar relaciones y/o asociaciones que brinden viabilidad a esta propuesta de investigación.

6. Validar la aplicabilidad del modelo de evaluación definido. 
Para el cumplimiento de este objetivo se procederá con el análisis de resultados obtenidos de los líderes de TSI. Para esto se utilizará métodos y técnicas estadísticas de investigación científica.

\subsection{HIPÓTESIS}

La hipótesis de la que se parte dice:

Es posible definir un modelo de evaluación de la calidad que establezca un nivel de excelencia del GoTSI basada en valor y que se puede afianzar por el juicio de directivos experimentados.

\subsection{ALCANCE}

La evolución que ha sufrido el mundo durante el pasado siglo XX en relación a las TSI, ha impactado en casi todos los aspectos de nuestras vidas, poniendo de manifiesto la realidad de las personas con su experiencia frente a la interdependencia de los sistemas tecnológicos y sus componentes. Es la nueva forma de percibir el mundo que nos rodea, en la que tienen especial importancia el valor, el comportamiento de las personas y la interacción, que cada vez más entra en las sociedades y, principalmente, en las organizaciones.

De acuerdo a las realidades contemporáneas, este trabajo basa sus definiciones en el Modelo Iberoamericano de Excelencia en la Gestión Pública y las relaciones con los criterios de valor que se encuentran en el estándar ISO/IEC 38500, principalmente. Para esto se toma en cuenta los principios, criterios y sub-criterios facilitadores que establece el modelo y evidenciados en el estándar, contrastados con las opiniones de expertos en GoTSI y calidad, por lo cual, se utilizaron valores de asignación dentro de una escala numérica. Para la selección de los sub-criterios, se tomó en cuenta aquellos que superaban en promedio la valoración indicada. Para validar el modelo se tomó en cuenta el juicio de directivos experimentados quienes han definido estilos de comportamiento e incidencia en sus organizaciones a través de la toma de decisiones. La implementación del sistema excede el alcance de este trabajo.

\subsection{CONTRIBUCIÓN CIENTÍFICA}

Las principales contribuciones de la presente tesis de evaluación de la calidad de GoTSI basada en valor son:

- Un enfoque integral, disciplinado, específico y exhaustivo para evaluar la calidad de GoTSI basada en valor. Tal como impulsa el estándar y el modelo de excelencia referente para el ámbito público.

- Un conjunto de criterios, sub-criterios, dimensiones y evidencias a ser utilizados en todo el ciclo de evaluación, en consideración de un ámbito público.

- Embebido en el modelo se propone un proceso de autoevaluación que conduzca la mejora.

- Contribuir potencialmente a comprender y mejorar la calidad en el ámbito público ecuatoriano a nivel estratégico organizacional en donde se desarrolla el gobierno de las tecnologías y sistemas de información.

\subsection{ENFOQUE METODOLÓGICO}

La figura 1.2 presenta el proceso metodológico de investigación empleado. Como se puede observar, se define un proceso sistemático cualitativo, que busca recurrencia e iteractividad, en donde cada una de las etapas que son en realidad actividades para involucrarse en el problema. 

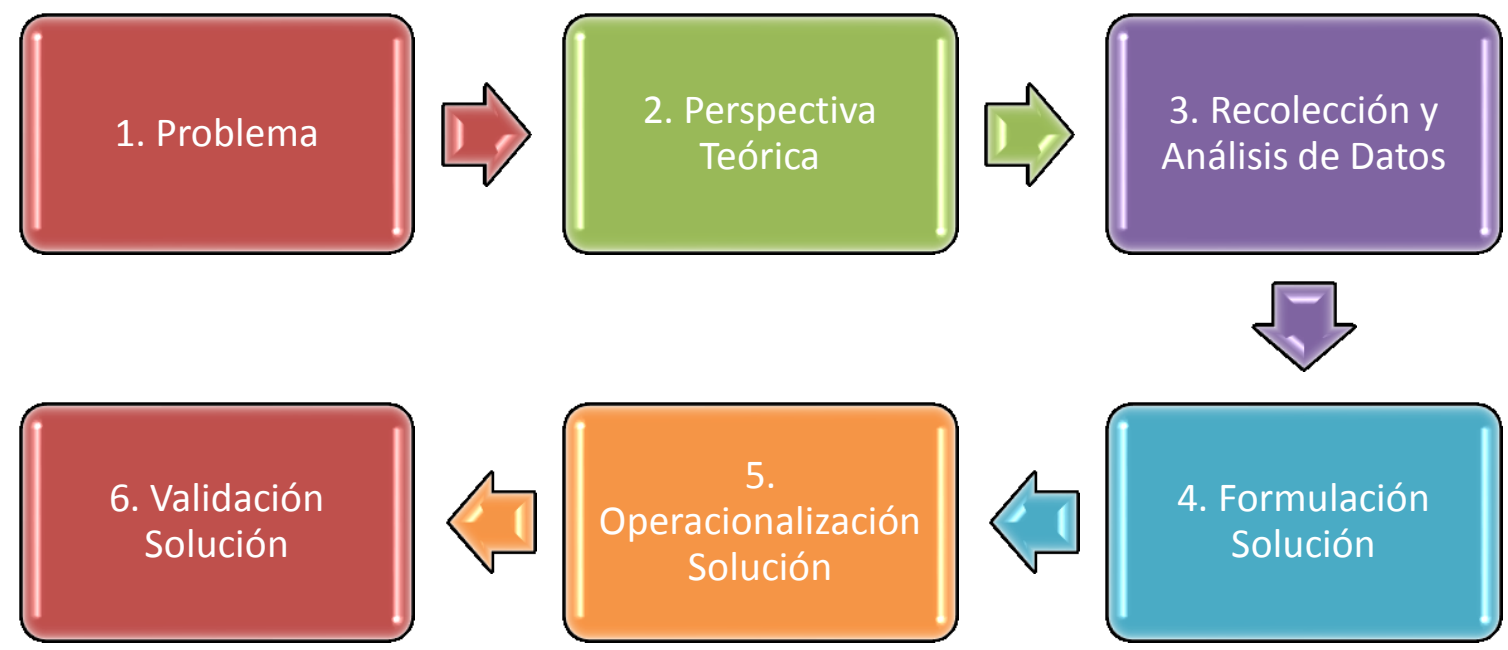

Figura 1.2. Proceso metodológico de investigación.

A continuación se describen cada una de las actividades identificadas en la figura anterior:

1. Problema: Tanto el planteamiento como la formulación del problema fueron descritos en las secciones 1.2 y 1.3 , respectivamente.

2. Perspectiva teórica: Comprende la teoría y trabajos relacionados, los mismos que se basan en ideas, detección y relación de conceptos claves, búsqueda, identificación, selección, relevamiento y análisis de trabajos relacionados; para esto se utilizó el marco teórico y el método del mapeo sistemático de estudios.

3. Recolección y Análisis de Datos: Se procedió con la búsqueda de datos importantes en modelos de excelencia establecidos. Luego se procedió con la organización y estructuración de lo que sería la propuesta. Finalmente, se aplicó un sentido de pertinencia para determinar su viabilidad.

4. Formulación de la Solución: Se estructuró el modelo de calidad compuesto por un conjunto de criterios, sub-criterios, dimensiones y evidencias en base a las sugerencias de expertos. Se definió una propuesta de valoración y medición. Luego se procedió con el diseño del proceso metodológico de autoevaluación.

5. Operacionalización de la Solución: Se diseñó una encuesta dirigida a un grupo selectivo de directivos de TSI que desarrollan estrategias relacionadas con el uso de las TSI. Se buscó consolidar el modelo mediante la opinión de importancia expresada en cada una de las preguntas del cuestionario.

6. Validación de la Solución: Se realizó el análisis estadístico de los datos obtenidos en cada una de las preguntas de la encuesta aplicada. En este se contrasta la hipótesis planteada en la tesis.

\subsection{ESTRUCTURA DE LA TESIS}

Esta tesis ha sido estructurada en 6 capítulos, cuyo contenido de describe de la siguiente manera:

\section{Capítulo 1 - INTRODUCCIÓN}

Se expone el tema introductorio al Gobierno de las Tecnologías y Sistemas de Información (GoTSI). En primer lugar, analizar algunos de los aspectos más característicos del contexto en el que se desenvuelven los GoTSI. En segundo lugar, el planteamiento y formulación del problema. 
$\mathrm{Y}$, finalmente, los objetivos, las interrogantes de investigación, hipótesis, la contribución y el enfoque metodológico de la investigación.

\section{Capítulo 2-MARCO TEÓRICO}

Se expone una síntesis de los principales conceptos, modelos, marcos y/o estándares de trabajos adecuados para el desarrollo del tema de investigación que gira en torno al GoTSI.

\section{Capítulo 3 - TRABAJOS RELACIONADOS}

Se exponen las investigaciones llevadas a cabo entre 2008 y 2014, para darle originalidad al trabajo desarrollado. Se revisan los trabajos relacionados a la evaluación de la calidad de GoTSI basada en valor mediante la técnica del mapeo sistemático de estudios.

\section{Capítulo 4 - ELABORACIÓN DEL MODELO DE EVALUACIÓN (VBISTGQM)}

En base a temas relacionados con la investigación propuesta. Se considera los criterios, subcriterios y dimensiones relevadas para el modelo de calidad propuesto. Se definen las técnicas de valoración y medición de las evidencias para la era del conocimiento. Se diseñan las fases del proceso de autoevaluación. Lo importante de este modelo es que recoge el criterio y opinión de expertos en GoTSI y Calidad.

\section{Capítulo 5 - VALIDACIÓN DEL MODELO DE EVALUACIÓN (VBISTGQM)}

Se expone el diseño de la investigación que responde a la validación de la hipótesis. Se explica con claridad la selección de los participantes de la encuesta y el proceso de recolección y procesamiento de información. Se validan los datos obtenidos a través de métodos estadísticos, tal como: Descriptivo, confiabilidad, correlacional por rangos, varianza por rangos y factorial por componentes. Se concluye con una expresión analítica del modelo propuesto.

\section{Capítulo 6-CONCLUSIONES Y TRABAJOS FUTUROS}

Se exponen las conclusiones obtenidas tras la realización de este trabajo y principalmente en función de los resultados obtenidos en la investigación. Se debaten los hallazgos encontrados, la importancia, reflexiones y la discusión para futuras líneas de investigación. Se presentan las publicaciones realizadas en revistas y congresos relacionados de manera directa e indirecta con el tema de la presente tesis.

Luego de los seis capítulos se presentan algunos documentos, como se estructuran a continuación.

\section{ACRÓNIMOS}

Se identifican los acrónimos específicos utilizados en el presente trabajo doctoral.

\section{REFERENCIAS}

Se enlistan los libros, revistas, memorias y materiales utilizados en el presente trabajo doctoral.

Los anexos de este trabajo doctoral muestran documentos e instrumentos que se fueron creando y/o utilizando para sustentar la construcción del modelo, cuyos contenidos se presenta a continuación.

\section{ANEXO A. GUÍA PRÁCTICA ISO/IEC BASADA EN VALOR}


Este anexo tiene el carácter de informativo, a su vez guía práctica del estándar ISO/IEC 38500 basada en valor. Permite trabajar en la correspondencia con el modelo de excelencia.

\section{ANEXO B. ESTUDIOS SELECCIONADOS}

Esta sección presenta una lista completa de los estudios seleccionados en el proceso de mapeo sistemático, a su vez proporciona conocimiento acerca del tema de investigación.

\section{ANEXO C. MAPEO DE ESTUDIOS}

Esta sección muestra las características de investigación identificadas en cada estudio seleccionado.

\section{ANEXO D. ENTIDADES COLABORADORAS}

Esta sección muestra la lista de entidades públicas que colaboraron con la validación operativa del modelo a través de la opinión que expresaron sus líderes de TSI.

\section{ANEXO E. CUESTIONARIO}

Esta sección muestra el cuestionario utilizado para conocer el nivel de importancia que directivos de TSI del ámbito público brindan a los distintos criterios de calidad que se utilizan para evaluar el GoTSI que atiende las necesidades dentro de una organización pública.

\section{ANEXO F. GUÍA DE APLICACIÓN DEL MODELO}

Esta sección muestra un caso de aplicación del modelo con el supuesto de diez participantes. 



\section{CAPÍTULO 2 - MARCO TEÓRICO}

\subsection{INTRODUCCIÓN}

Este capítulo tiene como objetivo presentar una síntesis de los principales conceptos, modelos, marcos y/o estándares de trabajos adecuados para el desarrollo del tema de investigación que gira en torno al GoTSI (Ver figura 2.1); además, facilitará a los lectores el entendimiento de la dinámica de los modelos de evaluación, principalmente.

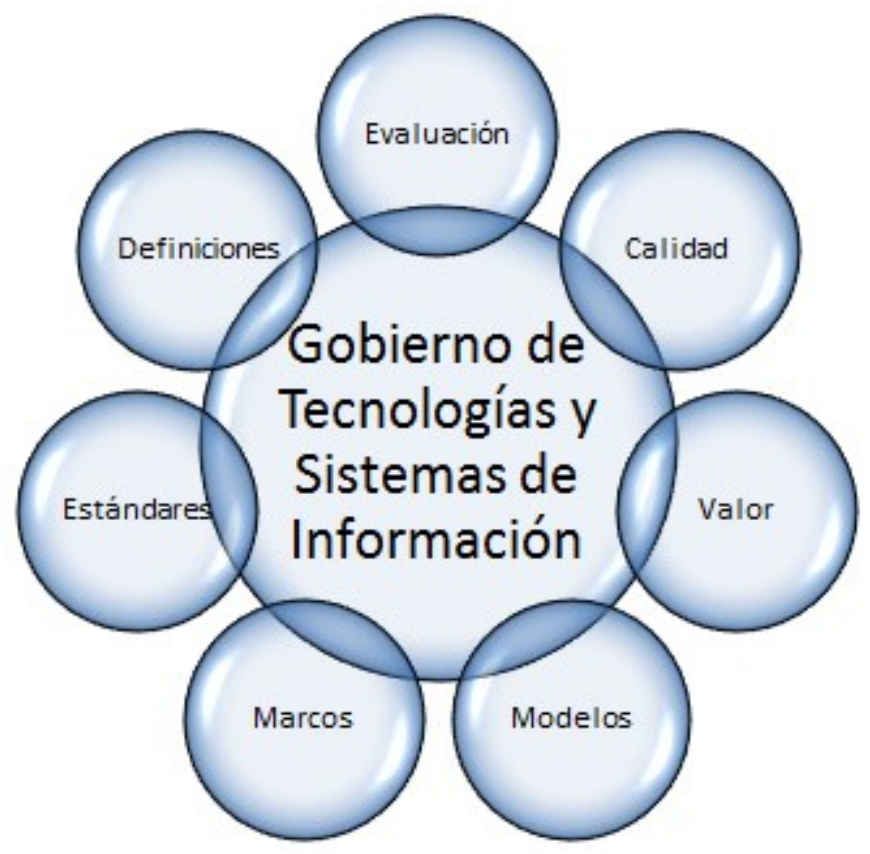

Figura 2.1. Mapa del marco teórico.

Se empieza con una sinopsis de las definiciones de calidad, valor y gobierno de las tecnologías y sistemas de información. Continúa con una síntesis del modelo iberoamericano de excelencia. Posteriormente se analiza modelos de evaluación con enfoque en gobierno y gestión. Finaliza con el análisis de los modelos de Gobierno de Tecnologías de la Información y sus relaciones con el Modelo de Excelencia Iberoamericano.

\subsection{LA CALIDAD}

La presente sección tiene como finalidad definir la calidad, su relación con la evaluación e importancia en el campo empresarial de las TSI.

\subsubsection{DEFINICIÓN DE CALIDAD}

La calidad es por esencia uno de los factores que permite que las organizaciones se vuelvan competitivas en el entorno actual. Para muchas, se ha constituido por décadas en su principal objetivo estratégico debido a que su supervivencia depende de la calidad de servicios que brindan a usuarios internos y externos. 
La calidad significa "grado de excelencia" y abarca dos aspectos importantes: el juicio de valor y el juicio de posición, en una escala cualitativa de bueno y malo. Por eso calificamos a un servicio de mejor o peor que otro (Pérez Juste, et al., 2014).

Hablar de calidad es remontarse en la historia, a través de la cual, los gurús de esta área han dado diferentes definiciones, algunas de ellas dicen:

- "Enfoque integral... la calidad, como realidad compleja, debe ser entendida como la armonización integradora de los diferentes elementos componentes: eficacia en el logro de un servicio, bien u objeto excelente, mediante procesos eficientes, satisfactorios tanto para sus destinatarios, directos e indirectos, como para el personal de la organización encargada de lograrlo" (Pérez Juste, et al., 2014).

- "La palabra calidad tiene múltiples significados, dos de ellos significan el dominio del uso de la palabra: 1. Calidad consiste en las características del producto que satisfacen las necesidades de clientes y les proporciona satisfacción con el producto. 2. Calidad consiste en ausencia de deficiencias... Es importante tener una corta frase la cual sea universalmente aceptada como una definición comprensible de calidad... como adecuación al uso" (Juran, 1988).

- "Debemos enfatizar la orientación al cliente... Cómo uno interpreta el término "calidad" es importante... Interpretado restringidamente, calidad significa calidad de producto. Interpretado ampliamente, calidad significa calidad de trabajo, calidad de servicio, calidad de información, calidad de proceso, calidad de división, calidad del personal -incluyendo trabajadores, ingenieros, directivos y ejecutivos -, calidad del sistema, calidad de la empresa, calidad de objetivos, etc." (Ishikawa, 1985).

De acuerdo a las definiciones anteriores, podemos inferir que la calidad es la forma de afrontar estratégicamente los nuevos retos del mundo contemporáneo, en temas de excelencia a través del reconocimiento multidimensional que representa el concepto de calidad.

La excelencia es el término en la calidad acuñado en los Modelos de Occidente. Con la aparición del Malcolm Baldrige en 1987, el Modelo Europeo en 1991 y el Modelo Iberoamericano en 1999, no sólo se cobija el término de excelencia, sino que sus criterios y los valores en que están basados constituyen los referentes de la excelencia.

\subsubsection{CALIDAD Y EVALUACIÓN}

La revolución científica y cultural de las organizaciones en el siglo XXI demanda un nuevo paradigma, que lo denominan "cultura integradora" (Pérez Juste, et al., 2014), porque responde a una nueva concepción del mundo y de la vida. La cultura integradora recoge aspectos históricos de calidad en búsqueda de una mejor solución a los problemas de las organizaciones en todos sus aspectos. La calidad deja de centrarse en el bien o producto y se convierte en una exigencia de toda la organización a través de quienes la dirigen. El rol de la dirección y la implicación de los empleados se convierten en el factor esencial del cambio.

El sistema de evaluación integrador parte de un enfoque preventivo que actúa a priori tratando de identificar si el proceso puede producir fallos. Actúa buscando la acción equilibrada que permita contribuir a la buena salud de la organización en su conjunto. Además, establece como premisa fundamental que la evaluación no tiene como objetivo castigar o reprimir a las personas sino mejorar los procesos, procedimientos o actividades (Municio, et al., 1998). Para culminar, la evaluación no tiene sentido si no se realiza desde dentro en forma de autoevaluación (Pérez Juste, et al., 2014). 


\subsubsection{LA CALIDAD EN EL ÁMBITO EMPRESARIAL DE LAS TSI}

Las empresas a través de sus altos directivos entienden el poder que tienen las TSI para contribuir a un desempeño más eficiente y eficaz, por lo cual, buscan maneras de trabajar con todas las demás funciones de la organización para encontrar soluciones a los problemas que aquejan el día a día en el entorno interno y el de los clientes.

Los problemas de calidad resultan ser costosos para muchas organizaciones que usan las TSI, por ejemplo, son frecuentes, entre otros, mantener en producción aplicaciones, base de datos, infraestructura. Sin embargo, el no afrontar estos problemas con entereza puede resultar más costoso y sin opción a competir con éxito en el mercado mundial.

Pero, ¿Cómo lograr la calidad en el GoTSI?, es la pregunta que se hacen muchos directivos, independientemente del nivel jerárquico en que se encuentren. Al respecto existen algunas estrategias para abordar y demostrar su compromiso con la calidad, muchas organizaciones han seguido metas de calidad desafiantes; de ellas, entre los marcos más conocidos en términos de gobierno que aportan a la calidad se encuentran la norma australiana AS 8015:2005 (AS 8015, 2005), ISO/IEC 38500 (ISO/IEC, 2008, 2015), Código King III (The Institute of Directors in Southern Africas, 2009), $\mathrm{COBIT}^{\circledR} 5$ (ISACA, 2012) y PMBOK ${ }^{\circledR}$ (Project Management Institute, 2013).

A juicio de este trabajo, lograr la calidad en el GoTSI de una forma específica y exhaustiva en una organización, demanda tomar en cuenta, de manera adecuada, modelos de calidad que persigan la mejora del sistema y por consiguiente de la organización; entre estos tenemos, el Modelo Malcolm Baldrige National Quality Award MBNQA (Brian, et al., 2009) (BNQP - Baldrige National Quality Program, 2015), el Modelo European Foundation for Quality Management EFQM (González Sánchez, et al., 2005) (European Foundation for Quality Management [EFQM], 2013) y el Modelo Iberoamericano de Excelencia en la Gestión (FUNDIBEQ, 2014).

En la figura 2.2 se muestran varios de los marcos citados anteriormente.

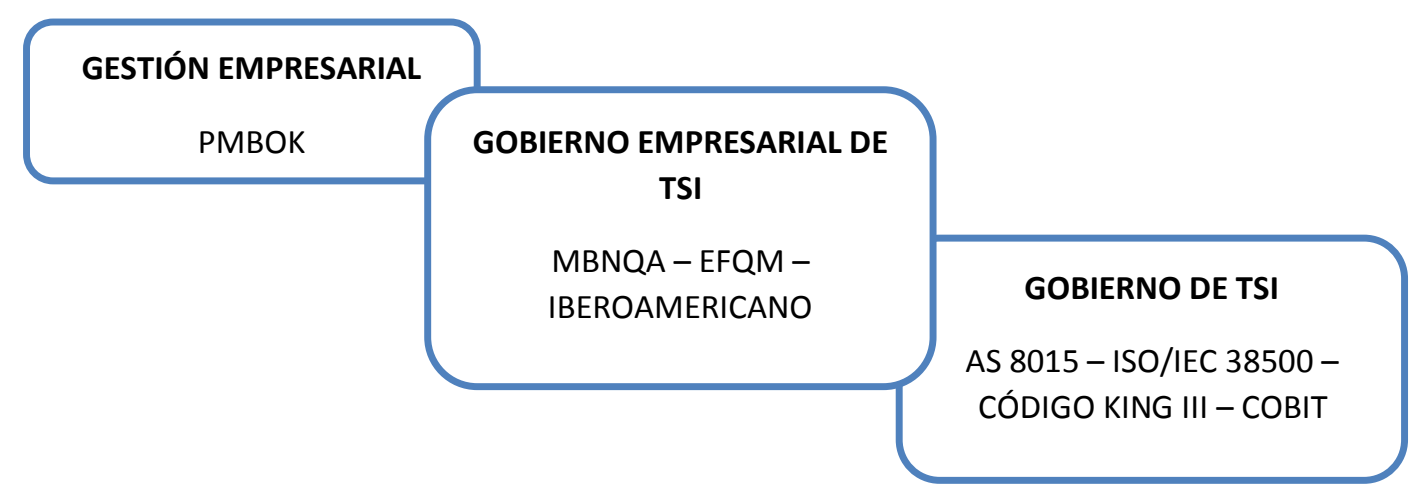

Figura 2.2. Marcos de Gobierno de TSI.

Aunque es importante el reconocimiento que hacen los gerentes al obtener muchos beneficios con una certificación de calidad, a través de un modelo, el beneficio clave es la mejora misma de la calidad de manera holística. En otras palabras, "la meta de una certificación de calidad debe ser contar con procesos y/o actividades de trabajo capaces de brindar a la organización y en sí a las personas la oportunidad de llevar a cabo su trabajo con calidad excelente y de manera constante" (Robbins, et al., 2005).

A continuación se describen las características de cada modelo, marco y/o estándar en función de sus propias definiciones. 


\subsubsection{AS 8015}

El estándar australiano AS 8015 (AS 8015, 2005), denominado "Corporate Governance of Information and Communication Technology", definido como norma nacional por el gobierno australiano en el año 2005; luego, en junio de 2008, pasaría a ser norma internacional, dando paso al estándar ISO/IEC 38500 denominado "Corporate Governance of Information Technology".

El marco australiano comprende tres elementos (Brand, et al., 2004):

1. El modelo

2. Principios rectores

3. Vocabulario

El Gobierno Corporativo de las Tecnologías de la Información es el sistema, por el cual, el uso actual y futuro de las TSI están dirigidas y controladas. El elemento modelo implica evaluar y dirigir los planes para el uso de las TSI en apoyo a la organización y el seguimiento en el uso para lograr los planes establecidos. Además, incluye la estrategia y las políticas para el uso de las TSI dentro de una organización, que soportan los seis principios de gobierno.

AS 8015 identifica tres tareas claves que deben dar cumplimiento los directores:

1. Evaluar el uso de las TSI

2. Dirigir la preparación e implementación de planes y políticas

3. Monitorear el cumplimiento de políticas y desempeño de acuerdo a los planes

\subsubsection{ISO/IEC 38500}

Es el estándar mundial más formal internacionalmente utilizado para el GoTSI y de las Telecomunicaciones; reconocido por profesionales que desean profundizar el tema de gobernabilidad en todo el mundo.

El estándar ISO/IEC 38500 (ISO/IEC, 2008, 2015) adoptó en gran parte el estándar australiano AS8015:2005, el cual está dirigido a los directores de las organizaciones en su responsabilidad con el uso de las TSI. Siendo declarada norma internacional en el año 2008, cuyo propósito es promover el uso eficiente, eficaz y aceptable de las TSI en todas las organizaciones, a través de:

- Una dirección que brinde confianza a las partes interesadas

- Una evaluación del uso de las TSI

- Un monitoreo de todos los procesos que sirva para informar y orientar al gobierno corporativo sobre el uso de las TSI en la organización y el cumplimiento de la dirección

La norma define seis principios para un buen gobierno corporativo de TSI, los mismos que son aplicables a la mayoría de organizaciones e independiente de su ámbito.

A criterio de expertos (Toomey, 2009), el estándar ISO/IEC 38500 cumple criterios de excelencia y calidad que no la define como un estándar de calidad, si no que le permite aportar en la mejora de la calidad que tenga implantada una organización de TSI. En una frase (Toomey, 2009): "Excelencia en Gobierno se trata de un programa de mejora continua, impulsado por la evaluación periódica según la norma ISO 38500".

\subsubsection{Código King III}

El Código King III (The Institute of Directors in Southern Africas, 2009) surge como un nuevo esfuerzo demostrado en sus antecesores: King I y King II; aprobado en el año 2010. Cuyo 
propósito es estar a la vanguardia del gobierno internacional. Con disparadores que se originan en los nuevos negocios y por los cuales hay que actuar con diligencia. Es un Código de buenas prácticas de gobierno corporativo, que debe su nombre en honor a Mervyn E. King, antiguo Presidente del Tribunal Supremo Sudafricano.

El Código King III se compone de setenta y cinco principios de gobernanza corporativa, de los cuales siete principios generales y veinte y cuatro recomendaciones prácticas son para el gobierno de TSI, cuya similitud con los principios de la norma ISO/IEC 38500, son evidentes.

\subsubsection{4. $\mathrm{COBIT}^{\circledR} 5$}

El marco de COBIT ${ }^{\circledR}$ versión 5 (ISACA, 2012), adoptó el estándar ISO/IEC 38500, volviéndose en un marco de control para el Gobierno y la Gestión de TSI de la empresa. Catalogado como un marco integral que apoya a las empresas a lograr sus metas y entregar valor mediante un gobierno y una administración efectiva de la TSI. La base del marco constituye cinco principios básicos que quedan cubiertos e incluyen una guía exhaustiva sobre los denominados catalizadores para el gobierno y la gestión de TSI de la organización.

$\mathrm{COBIT}^{\circledR}$ permite a las TSI ser gobernadas y gestionadas de manera holística, abarcando el negocio completo y las áreas funcionales de responsabilidad de TSI.

El marco de trabajo se creó con la finalidad de atender holísticamente a la organización (Fernández Sánchez, et al., 2012); sin embargo, aún existen productos en la versión inicial que deben superar algunos retos y resolver varios asuntos para poder implementar gobierno de TSI de manera exitosa.

El haber adoptado el estándar ISO/IEC 38500 lo lleva apoyar su trabajo en tres tareas:

1. Evaluar las necesidades de las partes interesadas

2. Fijar directivas

3. Monitorear el desempeño, cumplimiento y progreso, comparándolos con los objetivos prestablecidos

\subsubsection{5. $\mathrm{PMBOK}^{\circledR}$}

El Libro de Conocimiento para la Dirección de Proyectos PMBOK ${ }^{\circledast}$ (Project Management Institute, 2013), detalla un conjunto de buenas prácticas para la dirección de proyectos, aplicable de acuerdo a las circunstancias del proyecto, cuyo propósito es aumentar las posibilidades de éxito de los proyectos.

Reconocido como un estándar para la dirección de proyectos empresariales que se centra en áreas muy concretas (Fernández Sánchez, et al., 2012), cuya base de aplicación son los cinco grupos de procesos:

1. Inicio

2. Planificación

3. Ejecución

4. Monitoreo y Control

5. Cierre

Grupo de procesos que sirven para categorizar los cuarenta y siete subprocesos de la dirección de proyectos, enfocadas en diez áreas de conocimiento:

1. Integración 
2. Alcance

3. Tiempo

4. Costos

5. Calidad

6. Recursos Humanos

7. Comunicaciones

8. Riesgos

9. Adquisiciones

10. Interesados

Además, este grupo de procesos tiene la finalidad de aplicar e integrar adecuadamente las áreas de conocimiento.

Este marco para la dirección de proyectos constituye una guía más que una metodología específica. Se apoya en diferentes metodologías como Project In Controlled Enviroment PRINCE2 (Corbelli, 2006) para implementar el marco de la dirección de proyectos de TSI.

Si bien $\mathrm{PMBOK}^{\circledR}$ no es un marco de gobierno de TSI, específicamente, cumple una función de supervisión de proyectos que está alineada con el modelo de gobierno de la organización, el cual permite integrar los datos e información de los proyectos estratégicos de TSI y ser evaluados hasta el punto de certificar si cumplen los objetivos de alto nivel definidos por la alta dirección.

El cierre adecuado de los proyectos de inversión en TSI, ayudan a que la organización avance en su visión competitiva de mercado, abriéndose paso en la industria, mejorando el control y la calidad, y reduciendo los costos.

\subsubsection{Modelo Malcolm-Baldrige}

El modelo de excelencia Malcolm-Baldrige, de alcance a las operaciones en EEUU y patrocinado por el Instituto Nacional de Estandarización y Tecnología de EEUU (Benavides Velasco, et al., 2003), se encarga de evaluar y mejorar el desempeño mediante 7 criterios básicos (BNQP Baldrige National Quality Program, 2015):

1. Liderazgo

2. Planificación estratégica

3. Enfoque al cliente y el mercado

4. Información y análisis

5. Enfoque de los recursos humanos

6. Gestión de procesos

7. Resultados del negocio

Estos criterios tienen por objetivo: entregar mayor valor al cliente y, mejorar el rendimiento de la empresa. El programa otorga un puntaje total de 1000 puntos en la evaluación final.

Define el liderazgo cómo el alto rango que guía y mantiene a su organización. Incluye el sistema de gobierno, las responsabilidades éticas, sociales y comunidades claves. En efecto, le brinda mayor importancia al criterio de liderazgo en la consecución de la excelencia (Pastor Tejedor, et al., 2012).

\subsubsection{Modelo EFQM}

El modelo de excelencia EFQM, tiene como alcance a las operaciones en Europa y patrocinado por la European Foundation for Quality Management (Martínez-Vilanova y Martínez, 2008) (European 
Foundation for Quality Management [EFQM], 2013). Se encarga de mejorar el rendimiento de la empresa mediante la comprensión de puntos fuertes y débiles que necesitan perfeccionar a través de la evaluación de 5 agentes facilitadores o "criterios" que son:

1. Liderazgo

2. Estrategia

3. Personas

4. Proveedores y recursos

5. Procesos, productos y servicios

Además, tenemos 4 criterios resultados que tratan sobre lo que la organización logra, estos son:

1. Clientes

2. Personas

3. Sociedad

4. Clave

La premisa fundamental del modelo expresa que los resultados de rendimiento de la empresa, se logran mediante un Liderazgo que dirija e impulse la política y estrategia.

\subsubsection{Modelo Iberoamericano}

El modelo iberoamericano de excelencia tiene alcance en la gestión global de la calidad en el ámbito iberoamericano público y privado. Está patrocinado por la Fundación Iberoamericana para la Gestión de la Calidad (Fernández Martínez, et al., 2012). El trabajo se fundamenta en 5 criterios facilitadores y 4 criterios resultados, cada criterio compuesto por sub-criterios. Los criterios facilitadores son:

1. Liderazgo y estilo de gestión

2. Estrategia

3. Desarrollo de las personas

4. Recursos y asociados

5. Procesos y clientes-ciudadanos

Los criterios resultados son:

1. Clientes-ciudadanos

2. Desarrollo de las personas

3. Sociedad

4. Globales

Ambos grupos de criterios asignan un puntaje total de 1000 puntos en la evaluación final. Al igual que EFQM, brinda mayor importancia al criterio Liderazgo mediante la asignación de mayor ponderación (Pastor Tejedor, et al., 2012). Dentro de la libertad del modelo, cada empresa puede considerar los valores de mayor o menor importancia como resultado de los criterios de valor definidos (FUNDIBEQ, 2014).

\subsection{EL VALOR}

La presente sección tiene como finalidad definir el concepto de valor y su importancia en el campo de la investigación. 


\subsubsection{DEFINICIÓN DE VALOR}

En el contexto de los servicios que entregan las empresas de tecnología, el valor tiene algunas definiciones:

- “...en las organizaciones privadas, el valor creado por las TIC se refleja casi siempre en la eficiencia o la productividad de las empresas, que se observan a través de la medición de costos, ingresos, utilidades o a través del valor de las acciones de la empresa en el mercado. En el caso del sector público, además de estos indicadores, se requiere diseñar indicadores para dar seguimiento a metas relacionadas con mejorar la equidad, la transparencia, la rendición de cuentas, la participación ciudadana, el combate a la corrupción o la efectividad de las políticas públicas en un sentido más amplio, a lo que se ha llamado recientemente valor público" (Luna Reyes, et al., 2015).

- "...la importancia que tiene una acción específica en relación con las necesidades de un individuo (o empresa) en un momento específico, menos los costos que participan en la obtención de tales beneficios" (Lovelock, et al., 2011).

- "El aspecto esencial del concepto de servicio. Desde el punto de vista del cliente, el valor consta de dos componentes básicos: funcionalidad y garantía. La funcionalidad es lo que el cliente recibe, mientras que la garantía reside en cómo se proporciona" (OGC, 2011).

- "La cuantificación de la importancia que un determinado artefacto o tarea tiene para todos los implicados en ese sistema" (Cabrero Moreno, 2009). Esta definición trata de orientar los recursos hacia donde más puedan aportar a los implicados, que resulta ser una teoría sumamente predictiva dónde deben ser invertidos el tiempo y demás recursos. En el marco de la administración de las operaciones, se utiliza el término Valor en alusión a lo que los usuarios esperan recibir por la compra de un producto o servicio. Siendo las organizaciones quienes deben proporcionar ese valor para conservar el negocio a través de la satisfacción de los usuarios finales.

- “... el desarrollo de actividades dentro del tiempo establecido, dentro del presupuesto asignado, con la calidad apropiada, con los beneficios prometidos, etcétera ... “ (Fernández Vicente, 2009).

- "El Valor es el(los) resultado(s) final(es) de negocio esperado(s) de una inversión de negocio impulsada por TSI, donde dichos resultados pueden ser financieros, no financieros o una combinación de ambos" (ITGI, 2008).

- "Valor intrínseco se refiere a lo que el producto o servicio aporta al cliente. Esto significa en términos específico o valor de servicio" (Louis, 2003).

- "La calidad basada en valor se debe proyectar en forma congruente. Se debe establecer un proceso claro para la adopción, la puesta en práctica y el reforzamiento de esos valores en todos los niveles de la organización, para lograr la categoría de empresa con Control de Calidad Total CCT" (Rye, 2000).

- "El Valor consiste en las características, rasgos y atributos de desempeño o cualquier otro aspecto de los bienes y servicios por los cuales los clientes están dispuestos a entregar recursos (generalmente dinero)" (Robbins, et al., 2005). Siendo estos clientes los que determinan qué tiene valor (Sheridan, 1999).

EI GoTSI es importante para el rol de aumentar el valor y proteger los intereses de los accionistas de la organización; además, de asegurar que el uso de la tecnología sea eficaz, eficiente y aceptable. "El retorno de la inversión simplemente no es el único camino en la generación de Valor de las TSI; un programa de inversión en TSI puede contribuir mezclando muchos más beneficios que los rendimientos financieros, por ejemplo, la posibilidad de llevar a cabo una 
nueva capacidad estratégica de las TSI" (Thorp, 2007). Por último, medir el valor es un proceso difícil que demanda un soporte de estimación de valor para pasar de la subjetividad a la objetividad de los aspectos evaluados.

\subsubsection{EL VALOR EN EL CAMPO DE LA INVESTIGACIÓN}

Catton (1954) propuso una teoría del valor que esencialmente sugiere que los valores fundamentales de las personas guían su proceso de toma de decisiones. "El comportamiento preferencial de un individuo muestra ciertas regularidades y este patrón se puede atribuir a un cierto estándar o código, que persiste a través del tiempo. Los valores proporcionan una base sobre la cual las personas pueden controlar sus intensidades deseando desiderata (algo deseable)" (Catton, 1954). Sobre la base de las opciones disponibles, la gente hace las preferencias u opciones que se basan en sus valores. En el contexto de la organización, el conocimiento de tales preferencias de los individuos proporciona un contexto para la toma de decisiones de gestión.

El valor no es una propiedad de un objeto, sino que es una cualidad de la relación (Catton, $1954 \mathrm{p}$. 108). El deseo de una persona por algo bajo una situación dada depende de la percepción selectiva de esa persona. La percepción selectiva dirige la valoración intercalando objetivos finales con otras metas intermedias, es decir, un objetivo puede perseguirse con el fin de alcanzar algún objetivo final más alto. Así, la naturaleza de los principales objetivos aceptados por los individuos se complementa con sus nociones de formas en que estos objetivos podrían verse afectados por los acontecimientos futuros. Estos a su vez son los determinantes de valores de las personas. La teoría de Valor proporciona una plataforma teórica para afirmar que los valores son importantes para la toma de decisiones y la incorporación de los valores en el desarrollo de los objetivos de decisiones ayuda significativamente a los individuos que aceptan los resultados de esas decisiones.

Catton (1954) adopta un concepto de campo de los valores para entender y predecir el comportamiento humano a partir del estudio de los valores. En este enfoque, el concepto de valor es percibido como somática (en el cerebro) que rodean el valor del objeto (Catton, 1954). Se supone que tienen una correspondencia a algún campo externo postulado. La naturaleza de este campo de valor es multidimensional. Los psicólogos han estudiado ampliamente los valores, pero más en términos de motivaciones (Catton, 1954). Sin embargo, existe una diferencia intrínseca en lo que los sociólogos llaman valores y los psicólogos llaman motivaciones.

La idea detrás del estudio de las motivaciones en la gestión, tanto interna como externa, ha sido el mismo que en el campo de la sociología, es decir, predecir el comportamiento humano a partir del estudio de estos conceptos. Los psicólogos sostienen que la naturaleza humana no permite la valoración de todo lo que es fácilmente disponible e indispensable para su supervivencia (Catton, 1954).

Catton (1954) conceptualiza el valor como un campo de fuerzas. Sostiene que cuando observamos una persona valorando algo, ciertas cosas se hacen evidentes a partir del comportamiento de esa persona. Esto es cierto incluso para varias personas en diferentes momentos en relación con diversos objetos.

Catton (1954) define el comportamiento como la valoración "deseo de dar o hacer algo con el fin de obtener o mantener alguna otra cosa" (p. 172). Catton (1954) sugiere que cualquier estudio de una teoría del valor tiene la intención de convencer a la gente de que ciertas normas o códigos de conducta son más aceptables que los otros. Los valores no son más que productos de un código 
de conducta, que el defensor del código quiera hacer llegar. Las teorías acerca de los valores enuncian algunos valores más amplios a los que podrían estar subordinados otros valores.

En ciencias de la administración, este concepto de los valores que guían el proceso de toma de decisiones se desarrolló mediante Keeney (1992), quien sostiene que los valores son principios de orientación para evaluar la conveniencia de una consecuencia particular. Los valores son lo que nos preocupa y que debe ser la fuerza motriz de nuestra toma de decisiones (Keeney, 1992 pág. 3). Los valores son los principios de la evaluación, que utilizamos para evaluar las consecuencias reales o potenciales de acción y la inacción de las decisiones (Keeney, 1992). Enfoque en los valores que guían la situación de decisión hace que la búsqueda de alternativas de un proceso creativo, produce alternativas únicas.

Los cambios de época, traen un cambio que afecta profundamente a las organizaciones que ven soportados su productividad y eficiencia en las TSI. Lo paradigmático de todo es que la nueva forma de ver el mundo es con las personas en primer plano y, los sistemas de información y tecnologías, con todos sus componentes, en un segundo plano de importancia; en donde los primeros deben incidir en los segundos; además, la especial atención e importancia que tiene el valor de las decisiones sobre los sistemas y la interacción, que ha entrado en la sociedad para quedarse.

Las organizaciones crean valor al ofrecer los tipos de servicios que los clientes internos y externos necesitan, al presentar con exactitud sus capacidades y entregarlos de modo agradable y conveniente. A cambio las organizaciones reciben valor de aquellos clientes beneficiados, que puede ser en dinero o en desempeño (Lovelock, et al., 2011). El intercambio de valor es mutuo. La organización recibe el esmero del trabajador y, a cambio, éste recibe su sueldo, bonos y experiencias profesionales como formación y experiencias laborales.

De ahí que las organizaciones necesitan establecer una serie de valores que puedan defender moral y legalmente para guiar sus acciones y definir las relaciones, tanto con los empleados como con los clientes (Lovelock, et al., 2011). En el mejor de los escenarios posibles, los gerentes deben usar los valores que ha definido la organización como un punto de referencia para reclutar y motivar a los pares o subalternos.

Las organizaciones, están pasando de una mecánica tradicional a una basada en la importancia y urgencia de hacer las cosas, en donde si bien todas las acciones y decisiones merecen la misma atención, no todas son de igual importancia, ya que algunas de ellas aportan más "valor" que otras.

Con el pasar del tiempo el término Valor se ha vuelto un concepto importante de GoTSI, representado a través de dos formas: Mejorando la toma de decisiones a través de incrementar la calidad o la temporización de la información; e, Incrementando la eficacia, calidad y funcionalidad de los procesos (Hunter, et al., 2009).

De acuerdo a un estudio llevado a cabo por el Massachusetts Institute of Technology MIT, 100 de los ejecutivos de TSI y no TSI, mencionan que las organizaciones se guían a través de cuatro pasos para que el negocio obtenga el valor de TSI. Un paso anterior es requisito del siguiente, aunque no son necesariamente una relación de causalidad, tal como se muestra en la figura 2.3, extraída de ( (Hunter, et al., 2009). 


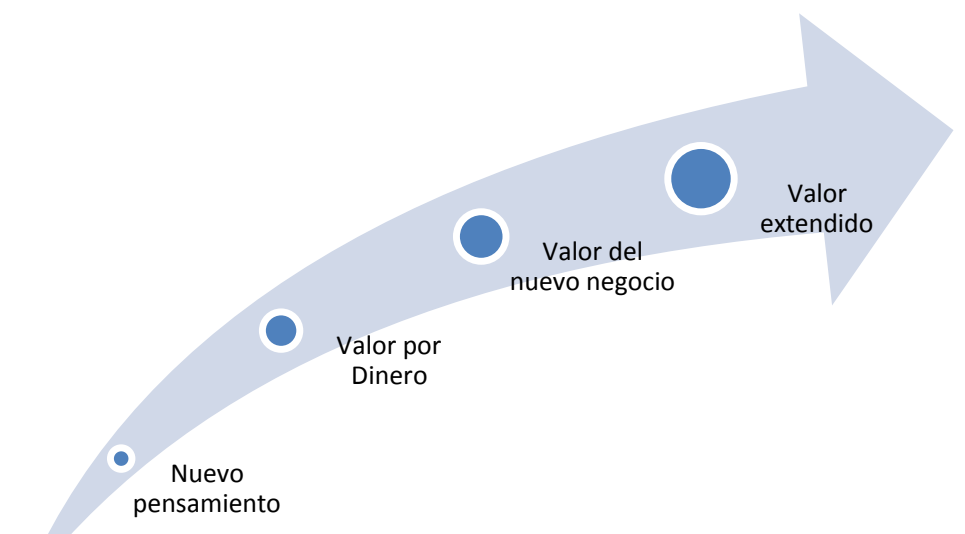

Figura 2.3. El camino para valorar las TSI.

El dilema que se presenta, es que las métricas disponibles para medir el valor de TSI están fuera de interés de cumplimiento que buscan los stakeholders; o en el peor de los casos, no están disponibles.

\subsection{GOBIERNO DE TECNOLOGIAS Y SISTEMAS DE INFORMACIÓN}

La presente sección tiene como propósito realizar una introducción al concepto de Gobierno de las TSI, beneficios e importancia en el campo de la investigación.

\subsubsection{DEFINICIÓN DE GoTSI}

El concepto de GoTSI no es nada nuevo, su historia se remonta a los años 80 y con mayor fuerza a fines del siglo XX. Su efecto se centra en cuestiones más relacionadas con la gestión y el gobierno (Piattini Velthuis, et al., 2007). De manera específica, los avances de la experimentación y tecnología, definen la necesidad de diferenciar estos dos aspectos (Gobierno y Gestión) a nivel de abstracción si se desea lograr un adecuado alineamiento de las TSI con los objetivos del negocio en procura de resultados medibles, surgiendo así el concepto de dirigir y controlar el uso adecuado de las TSI en las organizaciones: Gobierno de las TSI (Fernández Vicente, 2009).

Con el pasar del tiempo, autores de la temática han expresado diversas definiciones de GoTSI:

- “... subconjunto o dominio del gobierno de la organización, o en el caso de una corporación, como gobierno corporativo" (ISO/IEC, 2008, 2015).

- "El gobierno asegura que las necesidades, condiciones y opciones de las partes interesadas son evaluadas para determinar los objetivos de empresa acordados y equilibrados que han de ser alcanzados; establecer la dirección mediante la priorización y toma de decisiones; y supervisando el rendimiento y el cumplimiento respecto a la dirección y objetivos acordados" (ISACA, 2012).

- “... competencia organizacional para ejercitar de manera continuada la autoridad referente (guía) sobre la estrategia y el desarrollo de la arquitectura de $\mathrm{Tl}$, y el consiguiente diseño, implementación y operación de los sistemas de TI. Por ello, se centra en: Estrategia y Arquitectura de TI, Gestión de la cartera de proyectos y Gestión de los programas (y proyectos) de TI" (Hoogervorst, 2009).

- "... el liderazgo, los procesos, y las estructuras que aseguran que las tecnologías de la organización apoyan los objetivos y estrategias de las mismas ..." (Fernández Vicente, 2009). 
- "Es el sistema por el que se dirige y controla la utilización actual y futura de la tecnología de la información" (ISO/IEC, 2008, 2015).

- "El gobierno de TI se refiere a la manera en que un liderazgo lleva a cabo la entrega de capacidad importante al negocio usando la estrategia de TI, sus metas y objetivos. El gobierno de TSI se refiere a la alineación estratégica entre las metas y los objetivos del negocio y, la utilización de recursos de TI para lograr efectivamente los resultados deseados" (Mueller, et al., 2008).

- "El gobierno de las TI debe ser integral e incluir tanto los procesos de gobierno como las perspectivas de estructura, integrándolos, el alineamiento de negocio, las operaciones de TSI y la medición de desempeño y la entrega de valor" (Dahlberg, et al., 2006).

- "El gobierno de Tl es el alineamiento estratégico de TI con la organización tal que se consigue el máximo valor de negocio por medio del desarrollo y mantenimiento de un control y responsabilidades efectivas, gestión de desempeño y gestión de riesgos de $\mathrm{TI}^{\prime \prime}$ (Webb, et al., 2006).

- "Es el sistema mediante el cual se dirige y controla el uso actual y futuro de las TIC. Incluye la evaluación y la dirección de planes para el uso de las TIC en el soporte a la organización y la monitorización de este uso para el cumplimiento de los planes, así como la definición de estrategias y políticas relativas al uso de las TIC en la organización" (AS 8015, 2005).

- "Es responsabilidad del directorio de la empresa y se basa en el liderazgo, estructura organizacional y procesos que aseguren que las Tecnologías de Información den soporte a la estrategia y objetivos de la organización" (ITGI, 2005).

- "El Gobierno de TSI consiste en un completo marco de estructuras, procesos y mecanismos relacionales. Las estructuras implican la existencia de funciones de responsabilidad, como los ejecutivos y responsables de las cuentas de $\mathrm{TI}$, así como diversos Comités de TI. Los procesos se refieren a la monitorización y a la toma de decisiones estratégicas de TI. Los mecanismos relacionales incluyen las alianzas y la participación de la empresa/organización de TI, el diálogo en la estrategia y el aprendizaje compartido" (Van Grembergen, et al., 2004).

- "El gobierno de TI es el marco de trabajo de los derechos de decisión y la responsabilidad última para fomentar comportamientos deseables en el uso de las TI" (Weill, et al., 2004)

Por todo lo que antecede, el GoTSI permite que surjan nuevas estructuras y procesos en las que otros puedan gestionar sus actividades de forma eficaz. Definiendo y difundiendo mecanismos de trabajo necesarios para asegurar que los objetivos de alineamiento de negocio y TSI se cumplan.

El tema de GoTSI resulta ser importante para los procesos organizacionales, ya que muchas empresas hoy en día dependen en gran medida de la información; sin embargo, este tema se constituye en una disciplina con pocos estándares y marcos de trabajo reconocidos (Lucio Nieto, 2013).

\subsubsection{BENEFICIOS DE GoTSI}

Algunos de los beneficios de GoTSI (Toomey, 2009) (Stenzel, 2010) (Andaluz, et al., 2015) (Lo, et al., 2015) son:

- Orientado al entorno empresarial

- Mejora la gestión de riesgos relacionados con TSI

- Mejora la comunicación y relaciones de TSI-negocio

- Disminuye los costos de TSI contribuyendo a la excelencia operacional 
- Mejora la entrega de valor

- Aumento del ROI en proyectos de TSI de un $30 \%$ a un valor entre $135 \%$ y $240 \%$

- Aumento porcentual de proyectos exitosos

- Mejor selección y adopción de tecnologías emergentes

\subsubsection{GOTSI COMO ÁREA DE INVESTIGACIÓN}

Como se ha podido observar en la sección 2.4.1, el GoTSI es una disciplina que ha evolucionado con el tiempo. Uno de los estándares que ha reconocido su interés es el ISO/IEC 38500:2015 (ISO/IEC, 2008, 2015). Aunque el Sistema Universitario Español (SUE) ha hecho valiosas aplicaciones del estándar, se tiene la esperanza de que tome fuerza a partir del apoyo que le ha brindado la Conferencia de Rectores de las Universidades Españolas (CRUE) (Morales, 2015).

En el caso de COBIT ${ }^{\circledR} 5$ (ISACA, 2012), reconocido como un marco de referencia para el gobierno de TSI, es un conjunto de herramientas de apoyo que permiten a los gerentes de TSI encadenar los conceptos relacionados a los requerimientos de control y riesgos del negocio (Hamidovic, 2010).

Se destaca el trabajo de (Almeida, et al., 2013) acerca de los mecanismos de gobierno de TSI que utilizan las corporaciones para llevar a cabo un gobierno efectivo; no obstante, estos mecanismos de GoTSI carecen de adecuadas definiciones y en algunos casos existen incongruencias, que a opinión de los autores deben ser formalizados y mitigadas las ambigüedades.

Existen algunos marcos de gobierno de TSI y ninguno es en sí mismo un marco de gobierno completo. Por ejemplo, Calder-Moir propone un marco de gobierno de TSI, desde la óptica de ISO/IEC 38500, basado en un conjunto de modelos coordinados y organizados para el gobierno de TSI.

En la figura 2.4 se muestra el modelo de gobierno de TSI, extraída de (Calder, 2008). Como se observa, se presentan algunos marcos existentes.

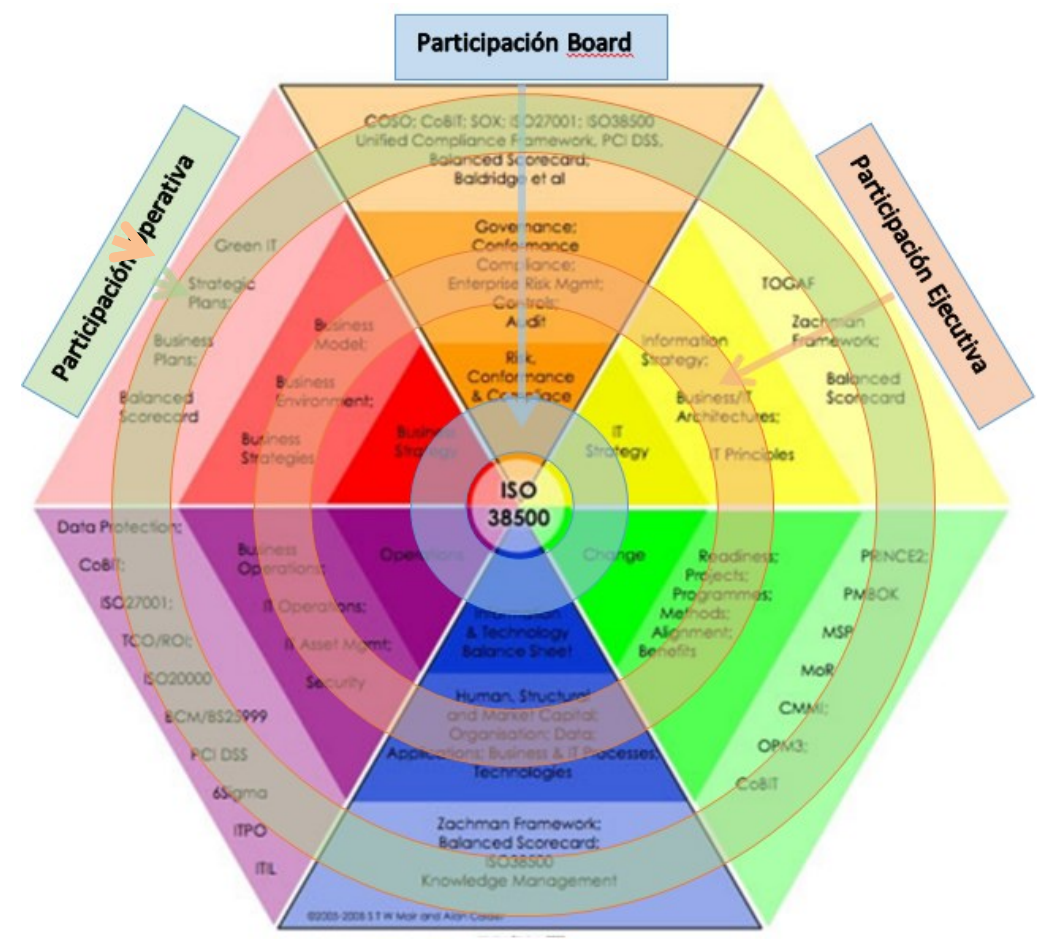

Figura 2.4. Modelo de Gobierno de TSI. 
El modelo de Calder-Moir cumple con los principios del estándar: evaluar, dirigir y monitorear. Al igual que COBIT, su proceso de desarrollo continuo es el de Deming (Calder, 2008): "PDCA: Planear, Hacer, Verificar, Actuar".

Para culminar, se observa que ningún marco de GoTSI es por sí sólo completo. Sin embargo, juegan un rol importante en las organizaciones que se traducen en términos de desempeño y rendimiento de las operaciones de TSI

\subsection{MODELO IBEROAMERICANO}

La presente sección tiene como propósito realizar una introducción al Modelo Iberoamericano de Excelencia: principios, criterios y beneficios.

\subsubsection{DEFINICIÓN DEL MODELO}

El Modelo Iberoamericano fue creado por Fundación Iberoamericana para la Gestión de la Calidad FUNDIBEQ en 1999 para la gestión de la calidad y el premio iberoamericano a la calidad (FUNDIBEQ, 2014). Su característica más importante es la autoevaluación (Lucio Nieto, 2013) (FUNDIBEQ, 2014) (Pastor Tejedor, et al., 2012), la cual permite a las organizaciones determinar su situación y emprender acciones de mejora (Cilla Álvarez, 2004) (Martínez-Moreno, et al., 2012).

El Modelo Iberoamericano basa su enfoque en determinados agentes facilitadores de la organización y en los resultados (FUNDIBEQ, 2014). Es un modelo supranacional que trata de crear un punto de referencia en el que se encuentran reflejados distintos modelos de excelencia nacionales de los países iberoamericanos (Rodríguez Maseda, 2015); entre los que encuentra el Ecuador.

De la investigación encontrada se determinan puntos en común entre el Modelo EFQM y el Modelo Iberoamericano, partiendo del hecho de que los criterios facilitadores del segundo son una adopción del primero, y existiendo pocas pero importantes diferencias entre ambos, como por ejemplo, el sistema organizativo, siendo mejor en el Modelo Iberoamericano; no obstante, los Resultados son su Talón de Aquiles (Nieto, et al., 2006).

En fin, el Modelo Iberoamericano es considerado un modelo de autoevaluación que se puede aplicar a cualquier tipo de organización y/o clase de actividad, enfocado en la dirección de la calidad con visión empresarial.

En el caso de Ecuador, el Modelo Iberoamericano de Excelencia, al formar parte de la Norma Técnica de Certificación de la Calidad del Servicio Público, es impulsado por la Secretaria Nacional de la Administración Pública (Secretaria Nacional de la Administración Pública, 2014).

\subsubsection{PRINCIPIOS Y CRITERIOS DEL MODELO}

El modelo se sitúa en el marco de una respuesta a los siguientes principios (FUNDIBEQ, 2014):

- Lograr resultados equilibrados

- Añadir valor a los clientes

- Liderar con visión, inspiración e integridad

- Gestionar por procesos

- Alcanzar el éxito mediante personas

- Favorecer la creatividad y la innovación

- Desarrollar alianzas

- Asumir la responsabilidad de un futuro sostenible 
Según FUNDIBEQ (2012), existen cinco criterios denominados "Facilitadores":

1. Liderazgo y Estilo de Gestión: Analiza el estilo de liderazgo con visión y, ¿Cómo este crea la cultura y los valores para el éxito en la organización?

2. Estrategia: Analiza, ¿Cómo la organización alcanza los resultados a través de la puesta en práctica de la misión y visión?

3. Desarrollo de las Personas: Analiza, ¿Cómo la organización maximiza el potencial de las personas en contribución efectiva y eficaz de la gestión?

4. Recursos y Asociados: Analiza, ¿Cómo la organización genera alianzas en contribución a la estrategia y gestión eficiente y eficaz de la organización?

5. Procesos y Clientes-Ciudadanos: Analiza, ¿Cómo la organización gestiona sus procesos en cumplimiento de las necesidades y expectativas de clientes-ciudadanos?

Según FUNDIBEQ (2012), existen cuatro criterios de "Resultados":

1. De clientes-ciudadanos: ¿Cuáles son los resultados que ha conseguido la organización con sus clientes-ciudadanos?

2. Desarrollo de las personas: ¿Cuáles son los resultados que ha conseguido la organización con el desarrollo de las personas?

3. Sociedad: ¿Cuáles son los resultados que ha conseguido la organización con las necesidades y expectativas de la sociedad en general?

4. Globales: ¿Cuáles son los resultados que ha conseguido la organización en relación a los objetivos establecidos y la de sus Interesados?

\subsubsection{BENEFICIOS DEL MODELO}

El Modelo Iberoamericano tiene beneficios considerados importantes, los cuales son expuestos en (FUNDIBEQ, 2014):

- Introducción de la autoevaluación

- A partir de este referente de modelo de excelencia, se facilita el esfuerzo en países de Iberoamérica

- En corto tiempo, introduce a la organización a un sistema de mejora continua

- Homogenización y/o estandarización de las características evaluadoras

\subsubsection{EL MODELO DE EXCELENCIA Y EL GOTSI}

Esta sección es importante porque, a partir de definiciones descritas en secciones anteriores, se analiza comparativamente el estándar ISO/IEC 38500 y el marco de trabajo COBIT ${ }^{\circledR} 5$ con el modelo de excelencia, con la perspectiva de definir las pautas para medir la calidad de sus procesos enfocados en valor.

En este trabajo se ha definido los siguientes criterios de comparación: Definición, alcance, ámbito, prácticas, beneficios, principios, métricas y enfoque; por considerarlos como aspectos importantes de influencia en un modelo de calidad.

La tabla 2.1 muestra la matriz comparativa entre dos modelos de gobierno de TSI. Como se observa, COBIT ${ }^{\circledR} 5$ adopta características del estándar ISO/IEC 38500. Por lo tanto, se puede trabajar con éste para desarrollar el modelo de calidad propuesto. 
Tabla 2.1. Comparativa entre los Modelos de Gobierno de TSI

\begin{tabular}{|c|c|c|}
\hline & ISO/IEC 38500 & $\mathrm{COBIT}^{\circledR} 5$ \\
\hline DEFINICIÓN & Define el qué hacer del buen gobierno & Define el qué y cómo lo debe hacer \\
\hline ALCANCE & $\begin{array}{l}\text { Tiene como alcance el qué del uso } \\
\text { aceptable de las TI por parte de gobierno } \\
\text { corporativo de TI }\end{array}$ & $\begin{array}{l}\text { Tiene como alcance la integralidad } \\
\text { representada en el qué del uso aceptable de } \\
\text { las TSI por parte del gobierno corporativo y el } \\
\text { gobierno de gestión de TSI. }\end{array}$ \\
\hline ÁMBITO & $\begin{array}{l}\text { Se aplica a todas las organizaciones, } \\
\text { pequeñas o grandes, públicas o privadas, } \\
\text { con fines y sin fines de lucro. }\end{array}$ & $\begin{array}{l}\text { Se aplica a todas las organizaciones, } \\
\text { pequeñas o grandes, públicas o privadas, con } \\
\text { fines y sin fines de lucro. }\end{array}$ \\
\hline PRÁCTICAS & Evaluar, Dirigir y Monitorear. & Evaluar, Orientar y Supervisar. \\
\hline BENEFICIOS & $\begin{array}{l}\text { Genera beneficios prestando la debida } \\
\text { atención al modelo y aplicando } \\
\text { correctamente los principios. }\end{array}$ & $\begin{array}{l}\text { Genera beneficios en el soporte a las } \\
\text { decisiones, valor en TSI, alcance de } \\
\text { excelencia operativa, control de riesgos, } \\
\text { costos óptimos y, cumplimiento regulatorio y } \\
\text { político. }\end{array}$ \\
\hline PRINCIPIOS & 6 & 5 \\
\hline MÉTRICAS & No & Si \\
\hline ENFOQUE & Actividades & Procesos \\
\hline
\end{tabular}

La tabla 2.2 muestra la matriz de criterios de calidad que promueven la entrega de valor en el modelo iberoamericano. Como se observa, todos los agentes facilitadores de calidad definen criterios de calidad basada en valor. Con estos criterios se podrán generar vínculos con los marcos de gobierno.

Tabla 2.2. Modelo Iberoamericano - Criterios de Calidad que promueven la Entrega de Valor

\begin{tabular}{|c|c|}
\hline Facilitadores & Criterios de Calidad \\
\hline Liderazgo & $\begin{array}{l}\text { 1a: Se promueve de manera formal la definición de valores. Se modeliza el papel de la } \\
\text { organización, con claros valores y expectativas, en línea con los principios de servicio } \\
\text { público, la misión, visión y valores de la organización. } \\
\text { 1b: Se definen las actividades y/o procesos claves de la organización; en especial } \\
\text { aquellos que generan mayor valor para el cliente y la misma organización, área o } \\
\text { servicio. }\end{array}$ \\
\hline Estrategia & $\begin{array}{l}\text { 2b: Se asume las responsabilidades y valores de la sostenibilidad en lo que se refiere a } \\
\text { aspectos económicos, sociales y ambientales; así como legales. } \\
\text { 2c: Se evidencia el desarrollo de estrategias coherentes con la misión, visión y valores, } \\
\text { y basada en las necesidades y expectativas de los grupos de interés y en información } \\
\text { obtenida a través de actividades basadas en la investigación y la innovación. }\end{array}$ \\
\hline $\begin{array}{l}\text { Desarrollo de las } \\
\text { personas }\end{array}$ & $\begin{array}{l}\text { 3d: Se promueven actividades sociales y culturales que identifican y aportan valor a la } \\
\text { organización, área o servicio. }\end{array}$ \\
\hline $\begin{array}{l}\text { Recursos y } \\
\text { asociados }\end{array}$ & $\begin{array}{l}\text { 4b: Se cultiva, desarrolla y protege la propiedad intelectual singular, con el fin de } \\
\text { maximizar su valor para el cliente. } \\
\text { 4d: Se establecen mecanismos que permitan conocer y mejorar el involucramiento y } \\
\text { resultados de los proveedores para maximizar el valor añadido de los mismos y su } \\
\text { incorporación en la cadena de valor. } \\
\text { Se estructuran las relaciones de asociación para crear una sinergia de valor. }\end{array}$ \\
\hline $\begin{array}{l}\text { Procesos y } \\
\text { Clientes - } \\
\text { ciudadanos }\end{array}$ & $\begin{array}{l}\text { 5a: Se evidencia un sistema que diseña, gestiona, mide y mejora los procesos y/o } \\
\text { actividades orientado a aumentar el valor percibido por clientes y stakeholders } \\
\text { 5c: Se evidencia aumentos en las propuestas de valor y mejoramiento del ciclo de vida } \\
\text { útil de los productos y servicios públicos, teniendo en cuenta su impacto en la salud } \\
\text { pública, la seguridad y el medio ambiente. }\end{array}$ \\
\hline
\end{tabular}

En el Anexo A, que es informativo, se proporciona una breve guía práctica de las actividades de ISO/IEC 38500 basadas en valor. 
La tabla 2.3 muestra la matriz del Modelo de Excelencia vs. ISO/IEC 38500. Como se observa, existe una aproximación de alto nivel para evaluar la calidad de Gobierno de TSI basada en Valor. Los criterios $4 \mathrm{~d}$ y $5 \mathrm{c}$ no identifican relación alguna de conveniencia con las prácticas de Evaluar (E.), Dirigir (D.) y Monitorear (M.) de ISO/IEC 38500 para implementar los principios. De igual manera sucede con las prácticas de los principios de Conformidad y Comportamiento de Personas que no identifica relación con los criterios del modelo.

Tabla 2.3. Modelo de Excelencia vs. ISO/IEC 38500

\begin{tabular}{|c|c|c|c|c|c|c|c|c|c|}
\hline \multirow{2}{*}{ ISO/IEC 38500 } & \multicolumn{7}{|c|}{ MODELO EXCELENCIA } \\
\hline & 1a & 1b & 2b & 2c & 3d & 4b & 4d & 5a & 5c \\
\hline E. RESPONSABILIDAD & & & & & & & & & \\
\hline D. RESPONSABILIDAD & & & & & & & & & \\
\hline M. RESPONSABILIDAD & & & & & & & & \\
\hline E. ESTRATEGIA & & & & & & & & \\
\hline D. ESTRATEGIA & & & & & & & & \\
\hline M. ESTRATEGIA & & & & & & & & \\
\hline E. ADQUISICIÓN & & & & & & & & & \\
\hline D. ADQUISICIÓN & & & & & & & & & \\
\hline M. ADQUISICIÓN & & & & & & & & & \\
\hline E. DESEMPEÑO & & & & & & & & \\
\hline D. DESEMPEÑO & & & & & & & & \\
\hline M. DESEMPEÑO & & & & & & & & \\
\hline E. CONFORMIDAD & & & & & & & & & \\
\hline D. CONFORMIDAD & & & & & & & & & \\
\hline M. CONFORMIDAD & & & & & & & & & \\
\hline E. COM. PERSONAS & & & & & & & & & \\
\hline D. COM. PERSONAS & & & & & & & & & \\
\hline M. COM. PERSONAS & & & & & & & & & \\
\hline
\end{tabular}

\subsection{CONCLUSIONES}

En este capítulo se ha abordado, bajo el criterio de síntesis, el marco teórico que sirve de referencia para la elaboración de la propuesta doctoral. Para la definición formal, bajo un criterio conceptual (Definición, Criterios y Beneficios) de lo que será el sistema de evaluación, se han revisado 3 propuestas estructuradas de calidad, con la finalidad de afianzar el conocimiento y poder comunicar de mejor manera las ideas que se vierten en torno al modelo iberoamericano que es el soporte principal de este trabajo. Un aspecto importante se ha encontrado en el análisis del estándar ISO/IEC 38500 y el modelo Iberoamericano, incrementando la opción de implementar el estándar en las organizaciones en pro de la calidad. Este aspecto ha sido publicado en (Merchán, et al., 2015). Otro aspecto importante constituye el concepto clave de Gobierno de TSI basada en valor, el mismo que está relacionado con 6 criterios de calidad: Liderazgo y estilo de gobierno, estrategia, personas, recursos, procesos y proyectos.

Los criterios relacionados tienen un mínimo de discusión en cuanto a su importancia y urgencia; así, el liderazgo y estilo de gobierno, son reiterativos en los modelos en su reconocimiento como clave para la consecución de organizaciones eficaces; la estrategia bajo concepto alguno es objeto de dudas; la necesidad de atender a las personas está más que sustentada como para incidir más en ellas; los recursos necesarios difícilmente son discutidos; el valor bajo un escenario evaluativo de los procesos como medio de mejora es difícilmente discutido; $y$, los proyectos son reconocidos como el criterio que impulsa la razón de ser de la organización de TSI. Finalmente, estos criterios 
necesariamente deben ser percibidos por quienes se benefician del Gobierno de TSI en la organización.

En el siguiente capítulo se investigarán trabajos relacionados a la temática con el fin de apoyar en el desarrollo de dimensiones. 


\section{CAPÍTULO 3 - TRABAJOS RELACIONADOS}

\subsection{INTRODUCCIÓN}

En el capítulo anterior se mostraron los modelos de excelencia, los mismos poseen criterios y sub criterios de calidad considerados relevantes e importantes para la presente tesis doctoral al estar orientados a la autoevaluación de la calidad organizacional con perspectiva directiva, que incluyen capacidades de evaluación holística y estratégica. El trabajo de Sánchez (2013) está relacionado con la calidad de gobierno, en el que se destacan dos modelos: EFQBIT y EFQ_TIL, tanto para gobierno como para gestión de TSI, respectivamente. No obstante, este trabajo expone algunas debilidades en los momentos actuales, en relación con el aporte nacional que busca la presente propuesta de tesis doctoral, entre las cuales se encuentran:

- No considera el estándar ISO/IEC 38500, en vista de que éste no forma parte de la versión 4.1 de COBIT.

- No se define el ámbito de aplicación de manera específica.

- No considera el modelo de excelencia iberoamericano, sino el modelo EFQM como modelo de evaluación de COBIT e ITIL.

- Si bien el modelo propuesto recoge los aspectos esenciales de evaluación de la calidad de un gobierno empresarial de tecnologías y sistemas de información. Este presenta un enfoque y diseño parcial, los mismos que están desapareciendo de las organizaciones más efectivas, tendiendo a adoptar enfoques más sistemáticos y comprensivos respecto a la excelencia en la calidad.

Por lo expuesto, se plantea la necesidad de crear un Modelo de Calidad de Gobierno de Tecnologías y Sistemas de Información Basada en Valor, denominado por sus siglas en inglés VBISTGQM (Valued-Based Information System Technology Governance Quality Model) para el ámbito público.

Este capítulo tiene como objetivo presentar un mapeo sistemático de trabajos relacionados con el tema de investigación. Exponiendo distintos enfoques estratégicos de las propuestas, con la finalidad de aportar en la determinación de características y estructura de calidad.

\subsection{MAPEO SISTEMÁTICO DE TRABAJOS}

Con el objetivo de identificar las investigaciones previas de calidad de GoTSI, se realizó un mapeo sistemático de estudios, de esta forma se determinó la situación actual de calidad del GoTSI basada en valor.

En cumplimiento de los objetivos de un mapeo sistemático de estudios, los resultados obtenidos son clasificados y sometidos a un análisis temático que usualmente resume el conocimiento generado en forma de mapas visuales (Petersen, et al., 2008). En otras palabras, el método de mapeo sistemático define un proceso y estructura de informe que permite categorizar los resultados publicados hasta un momento determinado en el tiempo. Lo beneficioso de este método es que genera una visión holística del tema a investigar lo que permitirá decidir en qué áreas concretas del campo es interesante abordar una revisión sistemática más detallada (Kitchenham, et al., 2010) (Kitchenham, et al., 2011). 
Trabajos relacionados previos demuestran que existe la necesidad de innovar al realizar una identificación más sistemática de: ¿Cuáles son esos trabajos que relacionan el valor y calidad con el Gobierno de Tecnologías y Sistemas de Información?, ¿Cómo se los puede organizar? y, ¿Cuál es su contribución en el contexto del GoTSI? (Sánchez Peña, 2013), (Aguilera, 2010). Además, aunque existen trabajos de evaluación de la calidad en el contexto de GoTSI, no se tiene conocimiento de trabajo alguno sobre mapeo sistemático de estudio.

\subsubsection{PLANIFICACIÓN}

Aunque existen publicaciones acerca de implementaciones de GoTSI basadas en COBIT (Fernández Martínez, et al., 2012) e ISO/IEC 38500 (Juiz, et al., 2014), no se conoce acerca de publicación alguna en el campo de la evaluación de la calidad de GoTSI basada en valor para el ámbito público.

En años recientes, un par de investigaciones científicas y técnicas han reportado evaluaciones de la calidad enfocado en gobierno y gestión de TSI (Sánchez Peña, 2013) (Aguilera, 2010).

El caso de (Sánchez Peña, 2013), aborda el problema de la medición de la calidad en la gestión de Servicios de Tl; realizando, analizando y justificando la elección de un modelo de excelencia universalmente aceptado como EFQM y poniendo a posteriori un conjunto de modelos de medición basados en la correlación de los procesos del Modelo de la Biblioteca de la Infraestructura de Tecnologías de la Información (ITIL) y COBIT 4.1, con EFQM. De esta manera se obtienen modelos genéricos que permitirán medir la calidad de los procesos que estén relacionados con ITIL y COBIT 4.1.

En cambio (Aguilera, 2010), aborda una investigación orientadora, que promueva el debate teórico, el análisis y la descripción de las condiciones no solamente pasadas sino actuales, buscando establecer las demandas de la ciudadanía con calidad. Exponiendo como casos de estudio a España y México.

Estos trabajos previos demuestran que existe la necesidad de innovar al realizar una identificación más sistemática de cuáles son los modelos de calidad basada en valor y cómo se aplican en el ámbito del GoTSI.

El mapeo sistemático aplicado en esta tesis está basado en los pasos establecidos por (Kitchenham, et al., 2011) (Petersen, et al., 2008); siendo estos:

1. Definición de la pregunta de investigación.

2. Proceso de búsqueda.

3. Selección de estudios.

4. Filtrado de estudios.

5. Esquema de clasificación.

6. Extracción de datos y proceso de mapeo.

7. Mapa sistemático.

\section{Definición de la pregunta de investigación}

Según (Kitchenham, et al., 2007) (Kitchenham, et al., 2011), una pregunta de investigación se define en función de cuatro componentes, los cuales aplicados a la presente temática, podrían ser definidos de la siguiente manera:

1. Población: Conjunto de trabajos que describen los estudios empíricos sobre la evaluación de la calidad de GoTSI basada en valor. 
2. Intervención: Modelos de evaluación, metodologías, herramientas de excelencia basadas en valor que han servido de base.

3. Diseño del estudio: Experimentos, casos de estudio, relatos de experiencia, la investigación-acción.

4. Resultado: Grado de evidencia empírica existente en el campo.

La pregunta global de este trabajo aborda el qué de la investigación realizada desde el siguiente punto de vista: ¿Cuáles son los estudios temporales recientes acerca de la evaluación de la calidad de GoTSI basada en valor que han sido desarrollados, y cómo han sido utilizados?. La tabla 3.1, muestra las sub preguntas (SP) de investigación, las cuales tienen como propósito brindar mayor detalle del tema global de investigación.

Tabla 3.1. Sub Preguntas de investigación

\begin{tabular}{|c|c|}
\hline Sub preguntas & Motivación \\
\hline $\begin{array}{l}\text { SP 1. ¿Cuál es el ámbito de aplicación de los } \\
\text { modelos de evaluación y cuál es el tipo de valor?. }\end{array}$ & $\begin{array}{l}\text { Permite determinar el ámbito de preferencia en el cuál } \\
\text { es aplicada la investigación que puede ser público, } \\
\text { privado o público-privado. El tipo de valor de acuerdo } \\
\text { a la teoría de valor puede ser Objetiva o Subjetiva } \\
\text { (Catton, 1954), no obstante, también puede ser } \\
\text { objetiva-subjetiva. }\end{array}$ \\
\hline $\begin{array}{l}\text { SP 2. ¿Cuál es la contribución de los trabajos } \\
\text { relevados de investigación en la temática?. }\end{array}$ & $\begin{array}{l}\text { Permite identificar las técnicas y soluciones que se han } \\
\text { propuesto. En el caso de los tipos de contribuciones, } \\
\text { éstas son extraídas de (Petersen, et al., 2008). }\end{array}$ \\
\hline SP 3. ¿Qué tipo de estudio es el más usual?. & $\begin{array}{l}\text { Permite determinar el tipo de estudio más usual. Para } \\
\text { ello se respetan las denominaciones de los autores. }\end{array}$ \\
\hline
\end{tabular}

\section{Proceso de búsqueda}

Para la realización del mapeo se seleccionaron las siguientes librerías digitales significativas en las disciplinas de Ingeniería del Software y Sistemas de Información:

- Librería digital Springer.

- Science@Direct, para el área de Computer Science.

- Librería digital IEEExplore.

- Librería digital ACM.

- Google Scholar.

El listado anterior hasta cierto punto puede resultar redundante debido a que Google Scholar (tal como afirma (Noruzi, 2005)) lidera los motores de búsqueda de la comunidad de investigadores académicos y científicos. Además, indexa un gran número de fuentes con documentación técnica, recuperando documentos que no aparecen en bibliotecas digitales organizadas. Por lo tanto, se consolidan documentos que no se encuentran en otras librerías digitales.

Para realizar la búsqueda en las fuentes anteriores, se definió una cadena de búsqueda que se compone de tres partes con el fin de cubrir los conceptos que representan el dominio de evaluación de la calidad de GoTSI basada en valor. Estas partes se focalizaron en estudios que: (1) Se desarrollan en el dominio de valor; (2) Se relacionan con el dominio de GoTSI; y, (3) Presentan las evaluaciones con criterios de calidad.

La tabla 3.2 muestra la cadena de búsqueda. Como se puede observar, las definiciones son como sigue:

- Definición de conceptos y, palabras alternativas \& sinónimas. 
- Uso del operador Booleano OR, para unir palabras alternativas \& sinónimas.

- Uso del operador Booleano AND, para unir los tres conceptos principales.

- Considerando las palabras alternativas \& sinónimas de la tabla 3.2, se ejecutaron 10 búsquedas que fueron introducidas en la base de datos de cada librería digital.

Tabla 3.2. Cadena de búsqueda aplicada

\begin{tabular}{|l|l|}
\hline \multicolumn{1}{|c|}{ Conceptos } & \multicolumn{1}{c|}{ Palabras alternativas \& sinónimas } \\
\hline Value & (“Value-Based") AND \\
\hline Government & $\begin{array}{l}\text { (“IT Government" OR “IT Governance" OR “Information Technology Government" OR } \\
\text { "Information Technology Governance" OR "eGovernment") AND }\end{array}$ \\
\hline $\begin{array}{l}\text { Quality } \\
\text { Assessment }\end{array}$ & (“Quality Evaluation" OR “Quality Assessment") \\
\hline
\end{tabular}

De acuerdo a la tabla anterior, la cadena de búsqueda aplicada es la siguiente:

"Value-Based AND (IT Government OR IT Governance OR Information Technology Government OR Information Technology Governance OR eGovernment) AND (Quality Evaluation OR Quality Assessment)"

El período a revisar incluye estudios publicados durante el período 2008 - 2014, puesto que a inicios de éste se liberaron nuevas versiones del modelo de excelencia (Fundación Iberoamericana para la Gestión de la Calidad [FUNDIBEQ], 2015) y Gobierno Corporativo de TI (ISO/IEC, 2008, 2015) (Calder, 2008). Es así que la búsqueda fue realizada en el año 2015, por lo cual, las publicaciones pertenecientes a partir de este año no fueron consideradas en el mapeo sistemático. Por otro lado, se aclara que la terminología utilizada está en idioma inglés, principalmente porque es el idioma universal en el campo de la investigación.

\section{Selección y filtrado de estudios}

Se definieron criterios de inclusión de forma, para analizar sólo los estudios que se consideran de utilidad para el mapeo. Así, los criterios de inclusión codificados son:

- C1: Publicado en el período definido.

- C2: Publicado usando los conceptos definidos en los títulos y resúmenes (Abstract).

- C3: Publicado en un formato que no sea de presentación.

- C4: De aquel publicado en varias bases de datos, será tomado en cuenta uno solo.

- C5: Identifica modelos, metodologías, métodos y/o herramientas de evaluación de la calidad en el contexto de GoTSI.

También fue necesario identificar criterios de exclusión, los cuales se detallan a continuación:

- E1: Publicado fuera del período definido.

- E2: Publicado en el contexto de la Evaluación de Calidad y que no tiene enfoque en valor o GoTSI.

- E3: Estudios concernientes a evaluación de la calidad basada en valor pero desde una perspectiva distinta a TSI.

Para la selección de trabajos se cuenta con el soporte de un experto con certificación en gobierno de tecnologías de la información (CGEIT), quién corroboró con la aplicación correcta de los criterios de inclusión/exclusión realizada por el autor de este trabajo doctoral. 


\section{Esquema de clasificación}

La clasificación estará determinada por: tipo de contribución, tipo de estudio, ámbito y tipo de valor (Petersen, et al., 2008).

\section{Estrategia de extracción de datos y proceso de mapeo}

La estrategia de extracción de datos empleada en esta fase tiene por objetivo diseñar un formulario valorado que permita obtener la información necesaria para contestar las preguntas de investigación a partir de los estudios seleccionados.

El formulario en mención tiene una estructura compuesta por metadatos: autor, título, año de publicación, tipo de contribución, resumen de la contribución, tipo de estudio, palabras claves, tipo de valor, ámbito de aplicación y tipo de publicación.

\section{Mapa sistemático}

Una vez definida la clasificación de estudios y el proceso de extracción de datos, se procede con el último paso que consiste en la síntesis de trabajos representado en un mapa sistemático. Para esto se parte de la definición cuantitativa de trabajos por tipo de valor y número de publicaciones anuales; ambas se cruzan con la contribución de los estudios.

\subsubsection{EJECUCIÓN}

Debido a las limitaciones que ofrecieron un par de fuentes de búsqueda para trabajar con cadenas complejas, fue necesario diseñar cadenas de búsqueda concretas y depurar los resultados obtenidos para los fines de este trabajo doctoral.

La tabla 3.3 muestra los resultados de la cadena de búsqueda y filtrado. Como se observa, se obtuvieron 220 trabajos que de manera relativa aplican al tema de investigación, el mayor número se obtuvo de Springer con 64 trabajos, seguido de ScienceDirect con 57 trabajos. Luego, se eliminaron los duplicados producto de lo cual se consideraron 188 trabajos. En una siguiente tarea se aplicaron los criterios de inclusión/exclusión quedando como resultado 14 trabajos relevantes.

Tabla 3.3. Resultados de la cadena de búsqueda y filtrado

\begin{tabular}{|l|c|c|c|c|c|c|}
\hline \multicolumn{1}{|c|}{ Buscador } & Scholar Google & Springer & Science Direct & IEEE & ACM & TOTAL \\
\hline Resultado general & 50 & 64 & 57 & 39 & 10 & 220 \\
\hline Trabajos sin duplicados & 44 & 64 & 32 & 39 & 9 & 188 \\
\hline Trabajos relevantes & 10 & 1 & 1 & 1 & 1 & 14 \\
\hline
\end{tabular}

Por la generalidad de la pregunta, se preveía encontrar más trabajos relevantes con la finalidad de conocer técnicas de evaluación de GoTSI, pero por lo obtenido esto no fue posible. La lista completa de estudios seleccionados en este mapeo sistemático se encuentra en el Anexo B.

La figura 3.1 muestra el esquema de clasificación de los trabajos obtenidos en la búsqueda. Como se observa, las publicaciones por tipo de contribución están determinadas por modelados, métodos y ontologías. El tipo de estudio está determinado por las publicaciones a nivel de cuestionario, entrevista, estudio de caso, investigación-acción y reporte de experiencias. Las publicaciones por ámbito están determinadas por lo público, privado y público-privado. Por último, la clasificación por tipo de valor está determinada por las publicaciones cuyo valor es objetivo, subjetivo y objetivo-subjetivo. 
Además, los trabajos fueron relevados con información importante como: Volumen, Fuente, Páginas, Publisher, URL y Números Estándar. Con la finalidad de facilitar la contestación de las preguntas de investigación.

\begin{tabular}{|c|c|}
\hline Tipo de contribución & $\begin{array}{l}\text {-Modelo } \\
\text {-Método } \\
\text { - Ontología }\end{array}$ \\
\hline Tipo de estudio & $\begin{array}{l}\text { - Cuestionario } \\
\text {-Entrevista } \\
\text {-Estudio de caso } \\
\text { - Investigación-Acción } \\
\text { - Reporte de experiencias }\end{array}$ \\
\hline Ámbito & $\begin{array}{l}\text {-Público } \\
\text {-Privado } \\
\text {-Público-Privado }\end{array}$ \\
\hline Tipo de valor & $\begin{array}{l}\text {-Objetivo } \\
\text { - Subjetivo } \\
\text {-Objetivo-Subjetivo }\end{array}$ \\
\hline
\end{tabular}

Figura 3.1. Esquema de Clasificación.

Se considera que la información de los trabajos obtenida a partir de los títulos y resúmenes ha sido clara como para poder clasificarlos. Además, la introducción también despejó inquietudes. Un resumen de esta actividad se muestra en la tabla 3.4.

Tabla 3.4. Trabajos relevantes

\begin{tabular}{|l|l|l|l|}
\hline \multicolumn{1}{|c|}{ Cita } & \multicolumn{1}{|c|}{ Contribución } & \multicolumn{1}{c|}{ Tipo de Estudio } & Año \\
\hline (Lima, et al., 2011) & Modelo de gestión de servicios de TI & Estudio de caso & 2011 \\
\hline (Viscusi, 2009) & Modelo de gestión en eGov & Estudio de caso & 2009 \\
\hline (Ibrahim H. Osman, 2011) & $\begin{array}{l}\text { Modelo de evaluación de la calidad de } \\
\text { portales web }\end{array}$ & Cuestionario & 2011 \\
\hline (Ziemba, 2014) & $\begin{array}{l}\text { Modelo de evaluación de la calidad de } \\
\text { portales web }\end{array}$ & Estudio de caso & 2014 \\
\hline (Gummerus, 2011) & Ontología & Estudio de caso & 2011 \\
\hline (Jin-fu, et al., 2009) & Modelo de evaluación de la calidad & Estudio de caso & 2009 \\
\hline (Mishra, et al., 2008) & Modelo de control basado en valor & Entrevista & 2008 \\
\hline (Misuraca, et al., 2011) & Modelo de Gobierno de las TIC & $\begin{array}{l}\text { Investigación - } \\
\text { Acción }\end{array}$ & 2011 \\
\hline (Silva, et al., 2012) & $\begin{array}{l}\text { Modelo de evaluación y monitoreo } \\
\text { empresarial }\end{array}$ & Estudio de caso & 2012 \\
\hline (Li, et al., 2010) & Modelo de evaluación de la calidad & Cuestionario & 2010 \\
\hline (Lima, et al., 2013) & Modelo de gestión de Seguridad de TSI & $\begin{array}{l}\text { Reporte } \\
\text { experiencia }\end{array}$ & 2013 \\
\hline (Lohrmann, et al., 2013) & $\begin{array}{l}\text { Modelo de gestión de procesos de } \\
\text { negocio }\end{array}$ & $\begin{array}{l}\text { Reporte } \\
\text { experiencia }\end{array}$ & 2013 \\
\hline (Chou, et al., 2013) & Modelo de calidad de servicio & Cuestionario & 2013 \\
\hline (Pérez, et al., 2014) & Método para evaluación & Cuestionario & 2014 \\
\hline
\end{tabular}


La clasificación de estudios seleccionados se proporciona en el Anexo C.

La figura 3.2 muestra el diagrama de burbuja. Como se observa, en ésta se presentan dos escenarios: tipo de valor y publicaciones anuales; ambos son comparados con la contribución de los estudios. Esta figura muestra que la mayoría de las evaluaciones contribuyen con la creación de modelos de evaluación, presentando más aplicaciones de valor subjetivo que objetivo. Siendo los años 2011 y 2013 los de mayores contribuciones. Existe la probabilidad de que haya mayor contribución de tipo metódico, a partir del año 2014.

El tamaño de la burbuja destaca el número de trabajos que están en el par de categorías que corresponden a la burbuja de las coordenadas. Existen 2 trabajos que no logran identificar el Tipo de Valor.

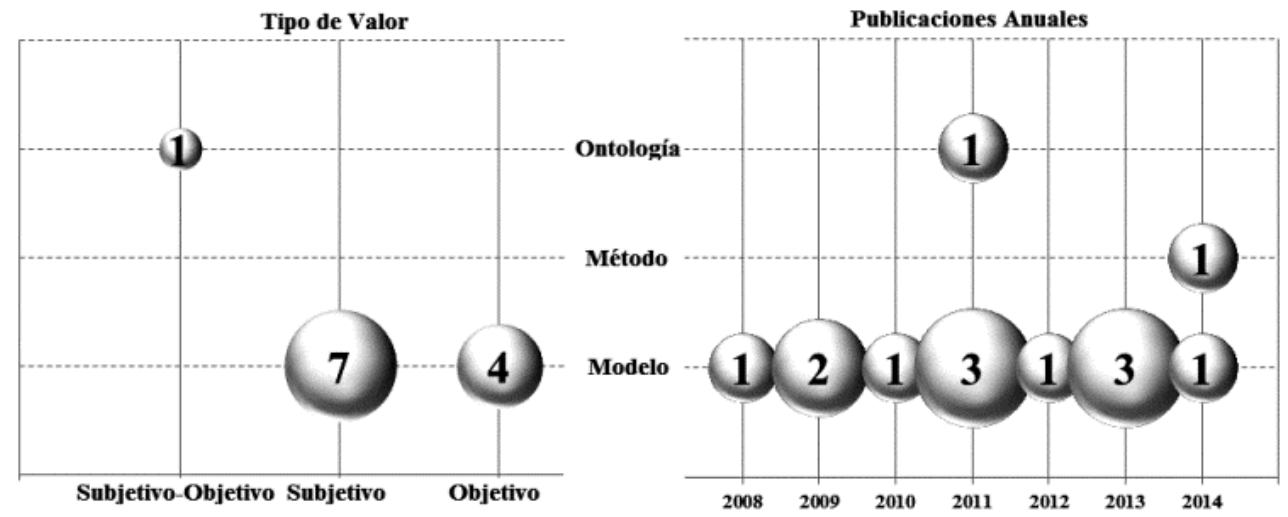

Figura 3.2. Diagrama de Burbuja. Mapeo sistemático de resultados obtenidos.

La figura 3.3 muestra el diagrama circular. Como se observa, éste está compuesto en dos partes, la parte a, muestra la distribución de trabajos por ámbito de aplicación; del total de trabajos, el $57 \%$ (8) se orientan al ámbito público-privado, el 36\% (5) al ámbito público y el 7\% (1) al ámbito privado. Y la parte b, muestra la distribución de trabajos por tipo de estudio; del total de trabajos, el $43 \%$ (6) se orientan por estudio de caso, el $29 \%$ (4) por cuestionario, el $14 \%$ (2) por reporte de experiencias, el 7\% (1) por investigación-acción y el 7\% (1) por entrevistas. En conclusión, la mayor cantidad de trabajos se ha concentrado en el ámbito mixto, así como un tipo de estudio orientado al estudio de caso.
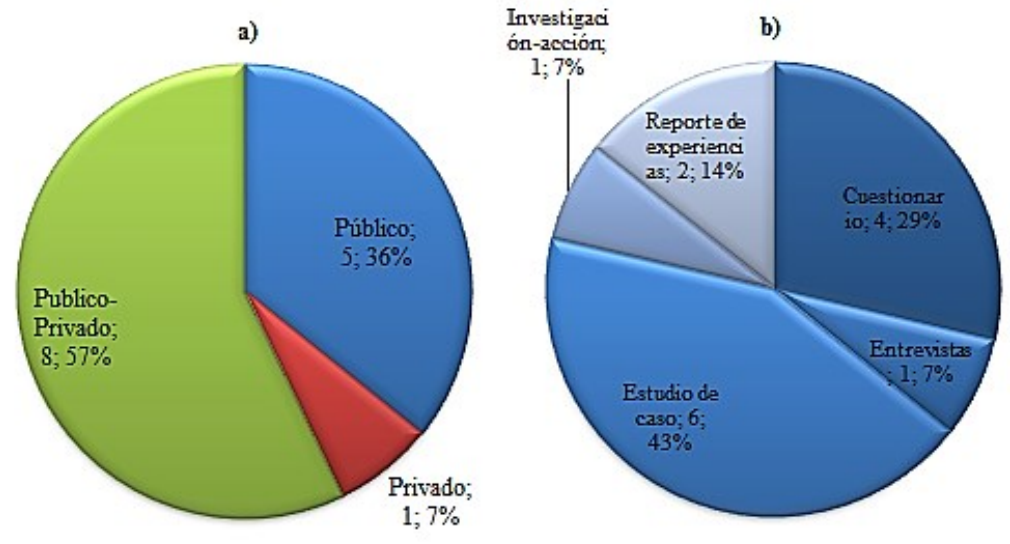

Figura 3.3. Diagrama Circular. a) Ámbito de aplicación. b) Tipo de estudio. 


\subsection{ANÁLISIS DE RESULTADOS}

Los 14 trabajos relevados probablemente demuestran que existe poca labor realizada en torno al tema de investigación. Estos conjugan el concepto de valor en el ámbito de la evaluación de calidad del GoTSI o simplemente una aplicación relacional.

A continuación, las respuestas a la pregunta principal y sub preguntas formuladas en la sección de definición de la pregunta de investigación.

a. Pregunta principal: ¿Cuáles son los estudios temporales y recientes acerca de la evaluación de la calidad de GoTSI basada en valor que han sido desarrollados, y cómo han sido utilizados?

La figura 3.4 muestra la frecuencia de trabajos seleccionados. Como se observa, en el año 2011 se publicaron aproximadamente el $29 \%$ de los trabajos de interés, siendo este año de mayor producción de artículos, seguido por el 2013 con un 22\%. Cabe destacar que no ha disminuido el interés por la temática dado que el 2014 también presenta un 14\% de artículos significativos.

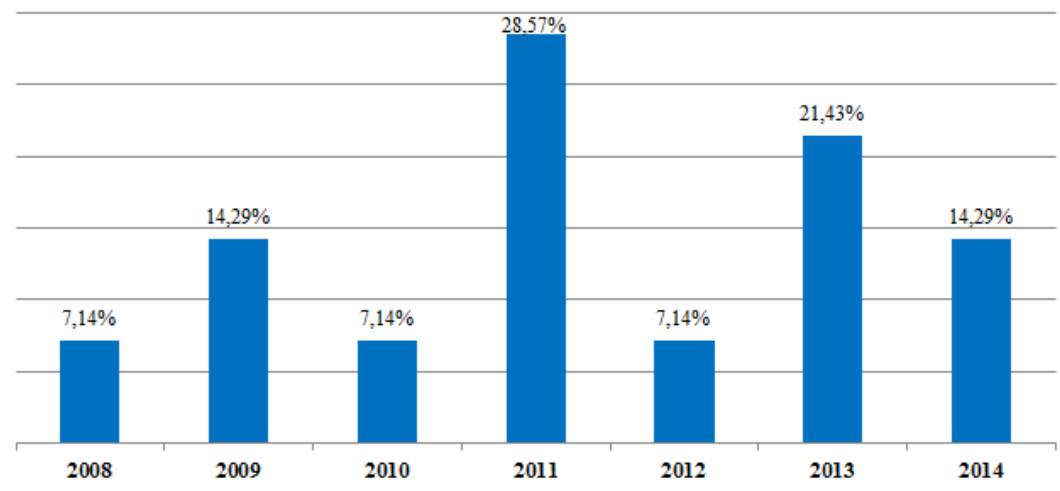

Figura 3.4. Frecuencia de trabajos seleccionados, por año de publicación.

En sí, 14 (6,36\%) de los 220 trabajos encontrados, cumplieron los criterios de inclusión y exclusión, por lo cual, fueron tomados en cuenta. No obstante, a excepción de los trabajos de Lima et al. (2011), Gummerus (2011) y Li et al. (2010), se observa la falta de criterios de evaluación de la calidad de GoTSI de manera holística y con perspectiva directiva, prueba de aquello son las propuestas de estructura holística de la calidad de servicios electrónicos (Ibrahim H. Osman, 2011) (Pérez, et al., 2014) (Viscusi, 2009) (Chou, et al., 2013) (Jin-fu, et al., 2009), evaluación de la calidad de portales eGov (Ziemba, 2014), impulsores de valor para la implementación de sistemas interoperables de gobierno electrónico (Misuraca, et al., 2011), gestión de la calidad de procesos de negocio (Lohrmann, et al., 2013), gestión de seguridad de la información en apoyo a la planificación estratégica (Mishra, et al., 2008) (Lima, et al., 2013); todos ellos enfocados en la gestión. En este sentido, el sector de las TSI tiene muchas propuestas para elegir pero muy pocas evidencias que hayan contribuido a la toma de decisiones por parte de la organización.

b. Sub pregunta 1: ¿Cuál es el ámbito de aplicación de los modelos de evaluación y cuál es el tipo de valor?.

De los resultados obtenidos se puede observar que el área de seguridad de la información cuenta con el aporte de un marco teórico de gestión en donde se definen objetivos de control motivados por los valores que expresan los administradores de TSI en la definición de controles internos 
(Mishra, et al., 2008). Es que los valores enfocados en el pensamiento juegan un rol importante en las decisiones de objetivos que los administradores deben tomar. También se observa la falta de criterios claros para la evaluación de calidad (Lima, et al., 2013), el uso de un indicador de calidad jerárquico para la mejora de servicios de TSI (Lima, et al., 2011), una estrategia del gobierno electrónico centrada en la mejora del tiempo de prestación de servicios desde la óptica del backend (Li, et al., 2010) y otras dimensiones (Misuraca, et al., 2011), (Chou, et al., 2013).

Por último, un estudio de fundamentos conceptuales concluye que la relación entre la creación de valor y la determinación de éste es poco investigada (Gummerus, 2011).

Como se mencionó en la sección 3.2.2, los números indican que de los 14 trabajos relevantes, el $57 \%$ (8) se aplica en el ámbito público-privado, el $36 \%$ (5) en el ámbito público y $7 \%$ (1) en el ámbito privado. En cuanto al tipo de valor, la subjetivación de valor marca la tónica con el $50 \%$ (7) de los trabajos relevados.

\section{c. Sub pregunta 2: ¿Cuál es la contribución de los trabajos relevados de investigación en la temática?.}

Las contribuciones, de manera general, se presentan en forma de modelos, métodos y ontologías; siendo los modelos los de mayor desarrollo. Por ejemplo, Lima et al. (2011) proponen un modelo de gestión para cuantificar el valor agregado de los servicios de TSI y, un indicador de la calidad jerárquica dentro de una instantánea de tiempo, que puede ser utilizado para ayudar a los gerentes en las actividades relativas a la mejora continua del servicio. Gummerus (2011) somete a una investigación crítica el concepto de valor cuyo beneficio será en el ámbito comercial. Los resultados muestran que los clientes pueden determinar los resultados de valor que reciben y comparar con las actividades internas a través de las cuales se crea y entrega valor. Además, que los clientes pueden determinar el valor de cuatro maneras diferentes: valor como un índice beneficio/esfuerzo, como resultado de la experiencia, como las cadenas de medios-finales y el valor como fenomenológica. No obstante, la interconexión entre estas dos actividades demanda mayor investigación.

Li \& Viscusi (2010) centran su estudio en el contexto del gobierno electrónico relevando un conjunto de características que exigen diferentes métricas de evaluación de la calidad adoptadas a los negocios en el sector privado (por lo general, más investigado en términos de alineamiento de la estrategia de TI).

En el contexto de gestión de la seguridad, Mishra \& Dhillon proponen un modelo de trabajo para determinar controles internos de seguridad en sistemas de información basados en el valor de las decisiones tomadas por los directores de TSI. Los resultados demuestran que es posible definir exposiciones teóricas acerca de valores para evaluar la gobernanza de seguridad como un área importante de GoTSI (Mishra, et al., 2008).

En fin, el 85,7\% (12) de trabajos relevados proponen un modelo de evaluación y/o gestión, el 7,1\% (1) un método y el $7,1 \%$ (1) restante propone una Ontología. Este resultado (ver tabla 3.5) permitiría corroborar los resultados de otros estudios en donde se destaca que dentro de los enfoques de evaluación y medición de servicios de TSI, están los subjetivos e híbridos, respectivamente (Pérez, et al., 2014), como los más aplicados.

Tabla 3.5. Trabajos por tipo de contribución

\begin{tabular}{|l|r|r|}
\hline Tipo de contribución & Trabajos & Porcentaje \\
\hline Modelo & 12 & $85,7 \%$ \\
\hline
\end{tabular}




\begin{tabular}{|l|r|r|}
\hline Método & 1 & $7,1 \%$ \\
\hline Ontología & 1 & $7,1 \%$ \\
\hline TOTAL & $\mathbf{1 4}$ & $\mathbf{1 0 0 , 0 \%}$ \\
\hline
\end{tabular}

\section{d. Sub pregunta 3: ¿Qué tipo de estudio es el más usual?.}

La tabla 3.6 muestra los trabajos por tipo de estudio. Como se observa, probablemente el estudio de caso resulte ser el de mayor predominio en estos trabajos. Además, son más fiables que los cuestionarios por la profundidad en la verificación con la que se lleva a cabo. Distantes se encuentran los reportes de experiencias, entrevistas e investigación-acción, en ese orden de prelación. Los números son concretos, indicando que la mayoría de los estudios se han dirigido por estudio de caso con 6 trabajos que representan el 42,9\% del total. Una justificación, basada en la definición de (Benbasat, et al., 1987), es que los autores prefieren utilizar un método de investigación que permita examinar un fenómeno en su entorno natural a través de métodos de recogida de datos para obtener información de las entidades objeto (personas, grupos $u$ organizaciones) de manera precisa, minimizando errores en la exposición de la información. El siguiente tipo de estudio es el cuestionario con un total de 4 trabajos que representan el $28,6 \%$. El aspecto importante de un cuestionario es que permite recoger información, describirla, compararla o explicarla en función del conocimiento, actitudes y comportamientos de las personas consultadas. Sigue siendo un método de investigación ampliamente utilizado (Pfleeger, et al., 2001).

Tabla 3.6. Trabajos por tipo de estudio

\begin{tabular}{|l|r|r|}
\hline \multicolumn{1}{|c|}{ Tipo de estudio } & Trabajos & Porcentaje \\
\hline Estudio de caso & 6 & $42,9 \%$ \\
\hline Cuestionario & 4 & $28,6 \%$ \\
\hline Reporte de experiencias & 2 & $14,3 \%$ \\
\hline Entrevistas & 1 & $7,1 \%$ \\
\hline Investigación-acción & 1 & $7,1 \%$ \\
\hline TOTAL & $\mathbf{1 4}$ & $\mathbf{1 0 0 , 0 \%}$ \\
\hline
\end{tabular}

\subsection{CONCLUSIONES}

En este capítulo se ha abordado, de manera concreta, los trabajos relacionados que han sido relevados a través del método de mapeo sistemático de estudios y que sirven de referencia para la elaboración de las dimensiones de la propuesta doctoral. Como resultado se obtuvieron 14 trabajos, entre los cuales se destacan Lima et al. (2011), Gummerus (2011) y Li et al. (2010), por considerar aspectos de valor de Gobierno de las TSI en el marco de la calidad. Además, la mayoría de contribuciones son modelos de evaluación de la calidad de portales de información, modelos de gestión de la calidad, seguido de métodos. Cada modelo define sus propias características de calidad basadas en un objeto en común. La mayoría de métodos de estudio son estudios de casos, seguido de cuestionarios. De igual manera, la mayoría de trabajos se los puede aplicar en un ámbito público-privado. Estos resultados han sido presentados en (Merchán, 2015), expuestos en Chilecon 2015 y publicados en la IEEE Xplore Digital Library. Un aspecto a resaltar es el hecho de que el tema de calidad y evaluación de gobierno tiene que madurar con la publicación de más artículos revisados por pares publicados en principales revistas. Además, existen muchos trabajos en relación a la gestión de TSI.

En el siguiente capítulo se presentará el modelo de evaluación de la calidad propuesto. 


\section{CAPÍTULO 4 - ELABORACIÓN DEL MODELO DE EVALUACIÓN (VBISTGQM)}

\subsection{INTRODUCCIÓN}

En el capítulo anterior se trataron los modelos que aportan calidad en el contexto de GoTSI en el ámbito público, privado o mixto. La mayoría de ellos con enfoque en la evaluación de la calidad con perspectiva operativa y de gestión. De igual manera, sus objetivos determinan si un conjunto de características de calidad basadas en un objeto en común se cumplen o no. Además, los estándares de Gobierno de las TSI no armonizan modelos de calidad con perspectiva de dirección organizacional para el ámbito público. Por ejemplo, se propone una evaluación de gobierno de TSI basado en COBIT, la gestión en ITIL y la calidad en un modelo muy utilizado como es EFQM. Es decir, evalúa la calidad de gobierno desde la perspectiva de gestión y operación, para el ámbito privado.

En este capítulo se presenta una propuesta soportada en el modelo de excelencia Iberoamericano para el ámbito público, con perspectiva de dirección estratégica organizacional; además, en los trabajos de Lima et al. (2011), Gummerus (2011), Li et al. (2010), Sánchez (2013), Merchán (2015), Toomey (2009), Municio (1998) y el aporte de expertos; resultando en un modelo conceptual y práctico, validado operativamente a través de la opinión de líderes de TSI de organizaciones públicas, quienes responden más a su experiencia que a un modelo teórico, debidamente contrastado a través de métodos y técnicas de investigación científica.

Este capítulo empieza describiendo de manera formal la propuesta del Modelo de Evaluación de la Calidad de Gobierno de las TSI basada en Valor (VBISTGQM), el cual se encuentra estructurado de la siguiente manera: Principios de calidad, estructura del modelo, método de medición y valoración. El capítulo culmina con las conclusiones.

\subsection{PRINCIPIOS DE CALIDAD}

Esta sección presenta la propuesta apalancada en la existencia de principios propios de una institución. Toda cultura integradora se caracteriza por la existencia de valores aceptados por la mayoría de sus empleados y su participación activa en el logro (Pérez Juste, et al., 2014). El modelo de evaluación propuesto se sitúa dentro de una nueva respuesta que se enmarca en el valor agregado que se debe entregar a las unidades funcionales, la importancia del liderazgo, el alcanzar el éxito a través de las personas y actuar asumiendo la responsabilidad de un futuro sostenible.

A nivel de calidad, las relaciones entre las personas que forman parte de un equipo de gobierno se basan en 2 principios básicos de calidad que están relacionados con el valor generado por las TSI. Estos principios son:

1. Un principio relativo al valor generado por las TSI está en el marco de las acciones, el apoyo sistemático y el compromiso del equipo directivo de TSI con la calidad mediante el proceso de decisiones sobre cómo las TSI se utilizan en la organización. En el proceso de gobierno, se formula la estrategia, misión y visión, expresa sus objetivos, aprueba planes y proyectos, organiza los recursos, selecciona tecnologías y evalúa los procesos y los 
resultados. La organización que gestiona la calidad lo hace de una forma consciente y coherente, bajo el gobierno y el liderazgo de un equipo directivo de TSI. Esto crea una cultura en la que cada acción y decisión está al servicio de la calidad.

2. La medida de evaluación, que traduce los criterios de valor en elementos de control que puedan ser evaluados en términos de su nivel de cumplimiento.

\subsection{ESTRUCTURA DEL MODELO DE EVALUACIÓN}

El modelo de calidad propuesto basa su eficacia en criterios correlacionados que resaltan las características pertinentes a un GoTSI. El conjunto de criterios y el valor percibido son coherentes con una percepción del gobierno.

Este modelo se caracteriza por dividir al gobierno en criterios y efectos propios de una organización que hace uso de las tecnologías y sistemas de información. El propósito es dotar de una herramienta de autoevaluación a quienes forman parte del equipo de gobierno. Para esto se ha recurrido al uso de una terminología adecuada y de uso común a nivel estratégico de las TSI.

Los criterios identificados resaltan el hecho de ser específicos para un GoTSI. Por ejemplo, el liderazgo y estilo de gobierno ocupa un lugar predominante por marcar la interdependencia que tiene el equipo de gobierno con la organización; de igual manera se tiene el criterio de proyectos, considerado pieza fundamental en el éxito del gobierno y de la organización desde el punto de vista de que los proyectos apoyan la visión de la organización de TSI. La figura 4.1 muestra la estructura del modelo propuesto. Como se observa, identifica los criterios y sub-criterios que conforma el modelo de evaluación, siendo en conjunto la medida total del GoTSI.

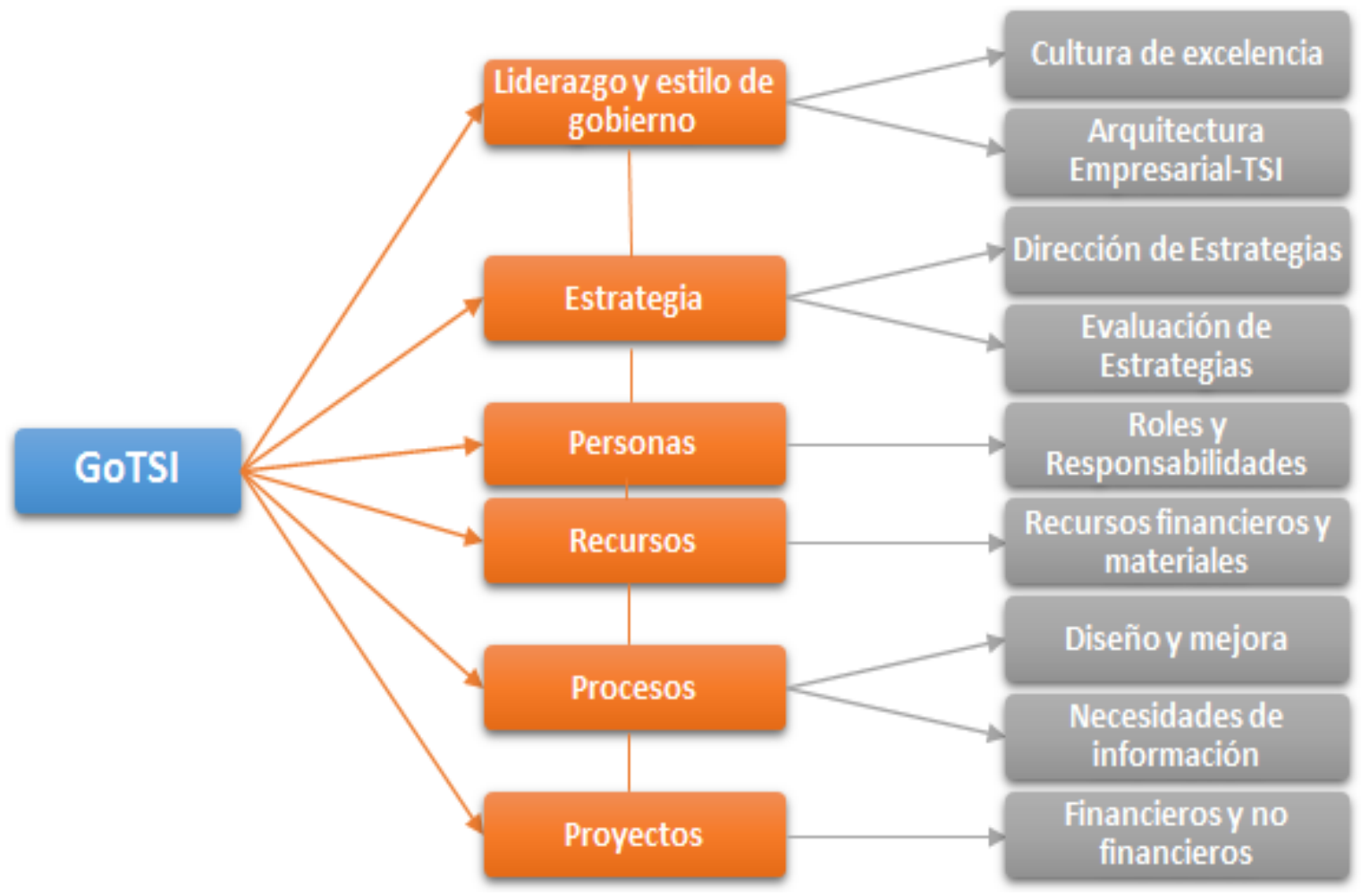

Figura 4.1. Estructura del modelo.

De acuerdo a la figura anterior, cada criterio del modelo representa una parte importante del gobierno que debe tomarse en cuenta para la evaluación. Cada sub-criterio recoge aquellas características de calidad de gobierno que son consideradas garantía para obtener buenos 
resultados para la organización y que tiene relación con cada criterio. Cada sub-criterio está definido en función de dimensiones propias y éstas a su vez en función de evidencias. En la figura 4.2 se presenta una jerarquización de criterios desde la óptica del valor. Como se observa, la inclusión de valor en los criterios dará como resultado un incremento en el valor percibido por el usuario interno de la organización de TSI, lo cual impactará en su desempeño a largo plazo.

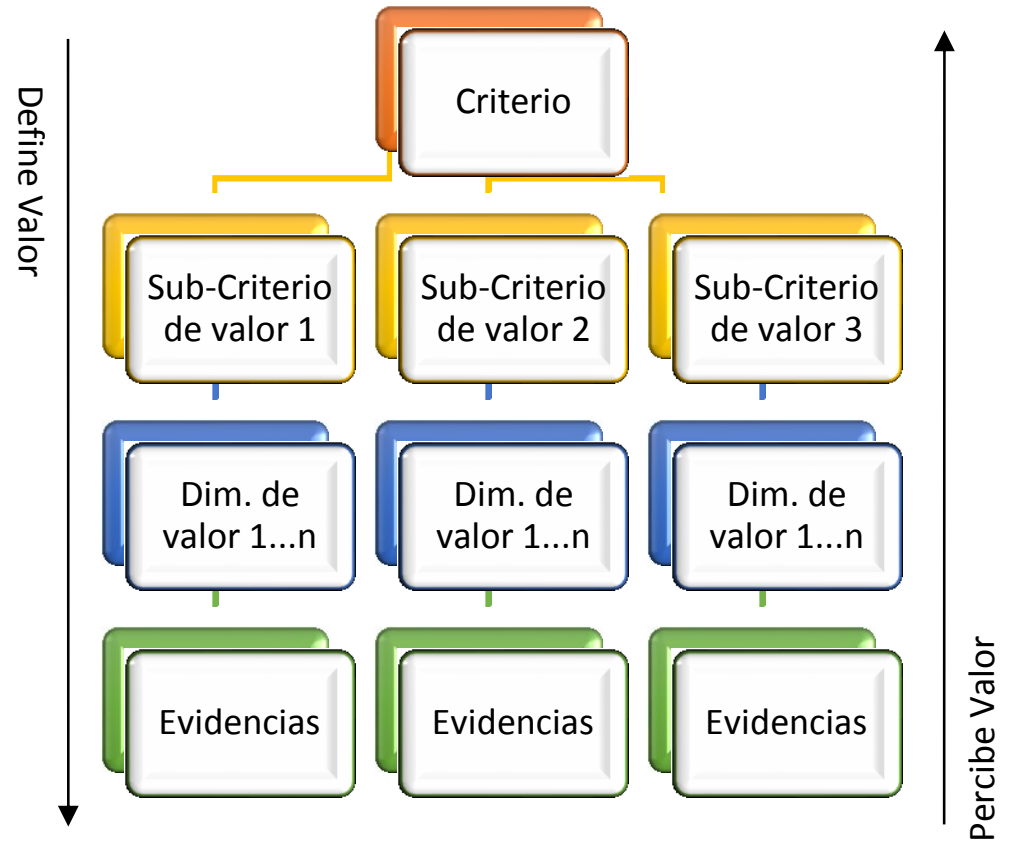

Figura 4.2. Jerarquía del modelo de evaluación.

\subsubsection{CRITERIOS Y SUBCRITERIOS}

\subsubsection{Liderazgo y estilo de gobierno}

Este criterio analiza cómo se desarrolla y pone en práctica la cultura necesaria para el éxito sostenido, mediante adecuados comportamientos y acciones de los líderes que gobiernan el valor de las TSI. Estudia cómo se desarrolla y pone en práctica el marco de los procesos necesarios para la eficaz ejecución de la política y la estrategia.

Los sub-criterios que se evalúan son:

1. Cultura de Excelencia basada en valor: Al compromiso que tienen los líderes con la cultura de excelencia. Se promueve de manera formal la definición de valor. Se modeliza el papel de la organización, en línea con los principios de servicio, la misión, visión y valores de la organización. Se define política de calidad. Ser activos e implicarse en actividades de mejora, estimulando y alentando la innovación y la creatividad.

2. Arquitectura Empresarial-TSI basada en valor: Más orientado al alineamiento empresarial. A las actividades claves de la organización; en especial aquellos que generan mayor valor para el cliente y la misma empresa, área o servicio. Los líderes formalizan el sistema de gestión y los resultados; y, la estructura empresarial.

De manera resumida, se define la arquitectura basada en las decisiones que los líderes de TSI y el negocio toman sobre ella, lo cual es congruente con los resultados de las investigaciones realizadas por Weill and Ross (2004) acerca del comportamiento de las organizaciones. 


\subsubsection{Estrategias}

Este criterio analiza cómo las unidades que gobiernan las Tecnologías y Sistemas de Información desarrollan su planificación y la ponen en práctica a la hora de diseñar y ejecutar la estrategia actual y futura del negocio. Principalmente, cuando se trata de emprender las inversiones que tengan valor alcanzable y apropiado para el negocio habilitadas por las TSI.

Los sub-criterios que se evalúan en este criterio son:

1. Dirección de estrategias: Analiza cómo ponen en práctica las direcciones del negocio, el alineamiento de las inversiones habilitadas por las TSI, tomando en cuenta la visión, misión, metas, objetivos y estrategias actuales; analizando el impacto potencial de las TSI en la estrategia del negocio y el rol que juegan éstas en la organización.

2. Evaluación de estrategias en base a Información obtenida por mediciones de los resultados y actividades relacionadas con la innovación y creatividad: Analiza los resultados. ¿Han sido eficaces las estrategias?. ¿Se requieren ajustes?. Esto con el propósito de mejorar el rendimiento y comportamiento estratégico que sea de utilidad para el GoTSI.

\subsubsection{Personas}

Este criterio analiza cómo la organización gobierna el pleno potencial de las personas, de forma individual o en equipo, con el fin de contribuir a su eficaz y eficiente gobierno de valor, así como para motivarlas e incrementar su compromiso con la organización.

El sub-criterio que se evalúa tiene que ver con los roles y responsabilidades de las personas para materializar y proteger el valor.

- Roles y responsabilidades para materializar y proteger el valor: Se evalúa cómo se define y comunica los roles y responsabilidades para todo el personal que se relaciona con la cartera de proyectos de inversión del negocio habilitados por las TSI, con el propósito de otorgar la autoridad suficiente para desempeñar con eficacia los roles y responsabilidades asignadas.

\subsubsection{Recursos}

Este criterio analiza cómo la organización gobierna los recursos financieros y materiales, con el fin de apoyar el despliegue de su estrategia y el eficiente gobierno de valor de la misma, así como su impacto en el negocio.

El sub-criterio que se evalúa tiene que ver con los recursos financieros y materiales.

- Recursos Financieros y Materiales: Se evalúa cómo se define y adecúan los recursos financieros y materiales con los objetivos estratégicos, y prioridades.

\subsubsection{Procesos}

Este criterio analiza cómo la organización gobierna sus procesos, diseña, desarrolla, produce y suministra productos y servicios de las TSI, y cómo gestiona las relaciones, con el fin de satisfacer plenamente las necesidades y expectativas de sus interesados del negocio.

Los sub-criterios que se evalúan son: 
1. Diseño y Mejora de Procesos de Gobierno de Valor: Se evalúa cómo se define y establece el sistema de gestión de procesos que vinculen al gobierno con la gestión de las TSI, como soporte en el vínculo entre la estrategia empresarial y el portafolio de proyectos de inversión habilitados por TSI. Esto orientado a incrementar el valor percibido de los usuarios y partes interesadas.

2. Necesidades de información: Se evalúa cómo la organización de TSI define, estructura y gestiona la información para apoyar las políticas y estrategias de los interesados del negocio. Además, cómo soporta de manera adecuada el proceso de toma de decisiones, la ejecución de decisiones y el monitoreo para evidenciar el alcance de resultados previstos.

\subsubsection{Proyectos}

Este criterio analiza cómo la organización gobierna sus procesos de portafolio de proyectos, y cómo gestiona las relaciones, con el fin de satisfacer plenamente las necesidades y expectativas de sus interesados del negocio.

- Financieros y No financieros: Se evalúa cómo las direcciones de negocio administran y gestionan los proyectos de inversión y no inversión habilitadas por las TSI, y que son prioritarias por la generación de valor.

\subsubsection{DIMENSIONES Y EVIDENCIAS}

Cada sub-criterio está definido mediante dimensiones que representan perspectivas específicas y exhaustivas sobre las cuales se evalúa la calidad del GoTSI basada en valor; siendo cada una de las dimensiones valoradas por 5 evidencias. La tabla 4.1 muestra las evidencias que valoran las dimensiones de calidad propuestas. Como se observa, cada dimensión es valorada por la Importancia y Difusión que estos criterios proporcionan a la medida del nivel de Implantación del sistema de gobierno de TSI; luego, la evidencia se valora por la Utilización y Seguimiento que estos criterios proporcionan a la medida del nivel de Aplicación del sistema de gobierno de TSI; por último, la evidencia se valora por el Valor percibido que este criterio proporciona a la medida del nivel de Efecto del sistema de GoTSI.

Tabla 4.1. Evidencias que valoran las dimensiones

\begin{tabular}{|l|l|}
\hline La evidencia se valora por.. & Proporciona la medida del nivel de.. \\
\hline $\begin{array}{l}\text { Importancia } \\
\text { Difusión }\end{array}$ & Implantación \\
\hline $\begin{array}{l}\text { Utilización } \\
\text { Seguimiento }\end{array}$ & Aplicación \\
\hline Valor percibido & Efecto \\
\hline
\end{tabular}

La tabla 4.2 muestra el ciclo de valoración de las dimensiones. Como se observa, se formulan 5 evidencias para valorar cada dimensión; empieza en la Importancia y termina en el valor percibido de la dimensión. Todas, tienen un objetivo y desarrollan una actividad en el proceso de valoración de las dimensiones. 
Tabla 4.2. Ciclo de valoración de las dimensiones

\begin{tabular}{|c|c|c|}
\hline Evidencias & Objetivo & Actividad \\
\hline Importancia & $\begin{array}{l}\text { Identificar las evidencias } \\
\text { documentadas y actualizadas que } \\
\text { manifiesten el interés que se brinda a } \\
\text { la dimensión, principalmente en la } \\
\text { toma de decisiones del equipo de } \\
\text { gobierno de TSI. }\end{array}$ & $\begin{array}{l}\text { Beneficios de la actividad del equipo de } \\
\text { gobierno en la toma de decisiones de } \\
\text { TSI. }\end{array}$ \\
\hline Difusión & $\begin{array}{l}\text { Identificar los mecanismos utilizados } \\
\text { por el equipo de gobierno de TSI para } \\
\text { la difusión de la dimensión en toda la } \\
\text { organización. Además, su implicación } \\
\text { en la difusión. }\end{array}$ & $\begin{array}{l}\text { Análisis de los mecanismos y estrategias } \\
\text { utilizadas por el gobierno de TSI en la } \\
\text { toma de decisiones para difundir la } \\
\text { dimensión. }\end{array}$ \\
\hline Utilización & $\begin{array}{l}\text { Identificar la utilidad de la dimensión } \\
\text { en las unidades, áreas o niveles de la } \\
\text { organización de TSI }\end{array}$ & $\begin{array}{l}\text { Análisis de la utilización o aplicación de } \\
\text { la dimensión. Se demuestra con } \\
\text { evidencia documentada de su } \\
\text { utilización. }\end{array}$ \\
\hline Seguimiento & $\begin{array}{l}\text { Identificar qué procedimientos son } \\
\text { utilizados para hacer el seguimiento y } \\
\text { registro de la información de las } \\
\text { actividades y sus efectos. }\end{array}$ & $\begin{array}{l}\text { Análisis del seguimiento y mejoras } \\
\text { introducidas en las decisiones del } \\
\text { gobierno de TSI. }\end{array}$ \\
\hline $\begin{array}{l}\text { Valor } \\
\text { percibido }\end{array}$ & $\begin{array}{l}\text { Identificar la funcionalidad que recibe } \\
\text { el beneficiario de las decisiones } \\
\text { tomadas por el equipo de gobierno de } \\
\text { TSI. }\end{array}$ & $\begin{array}{l}\text { Beneficios en las unidades funcionales } \\
\text { mediante lo que expresan sus líderes en } \\
\text { el uso de las TSI implementadas. }\end{array}$ \\
\hline
\end{tabular}

\subsubsection{DIMENSIONES POR CRITERIO}

\subsubsection{Liderazgo y estilo de gobierno}

La figura 4.3 muestra la estructura del criterio de liderazgo y estilo de gobierno. Como se observa, el criterio se compone de 2 sub-criterios de calidad interrelacionados: Cultura de excelencia y Arquitectura Empresarial-TSI; y, 11 dimensiones que se detallan más adelante en esta sección.

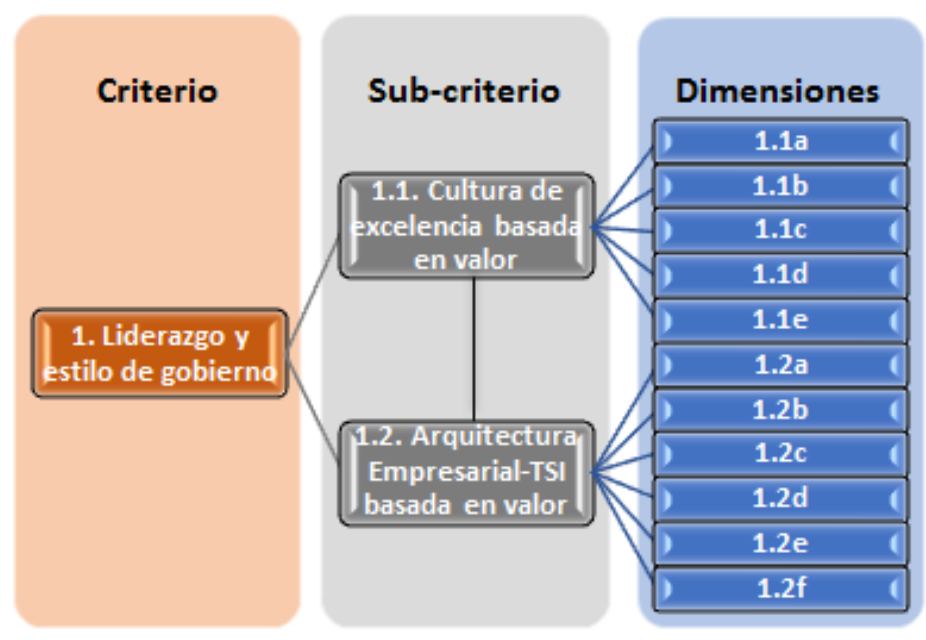

Figura 4.3. Estructura del criterio de Liderazgo y estilo de gobierno.

La tabla 4.3 muestra las dimensiones de calidad por sub-criterio del criterio liderazgo y estilo de gobierno. Como se observa, se formulan 5 dimensiones de calidad para el sub-criterio 1.1 y 6 
dimensiones para el sub-criterio 1.2; ambos sub-criterios caracterizan al criterio de liderazgo y estilo de gobierno.

Si un gobierno de TSI en ejercicio de sus funciones no cumple con estas dimensiones de calidad, su liderazgo apoyado en la cultura y arquitectura empresarial-TSI se verá claramente afectado. En la actualidad, un líder de TSI debe actuar como un mediador para la institución cuando se trata de apoyar en el cumplimiento de los grandes objetivos estratégicos de la organización. Los líderes deben promocionar las TSI generadoras de valor en cada nivel organizacional; dentro de cada uno de estos niveles deben actuar como enlace entre los miembros de los equipos funcionales de la institución.

Tabla 4.3. Dimensiones de calidad por sub-criterio del criterio Liderazgo y estilo de gobierno

\begin{tabular}{|c|c|}
\hline Sub-criterio & Dimensión \\
\hline 1.1. Cultura de excelencia & $\begin{array}{l}\text { 1.1a. Los líderes, ¿Se implican activa y visiblemente en la definición } \\
\text { de valor para la organización?. } \\
\text { 1.1b. Los líderes, ¿Se implican activa y visiblemente en la definición y } \\
\text { desarrollo de los objetivos estratégicos fundamentales del servicio } \\
\text { generador de valor?. } \\
\text { 1.1c. Los líderes, ¿Actúan como modelos de referencia para el } \\
\text { cumplimiento de los objetivos estratégicos fundamentales del } \\
\text { servicio generador de valor?. } \\
\text { 1.1d. Los líderes, ¿Se implican activa y visiblemente en la promoción } \\
\text { que estimule y aliente la innovación y creatividad basada en el valor } \\
\text { que debe entregar las TSI?. } \\
\text { 1.1e. La organización, ¿Tiene una política de gobierno de TSI } \\
\text { documentada y comunicada que incorpore criterios de calidad, } \\
\text { garantizando una información actualizada y transparente?. }\end{array}$ \\
\hline 1.2. Arquitectura Empresarial-TSI & $\begin{array}{l}\text { 1.2a. Los líderes empresariales, ¿Encargan a los ejecutivos senior la } \\
\text { definición del gobierno de valor de las TSI?. } \\
\text { 1.2b. Los líderes empresariales, ¿Disponen el establecimiento de } \\
\text { comisiones, comités y estructuras de soporte apropiadas capaz de } \\
\text { mantener una estructura óptima de coordinación, comunicación y } \\
\text { enlace entre la función de TSI y las otras partes interesadas del } \\
\text { negocio?. } \\
\text { 1.2c. Los líderes en el momento oportuno, ¿Evalúan los beneficios } \\
\text { que se entregan al negocio?. } \\
\text { 1.2d. Los líderes en el momento oportuno, ¿Delegan } \\
\text { responsabilidades y velan por el buen cumplimiento de las mismas?. } \\
\text { 1.2e. Los líderes en el momento oportuno, ¿Toman decisiones } \\
\text { importantes que les competen para mejorar el gobierno y por ende la } \\
\text { gestión del servicio que genere valor en el negocio?. } \\
\text { 1.2f. Los líderes, ¿Garantizan que se desarrolle e implante un sistema } \\
\text { de gobierno, gestión, evaluación y mejora de los procesos } \\
\text { generadores de valor del servicio para el negocio?. }\end{array}$ \\
\hline
\end{tabular}

La tabla 4.4 muestra la matriz Valor percibido del efecto de liderazgo y estilo de gobierno. Como se puede observar, se formula un listado ( 5 por cada sub-criterio) de efectos en términos de valor percibido que provoca cada sub-criterio de calidad para el criterio de liderazgo y estilo de gobierno. Este listado representa efectos genéricos del criterio de liderazgo en el marco de TSI, que se pueden esperar en la opinión de usuarios, directivos y accionistas de la organización. 
Uno de los objetivos del gobierno de TSI es la entrega de valor a la institución, por lo tanto, su valor percibido representa la política, la visión, misión, valores y una estructura organizativa que son considerados importantes en este proceso de evaluación.

Tabla 4.4. Valor percibido del efecto de Liderazgo y estilo de gobierno

\begin{tabular}{|c|c|}
\hline Sub-criterio & Valor percibido \\
\hline 1.1. Cultura de excelencia & $\begin{array}{l}\text { a. Percepción de una Política de calidad de Gobierno de TSI en los } \\
\text { resultados de la Gobernanza de TSI. } \\
\text { b. Percepción de la misión, visión y valores en los resultados de la } \\
\text { Gobernanza de TSI. } \\
\text { c. Percepción de valores empresariales para la integración del } \\
\text { negocio y las TSI. } \\
\text { d. Crecimiento de la eficacia y efectividad de cumplimiento de } \\
\text { objetivos estratégicos como resultado de la percepción que se } \\
\text { tiene de la Gobernanza de TI. } \\
\text { e. Participación de las personas en la innovación y mejoras y, } \\
\text { aceptadas por el negocio. }\end{array}$ \\
\hline 1.2. Arquitectura Empresarial-TSI & $\begin{array}{l}\text { a. Existencia de un gobierno de TSI. } \\
\text { b. Incremento de la comunicación y cooperación entre el equipo de } \\
\text { dirección de las TSI y las unidades de negocio. } \\
\text { c. Incremento de la comunicación, la relación y la cooperación } \\
\text { interpersonal. } \\
\text { d. Existencia estructura organizativa para facilitar la gobernanza y } \\
\text { gestión en la generación de valor. } \\
\text { e. Eficiencia en el gobierno y la gestión de procesos generadores de } \\
\text { valor del servicio de TSI. }\end{array}$ \\
\hline
\end{tabular}

\subsubsection{Estrategias}

La figura 4.4 muestra la estructura del criterio de estrategias. Como se observa, el criterio se compone de 2 sub-criterios de calidad interrelacionados y 6 dimensiones que se detallan más adelante en esta sección.

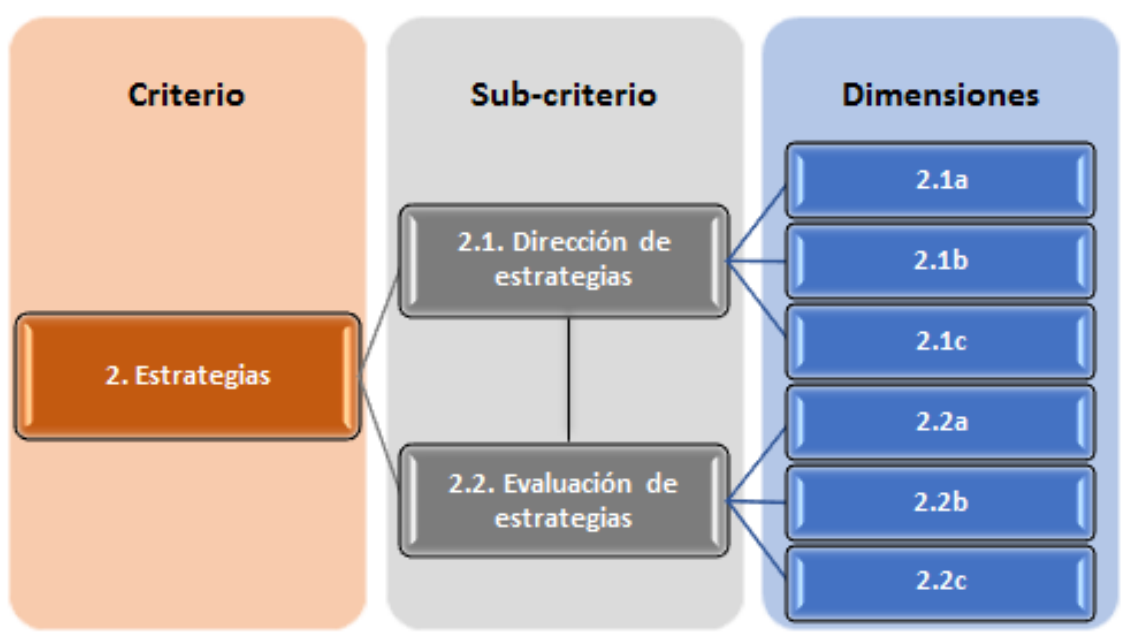

Figura 4.4. Estructura del criterio de Estrategias.

La tabla 4.5 muestra las dimensiones de calidad por sub-criterio que pertenecen al criterio de estrategias. Como se observa, se formularon 3 dimensiones de calidad para cada sub-criterio. Ambos sub-criterios caracterizan al criterio de estrategias. 
Se define el criterio de Estrategias por ser el camino para cristalizar el quehacer del equipo de gobierno, pero esta estrategia debe ser en términos de calidad para crear y entregar valor de TSI, aunque difícil pero posible. La estrategia presupone una definición para que se dirija y evalúe. Si no se cumplen las dimensiones de calidad que apoyan la evaluación de la dirección y evaluación de estrategias del equipo de gobierno, el liderazgo se verá muy afectado. En el proceso de evaluación, la estrategia precederá a los criterios de calidad: personas, recursos, procesos y proyectos. La planificación estratégica organizacional es un instrumento clave para que el equipo de gobierno defina sus propias estrategias; sólo así podrá plasmar su alineamiento, atender los requerimientos de negocio y realizar el seguimiento en términos de evaluación.

\section{Tabla 4.5. Dimensiones de calidad por sub-criterio del criterio Estrategias}

\begin{tabular}{|c|c|}
\hline Sub-criterio & Dimensión \\
\hline 2.1. Dirección de estrategias & $\begin{array}{l}\text { 2.1a. Los líderes de gobierno, ¿Aseguran su comprensión con la que se } \\
\text { deben alinear las inversiones de negocio habilitadas por TSI?. } \\
\text { 2.1b. Los líderes de gobierno, ¿Garantizan una política de } \\
\text { entendimiento asociada entre el "requerimiento de negocio" y la } \\
\text { función de TSI relativa al impacto potencial de las tecnologías en la } \\
\text { estrategia de negocio y el rol de la función de TSI en la organización?. } \\
\text { 2.1c. Los líderes de gobierno, ¿Garantizan una política de comprensión } \\
\text { que tome en cuenta "principios, visión, objetivos estratégicos y } \\
\text { prioridades de negocio" para los servicios definidos en un plan de } \\
\text { negocio?. }\end{array}$ \\
\hline 2.2. Evaluación de estrategias & $\begin{array}{l}\text { 2.2a. Los líderes de gobierno, ¿Garantizan la definición de criterios de } \\
\text { evaluación de estrategias de inversión habilitadas por TSI en base a } \\
\text { información que demuestre el alineamiento con objetivos estratégicos } \\
\text { de la organización; beneficios financieros y no financieros y; el riesgo?. } \\
\text { 2.2b. Los líderes de gobierno, ¿ ¿Garantizan la existencia de medidas de } \\
\text { rendimiento y comportamiento estratégico para uso del gobierno en el } \\
\text { contexto de valor?. } \\
\text { 2.2c. Los líderes de gobierno, ¿Garantizan la existencia de un proceso } \\
\text { para la asignación de responsabilidades y delegación de competencias } \\
\text { relacionadas con el establecimiento de indicadores de } \\
\text { desempeño/rendimiento de la organización?. }\end{array}$ \\
\hline
\end{tabular}

La tabla 4.6 muestra la matriz Valor percibido del efecto de estrategias. Como se puede observar, se formula 1 efecto para cada sub-criterio en términos de valor percibido que provoca cada subcriterio de calidad para el criterio de estrategias. Este listado representa efectos genéricos del criterio de estrategias en el marco de TSI, que se pueden esperar en la opinión de usuarios, directivos y accionistas de la organización.

Uno de los objetivos del gobierno de TSI es la entrega de valor a la institución, por lo tanto, su valor percibido en términos de estrategia de calidad representa la aplicación del ejercicio de dirección de estrategias y efectos de los resultados de evaluación de estrategias en la organización funcional, como por ejemplo, mejoras introducidas en la planificación estratégica de TSI.

Tabla 4.6. Valor percibido del efecto de Estrategias

\begin{tabular}{|l|l|}
\hline \multicolumn{1}{|c|}{ Sub-criterio } & \multicolumn{1}{c|}{ Valor percibido } \\
\hline 2.1. Dirección de estrategias & a. Aplicación del ejercicio de dirección estratégica. \\
\hline 2.2. Evaluación de estrategias & a. $\begin{array}{l}\text { Efectos de los resultados de evaluación de estrategias en el } \\
\text { negocio. }\end{array}$ \\
\hline
\end{tabular}




\subsubsection{Personas}

La figura 4.5 muestra la estructura del criterio de personas. Como se observa, el criterio tiene 1 sub-criterio de calidad y 5 dimensiones que se detallan más adelante en esta sección.

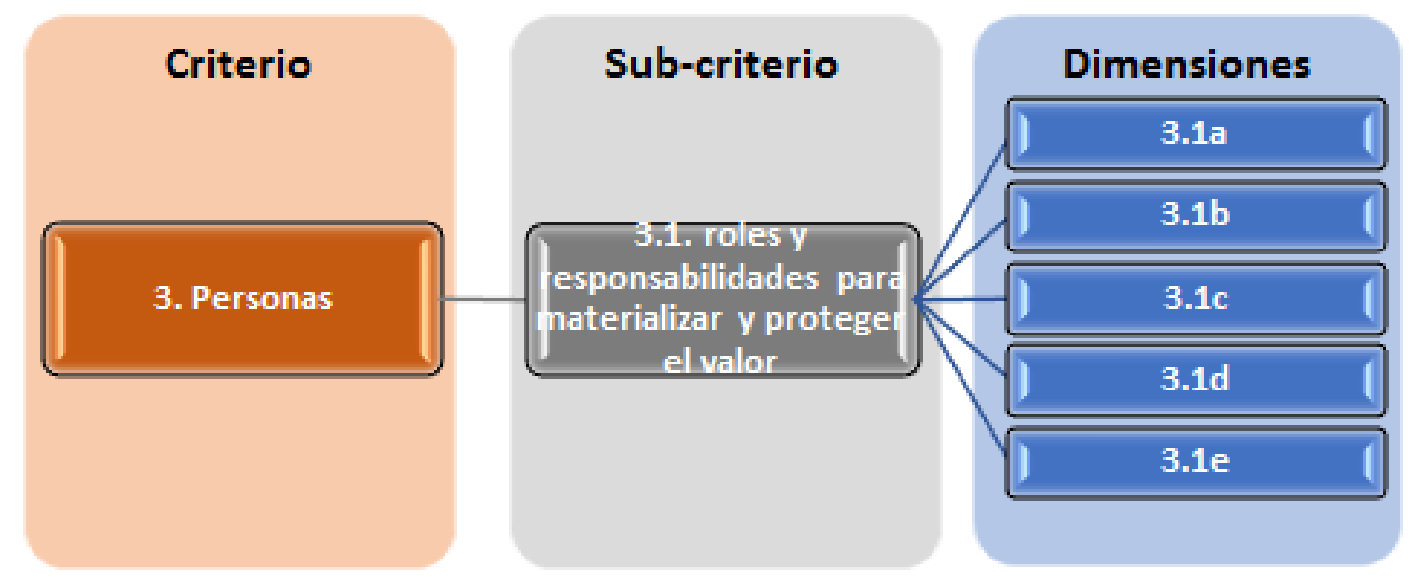

Figura 4.5. Estructura del criterio de Personas.

La tabla 4.7 muestra las dimensiones de calidad del sub-criterio roles y responsabilidades. Como se observa, se formulan 5 dimensiones para el sub-criterio que caracteriza al criterio de personas.

Las personas son el valor más importante para el gobierno de TSI, por lo tanto, las dimensiones de calidad que se han definido afectan a la calidad de comportamiento $y$, por ende, de las decisiones.

Tabla 4.7. Dimensiones de calidad por sub-criterio del criterio Personas

\begin{tabular}{|l|l|}
\hline \multicolumn{1}{|c|}{ Sub-criterio } & \multicolumn{1}{|c|}{ Dimensión } \\
\hline 3.1a. El gobierno de TSI, ¿Promueve el nivel de conciencia de los \\
beneficios de las TSI entre los tomadores de decisión de la \\
organización?. \\
3.1b. El gobierno de TSI, ¿Promueve el nivel de conciencia de los \\
beneficios de las TSI entre el staff de usuarios de la organización que no \\
pertenecen a la función de TSI?. \\
3.1c. El gobierno de TSI, ¿Promueve talleres de concientización para \\
tomadores de decisiones y el staff de usuarios que no pertenecen a la \\
función de TSI?. \\
3.1d. La organización, ¿Promueve la formación y evaluación del \\
gobierno de valor de TSI en función de las responsabilidades asignadas \\
en relación con la definición de la cartera de programas de inversión de \\
negocio habilitadas por las TSI?. \\
3.1e. El gobierno de TSI, ¿Promueve la entrega al usuario del negocio de \\
procedimientos, técnicas y herramientas que les permitan responder a \\
sus responsabilidades relacionadas con las inversiones de negocio \\
habilitadas por las TSI?.
\end{tabular}

La tabla 4.8 muestra la matriz Valor percibido del efecto de personas. Como se puede observar, se formulan 3 efectos para el sub-criterio 3.1 en términos de valor percibido que provoca este subcriterio de calidad para el criterio de personas. Este listado representa efectos genéricos del criterio de personas en el marco de las TSI que se pueden esperar en la opinión de usuarios, directivos y accionistas de la organización. 
El valor percibido de la entrega de valor del gobierno de TSI puede ser recibido en términos de mejora en la toma de decisiones, mejor preparación, formación y comportamiento. Mejoras propuestas por las personas del equipo de gobierno y aceptadas por la organización de TSI.

Tabla 4.8. Valor percibido del efecto de Personas

\begin{tabular}{|l|l|}
\hline \multicolumn{1}{|c|}{ Sub-criterio } & \multicolumn{1}{c|}{ Valor percibido } \\
\hline 3.1. Roles y responsabilidades & a. $\begin{array}{l}\text { Mejora en la toma de decisiones como efecto del impulso a través } \\
\text { de la concientización. }\end{array}$ \\
& b. $\begin{array}{l}\text { Participación del equipo rector de gobierno de TSI en la formación } \\
\text { y evaluación. }\end{array}$ \\
c. $\begin{array}{l}\text { Mejoras propuestas por las personas y aceptadas por el gobierno } \\
\text { empresarial de TSI. }\end{array}$
\end{tabular}

\subsubsection{Recursos}

La figura 4.6 muestra la estructura del criterio de recursos. Como se observa, el criterio tiene 1 sub-criterio de calidad y éste, 2 dimensiones que se detallan más adelante en esta sección.

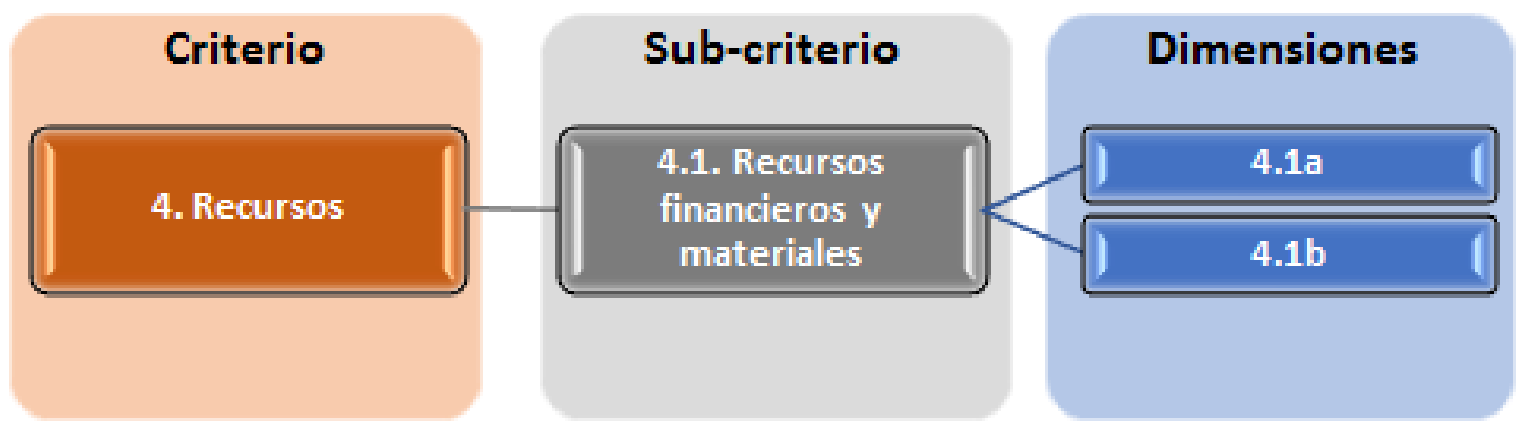

Figura 4.6. Estructura del criterio de Recursos.

La tabla 4.9 muestra las dimensiones de calidad del sub-criterio recursos financieros y materiales del criterio recursos. Como se observa, se formulan 2 dimensiones de calidad para este subcriterio que caracteriza al criterio recursos.

Si el gobierno de TSI no cumple con estos criterios de calidad, la toma de decisiones se verá afectada en términos financieros y materiales. Es que estas dimensiones son evaluadas con propósitos de adecuación y utilización en compromiso con los objetivos de calidad definidos por el equipo de gobierno.

Tabla 4.9. Dimensiones de calidad por sub-criterio del criterio Recursos

\begin{tabular}{|c|c|}
\hline Sub-criterio & Dimensiones \\
\hline 4.1. Recursos financieros y materiales & $\begin{array}{l}\text { 4.1a. El gobierno de TSI, ¿Garantiza que se gestione de manera } \\
\text { eficiente los recursos financieros de acuerdo a las prioridades } \\
\text { señaladas en el plan de inversiones del negocio habilitadas por } \\
\text { TSI?. } \\
\text { 4.1b. El gobierno de TSI, ¿Garantiza la disponibilidad de recursos } \\
\text { materiales para cubrir las necesidades prioritarias con criterio de } \\
\text { calidad?. }\end{array}$ \\
\hline
\end{tabular}

La tabla 4.10 muestra la matriz Valor percibido del efecto de recursos. Como se puede observar, se formula 1 efecto para el sub-criterio 4.1 en términos de valor percibido que provoca este subcriterio de calidad para el criterio de recursos. Esta lista representa el efecto genérico del criterio 
de recursos en el marco de TSI, que se pueden esperar en la opinión de usuarios, directivos y accionistas de la organización.

El valor percibido de la entrega de valor es la clave de calidad del gobierno de TSI. Las personas que evalúan el valor recibido pueden considerar como valor financiero y material, desde la óptica del valor monetario y la capacidad de hacer que las cosas sucedan con los materiales existentes.

Tabla 4.10. Valor percibido del efecto de Recursos

\begin{tabular}{|c|c|}
\hline Sub-criterio & Valor percibido \\
\hline 4.1. Recursos financieros y materiales & a. $\begin{array}{l}\text { Se percibe la eficiencia en la gestión de procesos: ahorro en } \\
\text { tiempo, recursos financieros y materiales. }\end{array}$ \\
\hline
\end{tabular}

\subsubsection{Procesos}

La figura 4.7 muestra la estructura del criterio de procesos. Como se observa, el criterio se compone del sub-criterio de diseño y mejora de procesos $y$, del sub-criterio necesidades de información; además, por cada sub-criterio se tiene 4 dimensiones que se detallan más adelante en esta sección.

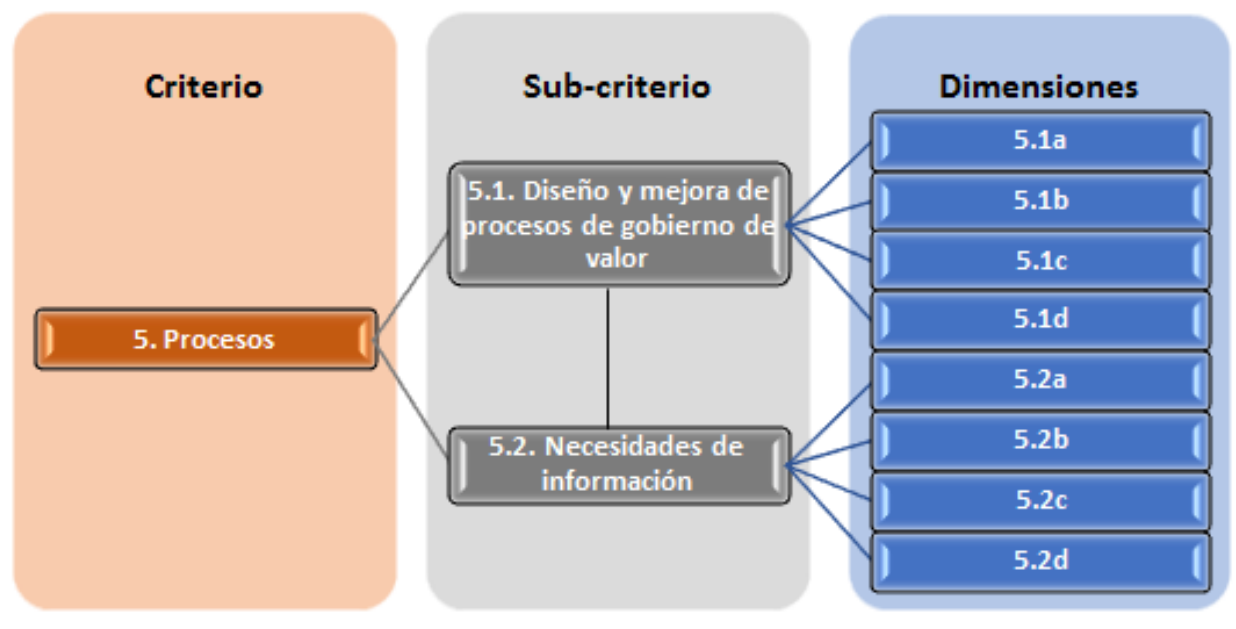

Figura 4.7. Estructura del criterio de Procesos.

La tabla 4.11 muestra las dimensiones de calidad por sub-criterio que pertenece al criterio de procesos. Como se observa, se formulan 4 dimensiones de calidad por cada sub-criterio. Ambos sub-criterios caracterizan al criterio procesos.

Existen estudios de diagnóstico de procesos en instituciones públicas que han encontrado que las organizaciones tienden a ignorar el mal rendimiento y/o funcionamiento hasta que se ven amenazadas por instituciones muy relacionadas dentro del mismo ámbito o incluso externas que tienen interés en absorberlas o desaparecerlas, y que de manera sistemática culpan de este mal rendimiento a fuerzas que están más allá de su control, en vez de encontrar responsabilidad en las direcciones funcionales y éstas a su vez en la dirección de TSI por su falta o mal asesoramiento acerca de cómo alcanzar los objetivos estratégicos de las instituciones habilitadas por las TSI.

Tabla 4.11. Dimensiones de calidad por sub-criterio del criterio Procesos

\begin{tabular}{|c|c|}
\hline Sub-criterio & \multicolumn{1}{c|}{ Dimensión } \\
\hline 5.1. Diseño y mejora de procesos & $\begin{array}{l}\text { 5.1a. El gobierno de TSI, ¿ ¿arantiza la definición, implementación y } \\
\text { seguimiento constante a los procesos que vinculan la estrategia con la }\end{array}$ \\
\hline
\end{tabular}




\begin{tabular}{|c|c|}
\hline & $\begin{array}{l}\text { cartera de los proyectos de inversión habilitadas por las TSI?. } \\
\text { 5.1b. El gobierno de TSI, ¿Garantiza la definición e impulso de la } \\
\text { implementación de un marco de gestión de programas de proyectos } \\
\text { de inversión habilitados por las TSI con el fin de aumentar el valor } \\
\text { percibido por el negocio e interesados?. } \\
\text { 5.1c. El gobierno de TSI, ¿Garantiza la creación de valor a través del } \\
\text { incremento de la calidad en los procesos y la toma de decisiones?. } \\
\text { 5.1d. El gobierno de TSI, ¿Garantiza un proceso para crear nuevo valor } \\
\text { por el uso de las TSI, que se alinee con la estrategia organizacional?. }\end{array}$ \\
\hline 5.2. Necesidades de información & $\begin{array}{l}\text { 5.2a. El gobierno de TSI, ¿Garantiza un conjunto de objetivos, } \\
\text { mediciones, metas y comparativas de rendimiento de interés para el } \\
\text { negocio y otras partes interesadas relevantes?. } \\
\text { 5.2b. El gobierno de TSI, ¿Garantiza un proceso para recoger datos } \\
\text { puntuales y exactos para informar sobre el progreso frente a los } \\
\text { objetivos estratégicos de la organización?. } \\
\text { 5.2c. El gobierno de TSI, ¿Garantiza un proceso de monitoreo que } \\
\text { establezca un método de Cuadro de Mando Integral que brinde una } \\
\text { visión completa del rendimiento del programa de proyectos de } \\
\text { inversión habilitadas por las TSI?. } \\
\text { 5.2d. El gobierno de TSI, ¿Garantiza un proceso de evaluación de la } \\
\text { integridad de la información y de la protección de la propiedad } \\
\text { intelectual de las TSI?. }\end{array}$ \\
\hline
\end{tabular}

La tabla 4.12 muestra la matriz Valor percibido del efecto de procesos. Como se puede observar, se formula un listado global de 5 efectos ( 3 para el sub-criterio 5.1 y 2 para el sub-criterio 5.2 ) en términos de valor percibido que provoca cada sub-criterio de calidad para el criterio de procesos. Este listado representa efectos genéricos del criterio de procesos en el marco de TSI, que se pueden esperar en la opinión de usuarios, directivos y accionistas de la organización.

Las personas que evalúan el criterio de procesos pueden considerar diversas opciones de valor percibido como buen funcionamiento de la estrategia, buen desempeño de los programas de proyectos, buen desempeño de procesos, información disponible y a tiempo y, uso de las TSI como apoyo en la toma de decisiones. Estos aspectos son considerados en la evaluación de la calidad.

Tabla 4.12. Valor percibido del efecto de Procesos

\begin{tabular}{|c|c|}
\hline Sub-criterio & Valor percibido \\
\hline 5.1. Diseño y mejora de procesos & $\begin{array}{l}\text { a. Buen funcionamiento de la estrategia apoyada en los proyectos } \\
\text { de inversión habilitadas por TSI. } \\
\text { b. Buen desempeño de los programas de proyectos de inversión } \\
\text { habilitadas por TSI. } \\
\text { c. Buen desempeño de procesos creadores de valor a través de } \\
\text { documentos que demuestren su actualización en el último año. }\end{array}$ \\
\hline 5.2. Necesidades de información & $\begin{array}{l}\text { a. Recursos de información disponibles para toma de decisiones. } \\
\text { b. Uso de las TSI como medios para la toma de decisiones. }\end{array}$ \\
\hline
\end{tabular}

\subsubsection{Proyectos}

La figura 4.8 muestra la estructura del criterio de proyectos. Como se observa, el criterio se relaciona con 1 sub-criterio de calidad denominado financiero y no financiero y, 2 dimensiones que se detallan más adelante en esta sección. 


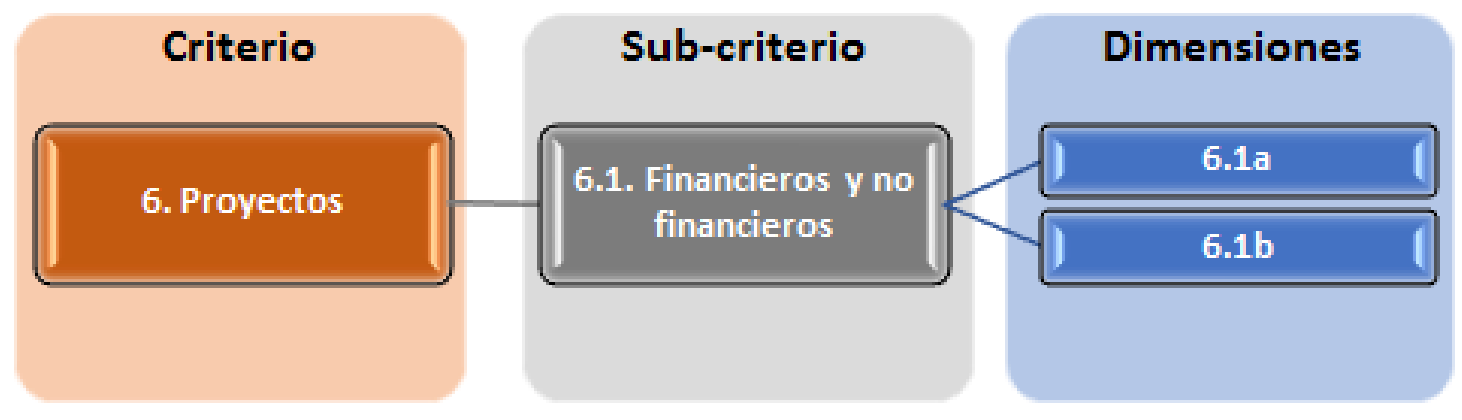

Figura 4.8. Estructura del criterio de Proyectos.

La tabla 4.13 muestra las dimensiones de calidad por el sub-criterio financiero y no financiero del criterio proyectos. Como se observa, se formulan 2 dimensiones para este sub-criterio que caracteriza al criterio de proyectos.

Se considera que, si el equipo de gobierno de TSI no cumple con estas dimensiones de calidad, la toma de decisiones se verá afectada. Aún con información ordenada, existen directores que toman malas decisiones. De todas maneras, se entiende que la alta dirección de la organización absorbe información a través de una serie de filtros para comprender el ambiente que les rodea desde el punto de vista financiero. Quienes ocupan cargos de dirección, tienen atención selectiva, que se enfocan en problemas y soluciones habilitadas por las TSI, y tienen una variedad de predisposiciones que rechazan aquella información que no cumple con sus razones previas.

Tabla 4.13. Dimensiones de calidad por sub-criterio del criterio de proyectos

\begin{tabular}{|l|l|}
\hline \multicolumn{1}{|c|}{ Sub-criterio } & \multicolumn{1}{c|}{ Dimensión } \\
\hline 6.1. Financieros y no financieros & $\begin{array}{l}\text { 6.1a. El gobierno de TSI, ¿'Garantiza la plena comprensión de la alta } \\
\text { dirección del negocio que hay varios tipos de portafolios de inversión } \\
\text { que difieren en complejidad y grado de libertad a la hora de recibir y } \\
\text { asignar fondos?. } \\
\text { 6.1b. El gobierno de TSI, ¿Garantiza un modelo de categorización de } \\
\text { proyectos de inversión debido a la complejidad con que se } \\
\text { gestionan?. }\end{array}$ \\
\hline
\end{tabular}

La tabla 4.14 muestra la matriz Valor percibido del efecto de proyectos. Como se puede observar, se formula un listado global de 2 efectos en términos de valor percibido que provoca el subcriterio de calidad para el criterio de proyectos. Este listado representa efectos genéricos del criterio de proyectos en el marco de TSI, que se pueden esperar en la opinión de usuarios, directivos y accionistas de la organización.

Las personas que evalúan el criterio de proyectos, y específicamente el sub-criterio financiero y no financiero, pueden considerar diversas opciones de valor percibido como valor social desarrollado por el portfolio de proyectos y valor moral basado en el cumplimiento de leyes, códigos, normas y derechos.

Tabla 4.14. Valor percibido el efecto de Proyectos

\begin{tabular}{|c|l|}
\hline Sub-criterio & \multicolumn{1}{c|}{ Valor percibido } \\
\hline 6.1. Financieros y no financieros & $\begin{array}{l}\text { a. Valor desarrollado por los portafolios. } \\
\text { b. Cumplimiento de la normativa legal. }\end{array}$ \\
\hline
\end{tabular}




\subsection{MÉTODO DE MEDICIÓN Y VALORACIÓN}

\subsubsection{VALORACIÓN GENERAL}

La calidad de GoTSI se evalúa siguiendo un proceso sistemático jerarquizado. Este proceso permite extraer de manera ordenada, sistemática y consistente, los elementos subjetivos de los evaluadores y luego incorporar elementos cuantitativos en la estimación del valor. En la tabla 4.15 se muestra la escala general de valoración. Como se observa, la escala está compuesta por tres niveles jerarquizados e independientes de evaluación que deben ser analizados en base a las dimensiones. Desde el punto de vista práctico, la sumatoria de los tres niveles (Implantación, Aplicación y Efecto) da la medida total del GoTSI.

Tabla 4.15. Escala general de valoración

\begin{tabular}{|c|c|c|}
\hline Jerarquía & Nivel de evaluación & Ponderación \\
\hline 1 & Implantación & 0,4 \\
\hline 2 & Aplicación & 0,3 \\
\hline 3 & Efecto & 0,3 \\
\hline
\end{tabular}

El primer nivel de evaluación mide la Implantación del sistema de calidad de GoTSI. Es indispensable, para evaluar la calidad, que exista un conjunto de procesos y procedimientos que se definan de forma coherente para lograr la calidad. En otras palabras, el primer paso determina que no es posible alcanzar la calidad si no existe un sistema de gobierno de TSI que incorpore criterios de calidad. La ponderación sugerida asignada a este nivel es 0,4 puntos, lo que en términos relativos significa $40 \%$, por la importancia que representa. En definitiva, no pueden existir resultados positivos de calidad si no existe un sistema de gobierno de TSI.

El segundo nivel de evaluación mide la Aplicación del sistema de calidad de gobierno de TSI. Aunque se puede alcanzar el primer nivel de manera satisfactoria, las organizaciones de TSI con políticas que involucran altos componentes administrativos o burocráticos pueden no dar paso para llevar a la práctica lo que los equipos directivos que controlan la norma de calidad proponen o difunden. La persona quien evalúa el sistema implantado tiene que valorar en qué medida el sistema se lleva a la práctica y no reflejar sólo buenas intenciones en documentos o actos ejecutivos. La ponderación que se sugiere a este nivel es 0,3 puntos, lo que en términos relativos significa $30 \%$ de la medida total del GoTSI. Se asigna esta ponderación porque se busca equiparación con el nivel de Efecto debido a que se consideran a ambos niveles directamente positivos.

El tercer nivel de evaluación recoge la medida de los efectos del sistema de gobierno de TSI en la organización en función del valor percibido por accionistas, ejecutivos y empleados; acerca de la eficacia y eficiencia del valor entregado a la organización a través de las TSI. La ponderación que se sugiere a este nivel es 0,3 puntos, lo que en términos relativos significa $30 \%$. Siendo razonable con el párrafo anterior, se asigna una ponderación equiparable con el nivel de aplicación porque se considera una meta directa de la organización.

Los niveles de evaluación permiten medir y valorar cada uno de los seis criterios con un total de 1 punto, distribuidos de acuerdo con los tres niveles analizados. Al final, la sumatoria de cada uno de los seis criterios (máximo 6 puntos) determinará el valor del sistema de calidad de GoTSI. 


\subsubsection{VALORACIÓN DE LAS DIMENSIONES, SUB-CRITERIOS Y CRITERIOS}

Las dimensiones son perspectivas desde las cuales se evalúan a los sub-criterios de calidad. Cada dimensión es valorada en términos de sus evidencias, para lo cual, se debe entender a cada dimensión en función de la evidencia valorada. Tal como se muestra en la tabla 4.16, cada evidencia se valora de acuerdo a la escala de puntuación de Likert, con cinco puntuaciones.

Tabla 4.16. Escala de puntuación

\begin{tabular}{|c|c|c|c|c|}
\hline Bajo/Pobre & $\begin{array}{c}\text { Bajo } \\
\text { Promedio }\end{array}$ & Promedio & $\begin{array}{c}\text { Encima } \\
\text { Promedio }\end{array}$ & Alta/Bueno \\
\hline 0,00 & 0,25 & 0,5 & 0,75 & 1,00 \\
\hline
\end{tabular}

Los conceptos de sucesiones y series (Allen R., 2008) se utilizan para desarrollar fórmulas que permitan calcular las evidencias, dimensiones, sub-criterios y criterios del modelo.

Las fórmulas 4.1 y 4.2 permiten valorar la Importancia I[i] y Difusión $D[i]$, respectivamente; de la $i$ ésima dimensión para un conjunto de $k$ evaluadores.

$I[i]=\sum_{j=1}^{k}\left(I[i, j]^{*}\right.$ puntuacion $) / k$

\section{Fórmula 4.1. Cálculo de la Importancia I[i]}

$\mathrm{D}[i]=\sum_{j=1}^{k}\left(\mathrm{D}[i, j]^{*}\right.$ puntuacion $) / k$

Fórmula 4.2. Cálculo de la Difusión $\mathrm{D}[i]$

Dónde:

puntuacion= valor asignado por evaluador a la evidencia de acuerdo a escala de puntuación

El nivel de Implantación del sub-criterio IMSC del conjunto de $n$ dimensiones se mide a través de las fórmulas 4.1 y 4.2 , tal como se muestra en la fórmula 4.3.

$\boldsymbol{I M S C}=\frac{\sum_{i=1}^{n} \mathrm{I}[i] * \mathrm{D}[i]}{\sum_{i=1}^{n} \mathrm{I}[i] * \text { peso }}$

\section{Fórmula 4.3. Cálculo de Implantación del sub-criterio IMSC}

Dónde:

peso= valor más alto de la escala de puntuación

Las fórmulas 4.4 y 4.5 permiten medir la Utilización U[i] y Seguimiento S[i], respectivamente; de la $i$-ésima dimensión para un conjunto de $k$ evaluadores.

$\mathrm{U}[i]=\sum_{j=1}^{k}\left(\mathrm{U}[i, j]^{*}\right.$ puntuacion $) / k$

Fórmula 4.4. Cálculo de la Utilización U[i]

$\mathrm{S}[i]=\sum_{j=1}^{k}\left(\mathrm{~S}[i, j]^{*}\right.$ puntuacion $) / k$

Fórmula 4.5. Cálculo del Seguimiento $S[i]$ 
Dónde:

puntuacion $=$ valor asignado por evaluador a la evidencia de acuerdo a escala de puntuación

El nivel de Aplicación del sub-criterio $\boldsymbol{A P S C}$ del conjunto de $n$ dimensiones se mide a través de las fórmulas 4.4 y 4.5 , tal como se muestra en la fórmula 4.6.

$\boldsymbol{A P S C}=\frac{\sum_{i=1}^{n} \mathrm{U}[i] * \mathrm{~S}[i]}{\sum_{i=1}^{n} \mathrm{U}[i] * \text { peso }}$

Fórmula 4.6. Cálculo de Aplicación del sub-criterio $A P S C$

Dónde:

peso= valor más alto de la escala de puntuación

La fórmula 4.7 permite medir el Valor Percibido V[i] de la i-ésima dimensión para un conjunto de $k$ evaluadores.

$\mathrm{V}[i]=\sum_{j=1}^{k}\left(\mathrm{~V}[i, j]^{*}\right.$ puntuacion $) / k$

\section{Fórmula 4.7. Cálculo del Valor Percibido V[i]}

Dónde:

puntuacion $=$ valor asignado por evaluador a la evidencia de acuerdo a escala de puntuación

El nivel de Efecto del sub-criterio EFSC del conjunto de $n$ dimensiones se mide a través de la fórmula 4.7, tal como se muestra en la fórmula 4.8.

EFSC $=\sqrt[n]{{V_{1} * \mathrm{~V}_{2} * \mathrm{~V}_{3} * \ldots * \mathrm{~V}_{\mathrm{n}}}_{\text {peso }}}$

\section{Fórmula 4.8. Cálculo de Efecto del sub-criterio EFSC}

Dónde:

peso= valor más alto de la escala de puntuación

La fórmula 4.9 determina la medida total de un sub-criterio SC.

$\mathbf{S C}=\left(I M S C^{*} P I M\right)+\left(A P S C^{*} P A P\right)+\left(E F S C^{*} P E F\right)$

\section{Fórmula 4.9. Cálculo del sub-criterio SC en medición}

Dónde:

IMSC= medida de Implantación del sub-criterio.

APSC $=$ medida de Aplicación del sub-criterio

$E F S C=$ medida de Efecto del sub-criterio.

$P I M=$ valor de ponderación asignado al nivel de Implantación.

$P A P=\quad$ valor de ponderación asignado al nivel de Aplicación. 
$P E F=\quad$ valor de ponderación asignado al nivel de Efecto.

La fórmula 4.10 determina la medida total del criterio CR.

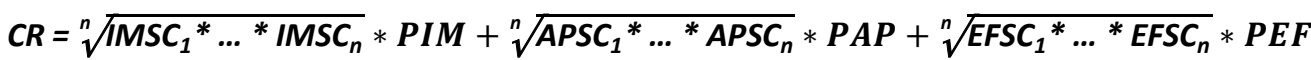

Fórmula 4.10. Cálculo del criterio CR

Dónde:

$n=\quad$ número de sub-criterios asociados a un criterio en medición.

IMSC = medida de Implantación del sub-criterio en cuestión $n$.

APSC $=$ medida de Aplicación del sub-criterio en cuestión $n$.

$E F S C=$ medida de Efecto del sub-criterio en cuestión $n$.

$P I M=$ valor de ponderación asignado al nivel de Implantación.

$P A P=$ valor de ponderación asignado al nivel de Aplicación.

$P E F=\quad$ valor de ponderación asignado al nivel de Efecto.

\subsubsection{VALORACIÓN DEL SISTEMA DE CALIDAD DE GOTSI}

Una vez que se ha llegado al mayor nivel de abstracción del modelo. La medida total del sistema de calidad se compone por los 6 criterios calculados sobre la base de 1 punto, en donde, la puntuación máxima a obtener es 6 puntos, que en términos relativos significa el 600\%, producto de la sumatoria de los 6 criterios. Tal como se muestra en la fórmula 4.11.

VGoTSI $=C R 1+C R 2+C R 3+C R 4+C R 5+C R 6$

\section{Fórmula 4.11. Cálculo de la medida total del sistema de calidad de GoTSI}

La figura 4.9 representaría gráficamente la medida que se obtiene por cada criterio de calidad del GoTSI en una organización de TSI.

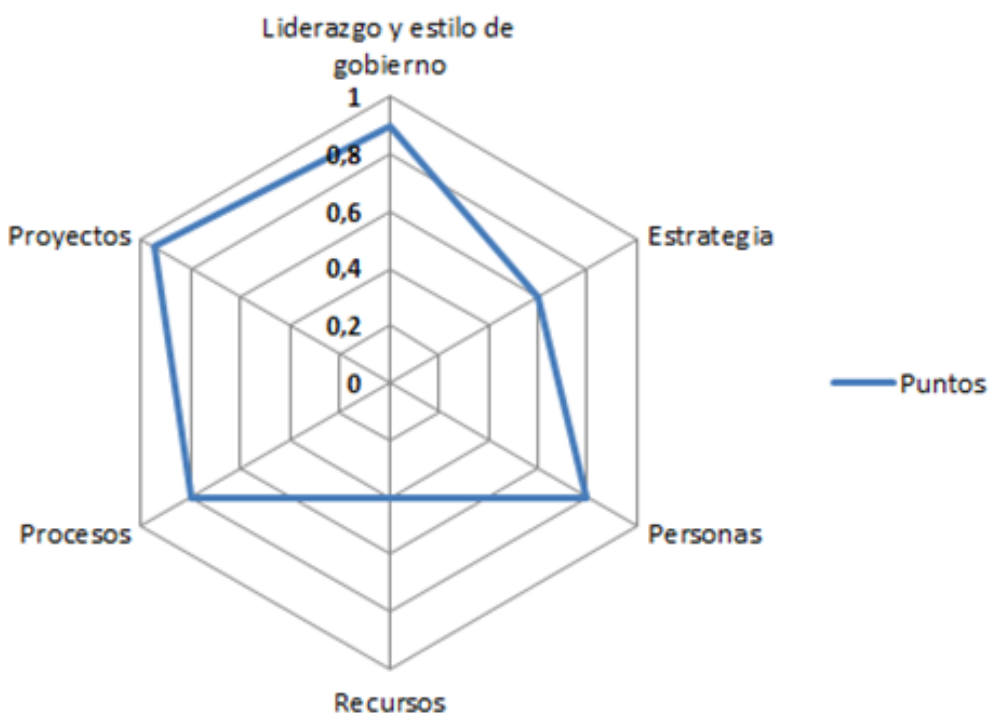

Figura 4.9. Representación de la calidad de GoTSI. 
La figura 4.10 representaría gráficamente la contribución que realiza cada criterio a la medida total de la calidad de GoTSI en una organización de TSI.

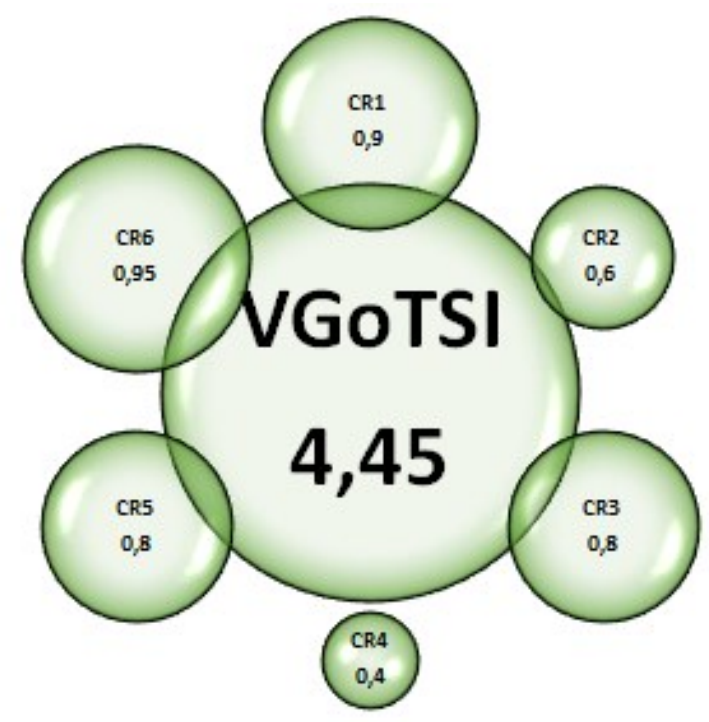

Figura 4.10. Contribución a la medida total de la calidad de GoTSI.

\subsection{FASES DEL PROCESO DE EVALUACIÓN}

Para proceder con la evaluación es preciso definirlo en fases con la finalidad de facilitar su dirección, planificación y control, las cuales pueden verse en la figura 4.11 y que son abordadas a continuación en esta sección.

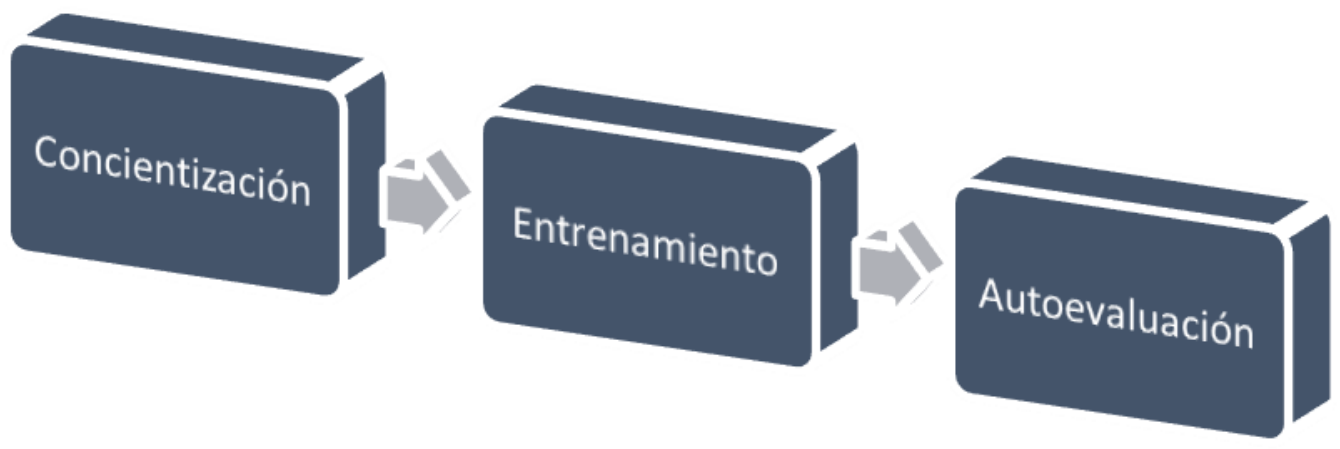

Figura 4.11. Fases de evaluación.

\subsubsection{FASE DE CONCIENTIZACIÓN}

Sin la concientización del equipo de gobierno y principalmente de la alta dirección, es posible que el trabajo de evaluación se convierta en un "simulacro inútil". La alta dirección debe tener una visión clara del futuro del equipo de gobierno de TSI, las oportunidades y amenazas que se le presentan. Su posición debe ser transparente y franca, atendiendo con compromiso las tareas que se le presente.

Es recomendable que este proceso de evaluación lo organice y dirija un equipo de evaluación de la calidad de la organización, que se puede constituir a partir de la unidad funcional de calidad y productividad por su naturaleza laboral. Además, porque este proceso demanda tiempo, conocimiento y dedicación. 


\subsubsection{FASE DE ENTRENAMIENTO}

A fin de asegurar un adecuado asesoramiento al equipo de gobierno de TSI, es necesario que el equipo de evaluación conozca los principios y conceptos de calidad y de gobierno de TSI. Es importante discutir los temas y obtener reflexiones, con la finalidad de afianzar el valor que busca la evaluación.

Es preciso dominar el modelo de evaluación. Es necesario que el equipo esté consciente de las ponderaciones del sistema y las puntuaciones de la escala de dimensiones. Esto definirá el nivel de rigurosidad del modelo de evaluación.

\subsubsection{FASE DE AUTOEVALUACIÓN}

Este proceso consta de cinco pasos, los cuales se detallan a continuación.

\section{Identificar la organización}

Esta es una actividad que consiste en identificar a la organización de GoTSI que impacta en el negocio, y documentar información relevante a su conformación, procesos, actividades y tareas que impacta en el éxito del negocio.

\section{Definir el alcance}

Puede parecer trivial este paso pero su importancia radica en definir y controlar qué se incluye y qué no se incluye en la evaluación.

\section{Definir las actividades}

El equipo de evaluación prepara las actividades necesarias a llevarse a cabo para cumplir con la evaluación. Entre éstas están: preparar el cuestionario que recoge todas las dimensiones, estimar la duración, relevar la información, tabular los datos, preparar el informe con propuestas pertinentes.

\section{Ejecutar la autoevaluación}

Esta actividad debe dirigirse, gestionarse, asegurarse la calidad, contar con el personal adecuado, manejar la información obtenida de tal manera que permita identificar actividades de mejora.

\section{Elaboración y presentación del informe final}

El informe de autoevaluación debe ser lo más exacto posible con la finalidad de identificar los aspectos que necesiten mejorar.

Este informe está dirigido al responsable del equipo de gobierno para que tome las decisiones de mejora. Cabe destacar que los responsables de las unidades funcionales deben estar conformes con las conclusiones para proseguir con las mejoras.

\subsection{CONCLUSIONES}

En este capítulo, se ha abordado de manera concreta la propuesta de modelo de calidad para GoTSI basada en valor, en base al conocimiento y experiencia del autor, la opinión de expertos y la revisión sistemática del material referencial existente. El modelo final constituye un aporte conceptual compuesto por 2 principios básicos, 6 criterios, 9 sub-criterios, 34 dimensiones de calidad, 3 niveles jerárquicos de evaluación y 5 evidencias que son valorados en función de una escala de puntuación (1 a 5) tipo Likert. 
Desde el punto de vista matemático se han desarrollado una serie de fórmulas basadas en los conceptos de sucesiones y series, con la finalidad de determinar la medida de dimensiones, subcriterios y criterios. Resultados de este trabajo han sido publicados en (Merchán, et al., 2016). Finalmente, se propone un proceso de evaluación estructurado en 3 fases y para la autoevaluación se propone 5 actividades.

En el siguiente capítulo se presenta la validación del modelo de calidad propuesto, cuyo objetivo será demostrar la utilidad en base a la opinión de líderes de TSI, cuyos resultados serán procesados con métodos y técnicas estadísticas utilizadas en investigación científica. 



\section{CAPÍTULO 5 - VALIDACIÓN EMPÍRICA DEL MODELO DE CALIDAD (VBISTGQM)}

\subsection{INTRODUCCIÓN}

En el capítulo anterior se presentó el modelo de calidad propuesto. En este capítulo se presenta al lector la validación del modelo desde la óptica de métodos estadísticos desarrollados para datos no paramétricos de tipo ordinal y nominal.

Este proceso, hasta cierto aspecto complejo, requiere el entendimiento de dos conceptos polémicos como son la objetividad y la subjetividad.

Al respecto, Olsina (1999), doctor en ciencias del sector software, discutió la objetividad y subjetividad en términos de evaluación, mencionando lo siguiente:

"En principio, dos conceptos extremos (aunque no excluyentes en la práctica) entran en juego: objetividad y subjetividad; y que, en el contexto de la evaluación (y sin entrar en detalles epistemológicos) estamos queriendo significar al proceso de decisión basado en modelos y métodos cuantitativos, o al proceso de decisión basado en la intuición.

Además, cuando hablamos de intuición, no lo decimos en un sentido peyorativo sino que por el contrario queremos significar al mecanismo mental, o conocimiento claro, íntimo o instantáneo, surgido de la experticia. Con todo, es importante resaltar que la evaluación intuitiva es un ejercicio mental del día a día que todo ser humano realiza, ya sea más o menos experto en el domino del objeto que evalúa. ( $Y$ de hecho, la evaluación intuitiva representa la base de muchas de las decisiones tomadas por el ser humano). Por otra parte, más de un investigador ha afirmado que la métrica de un atributo tiene que estar bien definida, esto es, basada en la observación empírica, consistente con la intuición y que represente una apropiada correspondencia entre el dominio empírico y el sistema numérico (Fenton, 1991) (Goldberg, et al., 1995).

Además, e intentando responder a la pregunta antes formulada, el proceso de evaluación siempre se basa en un conjunto de requerimientos que el artefacto (en nuestro caso el sitio Web), debe satisfacer. Estos requerimientos generalmente se derivan de un conjunto de metas dadas y/o elicitadas para el objeto de evaluación.

Obviamente, el conjunto de metas sólo puede ser elicitado y definido por los tomadores de decisión (esto es, seres humanos). Por lo tanto, ya las metas como los requerimientos correspondientes se especifican más bien de un modo subjetivo; según el pensamiento de varios investigadores no hay otro modo "más objetivo o racional" para iniciar un proceso de evaluación, comparación y selección (interpretando al concepto "subjetivo" en un sentido positivo, como mencionamos anteriormente). De manera que los componentes subjetivos no pueden ser obviados, pero deben ser minimizados $y / o$ usados apropiadamente".

Por lo expresado, es posible destacar que la opinión y decisión de expertos juega un rol importante en la determinación de las características relacionadas con el objeto de estudio. Su valor se encuentra representado en la riqueza de información que entregan a la investigación. 
Este capítulo trata la validación operativa del modelo, desde la opinión de los líderes de TSI debido a que son ellos los actores del mismo, por lo tanto, es importante que expresen su utilidad y aplicabilidad, a través de una encuesta que busca conocer el nivel de importancia empírica que le brindan a los criterios y sub-criterios de calidad definidos y validados por expertos. Es así que, primero se definen los encuestados, después el cuestionario, enseguida se lo valida y relevan los datos, y por último se los analizan estadísticamente.

\subsection{DEFINICIÓN DE LOS ENCUESTADOS}

La encuesta está dirigida a un grupo experimentado de profesionales que ocupan o han ocupado cargos de dirección de TSI u otra dirección funcional en el ámbito público ecuatoriano, con la experiencia de haber tomado decisiones acerca del uso de las TSI y, con conocimiento de sistemas de gestión de la calidad. Por lo tanto, la selección es informal desde el punto de vista de que es no probabilística (Hernández Sampieri, et al., 2010) (Anderson, et al., 2008), pues lo que se busca es obtener datos a partir de una muestra de población cualitativa elegida por conveniencia (por cuotas) cuya característica o variable en estudio serán no numéricas, o también denominadas variables cualitativas. La lista completa de entidades colaboradoras, de las cuales forman parte los profesionales de opinión, se encuentra en el anexo D.

La tabla 5.1 muestra la estructura técnica de los encuestados.

Tabla 5.1. Estructura técnica de los encuestados

\begin{tabular}{|l|c|}
\hline \multicolumn{1}{|c|}{ Variable } & Característica \\
\hline Número de identificados & 136 \\
\hline Número aceptados & 89 \\
\hline Número completado & 62 \\
\hline Número incompleto & 27 \\
\hline Tasa global de finalización & \multicolumn{1}{c|}{$69,66 \%$} \\
\hline Recogida de datos & $\begin{array}{l}\text { Focus group } \\
\text { eMail } \\
\text { Contact center }\end{array}$ \\
\hline
\end{tabular}

\subsection{DEFINICIÓN DEL CUESTIONARIO}

La encuesta desarrollada sigue los lineamientos de (Pfleeger, et al., 2001), cuya definición es la de un sistema que permite recoger información, describir, comparar o explicar conocimientos, actitudes y comportamientos; a decir de Hernández Sampieri et al. (2010), una encuesta se constituye en una técnica de opinión (survey) útil en procesos de investigación no experimental transversal o transeccional descriptivo o correlacional-causal.

La encuesta define como instrumento de investigación un cuestionario, con 40 preguntas, estructurado en 8 secciones (Criterios), tal como se muestra en la tabla 5.2.

Tabla 5.2. Estructura del cuestionario

\begin{tabular}{|l|l|c|}
\hline \multicolumn{1}{|c|}{ Sección } & \multicolumn{1}{|c|}{ Sub-sección } & Número de preguntas \\
\hline A. & Datos demográficos & \multicolumn{1}{|c|}{} \\
\hline \multirow{2}{*}{ B. $\begin{array}{l}\text { Liderazgo y estilo de } \\
\text { gobierno }\end{array}$} & B.1. Cultura de excelencia basada en valor & 5 \\
\cline { 2 - 3 } & B.2. Arquitectura empresarial-TSI basada en valor & 6 \\
\hline \multirow{2}{*}{ C. Estrategia } & C.1. Dirección de estrategias & 3 \\
\cline { 2 - 3 } D. Personas & C.2. Evaluación de estrategias & 3 \\
\hline E. Recursos & $\begin{array}{l}\text { D.1. Roles y responsabilidades para materializar y } \\
\text { proteger el valor }\end{array}$ & 5 \\
\hline
\end{tabular}




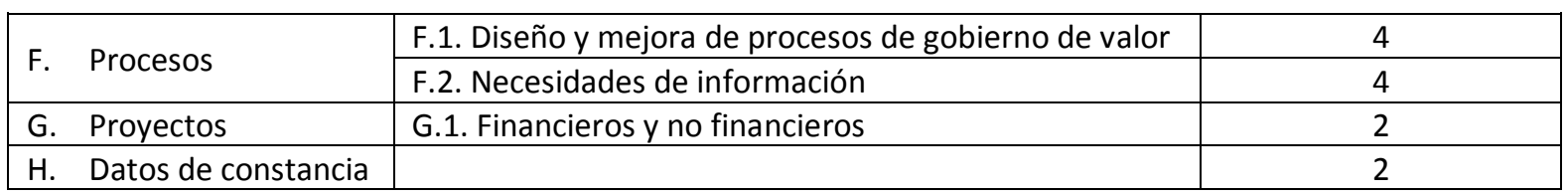

La sección A, de Datos Demográficos, está compuesta por 4 preguntas cuya finalidad es relevar información general del encuestado y analizar la asociatividad de sub-criterios. Los datos obtenidos en esta sección son de nivel nominal, útiles para realizar pruebas estadísticas aplicando métodos no paramétricos.

A continuación, se identifican los criterios de excelencia, a través de 6 secciones. La sección $B$, del criterio de liderazgo y estilo de gobierno, está compuesta por 5 preguntas que evalúan la cultura de excelencia basada en valor, y 6 preguntas que evalúan la arquitectura empresarial-TSI basada en valor. La sección $C$, del criterio de estrategia, está compuesta por 3 preguntas que evalúan la dirección de estrategias y, 3 preguntas que evalúan las estrategias en sí. La sección $D$, del criterio de personas, está compuesta de 5 preguntas que evalúan los roles y responsabilidades para materializar y proteger el valor. La sección $E$, del criterio de recursos, está compuesta de 2 preguntas que evalúan los recursos financieros y materiales. La sección $F$, del criterio de procesos, está compuesta de 4 preguntas que evalúan el diseño y mejora de procesos de gobierno de valor, y 4 preguntas que evalúan las necesidades de información. Por último, la sección G, del criterio de proyectos, está compuesta de 2 preguntas que evalúan los proyectos financieros y no financieros de TSI. Los datos obtenidos en estas 6 secciones son de nivel ordinal, útiles para realizar pruebas estadísticas aplicando métodos no paramétricos.

La sección $\mathrm{H}$, de datos de constancia, está compuesta de 2 preguntas que evidencian los datos de los líderes de TSI participantes en esta encuesta de opinión transeccional. Los datos obtenidos en esta sección son de nivel nominal.

Para recoger la opinión de las personas experimentadas, se utilizó en las respuestas la puntuación de Likert en una escala de 1 a 5. Dónde:

- 1 - COMPLETA INSIGNIFICANCIA

- 2 - MODERADA INSIGNIFICANCIA

- 3-INDIFERENCIA

- 4-MODERADA IMPORTANCIA

- 5 - COMPLETA IMPORTANCIA

El acceso al cuestionario se realiza a través del sitio https://www.survio.com/survey/d/encuestade-gotsi. Tal como se muestra en la figura 5.1. 


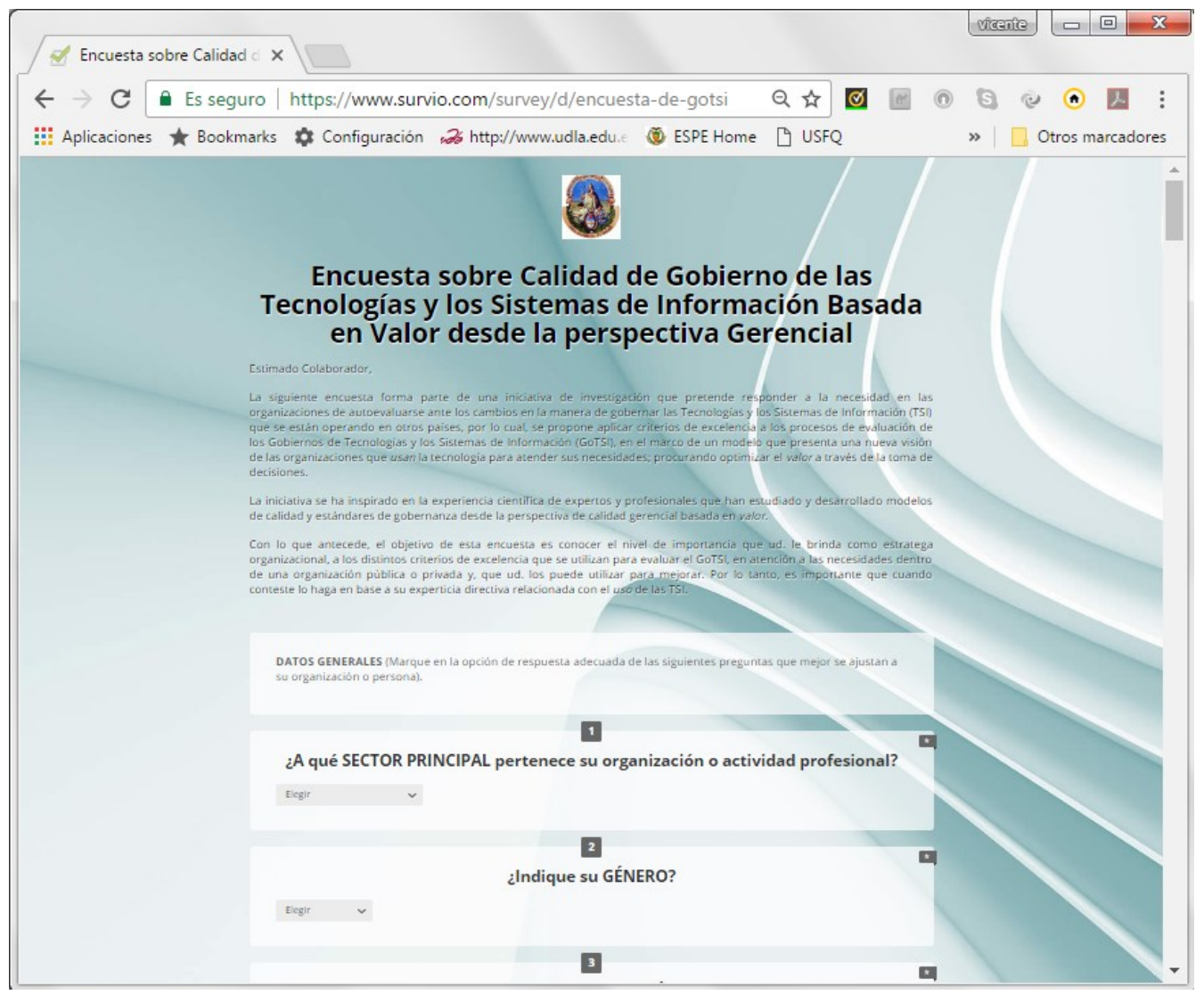

Figura 5.1. Sitio web de la encuesta.

El detalle del cuestionario puede verse en el Anexo E.

\subsection{VALIDACIÓN DEL CUESTIONARIO}

El cuestionario fue validado por expertos, quienes se encargaron de recomendar acerca de la comprensibilidad y entendimiento de las preguntas.

\subsection{RECOLECCIÓN DE DATOS}

La recolección de datos tomó alrededor de 180 días durante el año 2016. Una vez determinado el grupo de encuestados, se procedió con el contacto telefónico, vía email o presencial (focus group); se procedió a informarles el objetivo de la investigación y solicitarles su participación voluntaria en caso de que reúnan las competencias adecuadas. Como aspecto importante, se explicó a todo encuestado que la totalidad de información recopilada sería tratada con la máxima reserva del caso y los datos serían utilizados de forma anónima. Además, de que si era su intención podrían sus datos de contacto ser publicados en la investigación.

Se recalcó el hecho de que el cuestionario se compone de preguntas orientadas a la entrega de valor en el ámbito público.

Se utilizó la aplicación IBM SPSS Statistics 22 (IBM, 2013) para el análisis estadístico de resultados.

\subsection{ANÁLISIS ESTADÍSTICO DE RESULTADOS}

El análisis estadístico de resultados comprende los siguientes tipos:

- Análisis de fiabilidad

- Análisis descriptivo con pruebas de normalidad 
- Análisis de correlación rango-orden de Spearman

- Análisis de varianza por rangos de Kruskal-Wallis

- Análisis factorial o de componentes principales

\subsubsection{ANÁLISIS DE FIABILIDAD}

El análisis de fiabilidad, soportado en el coeficiente Alpha de Cronbach $(\alpha)$ (Cronbach, September 1951), permite estimar por excelencia la fiabilidad de un compuesto de otras mediciones (Cervantes, 2005). En otras palabras, el coeficiente determina la fiabilidad o consistencia de los resultados obtenidos en la encuesta de opinión agrupados por sub-criterios. Para esto se procedió con el análisis a través del método de varianza de preguntas (ítems). Tal como se muestra en la fórmula 5.1.

$\alpha=\frac{\mathrm{k}}{k-1}\left[1-\frac{\sum S_{i}^{2}}{S_{t}^{2}}\right]$

\section{Fórmula 5.1. Cálculo del coeficiente Alpha de Cronbach}

Dónde:
$\alpha=\quad$ es el Alpha de Cronbach
$k=\quad$ es el número de preguntas (ítems)
$S_{i}^{2}=\quad$ es la varianza de cada pregunta (ítem)
$S_{t}^{2}=$ es la varianza total (suma de todos los ítems)

El resultado de la prueba Alpha de Cronbach entrega un valor de 0,877 para las 9 variables. Este resultado se considera óptimo o de alta fiabilidad en vista de que se encuentra en el intervalo 0,80 - 1 (Aragón, et al., 2012); el cual se interpreta como eficiencia en la prueba.

\subsubsection{ANÁLISIS DESCRIPTIVO}

En esta sección se aplica el método estadístico de distribución de frecuencias que permite organizar los datos con el fin de indicar los sitios donde los valores de datos tienden a acumularse, y ayudar a distinguir los valores menores y mayores. Se continúa con los métodos que describen el conjunto de datos obtenidos en cada una de las secciones de calidad. El análisis considera 6 medidas descriptivas: la media aritmética, la mediana, la moda, el rango, la varianza y la desviación estándar. A estas pruebas, se complementa las pruebas de normalidad de KolmogorovSmirnov con el fin de determinar el uso de métodos no paramétricos de validación de variables.

\subsubsection{Datos demográficos}

La figura 5.2 muestra el SECTOR PRINCIPAL de la actividad económica en la que se desempeña la organización del encuestado. Como se puede observar, estadísticamente la mayoría representada en el $35,5 \%$ de encuestados pertenecen al sector servicios seguido por el $22,6 \%$ que pertenecen a otro sector. 


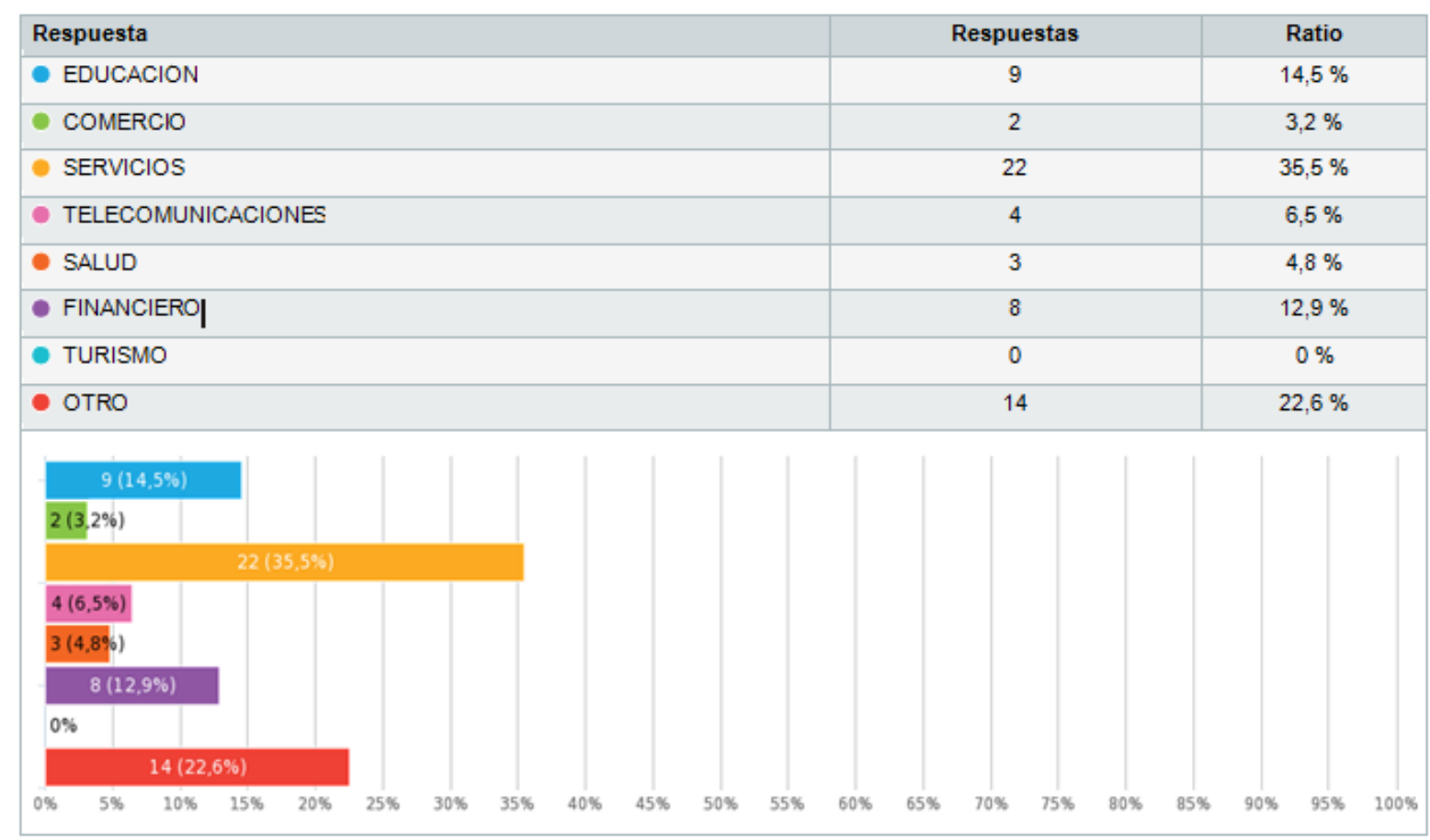

Figura 5.2. Sector principal

La figura 5.3 muestra el GÉNERO del encuestado. Como se puede observar, el $69,4 \%$ de encuestados son de género masculino frente al 30,6\% que son de género femenino.

\begin{tabular}{|c|c|c|c|c|c|c|c|c|c|c|c|c|c|c|c|c|c|c|c|c|}
\hline \multicolumn{9}{|c|}{ Respuesta } & \multicolumn{8}{|c|}{ Respuestas } & \multicolumn{4}{|c|}{ Ratio } \\
\hline \multicolumn{9}{|c|}{ - MASCULINO } & \multicolumn{8}{|c|}{43} & \multicolumn{4}{|c|}{$69,4 \%$} \\
\hline \multicolumn{9}{|c|}{ FEMENINO } & \multicolumn{8}{|c|}{19} & \multicolumn{4}{|c|}{$30,6 \%$} \\
\hline \multicolumn{21}{|c|}{$43(69,4 \%)$} \\
\hline \multicolumn{7}{|c|}{$19(30,6 \%)$} & & & & & & & & & & & & & & \\
\hline
\end{tabular}

Figura 5.3. Género.

La figura 5.4 muestra el nivel más alto de ESCOLARIDAD del encuestado. Como se puede observar, estadísticamente la mayoría representada en el 56,5\% de encuestados ha cursado una maestría como mayor nivel de escolaridad seguido por el $32,3 \%$ que ha cursado una ingeniería. 


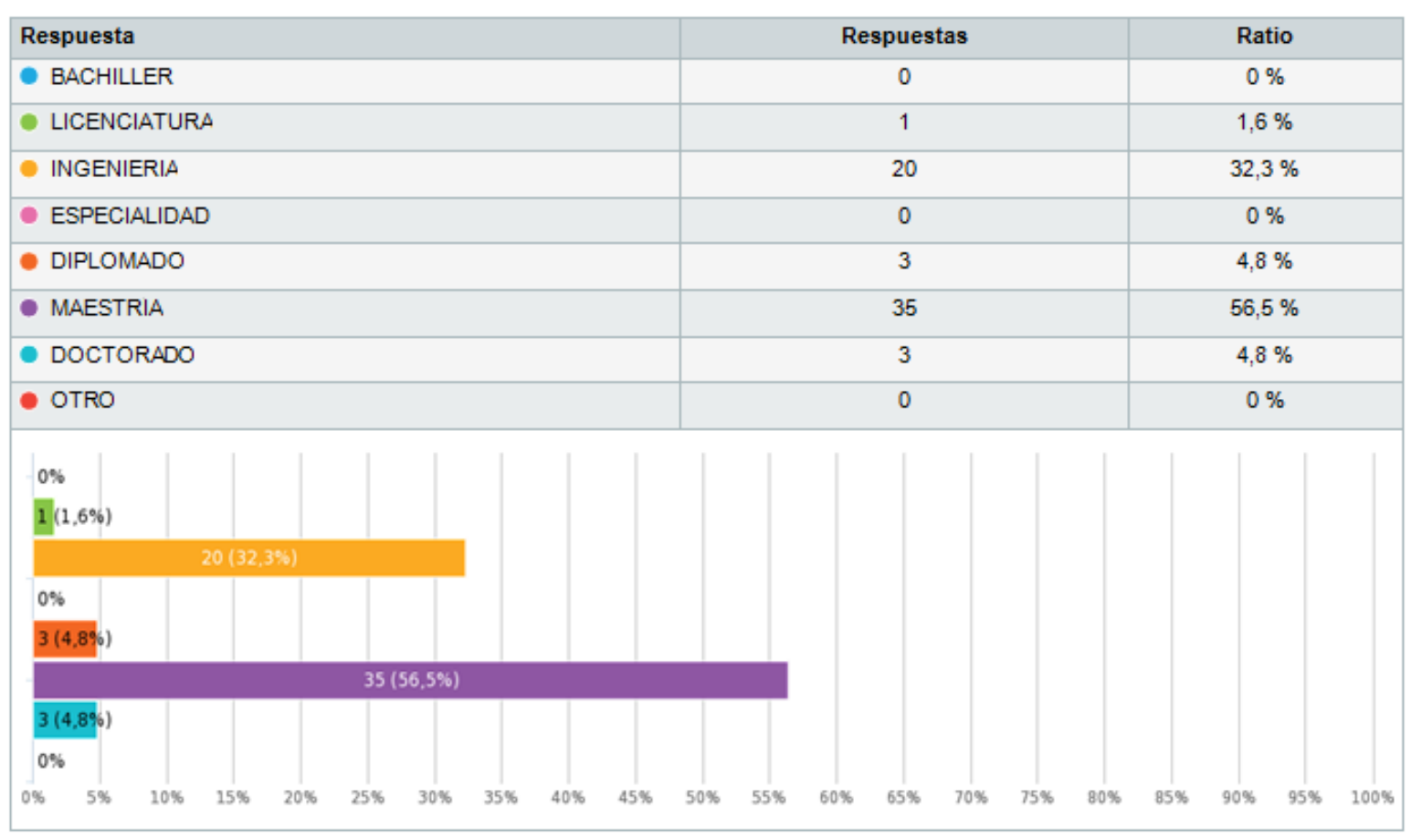

Figura 5.4. Nivel de escolaridad.

La figura 5.5 muestra el RANGO DE EDAD del encuestado. Como se puede observar, estadísticamente el 53,2\% de los encuestados se encuentran en el rango de 36 a 45 años de edad, constituyendo el intervalo de edad de la mayoría de encuestados.

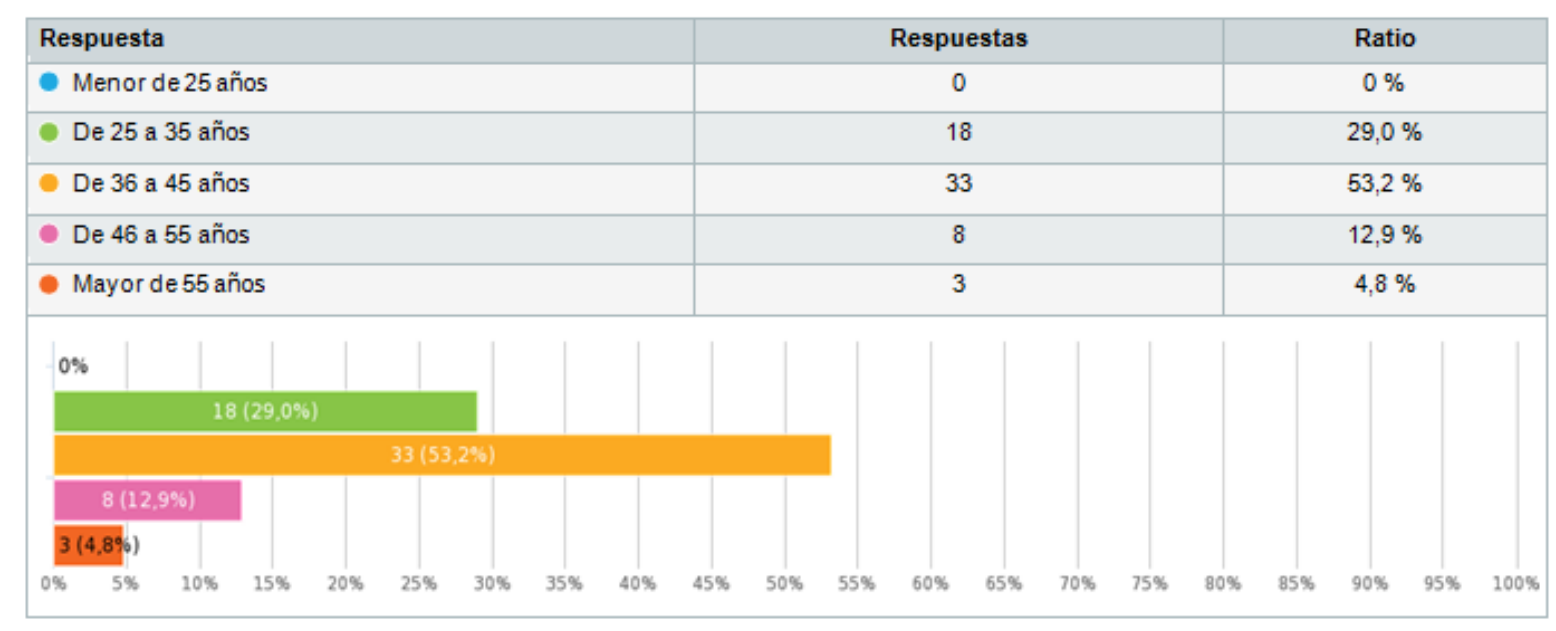

Figura 5.5. Rango de edad.

\subsubsection{Datos sobre criterios de excelencia}

La figura 5.6 muestra el nivel de importancia que los líderes de TSI brindan al criterio de Liderazgo y Estilo de gobierno a través de las dimensiones pertenecientes a los sub-criterios de Cultura de excelencia y Arquitectura empresarial-TSI. La figura 5.6 (a) que representa a la cultura de excelencia, se observa que las dimensiones con "completa importancia" son la 1.1.a y 1.1.b. En estas dimensiones predomina el involucramiento activo de los líderes de TSI en las definiciones de los objetivos estratégicos fundamentales generadores de valor en la organización. Por lo demás, sobresale el porcentaje de "completa importancia" en las otras dimensiones. En el caso de la figura 5.6 (b) que representa a la arquitectura empresarial-TSI, se observa que las dimensiones 
con "completa importancia" son 1.2.c, 1.2.d, 1.2.e y 1.2.f. En estas dimensiones predomina el seguimiento y control en la entrega de valor en la organización de TSI. Por otro lado, se debe destacar la variedad en el nivel de importancia que brindan los líderes encuestados a la dimensión 1.2.a. Según la opinión de expertos, la pregunta de definición del GoTSI a cargo de los ejecutivos senior pudo haber dado cabida a varias interpretaciones, por ejemplo, la participación del CEO y accionistas que no forman parte precisamente de los ejecutivos senior. En todo caso es un asunto de experiencia de GoTSI.

En conclusión, sobresale el 95\% en promedio el porcentaje de "completa importancia + moderada importancia" en todas las dimensiones del criterio de Liderazgo y estilo de gobierno.
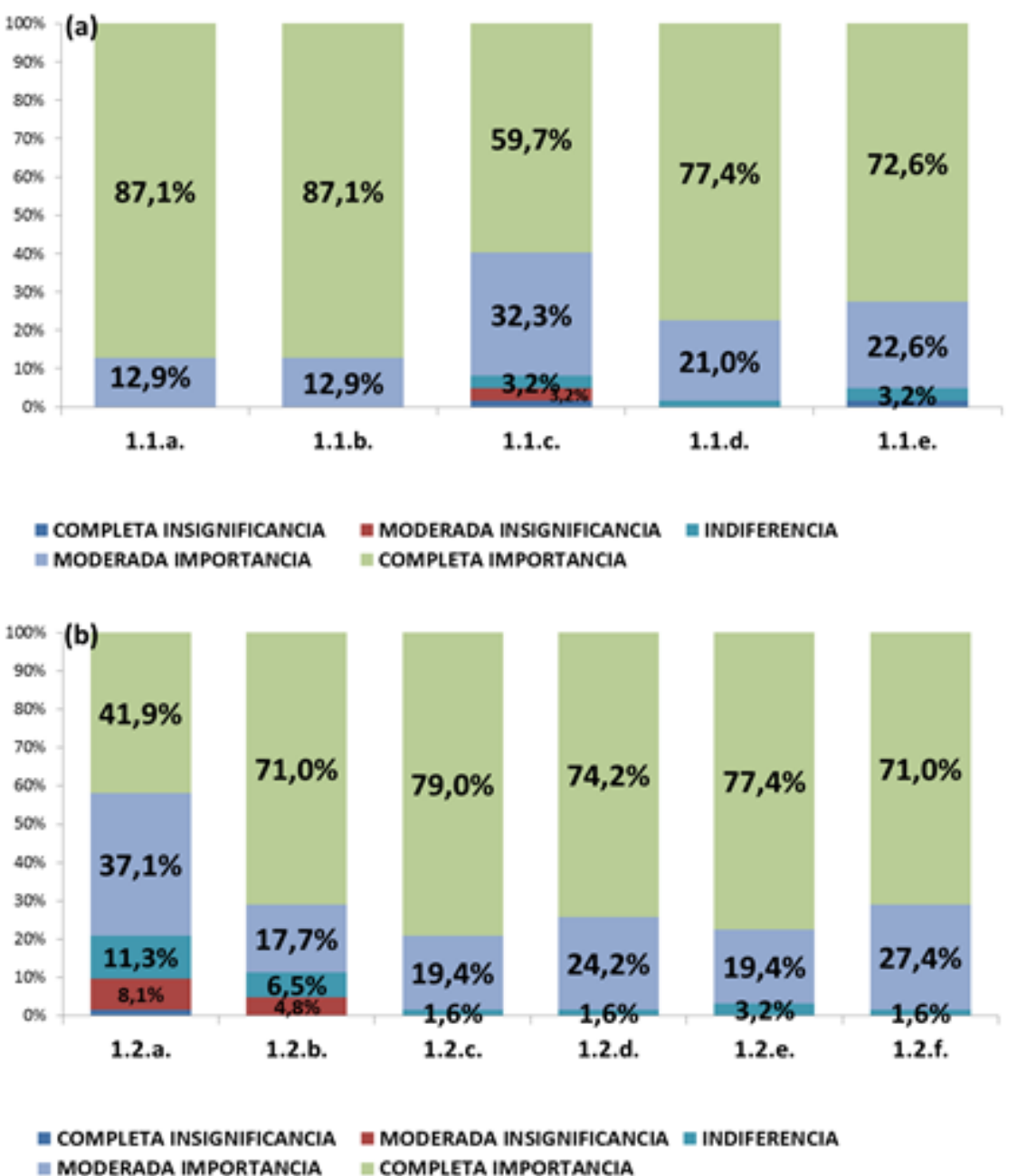

Figura 5.6. Liderazgo y estilo de gobierno. a) Cultura de Excelencia. b) Arquitectura EmpresarialTSI.

La figura 5.7 muestra el nivel de importancia que los líderes de TSI brindan al criterio de Estrategias a través de las dimensiones pertenecientes a los sub-criterios de Dirección de estrategias y Evaluación de estrategias.

En conclusión, sobresale el $94,35 \%$ en promedio el porcentaje de "completa importancia + moderada importancia" en todas las dimensiones del criterio de Estrategias. 

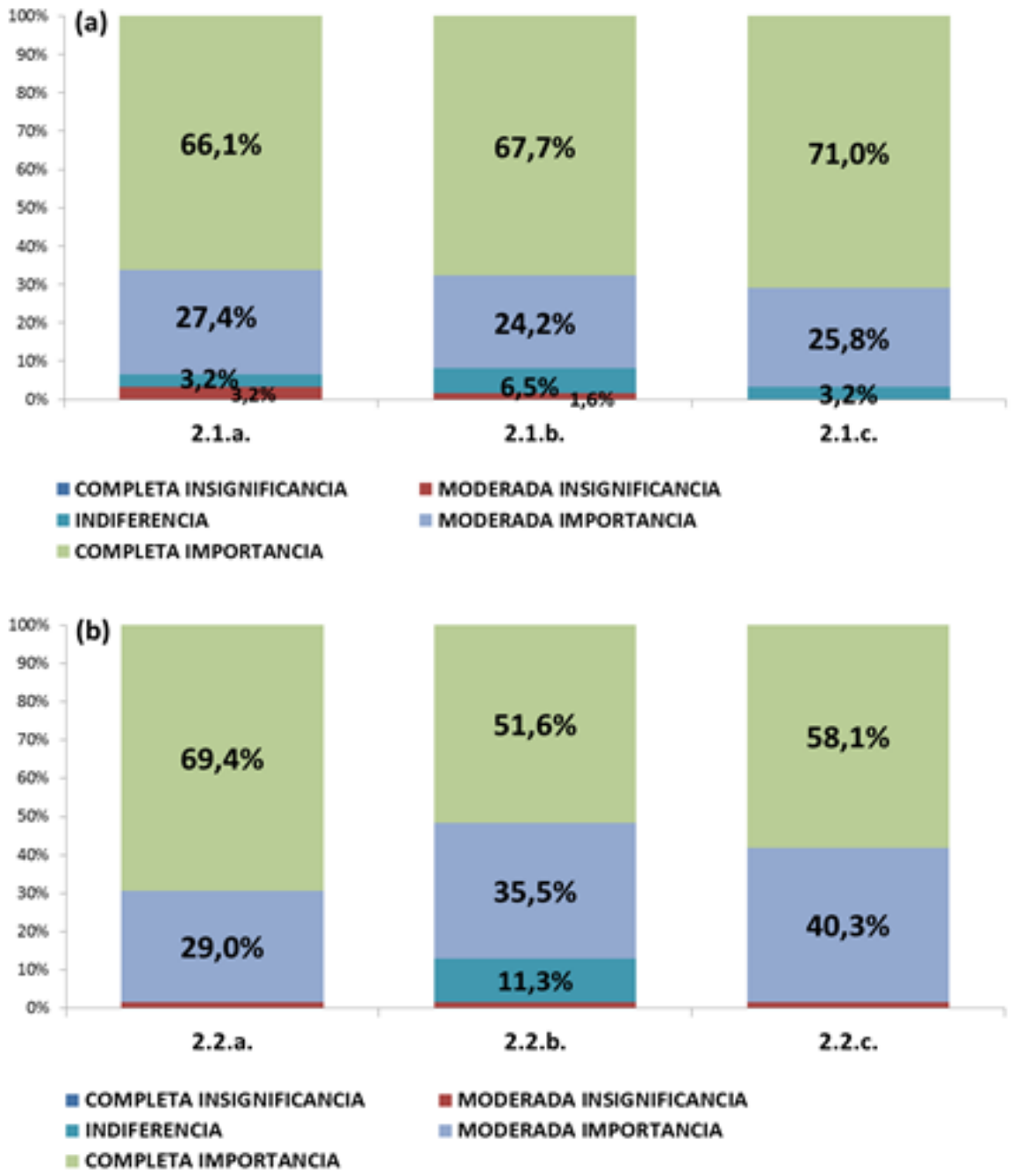

Figura 5.7. Estrategias. a) Dirección de estrategias. b) Evaluación de estrategias.

La figura 5.8 muestra el nivel de importancia que los líderes de TSI brindan al criterio de Personas a través de las dimensiones pertenecientes al sub-criterio de Roles y Responsabilidades. En esta figura, sobresale el $90 \%$ en promedio el porcentaje de "completa importancia + moderada importancia" en las dimensiones del criterio de Personas.

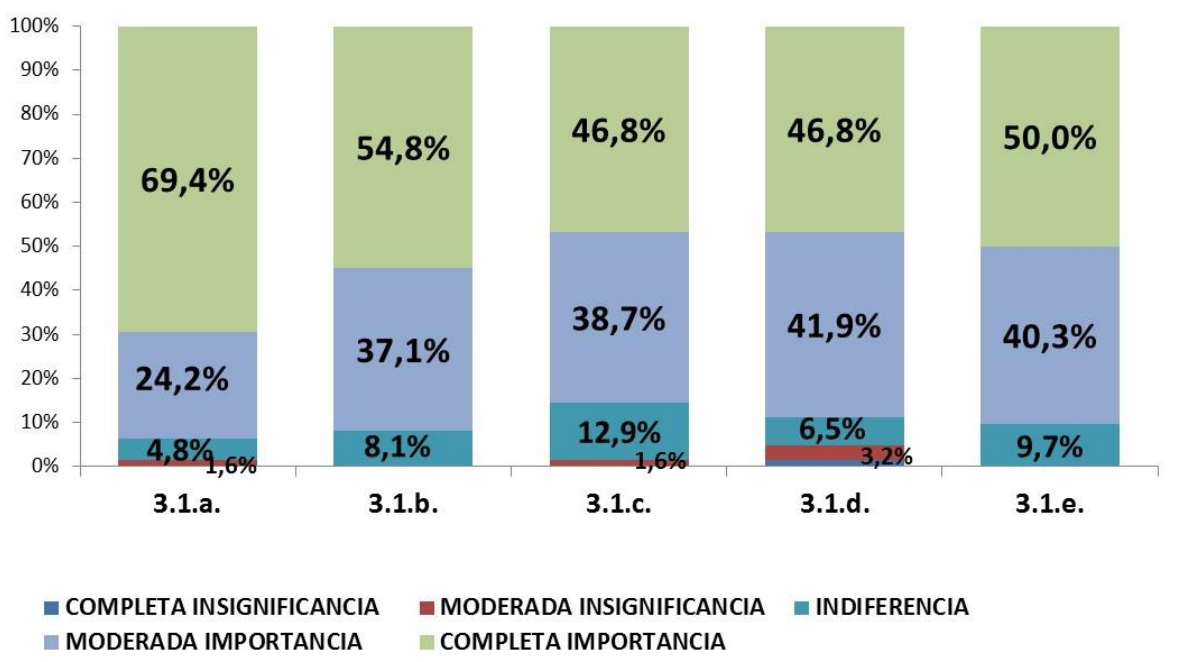

Figura 5.8. Personas: Roles y responsabilidades. 
La figura 5.9 muestra el nivel de importancia que los líderes de TSI brindan al criterio de Recursos a través de las dimensiones pertenecientes al sub-criterio de Recursos financieros y materiales. En esta figura, sobresale el 97,6\% en promedio el porcentaje de "completa importancia + moderada importancia" en las dimensiones del criterio de Recursos.

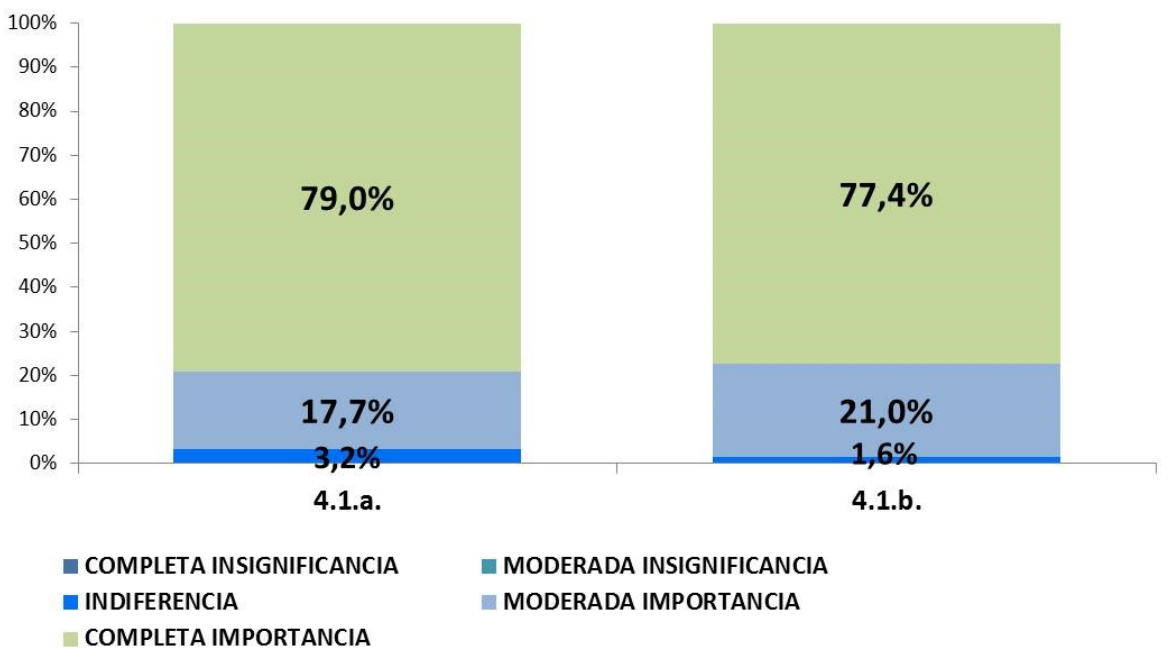

Figura 5.9. Recursos: Financieros y materiales.

La figura 5.10 muestra el nivel de importancia que los líderes de TSI brindan al criterio de Procesos mediante las dimensiones pertenecientes a los sub-criterios de Diseño y mejora de procesos de gobierno de valor y Necesidades de información. En esta figura, sobresale positivamente el $95,16 \%$ en promedio el porcentaje de "completa importancia + moderada importancia" en las dimensiones del criterio de Procesos. Del gráfico sobresale el porcentaje alto de "indiferencia" en la dimensión 5.1.b del sub-criterio diseño y mejora. De la misma manera en la dimensión 5.1.c del sub-criterio necesidad de información. 

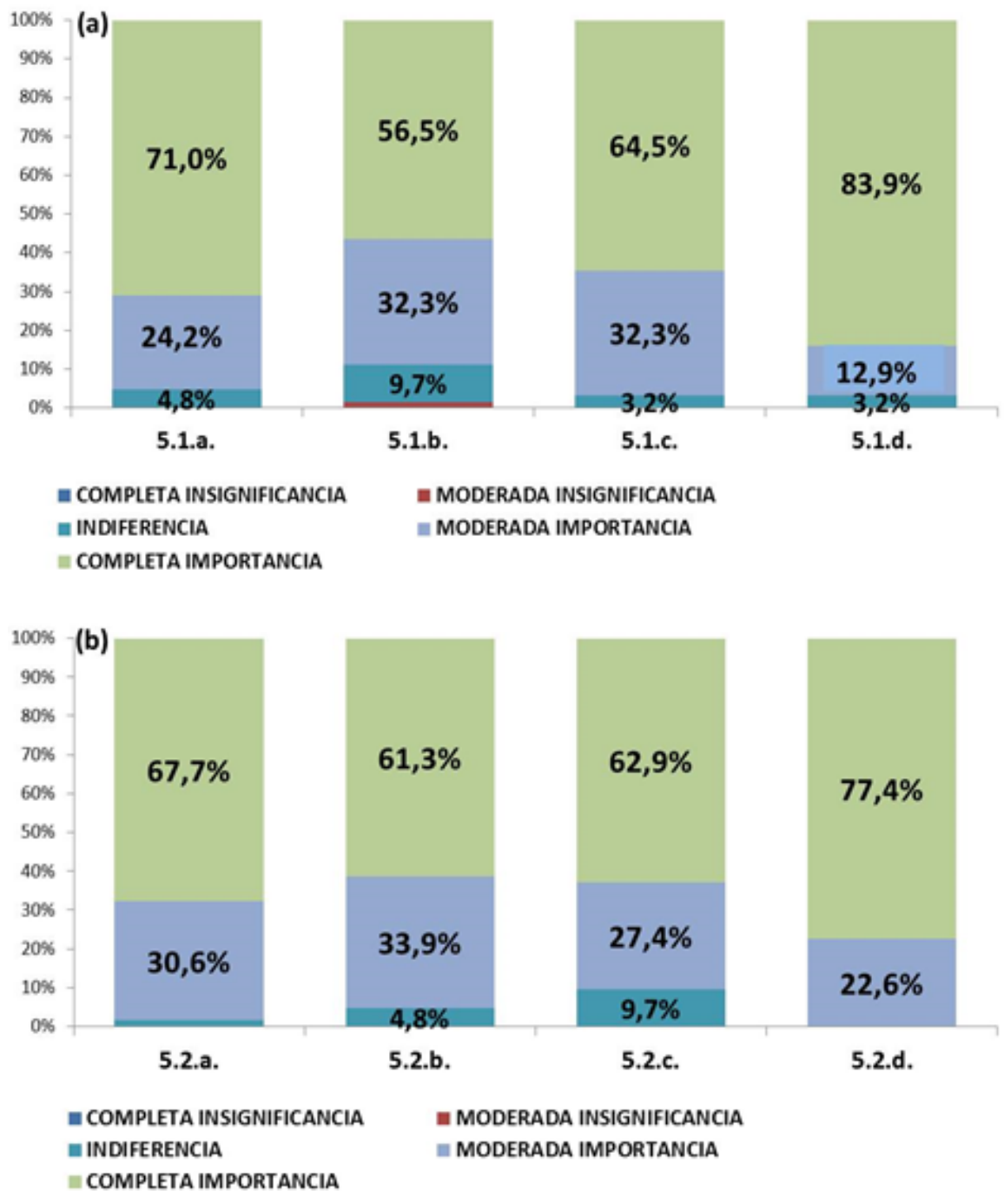

Figura 5.10. Procesos: a) Diseño y mejora. b) Necesidad de información.

La figura 5.11 muestra el nivel de importancia que los líderes de TSI brindan al criterio de Proyectos a través de las dimensiones pertenecientes al sub-criterio Financiero y no financiero. En esta figura, sobresale el 91,94\% en promedio el porcentaje de "completa importancia + moderada importancia" en las dimensiones del criterio de Proyectos. 


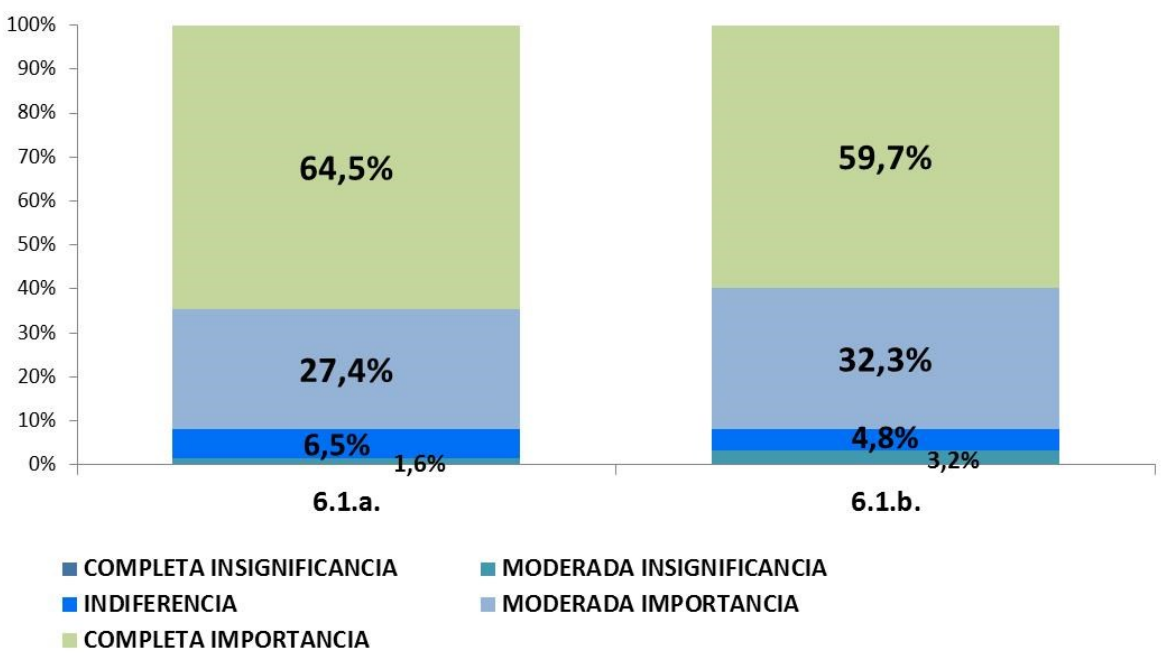

Figura 5.11. Proyectos: Financieros y no financieros.

Como se ha podido apreciar, la mayoría de líderes de TSI conceden una gran importancia a los criterios de calidad. Esto se refleja en la alta puntuación alcanzada en cada una de las preguntas.

La tabla 5.3 muestra la matriz de estadística descriptiva por pregunta. Como se observa, las variables 1 a 4 no constan por ser datos demográficos. Luego se muestran los valores de dispersión útiles en esta investigación, con el propósito de analizar la confiabilidad de las medias. Los resultados arrojan una media superior a 4 y una desviación estándar con menor y mayor concentración de opinión hacia la valoración. Por ejemplo, la variable 10 muestra la media más baja y mayor dispersión de opinión hacia la media; en contraste, las variables 5 y 6 muestran las más altas de las medias y menor dispersión de opinión hacia la media. La revisión de los valores asignados a cada variable revela que el valor de 5 aparece con mayor frecuencia que cualquier otra percepción, por lo cual, la moda es 5 .

Tabla 5.3. Estadística descriptiva por pregunta

\begin{tabular}{|c|c|c|c|c|c|c|c|c|c|c|}
\hline Variable & $\begin{array}{c}\text { Ítems } \\
\text { Válidos }\end{array}$ & Media & $\begin{array}{c}\text { Error estándar } \\
\text { de la media }\end{array}$ & Mediana & Moda & $\begin{array}{c}\text { Desviación } \\
\text { estándar }\end{array}$ & Varianza & Rango & Mínimo & Máximo \\
\hline 5 & 62 & 4,87 & 0,043 & 5,00 & 5 & 0,338 & 0,114 & 1 & 4 & 5 \\
\hline 6 & 62 & 4,87 & 0,043 & 5,00 & 5 & 0,338 & 0,114 & 1 & 4 & 5 \\
\hline 7 & 62 & 4,45 & 0,107 & 5,00 & 5 & 0,843 & 0,711 & 4 & 1 & 5 \\
\hline 8 & 62 & 4,76 & 0,059 & 5,00 & 5 & 0,468 & 0,219 & 2 & 3 & 5 \\
\hline 9 & 62 & 4,65 & 0,089 & 5,00 & 5 & 0,704 & 0,495 & 4 & 1 & 5 \\
\hline 10 & 62 & 4,10 & 0,127 & 4,00 & 5 & 1,003 & 1,007 & 4 & 1 & 5 \\
\hline 11 & 62 & 4,55 & 0,105 & 5,00 & 5 & 0,823 & 0,678 & 3 & 2 & 5 \\
\hline 12 & 62 & 4,77 & 0,058 & 5,00 & 5 & 0,459 & 0,210 & 2 & 3 & 5 \\
\hline 13 & 62 & 4,73 & 0,062 & 5,00 & 5 & 0,485 & 0,235 & 2 & 3 & 5 \\
\hline 14 & 62 & 4,74 & 0,065 & 5,00 & 5 & 0,510 & 0,260 & 2 & 3 & 5 \\
\hline 15 & 62 & 4,69 & 0,063 & 5,00 & 5 & 0,499 & 0,249 & 2 & 3 & 5 \\
\hline 16 & 62 & 4,56 & 0,091 & 5,00 & 5 & 0,716 & 0,512 & 3 & 2 & 5 \\
\hline 17 & 62 & 4,58 & 0,088 & 5,00 & 5 & 0,691 & 0,477 & 3 & 2 & 5 \\
\hline 18 & 62 & 4,68 & 0,068 & 5,00 & 5 & 0,536 & 0,288 & 2 & 3 & 5 \\
\hline 19 & 62 & 4,66 & 0,073 & 5,00 & 5 & 0,571 & 0,326 & 3 & 2 & 5 \\
\hline
\end{tabular}




\begin{tabular}{|l|l|l|l|l|l|l|l|l|l|l|}
20 & 62 & 4,37 & 0,095 & 5,00 & 5 & 0,752 & 0,565 & 3 & 2 & 5 \\
\hline 21 & 62 & 4,55 & 0,075 & 5,00 & 5 & 0,592 & 0,350 & 3 & 2 & 5 \\
\hline 22 & 62 & 4,61 & 0,084 & 5,00 & 5 & 0,662 & 0,438 & 3 & 2 & 5 \\
\hline 23 & 62 & 4,47 & 0,082 & 5,00 & 5 & 0,646 & 0,417 & 2 & 3 & 5 \\
\hline 24 & 62 & 4,31 & 0,096 & 4,00 & 5 & 0,759 & 0,577 & 3 & 2 & 5 \\
\hline 25 & 62 & 4,29 & 0,109 & 4,00 & 5 & 0,857 & 0,734 & 4 & 1 & 5 \\
\hline 26 & 62 & 4,40 & 0,084 & 4,50 & 5 & 0,664 & 0,441 & 2 & 3 & 5 \\
\hline 27 & 62 & 4,76 & 0,064 & 5,00 & 5 & 0,502 & 0,252 & 2 & 3 & 5 \\
\hline 28 & 62 & 4,76 & 0,059 & 5,00 & 5 & 0,468 & 0,219 & 2 & 3 & 5 \\
\hline 29 & 62 & 4,66 & 0,073 & 5,00 & 5 & 0,571 & 0,326 & 2 & 3 & 5 \\
\hline 30 & 62 & 4,44 & 0,094 & 5,00 & 5 & 0,738 & 0,545 & 3 & 2 & 5 \\
\hline 31 & 62 & 4,61 & 0,070 & 5,00 & 5 & 0,554 & 0,307 & 2 & 3 & 5 \\
\hline 32 & 62 & 4,81 & 0,060 & 5,00 & 5 & 0,474 & 0,224 & 2 & 3 & 5 \\
\hline 33 & 62 & 4,66 & 0,065 & 5,00 & 5 & 0,510 & 0,260 & 2 & 3 & 5 \\
\hline 34 & 62 & 4,56 & 0,075 & 5,00 & 5 & 0,590 & 0,348 & 2 & 3 & 5 \\
\hline 35 & 62 & 4,53 & 0,085 & 5,00 & 5 & 0,671 & 0,450 & 2 & 3 & 5 \\
\hline 36 & 62 & 4,77 & 0,054 & 5,00 & 5 & 0,422 & 0,178 & 1 & 4 & 5 \\
\hline 37 & 62 & 4,55 & 0,088 & 5,00 & 5 & 0,694 & 0,481 & 3 & 2 & 5 \\
\hline 38 & 62 & 4,48 & 0,094 & 5,00 & 5 & 0,741 & 0,549 & 3 & 2 & 5 \\
\hline
\end{tabular}

A partir de la tabla anterior y al confirmar la importancia que los líderes de TSI brindan a cada variable, se ha decidido continuar con el análisis en función de sub-criterios, por lo cual, cada subcriterio se valora en función de la media aritmética aplicada al grupo de preguntas que compone el sub-criterio en valoración. Si bien este procedimiento podría afectar la información sobre las variables individuales, se gana en cambio una mayor fiabilidad con las "nuevas" variables y se ven menos afectadas por peculiaridades de la redacción individual (MARSH, 1984) (Cattell, 1995).

La tabla 5.4 muestra la matriz de resultados de dispersión de sub-criterios. Como se observa, el criterio "Financieros y materiales" tiene la media más alta. En contraste, el sub-criterio "Roles y responsabilidades" arroja un valor de media más baja. En todas las variables se muestra la mediana superior a la media. Desde un enfoque práctico, el promedio de importancia que brindan los líderes de TSI a los criterios de calidad tiene una tendencia hacia la "Completa importancia". Así lo demuestra la alta coincidencia en los resultados de opinión.

Tabla 5.4. Estadística descriptiva por sub-criterio

\begin{tabular}{|c|c|c|c|c|c|c|c|c|c|c|}
\hline Variable & $\begin{array}{l}\text { Ítem } \\
\text { válido }\end{array}$ & Media & $\begin{array}{c}\text { Error } \\
\text { estándar } \\
\text { de la } \\
\text { media }\end{array}$ & Mediana & Moda & $\begin{array}{c}\text { Desviación } \\
\text { estándar }\end{array}$ & Varianza & Rango & Mínimo & Máximo \\
\hline CULTURA & 62 & 4,719 & 0,042 & 4,800 & 5 & 0,329 & 0,108 & 1,800 & 3,200 & 5 \\
\hline ARQUITECTURA & 62 & 4,597 & 0,047 & 4,667 & 5 & 0,368 & 0,135 & 1,333 & 3,667 & 5 \\
\hline $\begin{array}{l}\text { DIRECCION } \\
\text { ESTRATEGIAS }\end{array}$ & 62 & 4,608 & 0,063 & 4,667 & 5 & 0,496 & 0,246 & 2,000 & 3,000 & 5 \\
\hline $\begin{array}{l}\text { EVALUACION } \\
\text { ESTRATEGIAS }\end{array}$ & 62 & 4,527 & 0,063 & 4,667 & 5 & 0,492 & 0,242 & 2,333 & 2,667 & 5 \\
\hline $\begin{array}{l}\text { ROLES Y } \\
\text { RESPONSABILIDADES }\end{array}$ & 62 & 4,416 & 0,065 & 4,500 & 5 & 0,514 & 0,264 & 2,000 & 3,000 & 5 \\
\hline
\end{tabular}




\begin{tabular}{|l|c|c|c|c|c|c|c|c|c|c|}
$\begin{array}{l}\text { FINANCIEROS Y } \\
\text { MATERIALES }\end{array}$ & 62 & 4,758 & 0,047 & 5,000 & 5 & 0,370 & 0,137 & 1,000 & 4,000 & 5 \\
\hline DISEÑO Y MEJORA & 62 & 4,629 & 0,054 & 4,750 & 5 & 0,422 & 0,178 & 1,500 & 3,500 & 5 \\
\hline $\begin{array}{l}\text { NECESIDAD } \\
\text { INFORMACION }\end{array}$ & 62 & 4,633 & 0,046 & 4,750 & 5 & 0,364 & 0,133 & 1,250 & 3,750 & 5 \\
\hline $\begin{array}{l}\text { FINANCIEROS Y NO } \\
\text { FINANCIEROS }\end{array}$ & 62 & 4,516 & 0,081 & 5,000 & 5 & 0,640 & 0,410 & 2,500 & 2,500 & 5 \\
\hline
\end{tabular}

En la tabla anterior se describe numéricamente la tendencia central del conjunto de observaciones mediante la media, mediana y moda, como medidas características. De igual manera, existen otras medidas que muestran la magnitud de la dispersión en el conjunto de datos en estudio, medida por la amplitud de variación y la desviación estándar conocidas como asimetría y curtosis. Desde el punto de vista conceptual, estas dos medidas son utilizadas para observar el nivel de parecido de una distribución de frecuencias a la distribución teórica llamada de curva o distribución normal de la campana, cuya media es 0 y su desviación estándar es 1 . En otras palabras, una curva de distribución de frecuencias es normal cuando, curtosis $=0$ y asimetría $=0$.

La tabla 5.5 muestra la matriz de cálculo de asimetría y curtosis. Como se puede observar, TODOS los coeficientes de asimetría son negativos, esto significa que la curva tendrá una distribución no normal inclinada hacia la derecha. También se puede observar que los coeficientes de curtosis presentan valores positivos y negativos. En el caso positivo, significa que la curva de distribución de frecuencias es más elevada, en cambio, los valores negativos indican que la curva es más plana. En términos prácticos estos valores demuestran que la distribución de frecuencias no es normal y, por lo tanto, en las pruebas no paramétricas deben utilizarse métodos para poblaciones que siguen una distribución no normal de frecuencias.

Tabla 5.5. Cálculo de asimetría y curtosis

\begin{tabular}{|l|c|r|r|r|r|}
\hline \multirow{2}{*}{ Variable } & \multirow{2}{*}{ Sujetos } & \multicolumn{2}{c|}{ Asimetría } & \multicolumn{2}{c|}{ Curtosis } \\
\cline { 3 - 6 } & & Coeficiente & Error estándar & Coeficiente & Error estándar \\
\hline CULTURA & 62 & $-1,903$ & 0,304 & 6,139 & 0,599 \\
\hline ARQUITECTURA & 62 & $-0,750$ & 0,304 & $-0,162$ & 0,599 \\
\hline DIRECCION ESTRATEGIAS & 62 & $-1,444$ & 0,304 & 1,970 & 0,599 \\
\hline EVALUACION ESTRATEGIAS & 62 & $-1,440$ & 0,304 & 3,040 & 0,599 \\
\hline ROLES Y RESPONSABILIDADES & 62 & $-0,872$ & 0,304 & 0,294 & 0,599 \\
\hline FINANCIEROS Y MATERIALES & 62 & $-1,182$ & 0,304 & $-0,113$ & 0,599 \\
\hline DISEÑO Y MEJORA & 62 & $-1,035$ & 0,304 & 0,088 & 0,599 \\
\hline NECESIDAD INFORMACION & 62 & $-0,576$ & 0,304 & $-0,688$ & 0,599 \\
\hline FINANCIEROS Y NO FINANCIEROS & 62 & $-1,419$ & 0,304 & 1,713 & 0,599 \\
\hline
\end{tabular}

De todos modos, todo lo interpretado en la tabla anterior puede ser validado a través de una prueba estadística denominada de Kolmogorov-Smirnov para los 62 sujetos encuestados. Con esta prueba se va demostrar que las variables en estudio tienen distribución no normal de frecuencias.

En este caso se trabaja con nivel de significancia crítico de 0,05. Esto significa que valores de significancia calculados menores al valor crítico permiten aceptar la prueba de investigación. Los detalles de la prueba se presentan en la tabla 5.6. Como se puede observar, TODOS los valores calculados de significancia (bilateral) se encuentran por debajo del nivel de significancia crítico. Desde una óptica práctica, las variables que conforman el modelo de calidad GoTSI se deben 
estudiar aplicando métodos no paramétricos que siguen una población con distribución no normal de frecuencias.

Tabla 5.6. Prueba de normalidad de Kolmogorov-Smirnov

\begin{tabular}{|l|r|r|}
\hline \multicolumn{1}{|c|}{ Variable } & Estadístico de prueba & Significancia (bilateral) \\
\hline CULTURA & 0,21 & 0,000 \\
\hline ARQUITECTURA & 0,16 & 0,000 \\
\hline DIRECCION ESTRATEGIAS & 0,25 & 0,000 \\
\hline EVALUACION ESTRATEGIAS & 0,18 & 0,000 \\
\hline ROLES Y RESPONSABILIDADES & 0,15 & 0,002 \\
\hline FINANCIEROS Y MATERIALES & 0,40 & 0,000 \\
\hline DISEÑO Y MEJORA & 0,21 & 0,000 \\
\hline NECESIDAD INFORMACION & 0,23 & 0,000 \\
\hline FINANCIEROS Y NO FINANCIEROS & 0,29 & 0,000 \\
\hline
\end{tabular}

En términos generales, los resultados de las preguntas reflejan la importancia que los líderes de TSI brindan a los sub-criterios, criterios y, por ende, al modelo de evaluación de la calidad de GoTSI basada en valor. Estos datos son consistentes con el objetivo y la hipótesis de investigación planteada en esta tesis doctoral.

\subsubsection{ANÁLISIS DE CORRELACIÓN}

En esta sección se realiza el análisis de correlación de sub-criterios aplicando el método de Charles Spearman (Anderson, et al., 2008), con la finalidad de determinar la relación que existe entre cada variable (sub-criterio) soportado en la opinión dada por los líderes de TSI. Se utiliza este método porque es el más apropiado para datos ordinales como los que se están utilizando en la encuesta.

La fórmula 5.2 se utiliza para determinar el coeficiente de correlación de rangos de Spearman.

$r_{s}=1-\frac{6 \sum d^{2}}{n\left(n^{2}-1\right)}$

Fórmula 5.2. Cálculo del coeficiente de correlación de rangos de Spearman

Dónde:

$$
\begin{array}{ll}
r_{s}= & \text { es el coeficiente de correlación } \\
d= & \text { es la diferencia entre los rangos de cada par de evaluaciones } \\
n= & \text { es el número de pares de evaluadores }
\end{array}
$$

La tabla 5.7 resume la intensidad y la dirección del coeficiente de correlación (Lind, et al., 2004). Como se puede observar, la correlación puede tomar cualquier valor de $-1,00$ a $+1,00$, inclusive. Esto significa que son correlaciones perfectas, con la particularidad de que $-1,00$ es en sentido lineal negativo $y+1,00$ es en sentido lineal positivo.

Tabla 5.7. Intensidad y dirección del coeficiente de correlación

\begin{tabular}{|l|l|}
\hline \multicolumn{1}{|c|}{ Valoración } & \multicolumn{1}{c|}{ Descripción } \\
\hline$-1,00$ & Correlación negativa perfecta \\
\hline De $-0,99$ a $-0,67$ & Correlación negativa intensa \\
\hline De $-0,66$ a $-0,34$ & Correlación negativa moderada \\
\hline De $-0,33$ a $-0,01$ & Correlación negativa débil \\
\hline 0 & Sin correlación \\
\hline
\end{tabular}




\begin{tabular}{|l|l|}
\hline De 0,01 a 0,33 & Correlación positiva débil \\
\hline De 0,34 a 0,66 & Correlación positiva moderada \\
\hline De 0,67 a 0,99 & Correlación positiva intensa \\
\hline 1,00 & Correlación positiva perfecta \\
\hline
\end{tabular}

La tabla 5.8 muestra la matriz de correlación bivariada utilizada para analizar las variables (subcriterios) relacionadas. Como se puede observar, TODOS los coeficientes de correlación son positivos y ninguno con valor 0 . Esto significa que existe relación entre los 9 sub-criterios a nivel de grupos de rangos. Ahora, se presenta el siguiente cuestionamiento, ¿Es probable que la correlación que se observa entre los sub-criterios a nivel de grupos sea una cuestión de coincidencia y que la correlación en la población de líderes de TSI sea en realidad cero?. Para contestar esta pregunta se realiza una prueba de significancia de $r_{s}$ de una cola, en donde se trata de comprobar que, efectivamente, la relación entre las variables (sub-criterios) es positiva.

Para una muestra $n$ de 62 sujetos, la significancia de $r_{s}$ se determina calculando $t$. Tal como se muestra en la fórmula 5.3.

$t=r_{s} \sqrt{\frac{n-2}{1-r_{s}^{2}}}$

\section{Fórmula 5.3. Cálculo del factor $t$ para correlación de rangos}

Como se observa en la misma tabla 5.8, el valor calculado o factor $t$ es mayor que el $t$ crítico ( $t$ de Student crítico de 2,39 para un nivel de significancia de 0,01 y 1,671 para un nivel de significancia de 0,05 ) en todas las pruebas (36 valores en color MARRÓN). Por lo tanto, se acepta la tesis de la investigación en el sentido que existe correlación positiva entre los 9 grupos de rangos otorgados por los líderes de TSI a cada variable asignada durante la encuesta. En términos de individualidad de cada variable, el haber encontrado correlaciones significativas, significa que las posibles hipótesis de relacionamiento entre cada una de estas, se encontrarían plenamente apoyadas.

También se puede observar que, existen relaciones significativas a nivel de $p<0,01$ ( 2 colas) o confiabilidad del $99 \%$ (35 valores en color VERDE) y relaciones significativas a nivel de $p<0,05$ ( 2 colas) o confiabilidad del 95\% (1 valor en color AZUL), esto significa que si la propuesta está bien elaborada (control de sesgos) existe una probabilidad del $99 \%$ o del $95 \%$ de que el intervalo de confianza contenga el verdadero valor que afiance la propuesta de calidad. 
Tabla 5.8. Correlación de variables

\begin{tabular}{|c|c|c|c|c|c|c|c|c|c|c|}
\hline Variables & & CULTURA & ARQUITECTURA & $\begin{array}{c}\text { DIRECCION } \\
\text { ESTRATEGIAS }\end{array}$ & $\begin{array}{l}\text { EVALUACION } \\
\text { ESTRATEGIAS }\end{array}$ & \begin{tabular}{|c|} 
ROLES Y \\
RESPONSABILIDADES \\
\end{tabular} & $\begin{array}{c}\text { FINANCIEROS } \\
y \\
\text { MATERIALES } \\
\end{array}$ & $\begin{array}{l}\text { DISEÑO Y } \\
\text { MEJORA }\end{array}$ & $\begin{array}{l}\text { NECESIDAD } \\
\text { INFORMACION }\end{array}$ & \begin{tabular}{|c|} 
FINANCIEROS \\
Y NO \\
FINANCIEROS \\
\end{tabular} \\
\hline \multirow{3}{*}{ CULTURA } & Coeficiente & \multirow[t]{27}{*}{1,000} & 0,569 & 0,626 & 0,473 & 0,497 & 0,401 & 0,401 & 0,420 & 0,446 \\
\hline & \begin{tabular}{|l} 
Significancia \\
\end{tabular} & & 0,000 & 0,000 & 0,000 & 0,000 & 0,001 & 0,001 & 0,001 & 0,000 \\
\hline & factor $t$ & & 5,360 & 6,218 & 4,158 & 4,436 & 3,391 & 3,391 & 3,585 & 3,860 \\
\hline \multirow{3}{*}{ ARQUITECTURA } & Coeficiente & & 1,000 & 0,547 & 0,536 & 0,500 & 0,499 & 0,580 & 0,551 & 0,488 \\
\hline & Significancia & & & 0,000 & 0,000 & 0,000 & 0,000 & 0,000 & 0,000 & 0,000 \\
\hline & factor $t$ & & & 5,061 & 4,918 & 4,472 & 4,460 & 5,515 & 5,114 & 4,331 \\
\hline \multirow{3}{*}{$\begin{array}{l}\text { DIRECCION } \\
\text { ESTRATEGIAS }\end{array}$} & Coeficiente & & & 1,000 & 0,571 & 0,469 & 0,552 & 0,445 & 0,681 & 0,646 \\
\hline & Significancia & & & & 0,000 & 0,000 & 0,000 & 0,000 & 0,000 & 0,000 \\
\hline & factor $t$ & & & & 5,388 & 4,113 & 5,128 & 3,849 & 7,203 & 6,555 \\
\hline \multirow{3}{*}{$\begin{array}{l}\text { EVALUACION } \\
\text { ESTRATEGIAS }\end{array}$} & Coeficiente & & & & 1,000 & 0,405 & 0,324 & 0,457 & 0,654 & 0,506 \\
\hline & Significancia & & & & & 0,001 & 0,010 & 0,000 & 0,000 & 0,000 \\
\hline & factor $t$ & & & & & 3,431 & 2,653 & 3,980 & 6,696 & 4,544 \\
\hline \multirow{3}{*}{\begin{tabular}{|l|} 
ROLES Y \\
RESPONSABILIDAD \\
ES
\end{tabular}} & Coeficiente & & & & & 1,000 & 0,493 & 0,539 & 0,495 & 0,574 \\
\hline & Significancia & & & & & & 0,000 & 0,000 & 0,000 & 0,000 \\
\hline & factor $t$ & & & & & & 4,389 & 4,957 & 4,413 & 5,430 \\
\hline \multirow{3}{*}{$\begin{array}{l}\text { FINANCIEROS Y } \\
\text { MATERIALES }\end{array}$} & Coeficiente & & & & & & 1,000 & 0,373 & 0,491 & 0,599 \\
\hline & Significancia & & & & & & & 0,003 & 0,000 & 0,000 \\
\hline & factor $t$ & & & & & & & 3,114 & 4,366 & 5,794 \\
\hline \multirow{3}{*}{ DISEÑO Y MEJORA } & Coeficiente & & & & & & & 1,000 & 0,550 & 0,441 \\
\hline & Significancia & & & & & & & & 0,000 & 0,000 \\
\hline & factor $t$ & & & & & & & & 5,101 & 3,806 \\
\hline \multirow{3}{*}{$\begin{array}{l}\text { NECESIDAD } \\
\text { INFORMACION }\end{array}$} & Coeficiente & & & & & & & & 1,000 & 0,660 \\
\hline & Significancia & & & & & & & & & 0,000 \\
\hline & factor $t$ & & & & & & & & & 6,805 \\
\hline \multirow{3}{*}{$\begin{array}{l}\text { FINANCIEROS Y } \\
\text { NO FINANCIEROS }\end{array}$} & Coeficiente & & & & & & & & & \multirow[t]{3}{*}{1,000} \\
\hline & Significancia & & & & & & & & & \\
\hline & factor $t$ & & & & & & & & & \\
\hline
\end{tabular}

Desde una visión práctica, estos resultados dan a entender que, el sub-criterio que recibe una alta evaluación por el primer evaluador, también tiende a recibir una alta evaluación por parte de un segundo evaluador, independientemente de su criterio demográfico.

\subsubsection{ANÁLISIS DE VARIANZA}

En esta sección se analiza la varianza de los sub-criterios en un sentido de intervalos. Para esto se observan los supuestos que los datos son de nivel ordinal o, si la población no fuera normal, como son en nuestro caso de estudio. Por lo tanto, se usa la prueba no paramétrica de Kruskal Wallis (Lind, et al., 2004) (Anderson, et al., 2008) (Newbold, et al., 2013) en la que sólo se necesitan datos de nivel ordinal, al formular la regla de decisión con un nivel de significancia de 0,05 para soportar el $p$-valor calculado. Siendo así, se usarán las variables demográficas de la encuesta por ser independientes, con el propósito de responder a la siguiente interrogante de investigación:

- ¿Las valoraciones de los líderes de TSI de acuerdo al sector, género, escolaridad e intervalo de edad son diferentes?

En la práctica, la pregunta de investigación anterior se traduce en el análisis de las valoraciones de los 9 sub-criterios en función de las 4 variables independientes: Sector principal, género, escolaridad e intervalo.

En el caso de la variable SECTOR PRINCIPAL se toma en cuenta la opinión de 7 grupos contestatarios (EDUCACIÓN, COMERCIO, SERVICIOS, TELECOMUNICACIONES, SALUD, FINANCIERO y OTRO). Las respuestas de un grupo de ningún modo deben influir en las respuestas de los otros. La distribución del estadístico muestral $H$ que se utiliza en esta prueba, es muy parecido a la ji- 
cuadrado con $\mathrm{K}$-1 grados de libertad (gl). Por lo tanto, se usará la ji-cuadrada para formular la regla de decisión y la significancia asintótica que representa el $p$-valor calculado por la aplicación estadística. El valor crítico para $6 \mathrm{gl}$ y el nivel de significancia 0,05 será de 12,592 . Esto significa que NO existirá diferencia sí ji-cuadrado calculado es menor o igual a 12,592. Caso contrario, existirá diferencia sí, el ji-cuadrado calculado es mayor que 12,592. Los detalles de la prueba se presentan en la tabla 5.9. Como se puede observar, todos los $p$-valor calculados se encuentran por encima del nivel de significancia. Además, los coeficientes ji-cuadrados se encuentran por debajo del valor crítico. Esto significa que NO hay diferencia entre las valoraciones de los líderes de TSI de acuerdo al sector principal al que pertenecen. Desde una óptica práctica, el modelo de calidad GoTSI se podría aplicar a cualquier gobierno de TSI de manera independiente del sector principal en el que opera.

Tabla 5.9. ANOVA por rangos - SECTOR PRINCIPAL

\begin{tabular}{|l|r|r|c|}
\hline \multicolumn{1}{|c|}{ Variable } & ji-cuadrado & gl & Significancia \\
\hline CULTURA & 5,633 & 6 & 0,466 \\
\hline ARQUITECTURA & 7,559 & 6 & 0,272 \\
\hline DIRECCION ESTRATEGIAS & 5,835 & 6 & 0,442 \\
\hline EVALUACION ESTRATEGIAS & 2,295 & 6 & 0,891 \\
\hline ROLES Y RESPONSABILIDADES & 3,277 & 6 & 0,773 \\
\hline FINANCIEROS Y MATERIALES & 3,969 & 6 & 0,681 \\
\hline DISEÑO Y MEJORA & 3,363 & 6 & 0,762 \\
\hline NECESIDAD INFORMACION & 4,127 & 6 & 0,660 \\
\hline FINANCIEROS Y NO FINANCIEROS & 7,504 & 6 & 0,277 \\
\hline
\end{tabular}

En el caso de la variable GÉNERO se toma en cuenta la opinión de 2 grupos (MASCULINO y FEMENINO). Las respuestas de un grupo de ningún modo deben influir en las respuestas del otro. La distribución del estadístico muestral $H$ que se utiliza en esta prueba, es muy parecido a la jicuadrado con $\mathrm{K}-1$ grados de libertad (gl). Por lo tanto, se usará la ji-cuadrado para formular la regla de decisión y la significancia asintótica que representa el $p$-valor calculado por la aplicación estadística. El valor crítico para $1 \mathrm{gl}$ y el nivel de significancia 0,05 será de 3,841. Los detalles de la prueba se observa en la tabla 5.10. Como se puede observar, todos los p-valor calculados se encuentran por encima del nivel de significancia. Además, los coeficientes ji-cuadrados se encuentran por debajo del valor crítico. Esto significa que NO hay diferencia entre las valoraciones que dan los líderes de TSI a cada pregunta de acuerdo al género al que pertenecen. Desde una visión práctica, el modelo de calidad GoTSI se podría aplicar a cualquier gobierno de TSI de manera independiente al género que lo conforman.

Tabla 5.10. ANOVA por rangos - GÉNERO

\begin{tabular}{|l|c|c|c|}
\hline \multicolumn{1}{|c|}{ Variable } & ji-cuadrado & gl & Significancia \\
\hline CULTURA & 1,311 & 1 & 0,252 \\
\hline ARQUITECTURA & 0,001 & 1 & 0,975 \\
\hline DIRECCION ESTRATEGIAS & 0,000 & 1 & 1,000 \\
\hline EVALUACION ESTRATEGIAS & 1,873 & 1 & 0,171 \\
\hline ROLES Y RESPONSABILIDADES & 0,069 & 1 & 0,793 \\
\hline FINANCIEROS Y MATERIALES & 0,208 & 1 & 0,648 \\
\hline DISEÑO Y MEJORA & 0,178 & 1 & 0,673 \\
\hline NECESIDAD INFORMACION & 0,682 & 1 & 0,409 \\
\hline FINANCIEROS Y NO FINANCIEROS & 1,195 & 1 & 0,274 \\
\hline
\end{tabular}


En el caso de la variable ESCOLARIDAD se toma en cuenta la opinión de 5 grupos contestatarios (LICENCIATURA, INGENIERIA, DIPLOMADO, MAGISTER y DOCTORADO). La distribución del estadístico muestral $H$ que se utiliza en esta prueba, es muy parecido a la ji-cuadrado con $K-1$ grados de libertad (gl). Por lo tanto, se usará la ji-cuadrado para formular la regla de decisión y la significancia asintótica que representa el p-valor calculado por la aplicación estadística. El valor crítico para $4 \mathrm{gl}$ y el nivel de significancia 0,05 será de 9,488. Esto significa que NO existirá diferencia sí ji-cuadrado calculado es menor o igual a 9,488. Caso contrario, existirá diferencia sí el ji-cuadrado calculado es mayor que 9,488. Los detalles de la prueba se observa en la tabla 5.11. Como se puede observar, todos los p-valor calculados se encuentran por encima del nivel de significancia. Además, los coeficientes ji-cuadrados se encuentran por debajo del valor crítico, esto significa que NO hay diferencia entre las valoraciones de los líderes de TSI de acuerdo a la escolaridad más alta que poseen. Desde una óptica práctica, el modelo de calidad GoTSI se podría aplicar a cualquier gobierno de TSI de manera independiente de los 5 tipos de escolaridad de su equipo de gobierno.

Tabla 5.11. ANOVA por rangos - ESCOLARIDAD

\begin{tabular}{|l|c|c|c|}
\hline \multicolumn{1}{|c|}{ Variable } & ji-cuadrado & gl & Significancia \\
\hline CULTURA & 1,468 & 4 & 0,832 \\
\hline ARQUITECTURA & 1,897 & 4 & 0,755 \\
\hline DIRECCION ESTRATEGIAS & 4,317 & 4 & 0,365 \\
\hline EVALUACION ESTRATEGIAS & 2,656 & 4 & 0,617 \\
\hline ROLES Y RESPONSABILIDADES & 1,799 & 4 & 0,773 \\
\hline FINANCIEROS Y MATERIALES & 5,729 & 4 & 0,220 \\
\hline DISEÑO Y MEJORA & 4,863 & 4 & 0,302 \\
\hline NECESIDAD INFORMACION & 3,013 & 4 & 0,556 \\
\hline FINANCIEROS Y NO FINANCIEROS & 1,294 & 4 & 0,862 \\
\hline
\end{tabular}

En el caso de la variable RANGO DE EDAD o intervalo de edad, se toma en cuenta la opinión de 4 grupos contestatarios (De 25 a 35 años, De 36 a 45 años, De 46 a 55 años y Mayor de 55 años). Se usará ji-cuadrado para formular la regla de decisión y la significancia asintótica que representa el $p$-valor calculado por la aplicación estadística. El valor crítico para $3 \mathrm{gl}$ y el nivel de significancia 0,05 será de 7,815. Esto significa que NO existirá diferencia sí ji-cuadrado calculado es menor o igual a 7,815. Caso contrario, existirá diferencia sí ji-cuadrado calculado es mayor que 7,815. Los detalles de la prueba se observan en la tabla 5.12. Como se puede observar, a excepción de los sub-criterios de Cultura y Arquitectura, los $p$-valor calculados de los demás sub-criterios se encuentran por encima del nivel de significancia. Además, a excepción de los sub-criterios Cultura y Arquitectura, los coeficientes ji-cuadrados de los demás sub-criterios se encuentran por debajo del valor crítico, esto significa que NO hay diferencia entre las valoraciones de los líderes de TSI de acuerdo al intervalo de edad. No así para las variables de cultura y arquitectura en donde las valoraciones sí son diferentes de acuerdo al intervalo de edad, aunque apenas $p$-valor calculado cayó en la región de desigualdad. Desde una visión práctica, el modelo de GoTSI se "podría" aplicar a cualquier gobierno de TSI de manera independiente del intervalo de edad del equipo de gobierno. 
Tabla 5.12. ANOVA por rangos - INTERVALO DE EDAD

\begin{tabular}{|l|c|c|c|}
\hline \multicolumn{1}{|c|}{ Variable } & ji-cuadrado & gI & Significancia \\
\hline CULTURA & 8,502 & 3 & 0,037 \\
\hline ARQUITECTURA & 8,083 & 3 & 0,044 \\
\hline DIRECCION ESTRATEGIAS & 7,084 & 3 & 0,069 \\
\hline EVALUACION ESTRATEGIAS & 3,410 & 3 & 0,333 \\
\hline ROLES Y RESPONSABILIDADES & 2,874 & 3 & 0,411 \\
\hline FINANCIEROS Y MATERIALES & 3,905 & 3 & 0,272 \\
\hline DISEÑO Y MEJORA & 2,092 & 3 & 0,554 \\
\hline NECESIDAD INFORMACION & 2,988 & 3 & 0,394 \\
\hline FINANCIEROS Y NO FINANCIEROS & 1,673 & 3 & 0,643 \\
\hline
\end{tabular}

\subsubsection{ANÁLISIS FACTORIAL}

El procedimiento de análisis de correlación expuesto en la sección 5.6 .3 se empleaba para determinar la relación existente entre grupos de datos ordenados por rangos o intervalos. Con el análisis factorial se pretende simplificar la información que nos brinda esa matriz de correlaciones para hacerla más fácilmente interpretable (Morales Vallejo, 2013). Lo que se pretende es encontrar una respuesta a la interrogante: ¿Por qué unos sub-criterios representados por variables se relacionan más entre sí y menos con otras?. La respuesta hipotética es porque existen otras variables, otras dimensiones o factores que explican por qué unos ítems se relacionan más con unos que con otros. En definitiva se busca analizar la estructura subyacente a una serie de sub-criterios y en lo posible interpretar la realidad del modelo de calidad propuesto a través de una ecuación que defina su comportamiento.

Para que el análisis factorial sea aceptable, el método de Kaiser-Meyer-Olkin (KMO) y Bartlett deben proporcionar los resultados determinantes (Anderson, et al., 2008). Por lo tanto, se usará la prueba de esfericidad de Bartlett que se basa en ji-cuadrado, en gl grados de libertad y la significancia calculados por la aplicación estadística. Bartlett menciona que la matriz de correlaciones es la matriz de identidad para un modelo factorial inadecuado. La prueba de Bartlett establece que, para un nivel de significancia calculado menor o igual a 0,05, tiene sentido hacer un análisis factorial, caso contrario, NO es aceptable. En cambio, KMO establece que, para una prueba de $\mathrm{KMO}$ calculado mayor o igual a 0,5, tiene sentido hacer un análisis factorial, caso contrario, NO es aceptable. Los detalles de la prueba se observan en la tabla 5.13. Como se puede observar, el valor calculado de significancia 0,000 se encuentra por debajo del valor crítico de significancia 0,05 . Por otro lado, el valor calculado de la medida KMO de 0,869 se encuentra por encima del valor crítico 0,5 . Esto significa que, para ambos casos, tiene sentido hacer un análisis factorial. Desde una visión práctica, el modelo de calidad GoTSI se podría optimizar a partir de la conformación de grupos homogéneos de sub-criterios que harían más interpretable la información de los encuestados.

Tabla 5.13. Prueba de KMO y Bartlett

\begin{tabular}{|l|l|r|}
\hline \multicolumn{2}{|l|}{ Medida KMO de adecuación de muestreo } & 0,869 \\
\hline \multirow{2}{*}{ Prueba de esfericidad de Bartlett } & Aprox. ji-cuadrado & 251,779 \\
\cline { 2 - 3 } & gl & 36 \\
\cline { 2 - 3 } & Significancia & 0,000 \\
\hline
\end{tabular}

Dentro del análisis factorial está la definición de comunalidades (sustitución de unos de diagonal por estimaciones de la varianza) y su extracción inicial. Los detalles de la prueba se observa en la 
tabla 5.14. Como se puede observar, cada variable tiene un valor inicial de 1 debido a su correlación entre variables y un valor de extracción calculado que representa el grado de asociación inicial y con el cual empezará la rotación (transformación lineal de la variable).

Tabla 5.14. Matriz de Comunalidades

\begin{tabular}{|l|c|c|}
\hline \multicolumn{1}{|c|}{ Variable } & Inicial & Extracción \\
\hline CULTURA & 1,000 & 0,573 \\
\hline ARQUITECTURA & 1,000 & 0,684 \\
\hline DIRECCION ESTRATEGIAS & 1,000 & 0,523 \\
\hline EVALUACION ESTRATEGIAS & 1,000 & 0,540 \\
\hline ROLES Y RESPONSABILIDADES & 1,000 & 0,437 \\
\hline FINANCIEROS Y MATERIALES & 1,000 & 0,441 \\
\hline DISEÑO Y MEJORA & 1,000 & 0,550 \\
\hline NECESIDAD INFORMACION & 1,000 & 0,581 \\
\hline FINANCIEROS Y NO FINANCIEROS & 1,000 & 0,476 \\
\hline
\end{tabular}

El paso siguiente es determinar el número de componentes (factores). El conseguir una estructura factorial clara y simple depende en buena medida del número de componentes. Para esto se valora dos procedimientos que determinen el número de componentes que se deben rotar: a) Procedimiento de Gutman-Kaiser; y, b) Gráfico de sedimentación o Screen test de Cattell (Klein, 1994) (Beavers, et al., 2013). El procedimiento de Gutman-Kaiser: en un primer análisis rotan solamente los componentes cuyo valor autoasociado o autovalor total es mayor que 1. El gráfico de sedimentación (presentado más adelante en la figura 5.12) aporta con el número de componentes (en el eje de las $X$; el número de componente coincide con el número de subcriterio) y los autovalores (eje de las $Y$ ) o varianza explicada por cada componente. El número de factores que se van a rotar se sitúa en el punto de inflexión de la línea descendente del gráfico que va uniendo los diversos autovalores. Los detalles del procedimiento de Gutman-Kaiser se presentan en la tabla 5.15. Como se puede observar, el valor calculado de autovalor: 4,806 , se encuentra por encima del valor crítico de autovalor 1 . Por lo tanto, solo se puede definir 1 componente. Por otro lado, la varianza total explicada de $53,403 \%$ es menor al referente en ciencias sociales que es $60 \%$. Sin embargo, se continúa para analizar otros elementos en el análisis factorial.

Tabla 5.15. Varianza total explicada

\begin{tabular}{|c|r|r|r|r|r|r|}
\hline \multirow{2}{*}{ Componente } & \multicolumn{3}{|c|}{ Autovalores iniciales } & \multicolumn{3}{c|}{ Sumas de extracción de cargas al cuadrado } \\
\cline { 2 - 8 } & Total \% de varianza\% acumulado & Total & \% de varianza & \% acumulado \\
\hline 1 & 4,806 & 53,403 & 53,403 & 4,806 & 53,403 & 53,403 \\
\hline 2 & 0,914 & 10,150 & 63,553 & & & \\
\hline 3 & 0,799 & 8,881 & 72,434 & & & \\
\hline 4 & 0,640 & 7,112 & 79,546 & & & \\
\hline 5 & 0,493 & 5,479 & 85,025 & & & \\
\hline 6 & 0,482 & 5,350 & 90,375 & & & \\
\hline 7 & 0,357 & 3,965 & 94,340 & & & \\
\hline 8 & 0,280 & 3,111 & 97,451 & & & \\
\hline 9 & 0,229 & 2,549 & 100,000 & & & \\
\hline
\end{tabular}

Los detalles del gráfico de sedimentación se presentan en la figura 5.12. Como se puede observar, los valores calculados de autovalor están en número de 9 componentes. El componente con un autovalor superior a 1 es 1 (seleccionado con el procedimiento de Gutman-Kaiser), lo que es 
cercano al componente 2 muestra un punto de inflexión en línea descendente, por lo que efectivamente se pueden rotar solo 1 componente identificado. En fin, el 1 componente explica una menor varianza que un número mayor de componentes, pero la estructura será más clara e interpretable, de acuerdo al objetivo que se persigue.

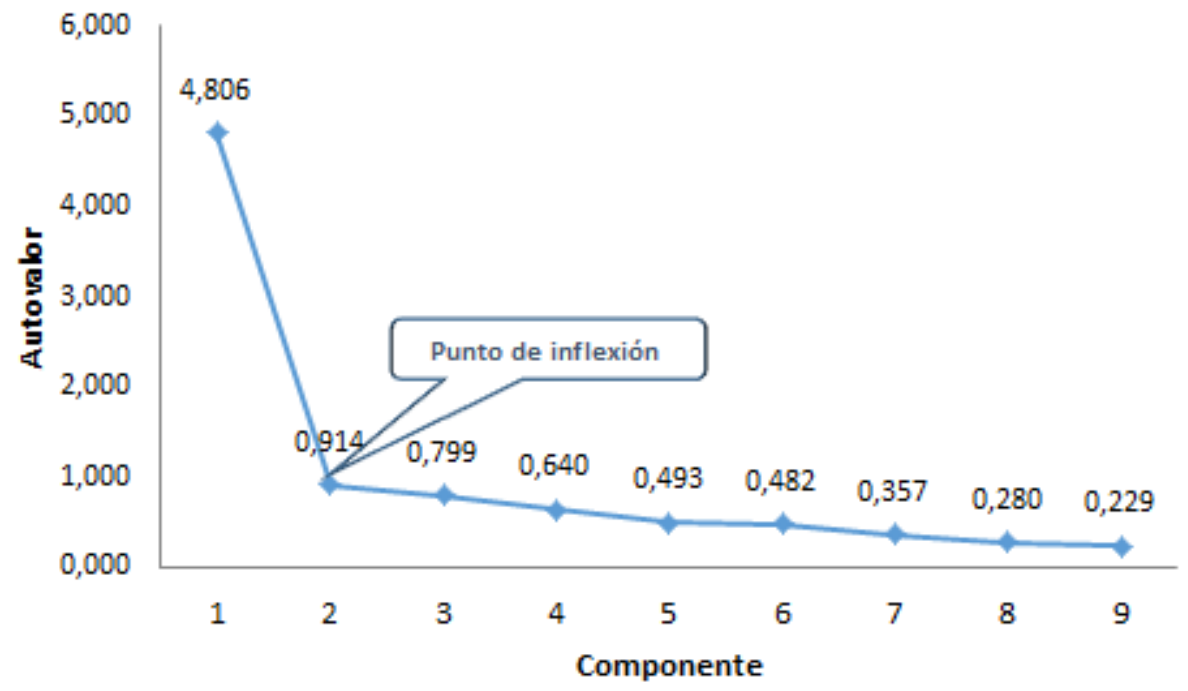

Figura 5.12. Gráfico de sedimentación.

La tabla 5.16 muestra la matriz de componentes no rotados con la composición del componente 1. Como se puede observar, todas las variables están ordenadas de manera descendente por coeficiente de correlación empezando por el componente 1. Lo característico de la tabla es que las 9 variables conforman un componente identificado como 1.

Tabla 5.16. Matriz de componentes

\begin{tabular}{|l|c|}
\hline \multicolumn{1}{|c|}{ Variable } & Componente \\
\cline { 2 - 2 } & $\mathbf{1}$ \\
\hline CULTURA & 0,757 \\
\hline ARQUITECTURA & 0,827 \\
\hline DIRECCION ESTRATEGIAS & 0,723 \\
\hline EVALUACION ESTRATEGIAS & 0,735 \\
\hline ROLES Y RESPONSABILIDADES & 0,661 \\
\hline FINANCIEROS Y MATERIALES & 0,664 \\
\hline DISEÑO Y MEJORA & 0,741 \\
\hline NECESIDAD INFORMACION & 0,763 \\
\hline FINANCIEROS Y NO FINANCIEROS & 0,690 \\
\hline
\end{tabular}

Los componentes rotados están compuestos por los coeficientes correspondientes a las variables que mejor definen cada componente. Las variables pertenecen al componente donde tienen el mayor peso y que en ningún caso debería ser inferior a 0,40. Kline (1994) recomienda 0,30 como un valor de peso orientador mínimo aceptable. En vista de que la prueba sólo ha extraído un componente, la solución no se puede rotar. En términos prácticos, esto significa que el componente 1 resume la consistencia correlacional entre variables (de manera balanceada) que podrían ayudar a mejorar las formulaciones de los sub-criterios, los criterios y, por ende, el modelo de calidad GoTSI.

Como respuesta a nuestro caso hipotético, planteado al inicio de esta sección, desde el punto de vista analítico, cada componente subyacente es una combinación lineal de las variables que la 
componen. Además, en cada componente, una variable tiene un índice de ponderación o peso. La tabla 5.17 detalla el modelo lineal para predecir el único componente. Como se puede observar, las cuatro ponderaciones más altas se encuentran en los subcriterios de arquitectura, necesidad de información, cultura y diseño y mejora; que pertenecen a los criterios de liderazgo y estilo de gobierno y procesos.

Tabla 5.17. Matriz de coeficiente de puntuación de componente

\begin{tabular}{|l|l|c|}
\hline \multirow{i}{*}{$\boldsymbol{|}$} & \multicolumn{1}{|c|}{ Variable (Vi) } & Componente \\
\cline { 3 - 3 } & \multicolumn{1}{|c|}{ CP1 } \\
\hline 1 & CULTURA & 0,158 \\
\hline 2 & ARQUITECTURA & 0,172 \\
\hline 3 & DIRECCION ESTRATEGIAS & 0,151 \\
\hline 4 & EVALUACION ESTRATEGIAS & 0,153 \\
\hline 5 & ROLES Y RESPONSABILIDADES & 0,137 \\
\hline 6 & FINANCIEROS Y MATERIALES & 0,138 \\
\hline 7 & DISEÑO Y MEJORA & 0,154 \\
\hline 8 & NECESIDAD INFORMACION & 0,159 \\
\hline 9 & FINANCIEROS Y NO FINANCIEROS & 0,144 \\
\hline
\end{tabular}

Como se puede observar en la tabla anterior, el componente determinado tendría una aproximación analítica representada en la fórmula 5.4.

$C P 1=0,158 * V 1+0,172 * V 2+0,151 * V 3-0,153 * V 4-0,137 * V 5+0,138 * V 6-0,154 * V 7-0,159 * V 8+0,144 * V 9$

\section{Fórmula 5.4. Representación analítica del modelo de calidad GoTSI}

La expresión analítica (fórmula 5.4) está asociada al modelo de calidad de GoTSI y a partir de la cual se lo puede entender estadísticamente.

\subsection{APLICACIÓN DEL MODELO}

Con el fin de aumentar la validez del modelo, se ha desarrollado una guía aplicativa que puede ser útil para evaluadores y administradores de calidad. Con esta guía se pueden orientar estas personas sobre los componentes que forman parte de la estructura del modelo de calidad.

En el anexo $F$, se presenta un ejemplo de aplicación a un caso de evaluación en una entidad pública. Para este caso se conoce que la organización no tiene implementado un sistema de gobierno de TSI, sin embargo, aplican criterios de gobernabilidad en actividades inherentes a las funciones del nivel gobernante produciendo efectos en las unidades funcionales que hacen uso de las tecnologías. El equipo evaluador ha identificado 10 personas de la organización, de las cuales, 7 tienen relación con el equipo o comité de gobierno de las TSI y 3 pertenecen a las áreas funcionales de no TSI. A estas personas se les entrega un cuestionario que recoge las dimensiones pertinentes y entendibles, de manera que una vez contestado el instrumento de datos se devolverá con la información del caso para que el equipo directivo de evaluadores realice el Informe Final o Reporte de Mejoramiento.

El equipo evaluador hace uso del aplicativo de acuerdo al siguiente procedimiento:

1. Analizar la información proporcionada en los términos de las dimensiones por cada subcriterio.

2. Asegurar las dimensiones a utilizar por cada sub-criterio de calidad. 
3. Valorar la implantación, aplicación y efecto por cada sub-criterio. Para lo cual se dispone de una matriz de valoración por cada nivel.

4. Valorar cada dimensión en términos de las evidencias (importancia, difusión, utilización, seguimiento y valor percibido).

5. Realizar los cálculos respectivos para obtener las medidas de cada sub-criterio, criterio y de la calidad de gobierno.

6. Utilizar un mapa de colores a las medidas obtenidas con el fin de ilustrar los niveles de tolerancia.

7. Realizar un análisis comparativo de la información proporcionada por el equipo de gobierno con la información obtenida en la guía con el propósito de describir los puntos a detallar en el reporte de mejoramiento.

8. Redactar el reporte de mejoramiento en términos que origine el debate encaminadas a la identificación de acciones para la mejora continua.

Una vez que el aplicativo ha procesado la información suministrada por el equipo evaluador, se puede observar que la medida de calidad del Gobierno de TSI es 3,82 sobre 6 puntos. Esta medida representa el $63 \%$ de la medida máxima. Lo cual demuestra que 6 de cada 10 condiciones de calidad de gobierno son cumplidas en el contexto de la organización. Siendo los criterios de personas y recursos, en ese orden, los que generan mayor impacto en la calidad y por ende los criterios a tomar en cuenta para mejorar.

Entonces, con este ejemplo, la guía de aplicación del modelo puede servir para soportar procesos de evaluación.

\subsection{CONCLUSIONES}

En este capítulo, se abordó el análisis de la propuesta mediante la aplicación de métodos y técnicas estadísticas a los datos proporcionados por los líderes de TSI encuestados. Este análisis validó los sub-criterios y, por ende, los criterios de calidad que recogen las características de gobierno de TSI basadas en valor consideradas necesarias para obtener buenos resultados, para lo cual, se solicitó a cada participante que asigne valores categóricos a las 38 (2 preguntas excluidas por ser datos de constancia) de las 40 preguntas que conforman el cuestionario. Esta validación se hizo considerando los criterios, sub-criterios y dimensiones por sí mismos, en su completa y moderada importancia como aspectos que deben tomarse en cuenta en la evaluación.

En primera instancia se realizó un análisis de fiabilidad, soportado en el coeficiente Alpha de Cronbach $(\alpha)$. El cual arroja un resultado de fiabilidad superior al $80 \%$ considerado como de eficiencia en la prueba.

En segunda instancia se realizó un análisis considerando 6 medidas descriptivas: la media aritmética, la mediana, la moda, el rango, la varianza y la desviación estándar. Los datos demuestran una tendencia hacia la "completa importancia" y con intervalo pequeño que los líderes de TSI brindan a los sub-criterios, criterios y, por ende, al modelo de evaluación de la calidad de GoTSI basada en valor. Resultados parciales de este trabajo han sido publicados en (Merchán, et al., 2016). De igual manera se realizó el cálculo de coeficientes de asimetría y curtosis por cada variable llegándose a interpretar que la curva no era normal, culminando con la validación a través de la prueba de normalidad de Kolmogorov-Smirnov.

En tercera instancia se realizó un análisis de correlación de sub-criterios aplicando el método no paramétrico de correlación por rangos de Spearman. Los resultados demuestran que en el 100\% 
de las relaciones existen correlaciones entre sub-criterios de calidad con nivel de significación menor al $1 \%$ y $5 \%$.

En cuarta instancia se realizó un análisis de la varianza de sub-criterios en un sentido de intervalos a través de la prueba no paramétrica de Kruskal-Wallis. Los resultados demuestran contundencia al expresar que NO hay diferencia entre las valoraciones de los líderes de TSI de acuerdo a las variables demográficas. Desde una óptica práctica, el modelo de calidad GoTSI se podría aplicar a cualquier gobierno de TSI de manera independiente del sector principal, género, edad y escolaridad.

Finalmente, en una quinta instancia se realizó un análisis factorial con la finalidad de encontrar una manera de simplificar la información que brinda la matriz de correlaciones de Spearman para hacerla más fácilmente interpretable. Los resultados demuestran que la solución propuesta sólo se puede conformar por 1 componente que resume las consistencias correlacionales entre variables (de manera balanceada) que podrían ayudar a mejorar las formulaciones de los subcriterios, los criterios y por ende el modelo de calidad GoTSI. Se aborda una expresión analítica que representan al único componente. En consecuencia, para los datos obtenidos, el modelo tiene consistencia y validez. 



\section{CAPÍTULO 6 - CONCLUSIONES Y TRABAJOS FUTUROS}

\subsection{INTRODUCCIÓN}

Es menester recordar que el Gobierno de las Tecnologías y Sistemas de Información es un concepto que trasciende en una organización sea pública, privada o mixta. Este incluye las políticas, estrategias y principios para dirigir y controlar el uso actual y futuro de las tecnologías y sistemas de información dentro de la organización. Especifica los aspectos de decisión y el marco de trabajo para la rendición de cuentas, asegurando que el uso de las TSI sea el apoyo eficiente y eficaz de los objetivos y estrategias de la organización. No obstante, evaluar la calidad de este concepto no es un aspecto sencillo, aunque pueda parecerlo, porque en muchos de los casos lleva implícita una concepción previa de las definiciones.

Este trabajo de investigación implicó revisar definiciones de trascendencia internacional que resulten coherentes y que contribuyan positivamente a un contexto cultural y tecnológico en el ámbito público ecuatoriano. Es así que, evaluar la calidad de gobierno de las tecnologías y sistemas de información involucra un proceso de validación basada en la experiencia de líderes de TSI y en el juicio de expertos que se encuentran involucrados en el sector tecnológico del ámbito público.

Este capítulo, presenta al lector una descripción de las principales conclusiones, reflexiones y publicaciones realizadas en este trabajo doctoral. Por lo tanto, el capítulo está estructurado de la siguiente manera. La sección 6.2 aborda las conclusiones en función de los objetivos formulados en el capítulo 1. La sección 6.3 aborda las reflexiones finales del trabajo. La sección 6.4 aborda las líneas de trabajos futuros para el proyecto de investigación. Finalmente, la sección 6.5 aborda las publicaciones realizadas en relación con el presente trabajo doctoral.

\subsection{CONCLUSIONES}

En la sección 1.3, capítulo 1 de este trabajo doctoral, se formuló el problema expresado en la necesidad de mejorar la calidad de gobierno de TSI basada en valor mediante un proceso que lo motive a nivel estratégico organizacional. Luego, en la sección 1.4, se formuló el objetivo general que dice: "Proponer un Modelo de Calidad de Gobierno de Tecnologías y Sistemas de Información (GoTSI) basada en Valor, con el fin de ayudar a comprender el sistema de gobierno y mejorar procedimientos internos, a través de un conjunto de componentes que respondan a principios de un buen gobierno de TSI en el ámbito público ecuatoriano". Este se traduce en la mejora de las tareas y actividades de decisión y, por ende, en los resultados que dé lugar a una mayor competencia organizacional habilitada por las TSI. Este objetivo principal de investigación se cumple con la realización de los objetivos específicos cuyos resultados se describen a continuación:

- Estudiar propuestas existentes de evaluación de calidad de GoTSI basada en valor.

En el capítulo 2 se analiza el marco teórico en el contexto de GoTSI. Se utilizó el criterio de síntesis para identificar y describir los diversos conceptos, definiciones y principios que se utilizaron como referencia para la formulación de la propuesta de investigación. Se contó 
con la guía de expertos en aspectos claves de calidad y GoTSI, con el fin de identificar temas importantes que aportarían en la definición del modelo de evaluación de la calidad. Al identificar el enfoque de calidad que se debe tomar en cuenta, se notó la importancia de considerar a la integralidad como lo más prioritario. De no ser así, la probabilidad de asimetría en la información a ser tomada en cuenta en la evaluación aumentaría de manera considerable.

Otro aspecto esencial de la calidad es el ámbito de aplicación, aquí se consideraron las pautas que se orientan al ámbito público, en este sentido son claros los requerimientos del modelo iberoamericano, como el más pertinente. Finalmente, queda el sujeto de aplicación, en este caso fue el GoTSI, en este sentido es clara la orientación del gobierno hacia las actividades desde la óptica del estándar ISO/IEC 38500.

En el capítulo 3 se estudiaron los trabajos relacionados. El método de investigación aplicado fue el mapeo sistemático de estudios. Como resultado se determinó la existencia de 14 trabajos entre modelos, métodos y ontologías que aportan a la calidad de GoTSI, siendo los más pertinentes los de Lima et al. (2011), Gummerus (2011) y Li et al. (2010). Cuyos criterios de calidad están más orientados al cumplimiento de requisitos técnicos y de gestión, lo cual corrobora para que esta propuesta doctoral sea pertinente.

- Establecer las características y principios de calidad que funcionan como componentes del sistema de evaluación de la calidad de GoTSI basada en valor.

Las características del modelo propuesto se derivan de la revisión de estudios y marco teórico pertinente: Modelo Iberoamericano (2015), Municio (1998) y Pérez (2014). Además, la experiencia del autor de este trabajo doctoral.

En el capítulo 4 se presentó la propuesta del Modelo de Evaluación de la Calidad de Gobierno de Tecnologías y Sistemas de Información Basada en Valor (VBISTGQM). EI mismo, a más de otros aspectos, se construye enmarcado en el valor agregado que se debe entregar a las unidades funcionales, el liderazgo, el éxito a alcanzar a través de las personas y acciones basadas en la responsabilidad para alcanzar un futuro sostenible. En consecuencia, se abordan 2 principios básicos de calidad: valor generado y medida de evaluación.

- Proponer una estructura de modelo que permita cumplir los principios de calidad establecidos.

Los principios de calidad responden a la caracterización del modelo propuesto y son fruto del análisis del modelo iberoamericano y de los otros modelos identificados.

La ejecución del modelo requiere una participación completa a nivel jerárquico estratégico o de la alta dirección organizacional. Su accionar tiene que ser protagónico en la autoevaluación. Para una ejecución exitosa de la evaluación se recomienda gestionarse como un proyecto, con criterios de calidad, estrategia de riesgos, asignación de recursos, tiempos asignados a cada actividad y, lo más importante, bajo la dirección de un gerente para que supervise y controle.

En el capítulo 4 se presentó la propuesta del Modelo de Evaluación de la Calidad de Gobierno de Tecnologías y Sistemas de Información Basada en Valor (VBISTGQM), como resultado del objetivo general propuesto en esta tesis doctoral. El modelo propuesto constituye un aporte conceptual que se valora mediante 3 niveles jerárquicos de 
evaluación ponderados: Implantación, Aplicación y Efecto. El mismo establece 2 principios básicos, 6 criterios, 9 sub-criterios y 34 dimensiones de calidad que se valoran a través de 5 componentes de evidencia que establecen una puntuación ordinal tipo Likert con valores de 0 a 1 para el análisis respectivo. El contenido de los 6 criterios responde a los 2 principios de calidad que son pertinentes con los modelos de calidad analizados.

Desde el punto de vista matemático se ha desarrollado una serie de fórmulas basadas en los conceptos de sucesiones y series, con la finalidad de determinar la medida de dimensiones, sub-criterios y criterios, sobre los cuales se concluirá la medida total del GoTSI. De todas maneras el equipo de evaluación puede establecer las ponderaciones de acuerdo a las necesidades que se establezcan al equipo de gobierno.

- Proponer un proceso de autoevaluación que facilite la mejora del accionar del equipo rector de gobierno.

En el capítulo 4 se presentó la propuesta del Modelo de Evaluación de la Calidad de Gobierno de Tecnologías y Sistemas de Información Basada en Valor (VBISTGQM). EI modelo propuesto establece un proceso de autoevaluación estructurado en 5 pasos. Los pasos propuestos son un modo de dividir el proceso que busca gestionar adecuadamente el plan de autoevaluación a nivel de planificación, dirección y control. Una característica importante es que está limitada a 3 fases únicas: concientización, entrenamiento y autoevaluación.

- Analizar la importancia que le brindan líderes de TSI a los diferentes criterios de excelencia.

En el capítulo 5 se presentó la validación empírica del modelo de calidad (VBISTGQM). Para la validación operativa del modelo se definió un muestreo no probabilístico de una población cualitativa. Los sujetos (o casos) seleccionados fueron adecuadamente escogidos en función de criterios de inclusión-exclusión; 62 fue el número de sujetos que completaron la encuesta de 89 que en principio aceptaron completarla, dando un índice global de finalización de $69,66 \%$. A continuación, se definió y aplicó una encuesta como técnica de investigación que contenía un cuestionario estructurado compuesto por 40 preguntas que formaban parte de 8 secciones. Los datos obtenidos fueron de tipo ordinal y nominal, apropiados para pruebas estadísticas no paramétricas.

Los resultados obtenidos fueron evaluados en dos partes, la primera con una muestra de 27 sujetos y luego con una muestra más amplia de 62 sujetos. Con el fin de precisar el modelo en un sentido de comprensión y entendimiento por parte de los autores que van utilizar el modelo. Además, por ser una recomendación de los autores de los métodos estadísticos aplicados, en el sentido de que la definición muestral no es una cuestión $a$ priori en investigación cualitativa sino de experiencia soportada en la definición del problema de investigación.

A pesar de las desventajas que técnicamente puede presentar un muestreo no probabilístico, este proceso de investigación generó un gran valor en la investigación, pues permitió obtener la información pertinente y consistente para el análisis de datos requerido.

En términos generales, los resultados de las preguntas reflejan la importancia que los líderes de TSI brindan a los sub-criterios, criterios y, por ende, al modelo de evaluación de 
la calidad de GoTSI basada en valor. Estos datos aportan con el objetivo y la hipótesis de investigación planteada en este trabajo doctoral.

- Validar la aplicabilidad del modelo de evaluación definido.

En el capítulo 5 se presentó la validación empírica del modelo de calidad (VBISTGQM) propuesto en el capítulo 4. Para esto se recurrido a métodos y pruebas estadísticas no paramétricas que permitan analizar los datos ordinales y nominales que relevó la investigación. Los análisis demuestran la relevancia que existe entre los sub-criterios y, por ende, los criterios del modelo. Quedando de la siguiente manera:

- Arquitectura tiene gran influencia en Cultura, ambos pertenecen al criterio de Liderazgo y estilo de gobierno.

- Necesidad de información tiene gran influencia en Diseño y mejora, ambos pertenecen al criterio de Procesos.

- Evaluación de estrategias tiene mayor influencia en dirección de estrategias, ambos pertenecen al criterio de Estrategias.

- Financieros y no financieros, recursos financieros y materiales y, roles $y$ responsabilidades generan influencias unos a otros a nivel de criterios.

Este análisis estadístico, también parece apoyar la conclusión de que el orden en que se presentan los criterios y sub-criterios tiene una justificación razonable basada en el nivel de influencia que ejerce un sub-criterio predecesor en su sucesor. Esto podría sugerir que el efecto de estos criterios para la calidad de gobierno tiene un impacto muy positivo en las instituciones del estado.

Con lo mencionado, se puede mantener la influencia del mayor ponderado al menor ponderado, conduciendo a resultados que garanticen valor en lo que se podría llamar un ciclo de evaluación de calidad.

Con los resultados obtenidos en los análisis llevados a cabo se puede afirmar que sí es posible definir un modelo estructurado de evaluación de la calidad de GoTSI basada en valor, que sea coherente, consistente y pertinente a las tecnologías y sistemas de información; que sea independiente al sector principal, género, edad y escolaridad del equipo de gobierno que lo conforman. Esto nos llevaría a sugerir posibles líneas de investigación a comentar en la sección 6.4 .

\subsection{REFLEXIONES FINALES}

Los resultados de las investigaciones realizadas demuestran que es posible proponer un modelo con criterios específicos y exhaustivos de calidad basada en valor. Cuyos contenidos son desarrollados por expertos y para expertos en TSI que apoyan estos criterios. Aunque puede parecer trivial el hecho de definir un modelo basado en criterios soportados por un conjunto de dimensiones que incluyen valor, es aconsejable que los inicios de este modelo sean apoyados por expertos para formar equipos de gobierno u oficiales de gobierno de TSI al interior de las organizaciones y, ayudar a establecer el sistema propuesto. Con posterioridad, buscar el apoyo de evaluadores independientes que aporten contrastes y nuevas soluciones en un claro proceso de mejora continua. Sin duda, esto permitirá la maduración y expansión del modelo.

Con el desarrollo de una guía aplicativa del modelo se ha demostrado su funcionalidad de manera correcta y ágil para el proceso de autoevaluación organizacional: seleccionando y manteniendo dimensiones adecuadas; valorando de manera flexible cada sub-criterio y criterio de acuerdo a su 
implantación, aplicación y efecto; logrando determinar rápidamente puntos fuertes y aspectos a mejorar; analizando comparativamente información de opinión con información de dimensión y logrando determinar la medida total de gobierno. También brindando confianza mediante los criterios definidos debido a que estos están positiva y fuertemente correlacionados a partir del criterio considerado como más importante: el liderazgo y estilo de gobierno.

A este respecto, cabe destacar la alta importancia y cada vez más justificada que brindan los modelos de calidad, así como los líderes de TSI, en el desarrollo y evolución de la calidad de gobierno. Al menos así lo demuestran quienes opinaron sobre el tema encuestado.

Con respecto al pensamiento de quienes aportaron con información en esta investigación, se puede manifestar que el $95 \%$ de los encuestados opinaron que el "optimizar el valor" en este tipo de modelos, garantiza la toma de decisiones de una forma más objetiva.

Finalmente, el modelo de evaluación propuesto tiene la intención de ser un modelo escalable, dando la oportunidad de incluir más criterios, subcriterios y dimensiones para mejorar los resultados enfocados en la calidad de los equipos de gobierno de TSI. Si bien el modelo es para el ámbito público ecuatoriano, es posible adaptarlo a otros gobiernos latinoamericanos tomando en cuenta que se revisó e incluyó conceptos y definiciones del modelo iberoamericano para la administración pública, perfilándose para que responda a necesidades propias de las tecnologías y sistemas de información. En el caso que las dimensiones o parámetros de puntuación y/o ponderación no se adapten a sus políticas públicas, es posible agregar o modificar las actuales configuraciones según la realidad del caso.

\subsection{FUTURAS LINEAS DE INVESTIGACIÓN}

El tema de GoTSI, desde la perspectiva de la calidad, es considerado un tópico multidisciplinario que abarca un amplio espectro de conocimiento en constante evolución. Por lo tanto, es necesario considerar, en el marco de una línea de investigación, la valoración y sobre todo la validación de este modelo con otros métodos de los aquí utilizados. Algunas de las aristas que pueden ser tratadas y que guardan relación positiva son:

- Personas: Considerado por los expertos y el autor de este trabajo como un criterio clave. El comportamiento del equipo de gobierno hacia el modelo de calidad. Una posición de indiferencia al modelo anularía sus capacidades de mejora. A modo de pregunta sería ¿Qué conocimientos debería tener el equipo o el oficial de gobierno de TSI para poder adecuar su comportamiento de manera estratégica en pro de la calidad de gobernabilidad de las TSI?.

- Producción: Contribución del modelo a la eficiencia y eficacia del gobierno en el logro de la excelencia personal. Las tareas y actividades de dirección del equipo de gobierno son importantes.

- Estructura: La estructura misma del modelo. La posición de nuevos criterios, sub-criterios y dimensiones, en especial por la relación que deben mantener para la entrega de valor. La investigación debe determinar la calidad de esas variables, garantizando la validez ya que se mediría lo que se quiere medir.

- Relación: Las relaciones de las variables entre sí, en sentido general. Se debe considerar la definición de un modelo conceptual adecuado desde el punto de vista estadístico para calcular la complejidad de la calidad con menos o más criterios y/o subcriterios participantes.

Posibilidades de más trabajos, se plantea a continuación: 
- La creación de descriptores para evitar el problema de la discrecionalidad de pruebas de conformidad por cada dimensión evaluada.

- Partiendo del conocimiento que se tiene de las organizaciones públicas, se debería comenzar a realizar estudios de caso de tipo mejora en donde la unidad de análisis debe ser el equipo de GoTSI. Esto permitirá incorporar nuevas dimensiones de calidad.

- La simplificación del modelo mediante la construcción de una aplicación informática en línea que incluya el concepto de trabajo colaborativo para ejecutar procesos de autoevaluación.

- Queda abierta la posibilidad que se realice un estudio con alcance específico a gobiernos seccionales o conocidos como Gobiernos Autónomos Descentralizados (GAD).

De manera particular, este trabajo doctoral se basó en el valor como una característica que producen los criterios, soportado en dos conceptos importantes: funcionalidad y garantía. No obstante, otros aspectos claves como el riesgo y la seguridad, pueden ser evaluados desde la óptica de la calidad de GoTSI. Una organización de TSI innovadora, responde con facilidad a las presiones del entorno interno, es decir, tiene un alto grado de flexibilidad para combinar las exigencias y la retroalimentación interna con la valoración que le proporciona la tecnología. Percibe de forma natural las discrepancias entre lo que es y lo que debe ser, identifica objetivos y problemas nuevos, llevando a cabo acciones sistemáticas y naturales porque los miembros de gobierno de TSI participan directamente en la mejora de la calidad: identificando, definiendo y controlando los riesgos que forman parte de sus principios. De esta manera se justifica la propuesta de una nueva línea de investigación.

\subsection{PUBLICACIONES EN REVISTAS Y CONGRESOS}

Las diversas aportaciones incluidas en esta tesis doctoral han sido presentadas en diferentes congresos y revistas científicas. La aceptación, de cada trabajo presentado, por parte de la comunidad científica otorga credibilidad a la calidad del trabajo desarrollado. La tabla 6.1 presenta un resumen de las publicaciones realizadas.

Tabla 6.1. Publicaciones realizadas

\begin{tabular}{|l|c|}
\hline \multicolumn{1}{|c|}{ Tipo } & Cantidad \\
\hline Congresos Nacionales e Internacionales & 7 \\
\hline Revistas Indexadas, SJR & 3 \\
\hline TOTAL & 10 \\
\hline
\end{tabular}

A continuación se enlistan las publicaciones (acompañadas de ponencias, exposiciones y conferencias) que se desplegaron a nivel nacional e internacional, como resultados del desarrollo de este trabajo doctoral.

\section{1}

TITULO:

Estrategia de evaluación de calidad de datos orientados a Web en Sistemas de Soporte a Negocios de Interconexión

REVISTA:

Revista Tecnológica ESPOL - RTE

NÚMERO DE ESTÁNDAR:

ISSN: 1390-3659

PUBLICACIÓN:

LUGAR Y FECHA:

Volumen 28 Número 1 Aplicaciones Ingenieriles

AUTOR:

Guayaquil-Ecuador; Junio 2015

Vicente Merchán

CONTRIBUCIÓN:

El trabajo presenta una estrategia para evaluar la calidad de datos de los sistemas BSS/OSS Compliance para el negocio de interconexión 
como parte de un modelo de calidad de datos. Los factores que inciden en la calidad son determinados por las fuentes existentes; la validación oportuna del modelo a través de encuestas como instrumento de recolección de información aplicadas a los usuarios internos expertos de la telco que gestionan el BSS/OSS de interconexión.

\section{2}

TITULO:

CONGRESO:

NÚMERO DE ESTÁNDAR:

LUGAR Y FECHA:

AUTOR:

CONTRIBUCIÓN:

Value-Based Information Technology Governance Quality Assessment: Systematic Mapping Study

IEEE CHILEAN CONFERENCE ON ELECTRICAL, ELECTRONICS ENGINEERING, INFORMATION AND COMMUNICATION TECHNOLOGIES - IEEE Chilecon 2015

ISBN: 978-1-4673-8756-9/15/\$31.00 c 2015

IEEE ISSN: 0719-6806 Pág. 583-589

Santiago de Chile; 28 al 30 de Octubre 2015

Vicente Merchán

El trabajo presenta los trabajos relacionados con el tema doctoral. Como resultado de la investigación empírica, se identificaron 220 artículos a través de diferentes motores de búsqueda académica, 14 fueron seleccionados para el cumplimiento; clasificados de acuerdo a su ámbito de aplicación, tipo de valor, tipo de estudio y contribución. Los estudios muestran que la evaluación de la calidad basada en el valor en el contexto del GoTSI parece ser un área que brinda oportunidades para una investigación y evaluación adicionales de los criterios de calidad centrados en el valor.

\section{3}

TITULO:

CONGRESO:

NÚMERO DE ESTÁNDAR:

LUGAR Y FECHA:

AUTORES:

CONTRIBUCIÓN:

Análisis de los modelos de Gobierno de Tecnologías de la Información y sus relaciones con el Modelo de Excelencia Iberoamericano.

XXI Congreso Argentino de Ciencias de la Computación - CACIC2015

Libro de actas ISBN: 978-987-3724-37-4

Junín-Argentina; 5 - 9 octubre de 2015

Vicente Merchán, Rocío Rodríguez

El trabajo presenta el nivel de relacionamiento existente entre el estándar ISO/IEC 38500 con el modelo iberoamericano de excelencia en la gestión basada en valor. Para esto, identifica los aspectos más relevantes de los modelos de gobierno, partiendo del propio concepto hasta llegar a los estándares y marcos aplicables que permitirán visualizar de manera global los actuales esquemas de Gobierno de TI en la organización, que faciliten una aproximación para medir la excelencia basada en valor.

\section{4}

TITULO:

Evaluación de e-Servicios en empresas de alimentos y bebidas de Ecuador

CONGRESO:

1er Congreso Internacional de Investigación en Turismo, Hotelería y Gastronomía - CITHG2015

NÚMERO DE ESTÁNDAR: Actas ISBN: 978-9942-21-749-3 
LUGAR Y FECHA:

AUTORES:

CONTRIBUCIÓN:

TITULO:

NÚMERO DE ESTÁNDAR:

LUGAR Y FECHA:

AUTORES:

CONTRIBUCIÓN:

TITULO:

REVISTA:

NÚMERO DE ESTÁNDAR:

PUBLICACIÓN.

LUGAR Y FECHA:

AUTORES:

CONTRIBUCIÓN:
CONGRESO:

Quito-Ecuador; 11 - 13 Noviembre 2015

Vicente Merchán, Diego Pinto

El trabajo evalúa los eServicios que presentan los sitios web de las empresas de turismo de Ecuador dedicadas a la prestación de servicios de alimentos y bebidas (incluidas las de alojamiento). Este trabajo pretende generar confianza en la aplicación de los métodos de validación del trabajo doctoral.

5

Towards Value-Based Information Technology Leadership Excellence. 11 vo Congreso Colombiano de Computación - IEEE 11CCC

Actas ISBN: 978-1-5090-2965-5

Popayán-Colombia; 27 - 29 Septiembre 2016

Vicente Merchán, Rocío Rodríguez

La investigación aplicada presenta una propuesta conceptual en el contexto de la calidad con un método para medir y evaluar la calidad basada en el valor del liderazgo de gobierno de TI. El resultado está compuesto de dos subcriterios, ocho dimensiones, cinco pruebas de calidad y cinco efectos de valor percibido para cada sub- criterio.

\section{6}

Strategic Vision Excellence in the Use of Information Technology. IEEE Latin America Transactions

ISSN: 1548-0992

Volumen 14 Issue 9

Región 9 IEEE; Septiembre 2016

Vicente Merchán, Jaime Hernández

El trabajo describe la calidad en el uso de las Tecnologías y Sistemas de Información desde la perspectiva del modelo iberoamericano de excelencia y la norma ISO/IEC 38500. Basada en el conocimiento sobre el alto uso que TI representa en la estrategia de la organización. Como resultado se propone un modelo teórico de calidad que aborda el gobierno y gestión de TSI para la organización de telecomunicaciones.

\section{7}

TITULO:

CONGRESO:

NÚMERO DE ESTÁNDAR: LUGAR Y FECHA:

AUTORES:

CONTRIBUCIÓN:
Assessment of the Quality of Leadership in the Government of Technologies and Information Systems

International Conference on Information Systems and Computer Science - INCISCOS2016

Proceedings ISBN: 978-9978-389-32-4

Quito-Ecuador; 24 - 26 Noviembre 2016

Vicente Merchán, Rocío Rodríguez

El trabajo estudia el Modelo Iberoamericano de Excelencia en la Administración Pública y el estándar GoTSI ISO/IEC 38500, con el fin de crear un modelo de evaluación de la calidad de liderazgo en el GoTSI basada en valor; soportado en el juicio de expertos; valorado y validado en la opinión expresada por los líderes de tecnologías y sistemas de información $y$, la aplicación de métodos y técnicas 
estadísticas de investigación científica.

\section{8}

TITULO:

Liderazgo: Criterio de Excelencia en el GoTSI

JORNADAS:

3eras JORNADAS DE INGENIERIA INFORMATICA - UTE

LUGAR Y FECHA:

EXPOSITOR:

Quito-Ecuador; julio 2016

CONTRIBUCIÓN:

Vicente Merchán

La exposición presenta la evolución del estándar ISO/IEC 38500 y cómo éste está relacionado con el modelo iberoamericano de excelencia desde la óptica del criterio de liderazgo y estilo de gobierno.

\section{9}

TITULO:

CONGRESO:

Quality of Leadership in the Government of Technologies and Information Systems

Congreso Internacional de Software Aplicado a la Agricultura, Turismo e Industria - SAATI2016

NÚMERO DE ESTÁNDAR: ISBN: 978-9942-8637-1-3

LUGAR Y FECHA:

CONFERENCISTA:

Milagro-Ecuador; 7 - 9 Diciembre 2016

Vicente Merchán

La conferencia tuvo un enfoque de calidad, en el cual se expuso la validación empírica del modelo propuesto de calidad (VBISTGQM). Demostrando la relevancia que existe entre los sub-criterios y, por ende, los criterios del modelo. En fin, dar a conocer que es posible evaluar la calidad de GoTSI basada en valor desde una perspectiva de dirección en donde el equipo de gobierno cumple tareas y actividades de soporte al gobierno empresarial.

\section{0}

TITULO:

Assessment of the Quality of Leadership in the Government of Technologies and Information Systems

REVISTA:

ENFOQUE UTE - Edición especial

NÚMERO DE ESTÁNDAR:

e-ISSN: 1390-6542 / p-ISSN: 1390-9363

PUBLICACIÓN:

V.7-Sup.1, pág. $62-76$

LUGAR Y FECHA:

Quito-Ecuador; Febrero 2017

AUTOR:

CONTRIBUCIÓN:

Vicente Merchán, Rocío Rodríguez

El trabajo estudia el Modelo Iberoamericano de Excelencia en la Administración Pública y el estándar GoTSI ISO/IEC 38500, con el fin de proponer un modelo de evaluación de la calidad de liderazgo en el GoTSI basada en valor; soportado en el juicio de expertos; evaluado en función de la opinión expresada por los líderes de tecnologías y sistemas de información y, la aplicación de métodos y técnicas estadísticas de investigación científica. 



\section{ACRÓNIMOS}

\begin{tabular}{|c|c|}
\hline ACM & Association for Computing Machinery \\
\hline ANOVA & ANalysis Of VAriance \\
\hline APSC & APlicación del Sub-Criterio \\
\hline AS & Australian Standard \\
\hline \multicolumn{2}{|l|}{ C } \\
\hline CAF & Common Assessment Framework \\
\hline CCT & Control de Calidad Total \\
\hline CEO & Chief Executive Officer \\
\hline $\mathrm{ClO}$ & Chief Information Officer \\
\hline COBIT & Control OBjectives for Information and related Technology \\
\hline $\mathrm{CR}$ & CRiterio \\
\hline CRUE & Conferencia de Rectores de las Universidades Españolas \\
\hline \multicolumn{2}{|l|}{$\mathbf{E}$} \\
\hline EFQM & European Foundation for Quality Management \\
\hline EFSC & EFecto del Sub-Criterio \\
\hline eGov & electronic Government \\
\hline \multicolumn{2}{|l|}{$\mathbf{G}$} \\
\hline GoTSI & Gobierno de las Tecnologías y Sistemas de Información \\
\hline IEC & International Electrotechnical Commission \\
\hline IEEE & Institute of Electrical and Electronic Engineer \\
\hline IMSC & IMplantación del Sub-Criterio \\
\hline ISACA & Information Systems Audit and Control Association \\
\hline ISO & International Organization for Standardization \\
\hline ITGI & IT Governance Institute \\
\hline ITIL & Information Technology Infrastructure Library \\
\hline \multicolumn{2}{|r|}{ 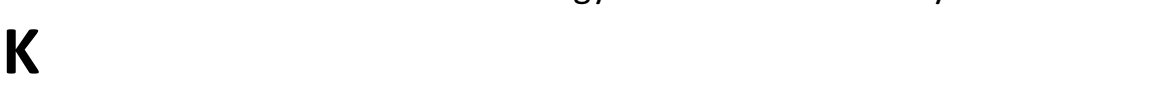 } \\
\hline KMO & Kaiser-Meyer-Olkin \\
\hline \multicolumn{2}{|l|}{$\mathbf{M}$} \\
\hline MBNQA & Malcolm Baldrige National Quality Award \\
\hline \multicolumn{2}{|l|}{$\mathbf{O}$} \\
\hline OCDE & Organización para la Cooperación y el Desarrollo Económico \\
\hline \multicolumn{2}{|l|}{$\mathbf{P}$} \\
\hline $\mathrm{P}$ & $\mathrm{p}$-valor \\
\hline PAP & Ponderación APlicación \\
\hline PEF & Ponderación EFecto \\
\hline PIM & Ponderación IMplantación \\
\hline PMBOK & Project Management BOdy of Knowledge \\
\hline
\end{tabular}


PRINCE2 PRojects IN Controlled Environments 2

S

SC Sub-Criterio

SLR Systematic Literature Review

SMS Systematic Mapping Study

SNAP Secretaría Nacional de la Administración Pública

SPSS Statistical Package for the Social Sciences

SUE Sistema Universitario Español

$\mathbf{T}$

TI Tecnologías de la Información

TIC Tecnologías de la Información y Comunicación

TSI Tecnologías y Sistemas de Información

U

URL Uniform Resource Locator

V

VBISTGQM Valued-Based Information System Technology Governance Quality Model 


\section{REFERENCIAS}

Aguilera Gustavo Modelos de evaluación de la calidad de las organizaciones dependientes de la administración pública en méxico y en españa [Report] : [Tesis Doctoral inédita] / Facultad de derecho ; Universidad de Salamanca. - Salamanca : [s.n.], 2010.

Allen R. Angel Álgebra Intermedia [Libro]. - [s.I.] : Pearson Educación, 2008. - Séptima : pág. 816. ISBN 978-970-26-1223-0.

Almeida Rafael, Pereira Rubén and Mira da Silva Miguel IT Governance Mechanisms: A Literature Review [Conference] // 1.3 International Conference on Exploring Service Science (IESS). [s.l.] : Springer, 2013. - p. 13.

Andaluz Víctor and Morales José Modelos de Gobierno TI para Instituciones de Educación Superior [Journal] // Revista Politécnica. - Quito : [s.n.], 2015. - 3 : Vol. 36.

Anderson David R., Sweeney Dennis J. and Williams Thomas A. Estadística para administración y economía [Book] / ed. Cervantes González Sergio R. / trans. Hano Roa Ma. del Carmen . México D.F. : CENGAGE Learning, 2008. - 10a. : p. 1091. - ISBN-13: 978-607-481-319-7.

Andreu Rafael Estrategias y Sistemas de Información [Book]. - Madrid: S.A. MCGRAW-HILL / INTERAMERICANA DE ESPAÑA, 1996. - ISBN 9788448105082.

Aragón Antonio and Sánchez Gregorio Metodología de la investigación [Online]. - Universidad de Murcia, 2012. - 2016. - https://www.youtube.com/watch?v=RvUllloY7w4.

AS 8015 Australian Standard for Corporate Governance of Information and Communication Technology [En línea]. - 2005. - 10 de Junio de 2014. www.ramin.com.au/itgovernance/as8015.html. - 073376438 X.

Barger Teresa Corporate Governance - A Working Definition [Informe] : International Corporate Governance Meeting / IFC/World Bank Corporate Governance Department. - Hanoi : [s.n.], 2004.

Beavers Amy S. [et al.] Practical Assessment, Research \& Evaluation [Online]. - 2013. - 11 10, 2016. - http://pareonline.net/pdf/v18n6.pdf. - ISSN 1531-7714.

Benavides Velasco Carlos and Quintana García Cristina Gestión del Conocimiento y Calidad Total [Book]. - Madrid : Díaz de Santos, 2003. - pp. 7-10 20-43 49-65 149-150 170 179-181. ISBN 84-7978-552-7.

Benbasat Izak, Goldstein David K. and Mead Melissa The Case Research Strategy in Studies of Information [Journal] // MIS Quarterly. - 1987. - 3 : Vol. 11. - pp. 369-386.

BNQP - Baldrige National Quality Program Criteria for Performance Excellence [Online]. - 2015. www.nist.gov.

Brand Koen and Boonen Harry IT Governance based on COBIT 4.1 - A Management Guide [Book]. - [s.I.] : Van Haren Publishing, 2004. - 9789087531164.

Brian C. and Ulmer J. Measuring Excellence: A Closer Look at Malcolm Baldrige National Quality Award Winners in the Manufacturing Category [Journal]// Journal of technology management \& innovation. - 2009. - 1 : Vol. 4. - pp. 134-142.

Cabrero Moreno Daniel Construcción y Evolución del Software Basados en Valor [Informe] : [Tesis Doctoral Inédita]/ Departamento de Tecnologías y Sistemas de la Información; Universidad de Castilla-La Mancha. - Ciudad Real - España : [s.n.], 2009.

Calder Alan The CALDER-MOIR IT Governance Framework [En línea] // IT Governance. - 2008. 2015. - http://www.itgovernance.co.uk/calder_moir.aspx\#.VVAe5v50zIU.

Cattell R. B., \& Cattell, H. E. Personality structure and the new fifth edition of the 16PF [Publicación periódica] // Educational and Psychological Measurement. - 1995. - 6 : Vol. 55. - págs. 926-937. 
Catton W.R. Exploring Techniques for Measuring Human Values [Book]. - Washington : American Sociological Review (19:1), 1954. - pp. 49-55..

Cervantes Víctor H. Interpretaciones del coeficiente Alpha de Cronbach [Publicación periódica] // Avances en medición. - Bogotá, Colombia : [s.n.], 2005. - Vol. 3. - págs. 9-28.

Chou Shih-Wei and Chiang Chun-Hsiung Understanding the formation of software-as-a-service (SaaS) satisfaction from the perspective of service quality [Book Section] // Decision Support Systems. - Taiwan : [s.n.], 2013. - Vol. 56. - http://dx.doi.org/10.10. - ISSN 01679236.

Cilla Álvarez Ana El modelo EFQM de Excelencia [Publicación periódica] // Anuario Jurídico y Económico Escurialense. - Madrid: [s.n.], 2004. - XXXVII. - págs. 581-605. - ISSN: 11333677.

Corbelli Oscar Fundamentos de PRINCE2 [Libro]. - Madrid : [s.n.], 2006.

Cronbach L. J. Coefficient alpha and the internal structure of tests [Publicación periódica] // Psychometrika . - [s.l.] : Springer-Verlag, September 1951. - 3 : Vol. 16. - págs. 297-334. ISSN 1860-0980.

Dahlberg T. and Kivijarvi H. An Integrated framework for IT Governance and the Development and validation o fan Assessment Instrument. [Conference] // Proc. of the 39th Hawaii International Conference on System Sciences. - Hawaii : IEEE Computer Society, 2006. - p. 194b.

European Foundation for Quality Management [EFQM] EFQM Excellence Model [En línea]. 2013. - 2015. - http://www.efqm.org/sites/default/files/overview_efqm_2013_v1.pdf.

Fenton N. E. Software Metrics a Rigorous Approach [Book]. - London : Chapman \& Hall, 1991.

Fernández Martínez Antonio and Llorens Largo Faraón Gobierno de las TI para las universidades [Book]. - Madrid : CRUE, 2012.

Fernández Sánchez Carlos Manuel and Piattini Velthuis Mario Modelo para el Gobierno de las TIC basado en las normas ISO [Book]. - Madrid : AENOR, 2012. - 978-84-8143-764-6.

Fernández Vicente Eugenio El Gobierno y la Gestión de las TIC. Una aproximación práctica al ámbito del sector público universitario. [eBook] = Ciencias experimentales y tecnológicas. - Madrid, España : Dykinson S.I. ; U servicio de publicaciones, 2009. - ISBN 978-84-9849-759-5.

Fundación Iberoamericana para la Gestión de la Calidad [FUNDIBEQ] FUNDIBEQ [En línea]. 2015. - 2015. - http://www.fundibeq.org.

FUNDIBEQ Modelos de Excelencia [En línea] // Fundación Iberoamericana para la Gestión de la Calidad. - 2014. - 2015. http://www.fundibeq.org/opencms/opencms/PWF/methodology/tools/index/index.html ?_ setlocale=es.

Goldberg A. and Rubin K. Succeeding with Objects: decision frameworks for project management [Book]. - [s.I.] : Addison-Wesley, 1995.

González Sánchez Miguel, Rodenes Adam Manuel and Álvarez Clau Sergio Valoración de la influencia relativa de las $\mathrm{TI}$ sobre los criterios resultado del modelo EFQM, en comparación con el efecto del resto de criterios causa [Journal] // ESIC MARKET. - 2005. 0 : Vol. 122.

Gummerus Johanna Customer Value in E-Service: Conceptual Foundation and Empirical Evidence [Report $]=[$ Tesis Doctoral inédita] / Marketing ; Hanken School of Economics. - HelsinkiFinlandia : Dhanken, 2011. - http://urn.fi/URN:ISBN:978-952-232-116-9. - ISSN 0424-7256.

Hamidovic Haris Gobierno de TI: Fundamentos del Gobierno de TI basados en ISO/IEC 38500 [Publicación periódica] // ISACA Journal. - 2010.

Hernández Sampieri Roberto, Fernández Collado Carlos and Baptista Lucio Pilar Metodología de la Investigación [Book]. - México D.F. : Mcgraw-Hill/ Interamericana Editores S.A. de C.V., 2010. - Quinta edición : pp. 299 - 350. - ISBN: 978-607-15-0291-9.

Hoogervorst Jan A. P. Enterprise Governance and Enterprise Engineering [Libro]. - [s.I.] : Springer, 2009. - ISBN 978-3-540-92670-2. 
Hunter Richard and Westerman George The Real Business of IT. How ClOs create and communicate value. [Book]. - Boston, Massachusetts : Harvard Business Press, 2009. - 5. ISBN 978-1-4221-4761-4.

Ibrahim H. Osman Abdel Latef Anouze, Zahir Irani, Habin Lee, Asım Balcı, Tunç D. Medeni \& Vishanth Weerakkody A new COBRAS framework to evaluate e-government services: A citizen centric perspective [Conference] // tGov Workshop'11 (1GOV11). - London, UK : Brunel University, 2011. - https://www.researchgate.net/publication/228845385.

ISACA COBIT 5: Implementación [Libro]. - Madrid, España : [s.n.], 2012.

ISACA COBIT 5: Un Marco de Negocio para el Gobierno y la Gestión de las TI de la Empresa [Libro] / trad. Madrid ISACA capítulo. - Madrid : ISACA, 2012. - Quinta. - 978-1-60420-2823.

Ishikawa Kaoru What is Total Quality Control? The Japanese Way [Libro]. - [s.I.] : Englewood Cliffs, NJ: Prentice-Hall Inc., 1985. - págs. 44-45.

ISO ISO/IEC 38500:2008. Corporate Governance of Information Technology [En línea]. - 2008. - 18 de $07 \quad$ de 2014. http://www.iso.org/iso/home/store/catalogue_tc/catalogue_detail.htm?csnumber=5163 9.

ISO/IEC ISO/IEC 38500:2008 Corporate Governance of Information Technology Standard [Book]. Geneva : [s.n.], 2008, 2015.

ITGI Enterprise Value: Governance of IT Investments. The Val IT Framework 2.0 [Book]. - [s.I.] : IT Governance Institute, 2008. - ISBN: 978-1-60420-066-9.

ITGI IT Governance Executive Summary [Report]. - USA : IT Governance Institute, 2005.

Jin-fu Wang and Hang Duo Customer-centered e-government service quality evaluation: Framework and case study [Conference] // Computing, Communication, Control, and Management, 2009. CCCM 2009. ISECS International Colloquium on / ed. Luo Qi, Yi Jiang and Bin Chen. - Sanya, China: [s.n.], 2009. - Vol. IV. - pp. 198 - 202. http://ieeexplore.ieee.org/stamp/stamp.jsp?tp=\&arnumber=5267880\&isnumber=526783 1. - ISBN 978-1-4244-4246-1.

Juiz Carlos [y otros] Modelo de Gobierno de las TI en Empresas Públicas, Privadas y Cooperativas para la Mejora de la Comunicación de los Objetivos Empresariales y los Resultados de Rendimiento con Diferentes Partes Interesadas [Sección de libro]// Gobernanza empresarial de tecnologías de la información / aut. libro Cobo Ortega Ángel y Alberto Vanti Adolfo / ed. Cobo Ortega Ángel y Alberto Vanti Adolfo. - Santander : Universidad de Cantabria, 2015. - ISBN 978-84-8102-760-0.

Juiz Carlos, Guerrero Carlos and Lera Isaac Implementing Good Governance Principles for the Public Sector in Information Technology Governance Frameworks [Journal] // Open Journal of Accounting. - Enero 2014. - Vol. 3. - pp. 9-27.

Juran Joseph M. Juran's Quality Control Handbook [Libro] / ed. Gryna Frank M.. - New York: McGraw-Hill Book Co, 1988. - fourth edition : págs. pp. 2.2, 2.8.

Keeney Ralph L. Value-focused thinking: A path to creative decisionmaking [Libro]. Cambridge:Massachusetts : Harvard University Press, 1992.

Kitchenham B. A. and Charters S. Guidelines for performing systematic literature reviews in software engineering [Report] / School of Computer Science and Mathematics; Keely University. - UK : Technical Report EBSE-2007-001, 2007.

Kitchenham B.A., Budgen D. and P. Brereton The value of mapping studies - A participant observer case study [Conference] // Proceedings of the 14th International Conference on Evaluation and Assessment in Software Engineering (EASE'10). - UK : [s.n.], 2010.

Kitchenham Barbara A., Budgen David and Brereton Pearl Using Mapping studies as the basis for further research - A participant - case study [Journal]// Information and Software Technology. - 2011. - 53. - pp. 638-651.

Klein Paul An Easy Guide to Factor Analysis [Libro]. - Newbury Park: Sage : Routledge, 1994. 
Laudon Kenneth C. and Laudon Jane P. Sistemas de Información Gerencial [Book] / ed. Cruz Castillo Luis Miguel / trans. Romero Elizondo Alfonso Vidal. - México : Pearson educación, 2012. - Decimosegunda : p. 640. - ISBN 978-607-32-0949-6.

Li Pei and Viscusi Gianluigi Quality Evaluation for Strategic Alignment Engineering: An eGovernment Application [Conference] // 5th International Workshop on Business/IT Alignment and Interoperability BUSITAL 2010 / ed. Petit Michaël , Gal Graham and Castiaux Annick . - Hammamet, Tunisia : Busital, 2010. - pp. 1-15. - http://ceur-ws.org/Vol599/BUSITAL2010_proceedings-one-document.pdf\#page=7. - ISSN 1613-0073.

Lima A.S. [et al.] A business-driven IT services improvement model [Conference] // 12th IFIP/IEEE International Symposium on Integrated Network Management (IM 2011) / ed. Agoulmine Nazim [et al.]. - Dublin : IEEE, 2011. - pp. 1095 - 1102. - ISBN 978-1-4244-9220-6.

Lima A.S. [et al.] Towards Value-based Information Security Management Monitoring [Conference] // 2013 IFIP/IEEE International Symposium on Integrated Network Management (IM 2013), / ed. De Turck Filip [et al.]. - Ghent, Belgium : [s.n.], 2013. - pp. 1260-1267. -

http://ieeexplore.ieee.org/stamp/stamp.jsp?tp=\&arnumber=6573175\&isnumber=657296 1. - ISBN: 978-3-901882-51-7.

Lind Douglas A., Marchal William G. and Mason Robert D. Estadística para Administración y Economía [Book] / trans. Hano Roa María del Carmen. - Bogotá : Alfaomega Grupo Editor S.A., 2004. - Onceava. - 958-682-513-2.

Lo Saide and Cusack Brian PROJECT GOVERNANCE: HOW PROCESSES CAN BE MANAGED WITH AN AIM TO IMPROVE PROJECT PERFORMANCE [Conference] // 19th Pacific Asia Conference on Information Systems (PACIS 2015). - Marina Bay Sands : [s.n.], 2015.

Lohrmann Matthias and Reichert Manfred Understanding Business Process Quality [Book Section] // Business Process Management / ed. Glykas Michael. - [s.I.] : Springer, 2013. Vol. 444. - ISBN 978-3-642-28408-3.

Louis P. J. Gestión de empresas de telecomunicaciones [Libro]. - Madrid : McGraw-Hill, 2003. ISBN: 84-481-3970-4.

Lovelock Christopher [et al.] Administración de servicios. Estrategias para la creación de valor en el nuevo paradigma de los negocios [Book]. - México D.F. : Pearson Educación, 2011. Segunda : p. 984. - ISBN: 978-607-32-0556-6.

Lucio Nieto Teresa de Jesús Marco para la definición y adecuación de una service management office en el contexto de los servicios de tecnologías de la información [Informe] $=$ [Tesis Doctoral inédita : [Tesis Doctoral inédita / ESCUELA POLITÉCNICA SUPERIOR ; Universidad Carlos III de Madrid. - Leganés : [s.n.], 2013.

Luna Reyes Luis Felipe, Gil García José Ramón and Sandoval Almazán Rodrigo Avances y Retos del Gobierno Digital en México [Book]. - Toluca de Lerdo : [s.n.], 2015. - Primera. - ISBN: 978-607-8087-27-3.

MARSH H. W. and O'NEILL, R. Self Description Questionnaire III: The Construct validity of multidimensional self-concept ratings by late adolescents [Publicación periódica] // Journal of Educational Measurement. - 1984.- 2: Vol. 21.- págs. 153-174.- DOI: 10.1111/j.1745-3984.1984.tb00227.x.

Martínez-Moreno A. [et al.] El modelo EFQM, análisis de los criterios resultados en un servicio deportivo municipal con más de 25.000 habitantes [Journal] // Cuadernos de Psicología del Deporte. - 2012. - 2 : Vol. 12. - pp. 71- 76.

Martínez-Vilanova y Martínez Ana María Modelo de Evaluación y Diagnósis de Excelencia en la Gestión, basado en el Cuadro de Mando Integral y el Modelo EFQM de Excelencia. Aplicación a las Cajas Rurales [Report]: Tesis doctoral / Organización de Empresas, Economía Financiera y Contabilidad; Universidad Politécnica de Valencia. - Valencia: [s.n.], 2008.

Merchán V. Value-Based Information Technology Governance Quality Assessment: Systematic Mapping Study [Conference] // Congreso chileno de ingeniería eléctrica, electrónica, 
tecnologías de la información y comunicaciones / ed. Lefranc Gaston , Pérez Ricardo and Fernández Mario. - Santiago de Chile : IEEE Chile, 2015, 2015. - pp. 583-589. - ISSN 07196806.

Merchán Vicente and Rodríguez Rocío Análisis de los modelos de Gobierno de Tecnologías de la Información y sus relaciones con el Modelo de Excelencia Iberoamericano [Conference] // XXI Congreso Argentino de Ciencias de la Computación-CACIC 2015. - Buenos Aires Argentina : [s.n.], 2015. - ISBN 978-987-3724-37-4.

Merchán Vicente and Rodriguez Rocío Towards Value-Based Information Technology Leadership Excellence [Conference] // IEEE 11CCC 2016/ ed. Collazos César. - Popayán: IEEE Colombia, 2016, 2016. - ISBN 978-1-5090-2965-5.

Merchán Vicente y Rodríguez Rocío Assessment of the Quality of Leadership in the Government of Technologies and Information Systems [Publicación periódica] // EnfoqueUTE. - QuitoEcuador: [s.n.], 2016. - 1 : Vol. 8. - ISSN 1390-6542.

Mishra Sushma and Dhillon Gaurpreet Defining Internal Control Objectives for Information Systems Security: A Value Focused Assessment [Conference] // ECIS 2008 Proceedings.. 2008. - Paper 210. http://aisel.aisnet.org/ecis2008/210.

Misuraca G., Alfano G. and Viscusi G. Interoperability challenges for ICT-enabled governance: towards a pan-European conceptual framework [Journal] // Journal of Theoretical and Applied Electronic Commerce Research. - Talca-Chile : [s.n.], 2011. - 1 : Vol. 6. - pp. 95 111. - www.jtaer.com. - ISSN 0718-1876.

Morales J. V. Modelos de Gobierno TI para Instituciones de Educación Superior [Publicación periódica] // Revista Politécnica. - 2015. - 3 : Vol. 36. - ISSN 1390-0129.

Morales Vallejo Pedro Análisis factorail en la construcción e interpretación de tests, escalas y cuestionarios [Informe] / Facultad de Ciencias Humanas y Sociales ; Universidad Pontificia Comillas. - Madrid-españa : [s.n.], 2013.

Mueller Lynn [et al.] IBM IT Governance Approach. Business Performance through IT Execution [Book]. - [s.I.] : IBM, 2008. - ISBN 073848590X.

Municio Pedro and Red Universitaria de Evaluación de la Calidad RUEC Evaluación de la Calidad de la Educación Superior. Un modelo de autoevaluación institucional. [Book]/ ed. Educación Wolters Kluwer. - Madrid-España: Red Universitaria de Evaluación de la Calidad, 1998. - 1 : p. 192. - ISBN: 84-605-8033-1.

Municio Pedro Evaluación de la Calidad de la Educación Superior. Un Modelo de Autoevaluación Institucional [Libro]. - Madrid : [s.n.], 1998.

Newbold Paul, Carlson William L. and Thorne Betty M. Estadística para administración y economía [Book] / ed. Cañizal Alberto / trans. Rabasco Espáriz Esther. - Madrid : PEARSON EDUCACIÓN, 2013. - 8va : p. 878. - ISBN: 97888415552208.

Nieto Carmen de Nieves and McDonnell Lorenzo Ros Comparación entre los Modelos de Gestión de la Calidad Total: EFQM, Gerencial de Deming, Iberoamericano para la Excelencia y Malccolm Baldrige. Situación frente a la ISO 9000 [Conference] // X Congreso de Ingeniería de Organizaciones. - Valencia : [s.n.], 2006.

Noruzi Alireza Google Scholar: The New Generation of Citation Indexes [Journal] // Libri/Copenhagen Journal. - Copenhage : [s.n.], 2005. - Vol. 55. - pp. 170-180. - 0024-2667.

OGC ITIL ${ }^{\circledR}$ Service Strategy [Book]. - London : TSO, 2011.

Olsina Luis Metodología Cuantitativa para la Evaluación y Comparación de la calidad de Sitios Web [Report] = Tesis doctoral inédita : Tesis doctoral inédita / Facultad de Ciencias Exactas ; Universidad Nacional de La Plata. - La Plata : [s.n.], 1999.

Pastor Tejedor Ana Clara [et al.] Comparación de los Modelos de Evaluación de la Excelencia Empresarial [Journal] // Book of Proceedings - Tourism and Management Studies International Conference Algarve. - Algarve - Portugal : ESGHT-University of the Algarve, 2012. - Vol. 4. - 978-989-8472-25-0.

Pereira Ruben and Mira da Silva Miguel A Literature Review IT Governance Guidelines and Main Areas [Conference] // ICEGOV 2012. - Albany : [s.n.], 2012. 
Pérez Jorge and Muñoz Giraldo Leandro What can't be ignored in service quality evaluation: Application contexts, tools and factors [Journal]// Revista Facultad de Ingeniería Universidad de Antioquia . - Medellín : [s.n.], 2014. - Vol. 72. - pp. 145-160. - Disponible en: http://www.redalyc.org/articulo.oa?id=43031750013. - ISSN: 0120-6230.

Pérez Juste Ramón [et al.] Hacia una educación de calidad. Gestión, Instrumentos y Evaluación [eBook]. - Madrid-España : Narcea ediciones, 2014. - 5ta. - ISBN: 9788427717008.

Petersen Kai [et al.] Systematic mapping studies in software engineering [Conference] // In 12th International Conference on Evaluation and Assessment in Software Engineering. - 2008. Vols. (Vol. 17, No. 1). - pp. 1 -10. - SN.

Pfleeger Shari Lawrence and Kitchenham Barbara A. Principles of Survey Research part 1: Turning lemons into Lemonade [Journal] // ACM SIGSOFT: Software Engineering Notes. - 2001. 6 : Vol. 26. - pp. 18-20.

Piattini Velthuis Mario Gerardo and Hervada Vidal Fernando Gobierno de las tecnologías y los sistemas de información [Book]. - Madrid : RA-MA, 2007. - RA-MA 2007.

Project Management Institute Guía de Fundamentos para la Dirección de Proyectos [Libro]. Newtown Square, Pennsylvania: Project Management Institute, Inc., 2013. - Quinta. 978-1-62825-009-1.

Real Academia Española Diccionario de la Real Academia Española [Online]. - 2012. - Febrero 23, 2015. - http://lema.rae.es/drae/?val=uso.

Robbins Stephen P. and Coulter Mary Administración [Book] / trans. De Antana Marisa. - México : Pearson educación, 2005. - Octava : p. 640. - ISBN 970-26-0555-5.

Rodríguez Maseda Manuel Fco. El Modelo FUNDIBEQ aplicado en la administración pública: La experiencia de REGTSA [En línea] // Fundación Iberoamericana de la Calidad. - 2015. www.fundibeq.org.

Ross J. and Weil P Six IT Decisions Your IT People Shouldn't Make. [Book]. - [s.I.] : Harvard Business review, 2002.

Rye David E. El juego empresarial [Book]. - Bogotá - Colombia : Kimpres Ltda., 2000.

Sánchez Juan José, Fernández Eugenio and Moratilla Antonio ITIL, COBIT and EFQM: Can They Work Together? [Journal]// International Journal of Combinatorial Optimization Problems and Informatics. - 2013. - 1 : Vol. 4. - pp. 54-64. - ISSN: 2007-1558.

Sánchez Peña Juan José La Evaluación de la Calidad en el ámbito del Gobierno y la Gestión de Servicios de TI [Informe] = [Tesis Doctoral inédita] : [Tesis Doctoral inédita] / Ciencias de la Computación ; Universidad de Alcalá. - Alcalá de Henares : [s.n.], 2013.

Secretaria Nacional de la Administración Pública www.administracionpublica.gob.ec [En línea] = Plan de Gobierno Eelctrónico 2014-2017. Versión 1.0 // www.administracionpublica.gob.ec. - 10 de mayo de 2014. - 1.0. - 10 de mayo de 2014. www.gobiernoelectronico.gob.ec/PlanGobiernoElectronicoV1.pdf.

Sheridan J. H. Managing the Value Chain [En línea] // www.industryweek.com/ ed. Week Industry. - 6 de septiembre de 1999. - www.industryweek.com.

Silva Patrício de Alencar and Weigand Hans Monitoring Value Webs [Book Section] // Advances in Enterprise Engineering VI / book auth. Albani Antonia, Aveiro David and Barjis Joseph. [s.I.] : Springer Berlin Heidelberg, 2012. - Vol. 110. http://link.springer.com/chapter/10.1007/978-3-642-29903-2_8. - ISBN 978-3-642-299025.

Stenzel Joe CIO Best Practices. Enabling Strategic Value with Information Technology [Libro] / ed. Inc John Wiley \& Sons. - North Carolina, USA : SAS Institute Inc., Cary, 2010. - 2. - ISBN 978-0-470-63540-7.

The Institute of Directors in Southern Africas King Code of Governance for South Africa 2009 (King III). [En línea]. - 2009. - 20 de febrero de 2014. african.ipapercms.dk/IOD/KINGIII/kingiiicode/.

Thorp Jhon The Information Paradox: Realizing the Business Benefits of Information Technology [Libro] / ed. Consulting Fujitsu. - [s.I.] : McGraw-Hill, 2007. - Revisión. - REVISION. 
Toomey Mark Waltzing with the Elephant: Una guía exhaustiva para la dirección y el control de la tecnología de la información = Tecnología de la información--Management. $/$ trad. Pardo Martínez Juan. - [s.I.] : Infonomics Pty Ltd., 2009. - Publicado originalmente: Australia: Infonomics, 2009 con el título: Waltzing with the elephant: a comprehensive guide to directing and controlling information technology.. - ISBN 9780980683028.

Torres Fragoso Jaime Posibilidades, logros y desafíos en la implementación de modelos de calidad en los gobiernos latinoamericanos [Publicación periódica] // Estudios Gerenciales. Oxaca : Universidad de Istmo, 2011. - 119 : Vol. 27. - págs. 33-57.

Tricker R. International Corporate Governance [Libro]. - 1994.

Van Grembergen Wim, De Haes Steven and Guldentops Erick Structures, Processes and Relational Mechanisms for IT Governance [Book Section] // Strategies for information Technology Governance / book auth. Van Grembergen Wim. - Hershey . London . Melbourne . Singapore : Idea Group Publishing, 2004.

Viscusi Gianluigi A Framework For Service Preliminary Planning In e-Government Initiatives. [Conference] // MCIS 2009 Proceedings. - 2009. - Paper 32. http://aisel.aisnet.org/mcis2009/32.

Webb P., Pollard C. and Ridley G. Attempting to Define IT Governance: Wisdom or Folly? [Conference] // Proceedings of the 39th Annual Hawaii International Conference on System Sciences. - Hawaii : IEEE Computer Society, 2006. - Vol. 8. - p. 194a. - 0-7695-25075.

Weill Peter and Ross Jeanne IT Governance: How Top Performers Manage IT Decision Rights for Superior Results [Book]. - Boston M.A. : Harvard Business Press, 2004. - 9781591392538.

Ziemba E., Papaj, T. \& Descours, D. Assessing the quality of e-government portals-the Polish experience [Conference]// 2014 Federated Conference on Computer Science and Information Systems. - Warsaw, Polonia: [s.n.], 2014. - pp. 1259-1267. http://ieeexplore.ieee.org/stamp/stamp.jsp?tp=\&arnumber=6933163\&isnumber=693298 2. - doi: 10.15439/2014F121. 



\section{ANEXO A. GUÍA PRÁCTICA ISO/IEC 38500 BASADA EN VALOR}

\begin{tabular}{|c|c|c|c|c|}
\hline Principios & Descripción & Evaluar ... & Dirigir... & Monitorizar... \\
\hline \multirow{3}{*}{ Responsabilidades } & \multirow{3}{*}{ 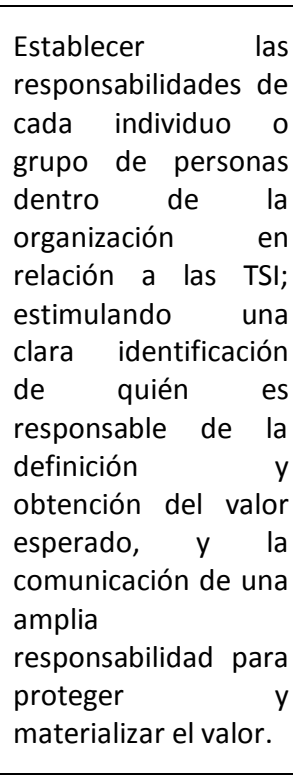 } & $\begin{array}{l}\text { 1.1. los modelos y } \\
\text { opciones de } \\
\text { comunicación para } \\
\text { asignar } \\
\text { responsabilidades } \\
\text { que permita } \\
\text { proteger y } \\
\text { materializar el valor. }\end{array}$ & $\begin{array}{l}\text { 1.3. para que se } \\
\text { lleven a cabo los } \\
\text { planes diseñados } \\
\text { para definir y } \\
\text { obtener el valor } \\
\text { esperado. }\end{array}$ & $\begin{array}{l}\text { 1.5. si están } \\
\text { establecidos los } \\
\text { mecanismos } \\
\text { (métodos y técnicas) } \\
\text { de Gobierno de las } \\
\text { TSI que le permitan } \\
\text { definir y obtener el } \\
\text { valor esperado. }\end{array}$ \\
\hline & & $\begin{array}{l}\text { 1.2. las capacidades } \\
\text { de aquellos que } \\
\text { reciben la } \\
\text { responsabilidad de } \\
\text { definir y obtener el } \\
\text { valor esperado. }\end{array}$ & $\begin{array}{l}\text { 1.4. para que los } \\
\text { directivos reciban la } \\
\text { información que } \\
\text { necesitan para } \\
\text { tomar decisiones } \\
\text { sobre la definición y } \\
\text { obtención del valor } \\
\text { esperado. }\end{array}$ & $\begin{array}{lr}\text { 1.6. sí se } & \text { sín } \\
\text { comprenden las } \\
\text { responsabilidades } \\
\text { asignadas para } \\
\text { proteger } \\
\text { materializar el valor. }\end{array}$ \\
\hline & & & & $\begin{array}{l}\text { 1.7. si rinden } \\
\text { adecuadamente las } \\
\text { responsabilidades } \\
\text { asignadas. }\end{array}$ \\
\hline \multirow{3}{*}{ 2. Estrategia } & \multirow{3}{*}{$\begin{array}{l}\text { Hay que tener en } \\
\text { cuenta el potencial } \\
\text { de las TI a la hora de } \\
\text { diseñar la estrategia } \\
\text { actual y futura de la } \\
\text { organización. } \\
\text { Principalmente } \\
\text { cuando se trata de } \\
\text { emprender } \\
\text { inversiones las } \\
\text { tengan que } \\
\text { alcanzable valor } \\
\text { apropiado. }\end{array}$} & $\begin{array}{l}\text { 2.1. los desarrollos } \\
\text { de TSI para } \\
\text { comprobar que } \\
\text { darán soporte al } \\
\text { negocio en un } \\
\text { futuro. }\end{array}$ & $\begin{array}{l}\text { 2.4. para que se } \\
\text { diseñen políticas y } \\
\text { planes que } \\
\text { aprovechen el valor } \\
\text { de las TSI. }\end{array}$ & $\begin{array}{l}\text { 2.6. si se alcanzan los } \\
\text { objetivos } \\
\text { estratégicos de valor } \\
\text { en el plazo y con los } \\
\text { recursos } \\
\text { planificados. }\end{array}$ \\
\hline & & $\begin{array}{l}\text { 2.2. si las actividades } \\
\text { de TSI están } \\
\text { alineadas con los } \\
\text { objetivos de negocio } \\
\text { principalmente } \\
\text { cuando se trata de } \\
\text { emprender las } \\
\text { inversiones que } \\
\text { tengan } \\
\text { alcanzable valor } \\
\text { apropiado. }\end{array}$ & $\begin{array}{l}\text { 2.5. para que se } \\
\text { innove en TSI con el } \\
\text { fin de obtener el } \\
\text { mejor provecho de } \\
\text { las inversiones. }\end{array}$ & $\begin{array}{l}\text { 2.7. los resultados } \\
\text { para comprobar que } \\
\text { se han alcanzado los } \\
\text { beneficios esperados } \\
\text { y apropiados de las } \\
\text { inversiones que } \\
\text { tienen valor. }\end{array}$ \\
\hline & & 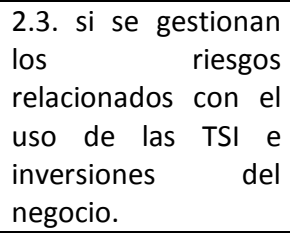 & & \\
\hline 3. Adquisición & $\begin{array}{l}\text { Las adquisiciones de } \\
\text { TSI deben realizarse } \\
\text { después de un } \\
\text { adecuado análisis y } \\
\text { tomando la decisión } \\
\text { en base a criterios } \\
\text { claros y } \\
\text { transparentes que }\end{array}$ & $\begin{array}{l}\text { 3.1. diferentes } \\
\text { opciones, ron } \\
\text { ofertas de TSI en } \\
\text { relación al costo y al } \\
\text { riesgo. }\end{array}$ & $\begin{array}{l}\text { 3.2. para que el } \\
\text { procedimiento de } \\
\text { compra sea el } \\
\text { adecuado. }\end{array}$ & $\begin{array}{l}\text { 3.4. que } \\
\text { inversiones } \\
\text { proporcionan } \\
\text { capacidades } \\
\text { esperadas. }\end{array}$ \\
\hline
\end{tabular}




\begin{tabular}{|c|c|c|c|c|c|}
\hline & & $\begin{array}{l}\text { demuestren la } \\
\text { posibilidad de lograr } \\
\text { el valor. Debe existir } \\
\text { un equilibrio } \\
\text { apropiador entre } \\
\text { beneficios, } \\
\text { oportunidades, costo } \\
\text { y riesgos, tanto a } \\
\text { corto como a largo } \\
\text { plazo. De manera } \\
\text { segura garantizando } \\
\text { la existencia de } \\
\text { métricas apropiadas, } \\
\text { para medir y } \\
\text { comprender, por } \\
\text { medio de las cuales } \\
\text { el valor pueda ser } \\
\text { medido y } \\
\text { comunicado. }\end{array}$ & & 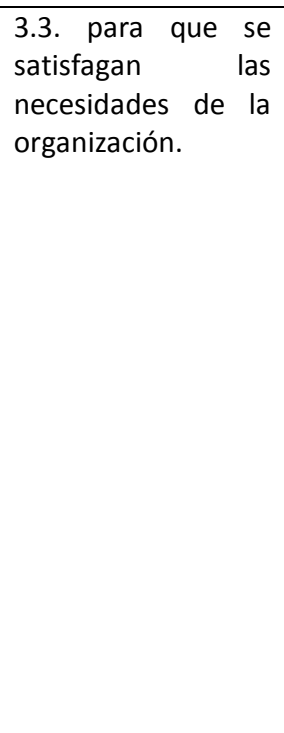 & $\begin{array}{l}\text { 3.5. hasta qué grado } \\
\text { se comparte los } \\
\text { objetivos de la } \\
\text { adquisición con el } \\
\text { proveedor. }\end{array}$ \\
\hline \multirow{3}{*}{\multicolumn{2}{|c|}{ 4. Rendimiento }} & \multirow{3}{*}{$\begin{array}{l}\text { Las TSI deben dar } \\
\text { soporte a la } \\
\text { organización, } \\
\text { ofreciendo servicios } \\
\text { con el nivel de } \\
\text { calidad requerido por } \\
\text { la organización. Es } \\
\text { decir, debería } \\
\text { resultar en medidas } \\
\text { exactas y oportunas } \\
\text { del valor y disparar } \\
\text { acciones correctivas } \\
\text { cuando el valor real } \\
\text { no esté en el nivel } \\
\text { requerido. }\end{array}$} & $\begin{array}{l}\text { 4.1. las propuestas } \\
\text { operativas y } \\
\text { oportunas de valor } \\
\text { de los gestores de } \\
\text { TSI para mantener la } \\
\text { capacidad del } \\
\text { negocio. }\end{array}$ & $\begin{array}{lr}\text { 4.4. para que } & \text { se } \\
\text { disponga } & \text { de } \\
\text { suficientes recursos } \\
\text { TSI. }\end{array}$ & $\begin{array}{l}\text { 4.6. la medida exacta } \\
\text { y oportuna del valor } \\
\text { en que las TSI dan } \\
\text { soporte al negocio. }\end{array}$ \\
\hline & & & $\begin{array}{l}\text { 4.2. la eficacia de las } \\
\text { decisiones de TSI } \\
\text { para el negocio. }\end{array}$ & $\begin{array}{lrr}\begin{array}{l}\text { 4.5. para que } \\
\text { proporcione a }\end{array} & \text { la } \\
\text { dirección } & & \text { la } \\
\text { información } & \\
\begin{array}{l}\text { correcta } \\
\text { actualizada }\end{array} & \text { y } \\
\begin{array}{l}\text { soporte a } \\
\text { decisiones. }\end{array} & \\
\end{array}$ & $\begin{array}{lr}4.7 . \quad \text { que } & \text { la } \\
\text { asignación } & \text { de } \\
\text { recursos se prioriza } \\
\text { en relación a los } \\
\text { objetivos } \\
\text { estratégicos } & \\
\text { negocio. del }\end{array}$ \\
\hline & & & $\begin{array}{l}\text { 4.3. el rendimiento } \\
\text { eficiente del sistema } \\
\text { de gobierno de las } \\
\text { TSI. }\end{array}$ & & $\begin{array}{l}\text { 4.8. que se cumplan } \\
\text { las políticas y } \\
\text { normas establecidas. }\end{array}$ \\
\hline \multirow{3}{*}{\multicolumn{2}{|c|}{ 5. Cumplimiento }} & \multirow{3}{*}{$\begin{array}{l}\text { Las TSI deben } \\
\text { cumplir con todas las } \\
\text { leyes y normativas, y } \\
\text { las políticas y los } \\
\text { procedimientos } \\
\text { internos deben estar } \\
\text { claramente } \\
\text { definidos, } \\
\text { implementados y } \\
\text { apoyados para } \\
\text { informar el valor } \\
\text { obtenido. }\end{array}$} & $\begin{array}{l}\text { 5.1. en qué medida } \\
\text { se cumple la } \\
\text { legislación y las } \\
\text { normas internas } \\
\text { establecidas. }\end{array}$ & $\begin{array}{lr}\text { 5.3. para que se } \\
\text { establezcan } \\
\text { mecanismos para } \\
\text { comprobar el } \\
\text { cumplimiento de } \\
\text { leyes, normas y } \\
\text { estándares } \\
\text { implementados } \\
\text { para informar el } \\
\text { valor obtenido. }\end{array}$ & $\begin{array}{lr}\text { 5.7. la realización de } \\
\text { auditorías } & \text { y } \\
\text { redacción } & \text { de } \\
\text { informes } & \text { del } \\
\text { rendimiento } & \text { y } \\
\text { cumplimiento } & \text { del } \\
\text { valor obtenido. } & \end{array}$ \\
\hline & & & $\begin{array}{l}\text { 5.2. el cumplimiento } \\
\text { interno de los } \\
\text { procedimientos } \\
\text { propios del gobierno } \\
\text { de las } \\
\text { establecido en la } \\
\text { organización. }\end{array}$ & $\begin{array}{l}\text { 5.4. para que se } \\
\text { establezcan } \\
\text { políticas que } \\
\text { apoyen el uso y la } \\
\text { integración de las } \\
\text { TSI. }\end{array}$ & $\begin{array}{ll}\begin{array}{l}\text { 5.8. que las } \\
\text { preservan }\end{array} & \\
\text { privacidad y } \\
\text { conocimiento } \\
\text { estratégico. }\end{array}$ \\
\hline & & & & 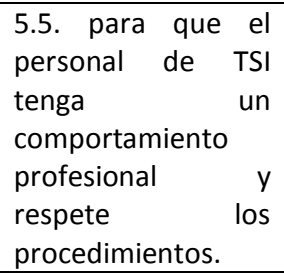 & \\
\hline
\end{tabular}




\begin{tabular}{|c|c|c|c|c|c|}
\hline & & & & $\begin{array}{l}\text { 5.6. para que se } \\
\text { realice un uso ético } \\
\text { de las TSI. }\end{array}$ & \\
\hline \multirow{2}{*}{\multicolumn{2}{|c|}{$\begin{array}{l}\text { 6. Comportamiento } \\
\text { de Personas }\end{array}$}} & \multirow{2}{*}{$\begin{array}{l}\text { Las políticas y } \\
\text { procedimientos } \\
\text { establecidos deben } \\
\text { incluir el máximo } \\
\text { respeto hacia el } \\
\text { componente } \\
\text { humano, } \\
\text { incorporando todas } \\
\text { las necesidades } \\
\text { propias de las } \\
\text { personas (incentivos } \\
\text { y recompensas) que } \\
\text { forman parte de los } \\
\text { procesos de TSI, con } \\
\text { el fin de maximizar la } \\
\text { apropiada } \\
\text { consecución del del } \\
\text { valor. }\end{array}$} & $\begin{array}{l}\text { 6.1. que el } \\
\text { componente } \\
\text { humano está } \\
\text { identificado y se } \\
\text { toma en cuenta en } \\
\text { todas las actividades } \\
\text { de TSI. }\end{array}$ & $\begin{array}{l}\text { 6.2. para que las } \\
\text { actividades de TSI } \\
\text { sean consistentes } \\
\text { con el componente } \\
\text { humano. }\end{array}$ & $\begin{array}{l}\text { 6.4. si se percibe } \\
\text { como importante el } \\
\text { componente } \\
\text { humano. }\end{array}$ \\
\hline & & & & $\begin{array}{lr}\text { 6.3. para que sean } \\
\text { identificados } \\
\text { reportados por } \\
\text { cualquiera } \\
\text { riesgos los } \\
\text { oportunidades para } \\
\text { que sean estimados } \\
\text { por los directivos. }\end{array}$ & $\begin{array}{l}\text { 6.5. si se aplican las } \\
\text { prácticas adecuadas } \\
\text { de componente } \\
\text { humano para } \\
\text { hacerlo consistente } \\
\text { con el uso de las TSI } \\
\text { en pos de maximizar } \\
\text { la consecución del } \\
\text { valor. }\end{array}$ \\
\hline
\end{tabular}





\section{ANEXO B. ESTUDIOS SELECCIONADOS}

Id.

[Ref01] Gummerus Johanna Customer Value in E-Service: Conceptual Foundation and Empirical Evidence [Report] $=$ [Tesis Doctoral inédita] / Marketing; Hanken School of Economics. - Helsinki-Finlandia: Dhanken, 2011. - http://urn.fi/URN:ISBN:978-952232-116-9. - ISSN 0424-7256.

[Ref02] Ibrahim H. Osman Abdel Latef Anouze, Zahir Irani, Habin Lee, Asım Balcı, Tunç D. Medeni \& Vishanth Weerakkody A new COBRAS framework to evaluate e-government services: A citizen centric perspective [Conference] // tGov Workshop'11 (1GOV11). London, UK: $\quad$ Brunel University, 2011. https://www.researchgate.net/publication/228845385

[Ref03] W. Jin-fu and H. Duo, "Customer-centered e-government service quality evaluation: Framework and case study," 2009 ISECS International Colloquium on Computing, Communication, Control, and Management, Sanya, 2009, pp. 198-202. doi: 10.1109/CCCM.2009.5267880

[Ref04] Li Pei and Viscusi Gianluigi Quality Evaluation for Strategic Alignment Engineering: An eGovernment Application [Conference] // 5th International Workshop on Business/IT Alignment and Interoperability BUSITAL 2010 / ed. Petit Michaël , Gal Graham and Castiaux Annick . - Hammamet, Tunisia : Busital, 2010. - pp. 1-15. - http://ceurws.org/Vol-599/BUSITAL2010_proceedings-one-document.pdf\#page=7. - ISSN 16130073.

[Ref05] A. S. Lima, J. N. de Souza, A. C. Callado, J. A. Oliveira, J. Sauvé and A. Moura, "A business-driven IT services improvement model," 12th IFIP/IEEE International Symposium on Integrated Network Management (IM 2011) and Workshops, Dublin, 2011, pp. 1095-1102. doi: 10.1109/INM.2011.5990519

[Ref06] A. S. Lima, J. N. de Souza, E. C. Branco and M. Ribas, "Towards value-based information security management monitoring," 2013 IFIP/IEEE International Symposium on Integrated Network Management (IM 2013), Ghent, 2013, pp. 12601267.

http://ieeexplore.ieee.org/stamp/stamp.jsp?tp=\&arnumber=6573175\&isnumber=657 2961

[Ref07] Lohrmann Matthias and Reichert Manfred Understanding Business Process Quality [Book Section] // Business Process Management / ed. Glykas Michael. - [s.I.]: Springer, $2013 . \quad$ - $\quad$ Vol. $444 . \quad$ - $\quad$ ISBN 978-3-642-28408-3. http://rd.springer.com/chapter/10.1007/978-3-642-28409-0_2.

[Ref08] Mishra, Sushma and Dhillon, Gaurpreet, "Defining Internal Control Objectives for Information Systems Security: A Value Focused Assessment" (2008). ECIS 2008 Proceedings. Paper 210.

[Ref09] Misuraca G., Alfano G. and Viscusi G. Interoperability challenges for ICT-enabled governance: towards a pan-European conceptual framework [Journal] // Journal of Theoretical and Applied Electronic Commerce Research. - Talca-Chile: [s.n.], 2011. - 1: Vol. 6. - pp. 95 - 111. - www.jtaer.com. - ISSN 0718-1876.

[Ref10] Muñoz Giraldo, Leandro, Pérez Rave, Jorge, What can't be ignored in service quality evaluation: Application contexts, tools and factors Revista Facultad de Ingeniería Universidad de Antioquia [en línea] 2014, (Septiembre-): Disponible en:<http://www.redalyc.org/articulo.oa?id=43031750013> ISSN 0120-6230

[Ref11] Shih-Wei Chou, Chun-Hsiung Chiang, Understanding the formation of software-as-a- 
service (SaaS) satisfaction from the perspective of service quality, Decision Support Systems, Volume 56, December 2013, Pages 148-155, ISSN 0167-9236, http://dx.doi.org/10.1016/j.dss.2013.05.013.

(//www.sciencedirect.com/science/article/pii/S0167923613001619)

[Ref12] Silva Patrício de Alencar and Weigand Hans Monitoring Value Webs [Book Section] // Advances in Enterprise Engineering VI / book auth. Albani Antonia, Aveiro David and Barjis Joseph. - [s.l.]: Springer Berlin Heidelberg, 2012. - Vol. 110. http://link.springer.com/chapter/10.1007/978-3-642-29903-2_8. - ISBN 978-3-64229902-5.

[Ref13] Viscusi, Gianluigi, "A Framework For Service Preliminary Planning In e-Government Initiatives" (2009).MCIS 2009 Proceedings. Paper 32. http://aisel.aisnet.org/mcis2009/32

[Ref14] E. Ziemba, T. Papaj and D. Descours, "Assessing the quality of e-government portals the Polish experience", 2014 Federated Conference on Computer Science and Information Systems, Warsaw, 2014, pp. 1259-1267. doi: 10.15439/2014F121 


\section{ANEXO C. MAPEO DE ESTUDIOS}

\begin{tabular}{|c|c|c|c|c|c|c|c|c|c|c|c|c|c|c|}
\hline \multirow{2}{*}{ Id. } & \multicolumn{3}{|c|}{ SP 1.1 } & \multicolumn{3}{|c|}{ SP 1.2} & \multicolumn{3}{|c|}{ SP 2.1} & \multicolumn{5}{|c|}{ SP 3.1} \\
\hline & $a$ & b & C & a & b & C & $a$ & b & C & $a$ & b & C & d & e \\
\hline [Ref01] & & & $x$ & & & $x$ & & & $x$ & & & $x$ & & \\
\hline [Ref02] & $x$ & & & & $x$ & & $x$ & & & $x$ & & & & \\
\hline [Ref03] & $x$ & & & & $x$ & & $x$ & & & & & $x$ & & \\
\hline [Ref04] & $x$ & & & & $x$ & & $x$ & & & $x$ & & & & \\
\hline [Ref05] & & & $x$ & & $x$ & & $x$ & & & & & $x$ & & \\
\hline [Ref06] & & & $x$ & $x$ & & & $x$ & & & & & & & $x$ \\
\hline [Ref07] & & & $x$ & $x$ & & & $x$ & & & & & & & $x$ \\
\hline [Ref08] & & & $x$ & & $x$ & & $x$ & & & & $x$ & & & \\
\hline [Ref09] & $x$ & & & & $x$ & & $x$ & & & & & & $x$ & \\
\hline [Ref10] & & & $x$ & & & & & $x$ & & $X$ & & & & \\
\hline [Ref11] & & & $x$ & & $x$ & & $x$ & & & $X$ & & & & \\
\hline [Ref12] & & $x$ & & $x$ & & & $x$ & & & & & $x$ & & \\
\hline [Ref13] & & & $x$ & $x$ & & & $x$ & & & & & $x$ & & \\
\hline [Ref14] & $x$ & & & & & & $x$ & & & & & $x$ & & \\
\hline
\end{tabular}

$\begin{array}{lll}\text { SP1.1:Ámbito } & \text { Público } & \text { Privado } \\ \text { SP1.2:Tipo Valor } & \text { Objetivo } & \text { (b) Subjetivo } \\ \text { SP2.1:Contribución } & \text { (a) Modelo } & \text { (b) Método } \\ \text { SP3.1:Tipo Estudio } & \text { (a) Cuestionario } & \text { (b) Entrevista }\end{array}$

Público-Privado

(c) Objetivo-Subjetivo

(c) Ontología

(c) Estudio de

(d) Investigaciónacción

(e) Reporte de caso Experiencias 



\section{ANEXO D. ENTIDADES COLABORADORAS}

A continuación se enlista las entidades que han colaborado en este estudio mediante la participación de sus líderes de TSI.

Agencia Nacional de Regulación Control y Vigilancia Sanitaria

Agencia de Regulación y Control de las Telecomunicaciones ARCOTEL

Banco del Ecuador BANECUADOR

Contraloría General del Estado CGE

Consejo de Educación Superior CES

Consejo de Regulación y Desarrollo de la Información y Comunicación CORDICOM

Coordinación Zonal 9 de Salud

Corporación Financiera Nacional CFN

Corte Nacional de Justicia CNJ

Dirección Nacional de Educación de la Policía Nacional

Dirección Nacional de Migración

Ejército Ecuatoriano

Empresa Coordinadora de Empresas Públicas

Empresa Nacional Minera Mariscal Sucre

Escuela Politécnica Nacional EPN

Fiscalía de Pichincha

Fuerza Aérea Ecuatoriana FAE

Instituto de Fomento al Talento Humano IFTH

Instituto Ecuatoriano de la Propiedad Intelectual IEPI

Ministerio Coordinador de Desarrollo Social

Ministerio de Agronomía, Ganadería y Pesca MAGAP

Ministerio de Educación

Ministerio de Finanzas

Ministerio de Inclusión Económica y Social MIES

Ministerio de Justicia

Ministerio de Patrimonio

Ministerio de Relaciones Exteriores

Ministerio de Telecomunicaciones MINTEL

Ministerio de Trabajo

Ministerio de Transporte y Obras Públicas

Ministerio de Vivienda

Ministerio del Interior

Presidencia de la República del Ecuador

Secretaria Técnica de Drogas

Televisión y Radio del Ecuador EP

Unión Cementera Nacional

Universidad Central del Ecuador UCE

Universidad de las Fuerzas Armadas ESPE

Universidad Tecnológica Equinoccial UTE 



\section{ANEXO E. CUESTIONARIO}

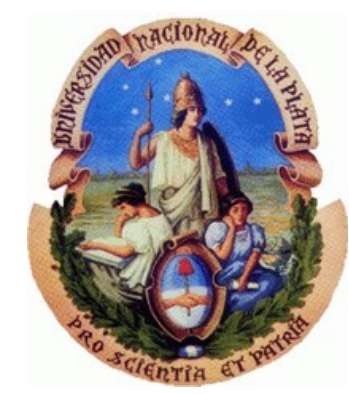

Universidad Nacional de La Plata - Grupo de Investigación

Encuesta sobre Calidad de Gobierno de las Tecnologías y los Sistemas de Información Basada en Valor desde la perspectiva Gerencial

Estimado Colaborador,

La siguiente encuesta forma parte de una iniciativa de investigación que pretende responder a la necesidad en las organizaciones de autoevaluarse ante los cambios en la manera de gobernar las Tecnologías y los Sistemas de Información (TSI) que se están operando en otros países, por lo cual, se propone aplicar criterios de excelencia a los procesos de evaluación de los Gobiernos de Tecnologías y los Sistemas de Información (GoTSI), en el marco de un modelo que presenta una nueva visión de las organizaciones que usan la tecnología para atender sus necesidades; procurando optimizar el valor a través de la toma de decisiones.

La iniciativa se ha inspirado en la experiencia científica de expertos y profesionales que han estudiado y desarrollado modelos de calidad y estándares de gobernanza desde la perspectiva de calidad gerencial basada en valor.

Con lo que antecede, el objetivo de esta encuesta es conocer el nivel de importancia que ud. le brinda, como estratega organizacional, a los distintos criterios de excelencia que se utilizan para evaluar el GoTSI que atiende las necesidades dentro de una organización en general y que ud. los puede utilizar para mejorar. Por lo tanto, es importante que cuando conteste lo haga en base a su experticia directiva relacionada con el uso de las TSI.

Atentamente,

Vicente Merchán Rodríguez

DATOS DEMOGRÁFICOS (Indique con una $\mathrm{X}$ en las opciones de respuesta de las siguientes preguntas que mejor se ajustan a su organización o persona)

1. ¿A qué SECTOR PRINCIPAL pertenece su organización o actividad profesional?
a. EDUCACIÓN
b. COMERCIO
c. SERVICIOS
d. TELECOMUNICACIONES
e. SALUD
f. FINANCIERO 

g. TURISMO
h. OTROS

2. ¿Indique su GÉNERO?
a. MASCULINO
b. FEMENINO

3. ¿̇Indique su ESCOLARIDAD DE MÁS ALTO NIVEL?
a. BACHILLER
b. LICENCIATURA
c. INGENIERIA
d. ESPECIALIDAD
e. DIPLOMADO
f. MAESTRÍA
g. DOCTORADO
h. OTROS

4. ¿Indique su rango de edad?
a. Menor de 25 años
b. De 25 a 35 años
c. De 36 a 45 años
d. De 46 a 55 años
e. Mayor de 55 años

DATOS SOBRE CRITERIOS DE EXCELENCIA (Responda en una escala de 1 a 5, considerando que 1 indica COMPLETA INSIGNIFICANCIA y 5 COMPLETA IMPORTANCIA, en las opciones de respuesta de las siguientes preguntas que mejor exprese su nivel de importancia a los criterios de excelencia para evaluar un GoTSI)

CRITERIO: LIDERAZGO y ESTILO DE GOBIERNO (Analiza cómo se desarrollan y se ponen en práctica la cultura necesaria para el éxito sostenido, mediante adecuados comportamientos y acciones de los líderes que gobiernan el valor de las TSI. Estudia cómo se desarrolla y se pone en práctica el marco de los procesos, necesarios para la eficaz ejecución de la política y la estrategia).

SUBCRITERIO: Cultura de Excelencia Basada en Valor

5. El Líder, debe implicarse activa y visiblemente en la definición de valor para la organización.

\begin{tabular}{|c|c|c|c|c|}
\hline $\begin{array}{c}\text { COMPLETA } \\
\text { INSIGNIFICANCIA } \\
1\end{array}$ & $\begin{array}{c}\text { MODERADA } \\
\text { INSIGNIFICANCIA } \\
2\end{array}$ & $\begin{array}{c}\text { INDIFERENCIA } \\
3\end{array}$ & $\begin{array}{c}\text { MODERADA } \\
\text { IMPORTANCIA } \\
4\end{array}$ & $\begin{array}{l}\text { COMPLETA } \\
\text { IMPORTANCIA } \\
5\end{array}$ \\
\hline & & & & \\
\hline
\end{tabular}

6. El Líder, debe implicarse activa y visiblemente en la definición y desarrollo de los objetivos estratégicos fundamentales del servicio generador de valor.

\begin{tabular}{|c|c|c|c|c|}
\hline COMPLETA & MODERADA & INDIFERENCIA & MODERADA & COMPLETA \\
INSIGNIFICANCIA & INSIGNIFICANCIA & & $\mathbf{2}$ & $\mathbf{4}$ \\
$\mathbf{1}$ & $\mathbf{2}$ & $\mathbf{3}$ & & $\mathbf{5}$ \\
\hline & & & & \\
\hline
\end{tabular}

7. El Líder, debe actuar como modelo de referencia para el cumplimiento de los objetivos estratégicos fundamentales del servicio generador de valor.

\begin{tabular}{|c|c|c|c|c|}
\hline COMPLETA & MODERADA & INDIFERENCIA & MODERADA & $\begin{array}{c}\text { COMPLETA } \\
\text { INSIGNIFICANCIA } \\
\text { INSIGNIFICANCIA }\end{array}$ \\
\hline & $\mathbf{2}$ & $\mathbf{3}$ & $\mathbf{4}$ & $\mathbf{5}$ \\
\hline & & & & \\
\hline
\end{tabular}


8. El Líder, debe implicarse activa y visiblemente en la promoción que estimule y aliente la innovación y creatividad basada en el valor que debe entregar las Tecnologías y los Sistemas de Información.

\begin{tabular}{|c|c|c|c|c|}
\hline COMPLETA & MODERADA & INDIFERENCIA & $\begin{array}{c}\text { MODERADA } \\
\text { INSIGNIFICANCIA }\end{array}$ & $\begin{array}{c}\text { COMPLETA } \\
\text { INSIGNIFICANCIA }\end{array}$ \\
$\mathbf{1}$ & $\mathbf{2}$ & $\mathbf{3}$ & $\mathbf{4}$ & $\mathbf{5}$ \\
\hline & & & & \\
\hline
\end{tabular}

9. La Política del GoTSI debe documentarse y comunicarse incorporando criterios de calidad de gobierno, garantizando una información actualizada y transparente.

\begin{tabular}{|c|c|c|c|c|}
\hline COMPLETA & MODERADA & INDIFERENCIA & MODERADA & $\begin{array}{c}\text { COMPLETA } \\
\text { INSIGNIFICANCIA } \\
\text { INSIGNIFICANCIA }\end{array}$ \\
\hline & $\mathbf{2}$ & $\mathbf{3}$ & $\mathbf{4}$ & $\mathbf{5}$ \\
\hline & & & & \\
\hline
\end{tabular}

SUBCRITERIO: Arquitectura Empresarial-TSI basada en valor

10. Debe definirse el gobierno de valor de las TSI a cargo de los ejecutivos senior.

\begin{tabular}{|c|c|c|c|c|}
\hline $\begin{array}{c}\text { COMPLETA } \\
\text { INSIGNIFICANCIA } \\
\mathbf{1}\end{array}$ & $\begin{array}{c}\text { MODERADA } \\
\text { INSIGNIFICANCIA }\end{array}$ & INDIFERENCIA & $\begin{array}{c}\text { MODERADA } \\
\text { IMPORTANCIA }\end{array}$ & $\begin{array}{c}\text { COMPLETA } \\
\text { IMPORTANCIA }\end{array}$ \\
\hline & $\mathbf{2}$ & $\mathbf{3}$ & $\mathbf{4}$ & $\mathbf{5}$ \\
\hline
\end{tabular}

11. Debe establecerse comisiones, comités y estructuras de soporte apropiadas capaz de mantener una estructura óptima de coordinación, comunicación y enlace entre la función de TSI y las otras partes interesadas del negocio.

\begin{tabular}{|c|c|c|c|c|}
\hline $\begin{array}{c}\text { COMPLETA } \\
\text { INSIGNIFICANCIA }\end{array}$ & $\begin{array}{c}\text { MODERADA } \\
\text { INSIGNIFICANCIA }\end{array}$ & INDIFERENCIA & $\begin{array}{c}\text { MODERADA } \\
\text { IMPORTANCIA }\end{array}$ & $\begin{array}{c}\text { COMPLETA } \\
\text { IMPORTANCIA }\end{array}$ \\
\hline $\mathbf{1}$ & $\mathbf{2}$ & $\mathbf{3}$ & $\mathbf{4}$ & $\mathbf{5}$ \\
\hline & & & & \\
\hline
\end{tabular}

12. El Líder, en el momento oportuno debe evaluar los beneficios que se entregan al negocio.

\begin{tabular}{|c|c|c|c|c|}
\hline $\begin{array}{c}\text { COMPLETA } \\
\text { INSIGNIFICANCIA } \\
1\end{array}$ & $\begin{array}{c}\text { MODERADA } \\
\text { INSIGNIFICANCIA } \\
\mathbf{2}\end{array}$ & $\begin{array}{c}\text { INDIFERENCIA } \\
3\end{array}$ & $\begin{array}{c}\text { MODERADA } \\
\text { IMPORTANCIA } \\
4\end{array}$ & $\begin{array}{l}\text { COMPLETA } \\
\text { IMPORTANCIA } \\
5\end{array}$ \\
\hline & & & & \\
\hline
\end{tabular}

13. El Líder, en el momento oportuno debe delegar responsabilidad y velar por el buen cumplimiento de la misma.

\begin{tabular}{|c|c|c|c|c|}
\hline COMPLETA & MODERADA & INDIFERENCIA & MODERADA & COMPLETA \\
INSIGNIFICANCIA & INSIGNIFICANCIA & & $\mathbf{2}$ & $\mathbf{4}$ \\
$\mathbf{1}$ & $\mathbf{2}$ & $\mathbf{3}$ & & $\mathbf{5}$ \\
\hline & & & & \\
\hline
\end{tabular}

14. El Líder, en el momento oportuno debe tomar decisiones importantes que le competen para mejorar el gobierno y por ende la gestión del servicio que genere valor en el negocio.

\begin{tabular}{|c|c|c|c|c|}
\hline COMPLETA & MODERADA & INDIFERENCIA & MODERADA & COMPLETA \\
INSIGNIFICANCIA & INSIGNIFICANCIA & & $\mathbf{2}$ & $\mathbf{4}$ \\
$\mathbf{1}$ & $\mathbf{2}$ & $\mathbf{3}$ & & $\mathbf{5}$ \\
\hline & & & & \\
\hline
\end{tabular}

15. Los líderes, deben asegurarse que se desarrolle e implante un sistema de gobierno, gestión, evaluación y mejora de los procesos generadores de valor de servicio para el negocio.

\begin{tabular}{|c|c|c|c|c|}
\hline COMPLETA & MODERADA & INDIFERENCIA & MODERADA & COMPLETA \\
INSIGNIFICANCIA & INSIGNIFICANCIA & & IMPORTANCIA & IMPORTANCIA \\
1 & 2 & 3 & 4 & 5 \\
\hline & & & & \\
\hline
\end{tabular}


CRITERIO: ESTRATEGIA (Analiza cómo las TSI apoyan en el desarrollo de la planificación organizacional a la hora de diseñar la estrategia actual y futura de la organización. Principalmente cuando se trata de emprender las inversiones que tengan valor alcanzable y apropiado para el negocio).

SUBCRITERIO: Dirección de Estrategias

16. Debe existir aseguramiento en la comprensión de los líderes del negocio con la que se deben alinear las inversiones de negocio habilitadas por las TSI.

\begin{tabular}{|c|c|c|c|c|}
\hline $\begin{array}{c}\text { COMPLETA } \\
\text { INSIGNIFICANCIA } \\
\mathbf{1}\end{array}$ & $\begin{array}{c}\text { MODERADA } \\
\text { INSIGNIFICANCIA }\end{array}$ & INDIFERENCIA & $\begin{array}{c}\text { MODERADA } \\
\text { IMPORTANCIA }\end{array}$ & $\begin{array}{c}\text { COMPLETA } \\
\text { IMPORTANCIA }\end{array}$ \\
\hline & $\mathbf{2}$ & $\mathbf{3}$ & $\mathbf{4}$ & $\mathbf{5}$ \\
\hline
\end{tabular}

17. Debe existir una política asociada con el "requerimiento de negocio" de la organización y la función de TSI relativa al impacto potencial de las tecnologías en la estrategia de negocio y el rol de la función de TSI en la organización.

\begin{tabular}{|c|c|c|c|c|}
\hline COMPLETA & MODERADA & INDIFERENCIA & MODERADA & $\begin{array}{c}\text { COMPLETA } \\
\text { INSIGNIFICANCIA } \\
\text { INSIGNIFICANCIA }\end{array}$ \\
\hline & $\mathbf{2}$ & $\mathbf{3}$ & $\mathbf{4}$ & $\mathbf{5}$ \\
\hline & & & & \\
\hline
\end{tabular}

18. Debe existir una política que tome en cuenta "principios, visión, objetivos estratégicos y prioridades" para los servicios definidos en un plan de negocio.

\begin{tabular}{|c|c|c|c|c|}
\hline $\begin{array}{c}\text { COMPLETA } \\
\text { INSIGNIFICANCIA } \\
1\end{array}$ & $\begin{array}{c}\text { MODERADA } \\
\text { INSIGNIFICANCIA } \\
2\end{array}$ & INDIFERENCIA & $\begin{array}{c}\text { MODERADA } \\
\text { IMPORTANCIA } \\
4\end{array}$ & $\begin{array}{l}\text { COMPLETA } \\
\text { IMPORTANCIA } \\
5\end{array}$ \\
\hline & & & & \\
\hline
\end{tabular}

SUBCRITERIO: Evaluación de estrategias en base a información obtenida por mediciones de los resultados y actividades relacionadas con la innovación y creatividad

19. Deben definirse criterios de evaluación de estrategias de inversión en base a información que demuestre el alineamiento con objetivos estratégicos de la organización; beneficios financieros y no financieros y; el riesgo.

\begin{tabular}{|c|c|c|c|c|}
\hline COMPLETA & MODERADA & INDIFERENCIA & MODERADA & COMPLETA \\
INSIGNIFICANCIA & INSIGNIFICANCIA & & $\mathbf{2}$ & $\mathbf{4}$ \\
$\mathbf{1}$ & $\mathbf{2}$ & $\mathbf{3}$ & & $\mathbf{5}$ \\
\hline & & & & \\
\hline
\end{tabular}

20. Deben existir medidas de rendimiento y comportamiento estratégico para uso del gobierno en el contexto de valor.

\begin{tabular}{|c|c|c|c|c|}
\hline $\begin{array}{c}\text { COMPLETA } \\
\text { INSIGNIFICANCIA } \\
1\end{array}$ & $\begin{array}{c}\text { MODERADA } \\
\text { INSIGNIFICANCIA } \\
\mathbf{2}\end{array}$ & $\begin{array}{c}\text { INDIFERENCIA } \\
3\end{array}$ & $\begin{array}{c}\text { MODERADA } \\
\text { IMPORTANCIA } \\
4\end{array}$ & $\begin{array}{l}\text { COMPLETA } \\
\text { IMPORTANCIA } \\
5\end{array}$ \\
\hline & & & & \\
\hline
\end{tabular}

21. Debe existir un proceso para la asignación de responsabilidades y delegación de competencias relacionadas con el establecimiento de indicadores de desempeño/rendimiento de la organización.

\begin{tabular}{|c|c|c|c|c|}
\hline COMPLETA & MODERADA & INDIFERENCIA & MODERADA & $\begin{array}{c}\text { COMPLETA } \\
\text { INSIGNIFICANCIA } \\
\text { INSIGNIFICANCIA }\end{array}$ \\
\hline & $\mathbf{2}$ & $\mathbf{3}$ & $\mathbf{4}$ & $\mathbf{5}$ \\
\hline & & & & \\
\hline
\end{tabular}

CRITERIO: PERSONAS (Analiza cómo la organización gobierna el pleno potencial de las personas, de forma individual o en equipo, con el fin de contribuir a su eficaz y eficiente gobierno de valor, así como para motivarlas e incrementar su compromiso con la organización). 
SUBCRITERIO. Roles y Responsabilidades para Materializar y Proteger el Valor

22. Debe existir el nivel de conciencia de los beneficios de las TSI entre los tomadores de decisión de la organización.

\begin{tabular}{|c|c|c|c|c|}
\hline $\begin{array}{c}\text { COMPLETA } \\
\text { INSIGNIFICANCIA } \\
\mathbf{1}\end{array}$ & $\begin{array}{c}\text { MODERADA } \\
\text { INSIGNIFICANCIA }\end{array}$ & INDIFERENCIA & $\begin{array}{c}\text { MODERADA } \\
\text { IMPORTANCIA }\end{array}$ & $\begin{array}{c}\text { COMPLETA } \\
\text { IMPORTANCIA }\end{array}$ \\
\hline & $\mathbf{2}$ & $\mathbf{3}$ & $\mathbf{4}$ & $\mathbf{5}$ \\
\hline
\end{tabular}

23. Debe existir el nivel de conciencia de los beneficios de las TSI entre el staff de usuarios de la organización que no pertenecen a la función de TSI.

\begin{tabular}{|c|c|c|c|c|}
\hline $\begin{array}{c}\text { COMPLETA } \\
\text { INSIGNIFICANCIA } \\
1\end{array}$ & $\begin{array}{c}\text { MODERADA } \\
\text { INSIGNIFICANCIA } \\
2\end{array}$ & $\begin{array}{c}\text { INDIFERENCIA } \\
3\end{array}$ & $\begin{array}{c}\text { MODERADA } \\
\text { IMPORTANCIA } \\
4\end{array}$ & $\begin{array}{l}\text { COMPLETA } \\
\text { IMPORTANCIA } \\
5\end{array}$ \\
\hline & & & & \\
\hline
\end{tabular}

24. Deben existir talleres de concienciación para tomadores de decisiones y el staff de usuarios que no pertenecen a la función de TSI.

\begin{tabular}{|c|c|c|c|c|}
\hline COMPLETA & MODERADA & INDIFERENCIA & MODERADA & $\begin{array}{c}\text { COMPLETA } \\
\text { INSIGNIFICANCIA } \\
\mathbf{1}\end{array}$ \\
$\begin{array}{c}\text { INSIGNIFICANCIA } \\
\mathbf{2}\end{array}$ & $\mathbf{3}$ & $\mathbf{4}$ & $\mathbf{5}$ \\
\hline & & & & \\
\hline
\end{tabular}

25. Debe formarse y evaluarse al gobierno de valor de TSI en función de las responsabilidades asignadas en relación con la definición de la cartera de programas de inversión de negocio habilitadas por las TSI.

\begin{tabular}{|c|c|c|c|c|}
\hline $\begin{array}{c}\text { COMPLETA } \\
\text { INSIGNIFICANCIA }\end{array}$ & $\begin{array}{c}\text { MODERADA } \\
\text { INSIGNIFICANCIA }\end{array}$ & INDIFERENCIA & $\begin{array}{c}\text { MODERADA } \\
\text { IMPORTANCIA }\end{array}$ & $\begin{array}{c}\text { COMPLETA } \\
\text { IMPORTANCIA }\end{array}$ \\
$\mathbf{1}$ & $\mathbf{2}$ & $\mathbf{3}$ & $\mathbf{4}$ & $\mathbf{5}$ \\
\hline & & & & \\
\hline
\end{tabular}

26. Debe proporcionarse al usuario del negocio procedimientos, técnicas y herramientas que les permitan responder a sus responsabilidades relacionadas con las inversiones de negocio habilitadas por las TSI.

\begin{tabular}{|c|c|c|c|c|}
\hline $\begin{array}{c}\text { COMPLETA } \\
\text { INSIGNIFICANCIA } \\
1 \\
\end{array}$ & $\begin{array}{c}\text { MODERADA } \\
\text { INSIGNIFICANCIA } \\
2 \\
\end{array}$ & $\begin{array}{c}\text { INDIFERENCIA } \\
3 \\
\end{array}$ & $\begin{array}{c}\text { MODERADA } \\
\text { IMPORTANCIA } \\
4 \\
\end{array}$ & $\begin{array}{c}\text { COMPLETA } \\
\text { IMPORTANCIA } \\
\mathbf{5} \\
\end{array}$ \\
\hline & & & & \\
\hline
\end{tabular}

CRITERIO: RECURSOS (Analiza cómo la organización gobierna los recursos financieros y materiales, con el fin de apoyar el despliegue de su estrategia y el eficiente gobierno de valor de la misma, así como su impacto en el negocio).

SUBCRITERIO: Recursos Financieros y Materiales

27. Debe gestionarse de manera eficiente los recursos financieros de acuerdo a las prioridades señaladas en el plan de inversiones del negocio.

\begin{tabular}{|c|c|c|c|c|}
\hline COMPLETA & MODERADA & INDIFERENCIA & MODERADA & COMPLETA \\
INSIGNIFICANCIA & INSIGNIFICANCIA & & $\mathbf{3}$ & $\mathbf{4}$ \\
\hline $\mathbf{1}$ & $\mathbf{2}$ & $\mathbf{3}$ & & $\mathbf{5}$ \\
\hline & & & & \\
\hline
\end{tabular}

28. Debe disponerse de recursos materiales para cubrir las necesidades prioritarias con criterio de calidad.

\begin{tabular}{|c|c|c|c|c|}
\hline $\begin{array}{c}\text { COMPLETA } \\
\text { INSIGNIFICANCIA } \\
1\end{array}$ & $\begin{array}{c}\text { MODERADA } \\
\text { INSIGNIFICANCIA } \\
\mathbf{2}\end{array}$ & $\begin{array}{c}\text { INDIFERENCIA } \\
3\end{array}$ & $\begin{array}{c}\text { MODERADA } \\
\text { IMPORTANCIA } \\
4\end{array}$ & $\begin{array}{c}\text { COMPLETA } \\
\text { IMPORTANCIA } \\
5\end{array}$ \\
\hline & & & & \\
\hline
\end{tabular}


CRITERIO: PROCESOS (Analiza cómo la organización gobierna sus procesos, diseña, desarrolla, produce y suministra productos y servicios de las TSI, y cómo gestiona las relaciones, con el fin de satisfacer plenamente las necesidades y expectativas de sus interesados del negocio).

SUBCRITERIO: Diseño y Mejora de Procesos de Gobierno de Valor

29. Debe definirse, implementarse y hacerse seguimiento constante a los procesos que vinculan la estrategia con la cartera de los proyectos de inversión habilitadas por las TSI.

\begin{tabular}{|c|c|c|c|c|}
\hline COMPLETA & MODERADA & INDIFERENCIA & $\begin{array}{c}\text { MODERADA } \\
\text { IMPORTANCIA }\end{array}$ & $\begin{array}{c}\text { COMPLETA } \\
\text { IMPORTANCIA }\end{array}$ \\
\hline $\begin{array}{c}\text { INSIGNIFICANCIA } \\
\mathbf{1}\end{array}$ & $\mathbf{2}$ & $\mathbf{2}$ & $\mathbf{4}$ & $\mathbf{5}$ \\
\hline & & & & \\
\hline
\end{tabular}

30. Debe definirse e impulsarse la implementación de un marco de gestión de programas de proyectos de inversión habilitados por las TSI con el fin de aumentar el valor percibido por el negocio e interesados.

\begin{tabular}{|c|c|c|c|c|}
\hline COMPLETA & MODERADA & INDIFERENCIA & MODERADA & COMPLETA \\
INSIGNIFICANCIA & INSIGNIFICANCIA & & $\begin{array}{c}\text { IMPORTANCIA } \\
\text { IMPORTANCIA }\end{array}$ & $\mathbf{4}$ \\
\hline & $\mathbf{2}$ & $\mathbf{3}$ & & \\
\hline & & & & \\
\hline
\end{tabular}

31. Debe crearse valor a través del incremento de la calidad en los procesos y la toma de decisiones.

\begin{tabular}{|c|c|c|c|c|}
\hline COMPLETA & MODERADA & INDIFERENCIA & $\begin{array}{c}\text { MODERADA } \\
\text { IMPORTANCIA }\end{array}$ & $\begin{array}{c}\text { COMPLETA } \\
\text { IMPORTANCIA }\end{array}$ \\
$\begin{array}{c}\text { INSIGNIFICANCIA } \\
\mathbf{1}\end{array}$ & $\mathbf{2}$ & $\mathbf{2}$ & $\mathbf{4}$ & $\mathbf{5}$ \\
\hline & & & & \\
\hline
\end{tabular}

32. Debe existir un proceso para crear nuevo valor por el uso de las TSI, que se alinee con la estrategia organizacional.

\begin{tabular}{|c|c|c|c|c|}
\hline $\begin{array}{c}\text { COMPLETA } \\
\text { INSIGNIFICANCIA } \\
1\end{array}$ & $\begin{array}{c}\text { MODERADA } \\
\text { INSIGNIFICANCIA }\end{array}$ & INDIFERENCIA & $\begin{array}{c}\text { MODERADA } \\
\text { IMPORTANCIA }\end{array}$ & $\begin{array}{c}\text { COMPLETA } \\
\text { IMPORTANCIA } \\
\end{array}$ \\
\hline & & 3 & 4 & 5 \\
\hline
\end{tabular}

SUBCRITERIO: Necesidades de Información

33. Debe definirse un conjunto de objetivos, mediciones, metas y comparativas de rendimiento de interés para el negocio y otras partes interesadas relevantes.

\begin{tabular}{|c|c|c|c|c|}
\hline COMPLETA & MODERADA & INDIFERENCIA & MODERADA & $\begin{array}{c}\text { COMPLETA } \\
\text { INSIGNIFICANCIA } \\
\text { INSIGNIFICANCIA }\end{array}$ \\
$\mathbf{1}$ & $\mathbf{2}$ & $\mathbf{3}$ & $\mathbf{4}$ & $\mathbf{5}$ \\
\hline & & & & \\
\hline
\end{tabular}

34. Debe definirse un proceso para recoger datos puntuales y exactos para informar sobre el progreso frente a los objetivos estratégicos de la organización.

\begin{tabular}{|c|c|c|c|c|}
\hline $\begin{array}{c}\text { COMPLETA } \\
\text { INSIGNIFICANCIA } \\
1\end{array}$ & $\begin{array}{c}\text { MODERADA } \\
\text { INSIGNIFICANCIA }\end{array}$ & INDIFERENCIA & $\begin{array}{c}\text { MODERADA } \\
\text { IMPORTANCIA }\end{array}$ & $\begin{array}{c}\text { COMPLETA } \\
\text { IMPORTANCIA } \\
\end{array}$ \\
\hline & $\mathbf{2}$ & $\mathbf{3}$ & $\mathbf{4}$ & $\mathbf{5}$ \\
\hline
\end{tabular}

35. Debe definirse un proceso de monitoreo que establezca un método de Cuadro de Mando Integral que brinde una visión completa del rendimiento del programa de proyectos de inversión habilitadas por las TSI.

\begin{tabular}{|c|c|c|c|c|}
\hline COMPLETA & MODERADA & INDIFERENCIA & $\begin{array}{c}\text { MODERADA } \\
\text { IMPORTANCIA }\end{array}$ & $\begin{array}{c}\text { COMPLETA } \\
\text { IMPORTANCIA }\end{array}$ \\
$\begin{array}{c}\text { INSIGNIFICANCIA } \\
\mathbf{1}\end{array}$ & $\begin{array}{c}\text { INSIGNIFICANCIA } \\
\mathbf{2}\end{array}$ & $\mathbf{3}$ & $\mathbf{4}$ & $\mathbf{5}$ \\
\hline
\end{tabular}


36. Debe existir un proceso de evaluación de la integridad de la información y de la protección de la propiedad intelectual de las TSI.

\begin{tabular}{|c|c|c|c|c|}
\hline $\begin{array}{c}\text { COMPLETA } \\
\text { INSIGNIFICANCIA } \\
1\end{array}$ & $\begin{array}{c}\text { MODERADA } \\
\text { INSIGNIFICANCIA } \\
\mathbf{2}\end{array}$ & $\begin{array}{c}\text { INDIFERENCIA } \\
3\end{array}$ & $\begin{array}{c}\text { MODERADA } \\
\text { IMPORTANCIA } \\
4\end{array}$ & $\begin{array}{c}\text { COMPLETA } \\
\text { IMPORTANCIA } \\
5\end{array}$ \\
\hline & & & & \\
\hline
\end{tabular}

CRITERIO: PROYECTOS (Analiza cómo la organización gobierna sus procesos de portafolio de proyectos, y cómo gestiona las relaciones, con el fin de satisfacer plenamente las necesidades y expectativas de sus interesados del negocio).

SUBCRITERIO: Financieros y no Financieros

37. Debe existir plena comprensión de la alta dirección del negocio que hay varios tipos de portafolios de inversión que difieren en complejidad y grado de libertad a la hora de recibir y asignar fondos.

\begin{tabular}{|c|c|c|c|c|}
\hline $\begin{array}{c}\text { COMPLETA } \\
\text { INSIGNIFICANCIA } \\
1\end{array}$ & $\begin{array}{c}\text { MODERADA } \\
\text { INSIGNIFICANCIA } \\
2\end{array}$ & $\begin{array}{c}\text { INDIFERENCIA } \\
3\end{array}$ & $\begin{array}{c}\text { MODERADA } \\
\text { IMPORTANCIA } \\
4\end{array}$ & $\begin{array}{c}\text { COMPLETA } \\
\text { IMPORTANCIA } \\
5\end{array}$ \\
\hline & & & & \\
\hline
\end{tabular}

38. Debe existir un modelo de categorización de proyectos de inversión debido a la complejidad con que se gestionan.

\begin{tabular}{|c|c|c|c|c|}
\hline COMPLETA & MODERADA & INDIFERENCIA & MODERADA & $\begin{array}{c}\text { COMPLETA } \\
\text { INSIGNIFICANCIA } \\
\text { IMPIGNIFICANCIA }\end{array}$ \\
\hline & $\mathbf{2}$ & $\mathbf{3}$ & $\mathbf{4}$ & $\mathbf{5}$ \\
\hline & & & & \\
\hline
\end{tabular}

DATOS DE CONSTANCIA (Registro de colaboradores en el resultado de la investigación)

39. ¿Desea que sus datos personales formen parte de la lista de colaboradores de esta investigación?.

\begin{tabular}{|c|c|}
\hline SI & NO \\
\hline & \\
\hline
\end{tabular}

40. En caso de ser positiva la contestación anterior, Favor proporcionar sus datos.

\begin{tabular}{|c|c|c|}
\hline $\begin{array}{c}\text { Apellidos y } \\
\text { Nombre }\end{array}$ & Organización & email \\
\hline & & \\
\hline
\end{tabular}





\section{ANEXO F. GUÍA DE APLICACIÓN DEL MODELO}

\section{Modelo de Evaluación de Calidad}

Gobierno de Tecnologías y Sistemas de Información Basada en Valor

\section{VBISTGQM}

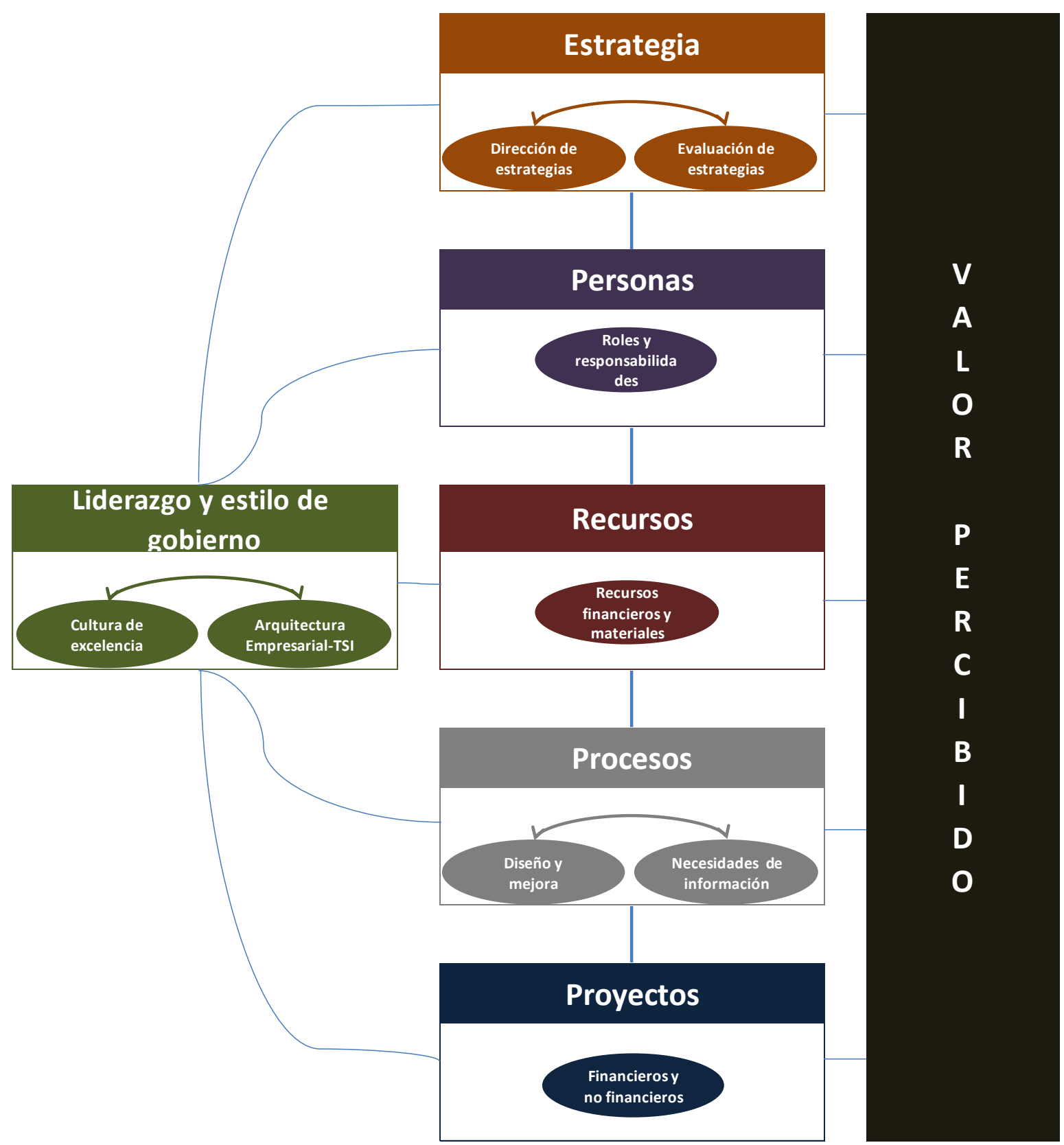




\section{Modelo de Evaluación de Calidad}

Gobierno de Tecnologías y Sistemas de Información Basada en Valor

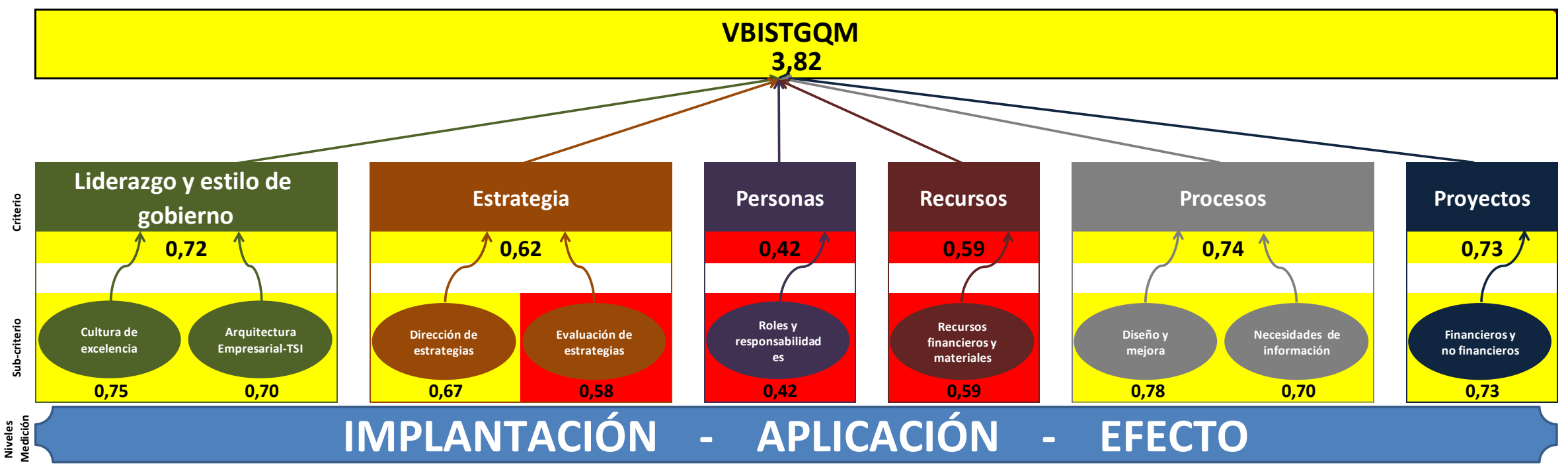




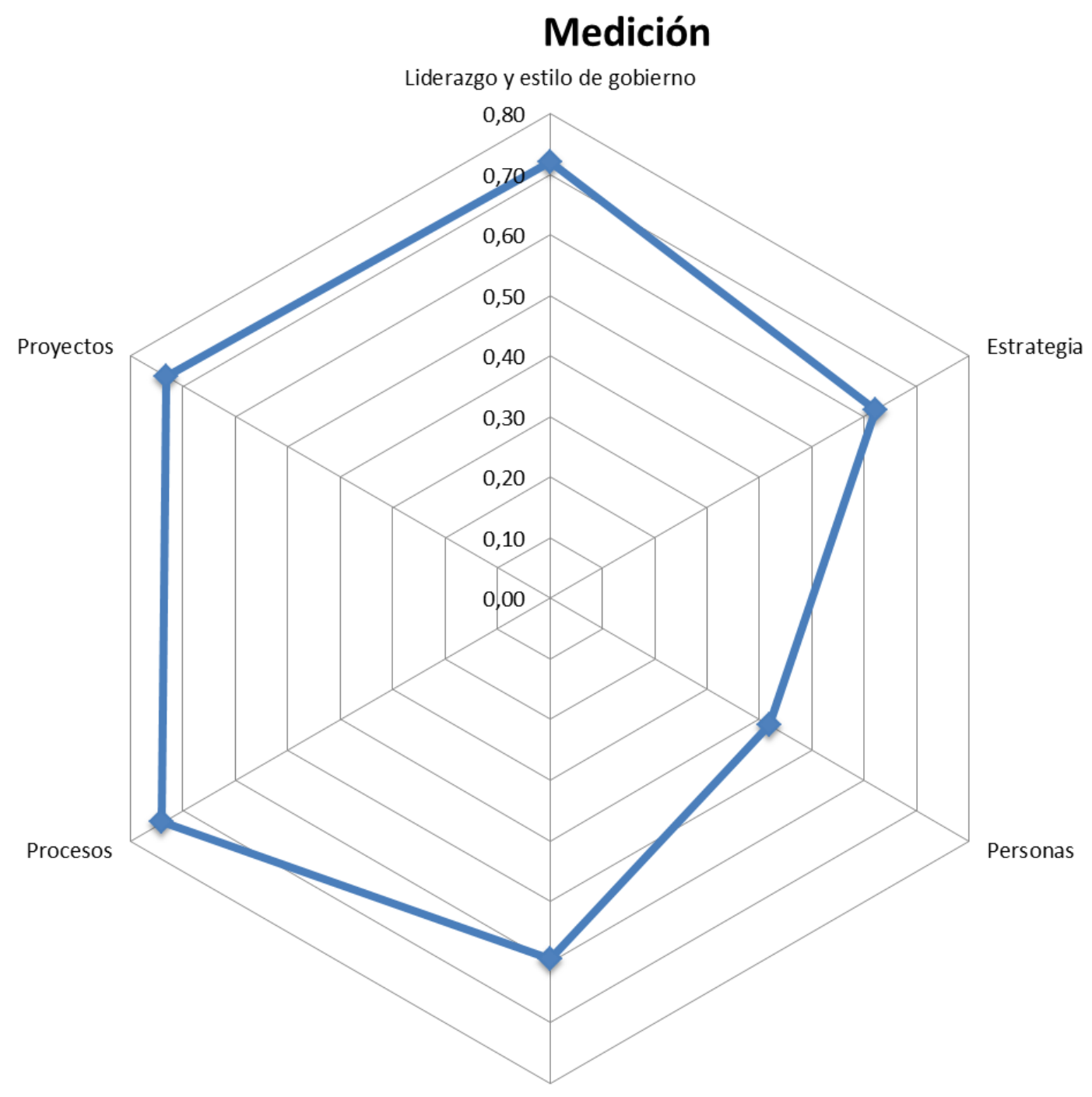




\section{Autoevaluación de Liderazgo y estilo de gobierno}

\section{CRITERIO: LIDERAZGO Y ESTILO DE GOBIERNO}

\begin{tabular}{|l|l|}
\hline \multicolumn{1}{|c|}{ Sub-criterios } & \multicolumn{1}{c|}{ Descripción } \\
\hline 1.1. Cultura de Excelencia & $\begin{array}{l}\text { Hace referencia al compromiso que tienen los líderes con la cultura de } \\
\text { excelencia. Se promueve de manera formal la definición de valores. Se modeliza } \\
\text { el papel de la organización, en línea con los principios de servicio, la misión, } \\
\text { visión y valores de la organización. Se define política de calidad. Ser activos e } \\
\text { implicarse en actividades de mejora, estimulando y alentando la innovación y la } \\
\text { creatividad. }\end{array}$ \\
\hline 1.2. Arquitectura Empresarial-TSI & $\begin{array}{l}\text { Hace referencia al alineamiento empresarial. A las actividades claves de la } \\
\text { organización; en especial aquellos que generan mayor valor para el cliente y la } \\
\text { misma empresa, área o servicio. Los líderes formalizan el sistema de gestión y } \\
\text { los resultados; y, estructura empresarial. }\end{array}$ \\
\hline
\end{tabular}

\begin{tabular}{|c|c|}
\hline Criterio de Valor: & 1. Liderazgo y estilo de gobierno \\
\hline Sub-criterio & Dimensiones \\
\hline \multirow{5}{*}{ 1.1. Cultura de Excelencia } & $\begin{array}{l}\text { 1.1a. Los líderes, ¿Se implican activa y visiblemente en la definición de valor } \\
\text { para la organización?. }\end{array}$ \\
\hline & $\begin{array}{l}\text { 1.1b. Los líderes, ¿Se implican activa y visiblemente en la definición y desarrollo } \\
\text { de los objetivos estratégicos fundamentales del servicio generador de valor?. }\end{array}$ \\
\hline & $\begin{array}{l}\text { 1.1c. Los líderes, ¿Actúan como modelos de referencia para el cumplimiento de } \\
\text { los objetivos estratégicos fundamentales del servicio generador de valor?. }\end{array}$ \\
\hline & $\begin{array}{l}\text { 1.1d. Los líderes, ¿Se implican activa y visiblemente en la promoción que } \\
\text { estimule y aliente la innovación y creatividad basada en el valor que debe } \\
\text { entregar las TSI?. }\end{array}$ \\
\hline & $\begin{array}{l}\text { 1.1e. La organización, ¿Tiene una política de gobierno de TSI documentada y } \\
\text { comunicada que incorpore criterios de calidad, garantizando una información } \\
\text { actualizada y transparente?. }\end{array}$ \\
\hline \multirow{6}{*}{ 1.2. Arquitectura Empresarial-TSI } & $\begin{array}{l}\text { 1.2a. Los líderes empresariales, ¿Encargan a los ejecutivos senior la definición } \\
\text { del gobierno de valor de las TSI?. }\end{array}$ \\
\hline & $\begin{array}{l}\text { 1.2b. Los líderes empresariales, ¿Disponen el establecimiento de comisiones, } \\
\text { comités y estructuras de soporte apropiadas capaz de mantener una estructura } \\
\text { óptima de coordinación, comunicación y enlace entre la función de TSI y las } \\
\text { otras partes interesadas del negocio?. }\end{array}$ \\
\hline & $\begin{array}{l}\text { 1.2c. Los líderes en el momento oportuno, ¿Evalúan los beneficios que se } \\
\text { entregan al negocio?. }\end{array}$ \\
\hline & $\begin{array}{l}\text { 1.2d. Los líderes en el momento oportuno, ¿Delegan responsabilidades y velan } \\
\text { por el buen cumplimiento de las mismas?. }\end{array}$ \\
\hline & $\begin{array}{l}\text { 1.2e. Los líderes en el momento oportuno, ¿Toman decisiones importantes que } \\
\text { les competen para mejorar el gobierno y por ende la gestión del servicio que } \\
\text { genere valor en el negocio?. }\end{array}$ \\
\hline & $\begin{array}{l}\text { 1.2f. Los líderes, ¿Garantizan que se desarrolle e implante un sistema de } \\
\text { gobierno, gestión, evaluación y mejora de los procesos generadores de valor del } \\
\text { servicio para el negocio?. }\end{array}$ \\
\hline
\end{tabular}

\begin{tabular}{|l|l|}
\hline \multicolumn{1}{|c|}{ Sub-criterio } & \multicolumn{1}{|c|}{ Valor percibido } \\
\hline & $\begin{array}{l}\text { a. Percepción de una Política de calidad de Gobierno de TSI en los resultados } \\
\text { de la Gobernanza de TSI }\end{array}$ \\
\cline { 2 - 3 } 1.1. Cultura de Excelencia & $\begin{array}{l}\text { b. Percepción de la misión, visión y valores en los resultados de la } \\
\text { Gobernanza de TSI. }\end{array}$ \\
\cline { 2 - 2 } & $\begin{array}{l}\text { c. Percepción de valores empresariales para la integración del negocio y las } \\
\text { TSI. }\end{array}$ \\
\hline
\end{tabular}




\begin{tabular}{|c|c|}
\hline & $\begin{array}{l}\text { d. Crecimiento de la eficacia y efectividad de cumplimiento de objetivos } \\
\text { estratégicos como resultado de la percepción que se tiene de la Gobernanza de } \\
\text { TI. }\end{array}$ \\
\hline & $\begin{array}{l}\text { e. Participación de las personas en la innovación y mejoras y, aceptadas por } \\
\text { el negocio. }\end{array}$ \\
\hline \multirow{5}{*}{ 1.2. Arquitectura Empresarial-TSI } & a. Existencia de un gobierno de TSI \\
\hline & $\begin{array}{l}\text { b. Incremento de la comunicación y cooperación entre el equipo de dirección } \\
\text { de las TSI y las unidades de negocio. }\end{array}$ \\
\hline & c. Incremento de la comunicación, la relación y la cooperación interpersonal. \\
\hline & $\begin{array}{l}\text { d. Existencia estructura organizativa para facilitar la gobernanza y gestión en } \\
\text { la generación de valor. }\end{array}$ \\
\hline & $\begin{array}{l}\text { e. Eficiencia en el gobierno y la gestión de procesos generadores de valor del } \\
\text { servicio de TSI. }\end{array}$ \\
\hline
\end{tabular}




\begin{tabular}{|c|c|c|c|c|c|c|c|c|c|c|c|c|c|c|}
\hline \multirow{4}{*}{$\begin{array}{c}\text { Criterio: } \\
\begin{array}{l}\text { Sub- } \\
\text { criterio: }\end{array} \\
{[i]}\end{array}$} & \multirow{2}{*}{\multicolumn{9}{|c|}{$\begin{array}{l}\text { 1. Liderazgo y estilo de gobierno } \\
\text { 1.1. Cultura de Excelencia }\end{array}$}} & \multicolumn{5}{|c|}{ Medición Implantación } \\
\hline & & & & & & & & & & \multicolumn{2}{|c|}{$\begin{array}{l}\text { Ponderación } \\
\text { [PIM]: }\end{array}$} & \multicolumn{3}{|c|}{0,40} \\
\hline & \multirow{2}{*}{$\begin{array}{c}\text { Dim } \\
\text { [i] }\end{array}$} & \multicolumn{5}{|c|}{$\begin{array}{c}\text { Valoración Importancia } \\
\text { I [i] }\end{array}$} & \multirow{2}{*}{$\begin{array}{c}\text { Total } \\
\text { I [i] }\end{array}$} & \multicolumn{5}{|c|}{$\begin{array}{c}\text { Valoración Difusión } \\
\text { D [i] }\end{array}$} & \multirow{2}{*}{$\begin{array}{l}\text { Total } \\
\text { D [i] }\end{array}$} & \multirow{2}{*}{ Peso } \\
\hline & & $\mathbf{0 , 0 0}$ & 0,25 & $\mathbf{0 , 5 0}$ & 0,75 & 1,00 & & $\mathbf{0 , 0 0}$ & 0,25 & $\mathbf{0 , 5 0}$ & 0,75 & 1,00 & & \\
\hline 1 & $\begin{array}{l}\text { 1.1a. Los líderes, } \\
\text { ¿Se implican activa } \\
\text { y visiblemente en la } \\
\text { definición de valor } \\
\text { para la } \\
\text { organización?. }\end{array}$ & 0 & 0 & 1 & 2 & 4 & 0,86 & 0 & 0 & 0 & 5 & 2 & 0,82 & 1,00 \\
\hline 2 & $\begin{array}{l}\text { 1.1b. Los líderes, } \\
\text { ¿Se implican activa } \\
\text { y visiblemente en la } \\
\text { definición r y } \\
\text { desarrollo de los } \\
\text { objetivos } \\
\text { estratégicos } \\
\text { fundamentales del } \\
\text { servicio generador } \\
\text { de valor?. }\end{array}$ & 0 & 0 & 1 & 3 & 3 & 0,82 & 0 & 0 & 3 & 2 & 2 & 0,71 & 1,00 \\
\hline 3 & $\begin{array}{l}\text { 1.1c. Los } r \text { líderes, } \\
\text { ¿Actúan romo } \\
\text { modelos r r de } \\
\text { referencia para el } \\
\text { cumplimiento de } \\
\text { los objetivos } \\
\text { estratégicos } \\
\text { fundamentales del } \\
\text { servicio generador } \\
\text { de valor?. }\end{array}$ & 0 & 0 & 0 & 0 & 7 & 1,00 & 0 & 0 & 0 & 2 & 5 & 0,93 & 1,00 \\
\hline 4 & $\begin{array}{l}\text { 1.1d. Los líderes, } \\
\text { ¿Se implican activa } \\
\text { y visiblemente en la } \\
\text { promoción que } \\
\text { estimule y aliente la } \\
\text { innovación r y } \\
\text { creatividad basada } \\
\text { en el valor que } \\
\text { debe entregar las } \\
\text { TSI?. }\end{array}$ & 0 & 0 & 0 & 3 & 4 & 0,89 & 0 & 0 & 0 & 3 & 4 & 0,89 & 1,00 \\
\hline 5 & $\begin{array}{l}\text { 1.1e. La } \\
\text { organización, } \\
\text { ¿Tiene una política } \\
\text { de gobierno de TSI } \\
\text { documentada r y } \\
\text { comunicada que } \\
\text { incorpore criterios } \\
\text { de calidad, } \\
\text { garantizando una } \\
\text { información } \\
\text { actualizada } \\
\text { transparente? }\end{array}$ & 0 & 0 & 0 & 7 & 0 & 0,75 & 0 & 0 & 0 & 7 & 0 & 0,75 & 1,00 \\
\hline \multicolumn{7}{|c|}{ Valor de la Implantación: IMSC } & \multicolumn{8}{|c|}{0,83} \\
\hline
\end{tabular}




\begin{tabular}{|c|c|c|c|c|c|c|c|c|c|c|c|c|c|c|}
\hline \multirow{4}{*}{$\begin{array}{c}\text { Criterio: } \\
\begin{array}{l}\text { Sub- } \\
\text { criterio: }\end{array} \\
{[i]}\end{array}$} & \multirow{2}{*}{\multicolumn{9}{|c|}{$\begin{array}{l}\text { 1. Liderazgo y estilo de gobierno } \\
\text { 1.2. Arquitectura Empresarial-TSI }\end{array}$}} & \multicolumn{5}{|c|}{ Medición Implantación } \\
\hline & & & & & & & & & & \multicolumn{2}{|c|}{$\begin{array}{l}\text { Ponderación } \\
\text { [PIM]: }\end{array}$} & \multicolumn{3}{|c|}{0,40} \\
\hline & \multirow{2}{*}{$\begin{array}{c}\text { Dim } \\
\text { [i] }\end{array}$} & \multicolumn{5}{|c|}{$\begin{array}{c}\text { Valoración Importancia } \\
\text { I [i] }\end{array}$} & \multirow{2}{*}{$\begin{array}{l}\text { Total } \\
\text { I [i] }\end{array}$} & \multicolumn{5}{|c|}{$\begin{array}{c}\text { Valoración Difusión } \\
\text { D [i] }\end{array}$} & \multirow{2}{*}{$\begin{array}{l}\text { Total } \\
\text { D [i] }\end{array}$} & \multirow{2}{*}{ Peso } \\
\hline & & $\mathbf{0 , 0 0}$ & 0,25 & $\mathbf{0 , 5 0}$ & 0,75 & 1,00 & & $\mathbf{0 , 0 0}$ & 0,25 & $\mathbf{0 , 5 0}$ & 0,75 & $\mathbf{1 , 0 0}$ & & \\
\hline 1 & $\begin{array}{l}\text { 1.2a. Los líderes } \\
\text { empresariales, } \\
\text { ¿Encargan a los } \\
\text { ejecutivos senior la } \\
\text { definición del } \\
\text { gobierno de valor de } \\
\text { las TSI?. }\end{array}$ & 0 & 0 & 0 & 3 & 4 & 0,89 & 0 & 0 & 2 & 2 & 3 & 0,79 & 1,00 \\
\hline 2 & 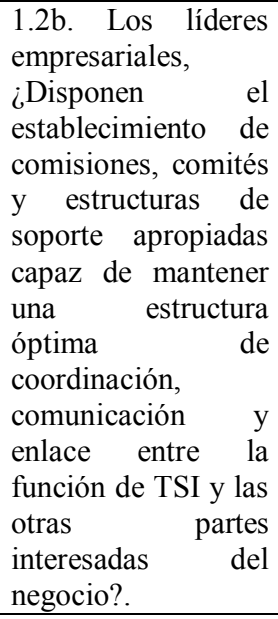 & 0 & 0 & 0 & 3 & 4 & 0,89 & 0 & 0 & 1 & 2 & 4 & 0,86 & 1,00 \\
\hline 3 & $\begin{array}{lrr}\text { 1.2c. Los líderes en } \\
\text { el } & \text { momento } \\
\text { oportuno, ¿Evalúan } \\
\text { los beneficios que } \\
\text { se entregan al } \\
\text { negocio?. }\end{array}$ & 0 & 0 & 0 & 1 & 6 & 0,96 & 0 & 0 & 0 & 3 & 4 & 0,89 & 1,00 \\
\hline 4 & $\begin{array}{l}\text { 1.2d. Los líderes en } \\
\text { el momento } \\
\text { oportuno, ¿Delegan } \\
\text { responsabilidades y } \\
\text { velan por el buen } \\
\text { cumplimiento de las } \\
\text { mismas?. }\end{array}$ & 0 & 0 & 0 & 1 & 6 & 0,96 & 0 & 0 & 0 & 0 & 7 & 1,00 & 1,00 \\
\hline 5 & $\begin{array}{l}\text { 1.2e. Los líderes en } \\
\text { el momento } \\
\text { oportuno, ¿Toman } \\
\text { decisiones } \\
\text { importantes que les } \\
\text { competen para } \\
\text { mejorar el gobierno } \\
\text { y por ende la } \\
\text { gestión del servicio } \\
\text { que genere valor en } \\
\text { el negocio?. }\end{array}$ & 0 & 0 & 0 & 2 & 5 & 0,93 & 0 & 0 & 0 & 1 & 6 & 0,96 & 1,00 \\
\hline 6 & $\begin{array}{l}\text { 1.2f. Los líderes, } \\
\text { ¿Garantizan que se } \\
\text { desarrolle } \\
\text { implante un sistema } \\
\text { de gobierno, } \\
\text { gestión, evaluación } \\
\text { y mejora de los } \\
\text { procesos } \\
\text { generadores }\end{array}$ & 0 & 0 & 1 & 1 & 5 & 0,89 & 0 & 0 & 1 & 3 & 3 & 0,82 & 1,00 \\
\hline
\end{tabular}




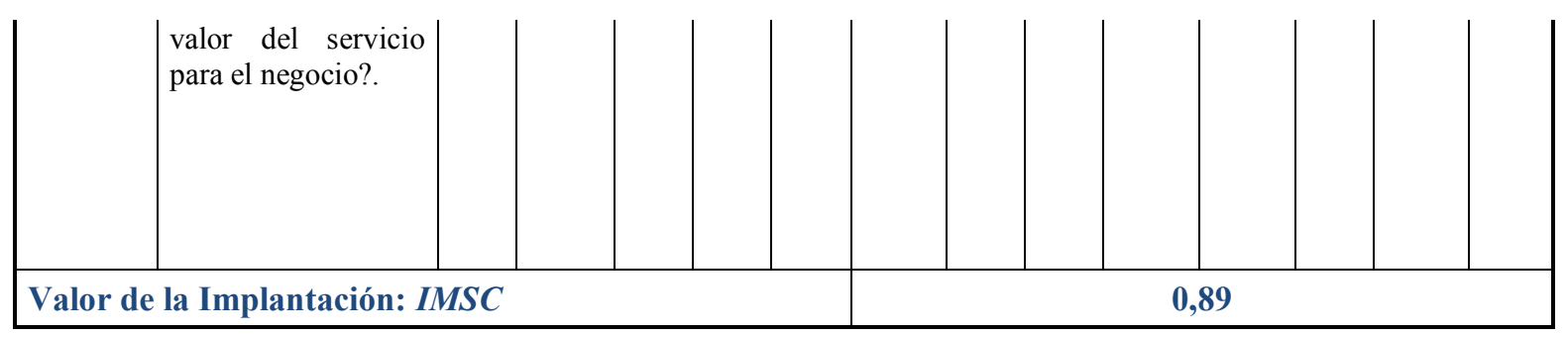




\begin{tabular}{|c|c|c|c|c|c|c|c|c|c|c|c|c|c|c|}
\hline \multirow{4}{*}{$\begin{array}{c}\text { Criterio: } \\
\begin{array}{l}\text { Sub- } \\
\text { criterio: }\end{array} \\
{[i]}\end{array}$} & \multirow{2}{*}{\multicolumn{9}{|c|}{$\begin{array}{l}\text { 1. Liderazgo y estilo de gobierno } \\
\text { 1.1. Cultura de Excelencia }\end{array}$}} & \multicolumn{5}{|c|}{ Medición Aplicación } \\
\hline & & & & & & & & & & \multicolumn{2}{|c|}{$\begin{array}{l}\text { Ponderación } \\
\text { [PAP]: }\end{array}$} & \multicolumn{3}{|c|}{0,30} \\
\hline & \multirow{2}{*}{$\begin{array}{c}\text { Dim } \\
\text { [i] }\end{array}$} & \multicolumn{5}{|c|}{$\begin{array}{c}\text { Valoración Utilización } \\
\text { U [i] }\end{array}$} & \multirow{2}{*}{$\begin{array}{l}\text { Total } \\
\text { U [i] }\end{array}$} & \multicolumn{5}{|c|}{$\begin{array}{c}\text { Valoración Seguimiento } \\
\mathrm{S}[\mathrm{i}]\end{array}$} & \multirow{2}{*}{$\begin{array}{l}\text { Total } \\
\text { S [i] }\end{array}$} & \multirow{2}{*}{ Peso } \\
\hline & & $\mathbf{0 , 0 0}$ & 0,25 & 0,50 & 0,75 & 1,00 & & $\mathbf{0 , 0 0}$ & 0,25 & $\mathbf{0 , 5 0}$ & 0,75 & 1,00 & & \\
\hline 1 & $\begin{array}{l}\text { 1.1a. Los líderes, } \\
\text { ¿Se implican activa } \\
\text { y visiblemente en la } \\
\text { definición de valor } \\
\text { para la } \\
\text { organización?. }\end{array}$ & 0 & 0 & 0 & 4 & 3 & 0,86 & 0 & 0 & 3 & 3 & 1 & 0,68 & 1,00 \\
\hline 2 & $\begin{array}{l}\text { 1.1b. Los líderes, } \\
\text { ¿Se implican activa } \\
\text { y visiblemente en la } \\
\text { definición r y } \\
\text { desarrollo de los } \\
\text { objetivos } \\
\text { estratégicos } \\
\text { fundamentales del } \\
\text { servicio generador } \\
\text { de valor?. }\end{array}$ & 0 & 0 & 0 & 3 & 4 & 0,89 & 0 & 0 & 3 & 3 & 1 & 0,68 & 1,00 \\
\hline 3 & 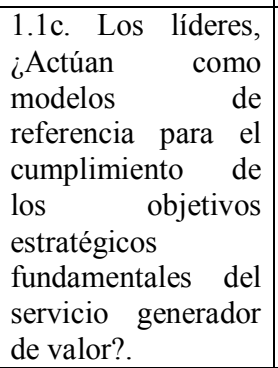 & 0 & 0 & 1 & 2 & 4 & 0,86 & 0 & 1 & 3 & 2 & 1 & 0,61 & 1,00 \\
\hline 4 & \begin{tabular}{l} 
1.1d. Los líderes, \\
¿Se implican activa \\
\multicolumn{2}{l}{ y visiblemente en la } \\
promoción que \\
estimule y aliente la \\
innovación r y \\
creatividad basada \\
en el valor que \\
debe entregar las \\
TSI?.
\end{tabular} & 0 & 0 & 0 & 3 & 4 & 0,89 & 0 & 0 & 1 & 4 & 2 & 0,79 & 1,00 \\
\hline 5 & $\begin{array}{l}\text { 1.1e. } \\
\text { organización, } \\
\text { ¿Tiene una política } \\
\text { de gobierno de TSI } \\
\text { documentada y } \\
\text { comunicada que } \\
\text { incorpore criterios } \\
\text { de yalidad, } \\
\text { garantizando una } \\
\text { información } \\
\text { actualizada } \\
\text { transparente? }\end{array}$ & 0 & 2 & 3 & 2 & 0 & 0,50 & 0 & 3 & 3 & 1 & 0 & 0,43 & 1,00 \\
\hline \multicolumn{7}{|c|}{ Valor de la Aplicación: $A P S C$} & \multicolumn{8}{|c|}{0,66} \\
\hline
\end{tabular}




\begin{tabular}{|c|c|c|c|c|c|c|c|c|c|c|c|c|c|c|}
\hline \multirow{4}{*}{\begin{tabular}{|c|} 
Criterio: \\
$\begin{array}{l}\text { Sub- } \\
\text { criterio: }\end{array}$ \\
{$[i]$}
\end{tabular}} & \multirow{2}{*}{\multicolumn{9}{|c|}{$\begin{array}{l}\text { 1. Liderazgo y estilo de gobierno } \\
\text { 1.2. Arquitectura Empresarial-TSI }\end{array}$}} & \multicolumn{5}{|c|}{ Medición Aplicación } \\
\hline & & & & & & & & & & \multicolumn{2}{|c|}{$\begin{array}{l}\text { Ponderación } \\
\text { [PAP]: }\end{array}$} & \multicolumn{3}{|c|}{0,30} \\
\hline & \multirow{2}{*}{$\begin{array}{c}\text { Dim } \\
\text { [i] }\end{array}$} & \multicolumn{5}{|c|}{$\begin{array}{c}\text { Valoración Utilización } \\
\text { U [i] }\end{array}$} & \multirow{2}{*}{$\begin{array}{l}\text { Total } \\
\text { U [i] }\end{array}$} & \multicolumn{5}{|c|}{$\begin{array}{c}\text { Valoración Seguimiento } \\
\text { S [i] }\end{array}$} & \multirow{2}{*}{$\begin{array}{l}\text { Total } \\
\text { S [i] }\end{array}$} & \multirow{2}{*}{ Peso } \\
\hline & & $\mathbf{0 , 0 0}$ & 0,25 & $\mathbf{0 , 5 0}$ & 0,75 & 1,00 & & $\mathbf{0 , 0 0}$ & 0,25 & $\mathbf{0 , 5 0}$ & 0,75 & $\mathbf{1 , 0 0}$ & & \\
\hline 1 & $\begin{array}{l}\text { 1.2a. Los líderes } \\
\text { empresariales, } \\
\text { ¿Encargan a los } \\
\text { ejecutivos senior la } \\
\text { definición del } \\
\text { gobierno de valor de } \\
\text { las TSI?. }\end{array}$ & 0 & 0 & 0 & 4 & 3 & 0,86 & 0 & 4 & 3 & 0 & 0 & 0,36 & 1,00 \\
\hline 2 & $\begin{array}{l}\text { 1.2b. Los líderes } \\
\text { empresariales, } \\
\text { ¿Disponen } \\
\text { establecimiento de } \\
\text { comisiones, comités } \\
\text { y estructuras de } \\
\text { soporte apropiadas } \\
\text { capaz de mantener } \\
\text { una estructura } \\
\text { óptima } \\
\text { coordinación, } \\
\text { comunicación } \\
\text { enlace entre la } \\
\text { función de TSI y las } \\
\text { otras partes } \\
\text { interesadas del } \\
\text { negocio?. }\end{array}$ & 0 & 0 & 0 & 3 & 4 & 0,89 & 0 & 2 & 3 & 2 & 0 & 0,50 & 1,00 \\
\hline 3 & $\begin{array}{lr}\text { 1.2c. Los líderes en } \\
\text { el momento } \\
\text { oportuno, ¿Evalúan } \\
\text { los beneficios que } \\
\text { se entregan al } \\
\text { negocio?. }\end{array}$ & 0 & 0 & 1 & 3 & 3 & 0,82 & 0 & 0 & 3 & 3 & 1 & 0,68 & 1,00 \\
\hline 4 & $\begin{array}{l}\text { 1.2d. Los líderes en } \\
\text { el momento } \\
\text { oportuno, ¿Delegan } \\
\text { responsabilidades y } \\
\text { velan por el buen } \\
\text { cumplimiento de las } \\
\text { mismas?. }\end{array}$ & 0 & 0 & 1 & 3 & 3 & 0,82 & 0 & 0 & 2 & 3 & 2 & 0,75 & 1,00 \\
\hline 5 & $\begin{array}{l}\text { 1.2e. Los líderes en } \\
\text { el momento } \\
\text { oportuno, ¿Toman } \\
\text { decisiones } \\
\text { importantes que les } \\
\text { competen para } \\
\text { mejorar el gobierno } \\
\text { y por ende la } \\
\text { gestión del servicio } \\
\text { que genere valor en } \\
\text { el negocio?. }\end{array}$ & 0 & 0 & 1 & 3 & 3 & 0,82 & 0 & 0 & 2 & 4 & 1 & 0,71 & 1,00 \\
\hline 6 & $\begin{array}{l}\text { 1.2f. Los líderes, } \\
\text { ¿Garantizan que se } \\
\text { desarrolle } \\
\text { implante un sistema } \\
\text { de gobierno, } \\
\text { gestión, evaluación } \\
\text { y mejora de los } \\
\text { procesos } \\
\text { generadores }\end{array}$ & 0 & 2 & 2 & 3 & 0 & 0,54 & 0 & 0 & 4 & 3 & 0 & 0,61 & 1,00 \\
\hline
\end{tabular}




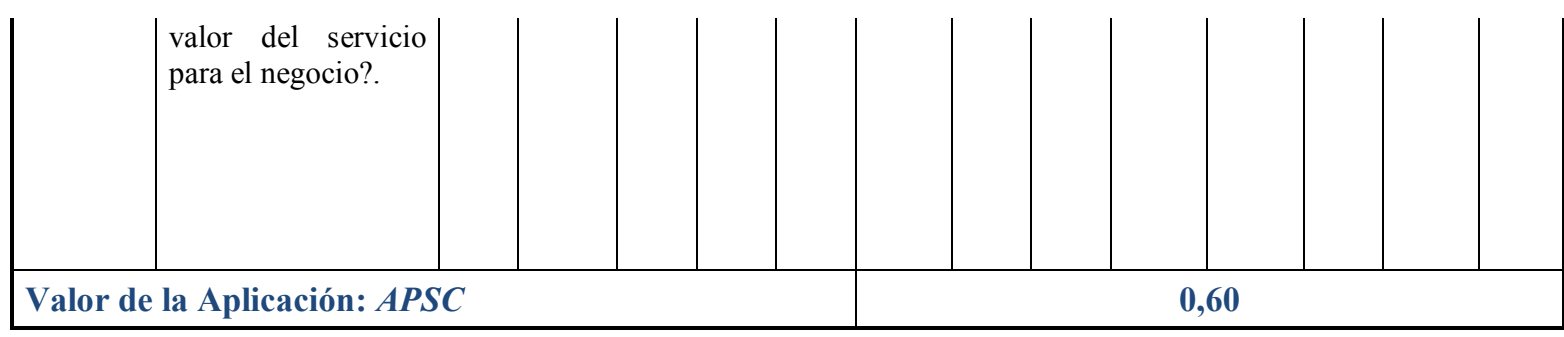

\begin{tabular}{|c|c|c|c|c|c|c|c|}
\hline \multirow{4}{*}{$\begin{array}{c}\text { Criterio: } \\
\text { Sub-criterio: } \\
{[i]}\end{array}$} & \multirow{2}{*}{\multicolumn{4}{|c|}{$\begin{array}{l}\text { 1. Liderazgo y estilo de gobierno } \\
\text { 1.1. Cultura de Excelencia }\end{array}$}} & \multicolumn{3}{|c|}{ Medición Efecto } \\
\hline & & & & & \multicolumn{2}{|c|}{$\begin{array}{l}\text { Ponderación } \\
{[\text { PEF]: }}\end{array}$} & \multirow{3}{*}{$\begin{array}{r}0,30 \\
\text { Total } \\
\text { V [i] }\end{array}$} \\
\hline & \multirow{2}{*}{ Dim } & \multicolumn{5}{|c|}{$\begin{array}{c}\text { Valoración del Valor Percibido } \\
\text { V [i] }\end{array}$} & \\
\hline & & $\mathbf{0 , 0 0}$ & 0,25 & $\mathbf{0 , 5 0}$ & 0,75 & 1,00 & \\
\hline 1 & $\begin{array}{l}\text { a. Percepción de una Política } \\
\text { de calidad de Gobierno de TSI en } \\
\text { los resultados de la Gobernanza de } \\
\text { TSI }\end{array}$ & 0 & 1 & 2 & 0 & 0 & 0,42 \\
\hline 2 & $\begin{array}{l}\text { b. Percepción de la misión, } \\
\text { visión y valores en los resultados } \\
\text { de la Gobernanza de TSI. }\end{array}$ & 0 & 0 & 0 & 1 & 2 & 0,92 \\
\hline 3 & $\begin{array}{l}\text { c. Percepción de valores } \\
\text { empresariales para la integración } \\
\text { del negocio y las TSI. }\end{array}$ & 0 & 0 & 1 & 2 & 0 & 0,67 \\
\hline 4 & $\begin{array}{l}\text { d. Crecimiento de la eficacia y } \\
\text { efectividad de cumplimiento de } \\
\text { objetivos estratégicos como } \\
\text { resultado de la percepción que se } \\
\text { tiene de la Gobernanza de TI. }\end{array}$ & 0 & 0 & 0 & 1 & 2 & 0,92 \\
\hline 5 & $\begin{array}{l}\text { e. Participación de las personas } \\
\text { en la innovación y mejoras y, } \\
\text { aceptadas por el negocio. }\end{array}$ & 0 & 0 & 0 & 1 & 2 & 0,92 \\
\hline \multicolumn{7}{|c|}{ Valor del Efecto: $E F S C$} & 0,73 \\
\hline
\end{tabular}




\begin{tabular}{|c|c|c|c|c|c|c|c|}
\hline \multirow{4}{*}{$\begin{array}{c}\text { Criterio: } \\
\text { Sub-criterio: } \\
\text { ii] }\end{array}$} & \multirow{2}{*}{\multicolumn{4}{|c|}{$\begin{array}{l}\text { 1. Liderazgo y estilo de gobierno } \\
\text { 1.2. Arquitectura Empresarial-TSI }\end{array}$}} & \multicolumn{3}{|c|}{ Medición Efecto } \\
\hline & & & & & \multicolumn{2}{|c|}{$\begin{array}{l}\text { Ponderación } \\
\text { [PEF]: }\end{array}$} & \multirow{3}{*}{$\begin{array}{c}0,30 \\
\begin{array}{c}\text { Total } \\
\text { V [i] }\end{array}\end{array}$} \\
\hline & \multirow{2}{*}{$\begin{array}{c}\text { Dim } \\
\text { [i] }\end{array}$} & \multicolumn{5}{|c|}{$\begin{array}{c}\text { Valoración del Valor Percibido } \\
\text { V [i] }\end{array}$} & \\
\hline & & $\mathbf{0 , 0 0}$ & 0,25 & $\mathbf{0 , 5 0}$ & 0,75 & 1,00 & \\
\hline 1 & $\begin{array}{l}\text { a. Existencia de un gobierno } \\
\text { de TSI }\end{array}$ & 0 & 3 & 0 & 0 & 0 & 0,25 \\
\hline 2 & $\begin{array}{l}\text { b. Incremento de la } \\
\text { comunicación y cooperación entre } \\
\text { el equipo de dirección de las TSI y } \\
\text { las unidades de negocio. }\end{array}$ & 0 & 0 & 0 & 2 & 1 & 0,83 \\
\hline 3 & $\begin{array}{lll}\text { c. Incremento de la } & \text { la } \\
\text { comunicación, la relación y la } \\
\text { cooperación interpersonal. }\end{array}$ & 0 & 0 & 0 & 3 & 0 & 0,75 \\
\hline 4 & $\begin{array}{l}\text { d. Existencia estructura } \\
\text { organizativa para facilitar } \\
\text { gobernanza y gestión en la } \\
\text { generación de valor. }\end{array}$ & 0 & 0 & 3 & 0 & 0 & 0,50 \\
\hline 5 & $\begin{array}{l}\text { e. Eficiencia en el gobierno y } \\
\text { la gestión de procesos generadores } \\
\text { de valor del servicio de TSI. }\end{array}$ & 0 & 0 & 2 & 1 & 0 & 0,58 \\
\hline \multicolumn{7}{|c|}{ Valor del Efecto: $E F S C$} & 0,54 \\
\hline
\end{tabular}

$\mathrm{SC} 1=$

$\mathrm{SC} 1=$

$\mathrm{SC} 1=$

$\mathrm{SC} 2=$

$\mathrm{SC} 2=$

$\mathrm{SC} 2=$
Implantación IM * PIM + Aplicación AP * PAP + Efecto EF * PEF
0,33
$+\quad 0,20$
$+\quad 0,22$

0,75

Implantación IM * PIM + Aplicación AP * PAP + Efecto EF * PEF

0,36

$+\quad 0,18$

0,16 


\section{Autoevaluación de Estrategias}

\section{CRITERIO: ESTRATEGIA}

\begin{tabular}{|l|l|}
\hline \multicolumn{1}{|c|}{ Sub-criterios } & \multicolumn{1}{c|}{ Descripción } \\
\hline 2.1. Dirección de estrategias & $\begin{array}{l}\text { Analiza cómo ponen en práctica las direcciones del negocio, el alineamiento de } \\
\text { las inversiones habilitadas por las TSI, tomando en cuenta la visión, misión, } \\
\text { metas, objetivos y estrategias actuales; analizando el impacto potencial de las TSI } \\
\text { en la estrategia del negocio y el rol que juegan éstas en la organización. }\end{array}$ \\
\hline $\begin{array}{l}\text { 2.2. Evaluación de estrategias en } \\
\text { base a información obtenida por } \\
\text { mediciones de los resultados y } \\
\text { actividades relacionadas con la } \\
\text { innovación y creatividad. }\end{array}$ & $\begin{array}{l}\text { Analiza los resultados. ¿Han sido eficaces las estrategias?. ¿Se requieren ajustes?. } \\
\text { Esto con el propósito de mejorar el rendimiento y comportamiento estratégico } \\
\text { que sea de utilidad para el GoTSI. }\end{array}$ \\
\hline
\end{tabular}

\begin{tabular}{|c|c|}
\hline Criterio de Valor: & 2. Estrategias \\
\hline Sub-criterio & Dimensiones \\
\hline \multirow{3}{*}{ 2.1. Dirección de estrategias } & $\begin{array}{l}\text { 2.1a. Los líderes de gobierno, ¿Aseguran su comprensión con la que se deben } \\
\text { alinear las inversiones de negocio habilitadas por TSI?. }\end{array}$ \\
\hline & $\begin{array}{l}\text { 2.1b. Los líderes de gobierno, ¿Garantizan una política de entendimiento } \\
\text { asociada entre el "requerimiento de negocio" y la función de TSI relativa al } \\
\text { impacto potencial de las tecnologías en la estrategia de negocio y el rol de la } \\
\text { función de TSI en la organización?. }\end{array}$ \\
\hline & $\begin{array}{l}\text { 2.1c. Los líderes de gobierno, ¿Garantizan una política de comprensión que tome } \\
\text { en cuenta "principios, visión, objetivos estratégicos y prioridades de negocio" } \\
\text { para los servicios definidos en un plan de negocio?. }\end{array}$ \\
\hline \multirow{3}{*}{$\begin{array}{l}\text { 2.2. Evaluación de estrategias en } \\
\text { base a información obtenida por } \\
\text { mediciones de los resultados y } \\
\text { actividades relacionadas con la } \\
\text { innovación y creatividad. }\end{array}$} & $\begin{array}{l}\text { 2.2a. Los líderes de gobierno, ¿Garantizan la definición de criterios de evaluación } \\
\text { de estrategias de inversión habilitadas por TSI en base a información que } \\
\text { demuestre el alineamiento con objetivos estratégicos de la organización; } \\
\text { beneficios financieros y no financieros y; el riesgo?. }\end{array}$ \\
\hline & $\begin{array}{l}\text { 2.2b. Los líderes de gobierno, ¿Garantizan la existencia de medidas de } \\
\text { rendimiento y comportamiento estratégico para uso del gobierno en el contexto } \\
\text { de valor?. }\end{array}$ \\
\hline & $\begin{array}{l}\text { 2.2c. Los líderes de gobierno, ¿Garantizan la existencia de un proceso para la } \\
\text { asignación de responsabilidades y delegación de competencias relacionadas con } \\
\text { el establecimiento de indicadores de desempeño/rendimiento de la organización?. }\end{array}$ \\
\hline
\end{tabular}

\begin{tabular}{|c|c|}
\hline Sub-criterio & Valor percibido \\
\hline 2.1. Dirección de estrategias & a. Aplicación del ejercicio de dirección estratégica. \\
\hline $\begin{array}{l}\text { 2.2. Evaluación de estrategias en } \\
\text { base a información obtenida por } \\
\text { mediciones de los resultados y } \\
\text { actividades relacionadas con la } \\
\text { innovación y creatividad. }\end{array}$ & a. Efectos de los resultados de evaluación de estrategias en el negocio. \\
\hline
\end{tabular}




\begin{tabular}{|c|c|c|c|c|c|c|c|c|c|c|c|c|c|c|}
\hline Criterio: & \multicolumn{9}{|l|}{ 2. Estrategias } & \multicolumn{5}{|c|}{ Medición Implantación } \\
\hline $\begin{array}{l}\text { Sub- } \\
\text { criterio: }\end{array}$ & \multicolumn{9}{|c|}{ 2.1. Dirección de estrategias } & $\begin{array}{l}\text { Pond } \\
\text { [PIM }\end{array}$ & ación & \multicolumn{3}{|c|}{0,40} \\
\hline \multirow{2}{*}{ [i] } & \multirow{2}{*}{$\begin{array}{l}\text { Dim } \\
{[i]}\end{array}$} & \multicolumn{5}{|c|}{$\begin{array}{l}\text { Valoración Importancia } \\
\text { I [i] }\end{array}$} & \multirow{2}{*}{$\begin{array}{l}\text { Total } \\
\text { I [i] }\end{array}$} & \multicolumn{5}{|c|}{$\begin{array}{c}\text { Valoración Difusión } \\
\text { D [i] }\end{array}$} & \multirow{2}{*}{$\begin{array}{l}\text { Total } \\
\text { D [i] }\end{array}$} & \multirow{2}{*}{ Peso } \\
\hline & & $\mathbf{0 , 0 0}$ & 0,25 & $\mathbf{0 , 5 0}$ & 0,75 & 1,00 & & $\mathbf{0 , 0 0}$ & 0,25 & $\mathbf{0 , 5 0}$ & 0,75 & 1,00 & & \\
\hline 1 & $\begin{array}{l}\text { 2.1a. Los líderes de } \\
\text { gobierno, } \\
\text { ¿Aseguran } \\
\text { comprensión con la } \\
\text { que se deben } \\
\text { alinear r las } \\
\text { inversiones de } \\
\text { negocio habilitadas } \\
\text { por TSI? }\end{array}$ & 0 & 4 & 3 & 0 & 0 & 0,36 & 2 & 5 & 0 & 0 & 0 & 0,18 & 1,00 \\
\hline 2 & 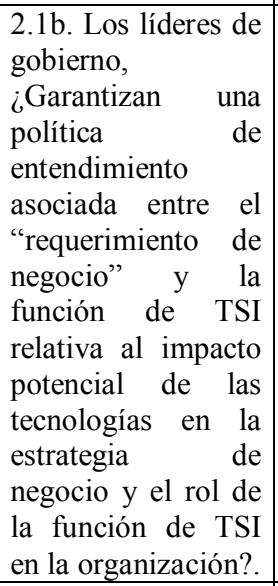 & 0 & 3 & 4 & 0 & 0 & 0,39 & 0 & 5 & 2 & 0 & 0 & 0,32 & 1,00 \\
\hline 3 & $\begin{array}{l}\text { 2.1c. Los líderes de } \\
\text { gobierno, } \\
\text { ¿Garantizan r una } \\
\text { política } \\
\text { comprensión } \text { de } \\
\text { tome en } \\
\text { "principios, visión, } \\
\text { objetivos } \\
\text { estratégicos } \\
\text { prioridades } \\
\text { negocio" para de } \\
\text { servicios definidos } \\
\text { en un plan de } \\
\text { negocio?. }\end{array}$ & 0 & 4 & 3 & 0 & 0 & 0,36 & 0 & 6 & 1 & 0 & 0 & 0,29 & 1,00 \\
\hline \multicolumn{7}{|c|}{ Valor de la Implantación: IMSC } & \multicolumn{8}{|c|}{0,26} \\
\hline
\end{tabular}




\begin{tabular}{|c|c|c|c|c|c|c|c|c|c|c|c|c|c|c|}
\hline $\begin{array}{l}\text { Criterio } \\
:\end{array}$ & \multicolumn{9}{|l|}{ 2. Estrategias } & \multicolumn{5}{|c|}{ Medición Implantación } \\
\hline $\begin{array}{l}\text { Sub- } \\
\text { criterio: }\end{array}$ & \multicolumn{9}{|c|}{$\begin{array}{l}\text { 2.2. Evaluación de estrategias en base a información obtenida por } \\
\text { mediciones de los resultados y actividades relacionadas con la innovación } \\
\text { y creatividad. }\end{array}$} & $\begin{array}{l}\text { Ponde } \\
\text { n [PIN }\end{array}$ & ració & \multicolumn{3}{|c|}{0,40} \\
\hline \multirow{2}{*}{ [i] } & \multirow{2}{*}{$\begin{array}{c}\text { Dim } \\
\text { [i] }\end{array}$} & \multicolumn{5}{|c|}{$\begin{array}{c}\text { Valoración Importancia } \\
\text { I [i] }\end{array}$} & \multirow{2}{*}{$\begin{array}{c}\text { Tota } \\
1 \\
\text { I [i] }\end{array}$} & \multicolumn{5}{|c|}{$\begin{array}{c}\text { Valoración Difusión } \\
\text { D [i] }\end{array}$} & \multirow{2}{*}{$\begin{array}{l}\text { Tota } \\
1 \\
\text { D [i] }\end{array}$} & \multirow{2}{*}{$\begin{array}{c}\text { Pes } \\
\text { o }\end{array}$} \\
\hline & & $\begin{array}{c}\mathbf{0 , 0} \\
\mathbf{0}\end{array}$ & $\begin{array}{c}0,2 \\
5\end{array}$ & $\begin{array}{c}0,5 \\
0\end{array}$ & $\begin{array}{c}0,7 \\
5\end{array}$ & $\begin{array}{c}1,0 \\
0\end{array}$ & & $\begin{array}{c}\mathbf{0 , 0} \\
\mathbf{0}\end{array}$ & $\begin{array}{c}0,2 \\
5\end{array}$ & $\mathbf{0 , 5 0}$ & 0,75 & $\begin{array}{c}1,0 \\
0\end{array}$ & & \\
\hline 1 & $\begin{array}{l}\text { 2.2a. Los líderes de } \\
\text { gobierno, ¿Garantizan } \\
\text { la definición de } \\
\text { criterios de evaluación } \\
\text { de estrategias de } \\
\text { inversión habilitadas } \\
\text { por TSI en base a } \\
\text { información r que } \\
\text { demuestre r el } \\
\text { alineamiento ron } \\
\text { objetivos estratégicos } \\
\text { de la organización; } \\
\text { beneficios financieros } \\
\text { y no financieros y; el } \\
\text { riesgo?. }\end{array}$ & 0 & 5 & 2 & 0 & 0 & 0,32 & 0 & 6 & 1 & 0 & 0 & 0,29 & 1,00 \\
\hline 2 & $\begin{array}{lr}2.2 \mathrm{~b} . \text { Los líderes de } \\
\text { gobierno, ¿Garantizan } \\
\text { la existencia de } \\
\text { medidas } & \text { de } \\
\text { rendimiento } & \text { y } \\
\text { comportamiento } & \\
\text { estratégico para uso del } \\
\text { gobierno en el contexto } \\
\text { de valor?. }\end{array}$ & 0 & 4 & 3 & 0 & 0 & 0,36 & 2 & 5 & 0 & 0 & 0 & 0,18 & 1,00 \\
\hline 3 & $\begin{array}{lr}\text { 2.2c. Los líderes de } \\
\text { gobierno, ¿Garantizan } \\
\text { la existencia de un } \\
\text { proceso para la } \\
\text { asignación } & \text { de } \\
\text { responsabilidades } & \text { y } \\
\text { delegación } & \text { de } \\
\text { competencias } & \\
\text { relacionadas con el } \\
\text { establecimiento } \\
\text { indicadores de } \\
\text { desempeño/rendimient } \\
\text { o de la organización?. }\end{array}$ & 0 & 5 & 2 & 0 & 0 & 0,32 & 0 & 2 & 5 & 0 & 0 & 0,43 & 1,00 \\
\hline \multicolumn{7}{|c|}{ Valor de la Implantación: IMSC } & \multicolumn{8}{|c|}{0,29} \\
\hline
\end{tabular}




\begin{tabular}{|c|c|c|c|c|c|c|c|c|c|c|c|c|c|c|}
\hline Criterio: & \multicolumn{9}{|l|}{ 2. Estrategias } & \multicolumn{5}{|c|}{ Medición Aplicación } \\
\hline $\begin{array}{l}\text { Sub- } \\
\text { criterio: }\end{array}$ & \multicolumn{9}{|c|}{ 2.1. Dirección de estrategias } & $\begin{array}{l}\text { Pond } \\
\text { [PAP }\end{array}$ & ación & \multicolumn{3}{|c|}{0,30} \\
\hline \multirow{2}{*}{ [i] } & \multirow{2}{*}{$\begin{array}{c}\text { Dim } \\
\text { [i] }\end{array}$} & \multicolumn{5}{|c|}{$\begin{array}{c}\text { Valoración Utilización } \\
\text { U [i] }\end{array}$} & \multirow{2}{*}{$\begin{array}{l}\text { Total } \\
\text { U [i] }\end{array}$} & \multicolumn{5}{|c|}{$\begin{array}{c}\text { Valoración Seguimiento } \\
\text { S [i] }\end{array}$} & \multirow{2}{*}{$\begin{array}{l}\text { Total } \\
\text { S [i] }\end{array}$} & \multirow{2}{*}{ Peso } \\
\hline & & $\mathbf{0 , 0 0}$ & 0,25 & $\mathbf{0 , 5 0}$ & 0,75 & $\mathbf{1 , 0 0}$ & & $\mathbf{0 , 0 0}$ & 0,25 & $\mathbf{0 , 5 0}$ & 0,75 & 1,00 & & \\
\hline 1 & $\begin{array}{l}\text { 2.1a. Los líderes de } \\
\text { gobierno, } \\
\text { ¿Aseguran } \\
\text { comprensión con la } \\
\text { que se deben } \\
\text { alinear } r \text { las } \\
\text { inversiones re } \\
\text { negocio habilitadas } \\
\text { por TSI?. }\end{array}$ & 0 & 0 & 0 & 4 & 3 & 0,86 & 0 & 0 & 0 & 2 & 5 & 0,93 & 1,00 \\
\hline 2 & 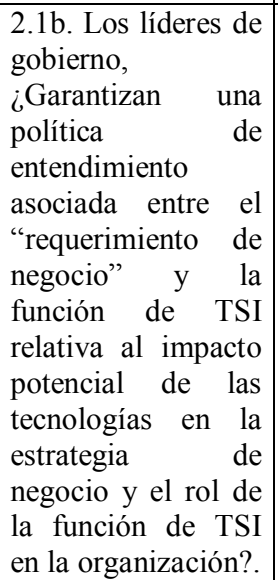 & 0 & 0 & 0 & 3 & 4 & 0,89 & 0 & 0 & 0 & 2 & 5 & 0,93 & 1,00 \\
\hline 3 & $\begin{array}{l}\text { 2.1c. Los líderes de } \\
\text { gobierno, } \\
\text { ¿Garantizan } \\
\text { política } \\
\text { comprensión } r \text { que } \\
\text { tome en cuenta } \\
\text { "principios, visión, } \\
\text { objetivos } \\
\text { estratégicos } \\
\text { prioridades } \\
\text { negocio" para de } \\
\text { servicios definidos } \\
\text { en un plan de } \\
\text { negocio?. }\end{array}$ & 0 & 0 & 0 & 2 & 5 & 0,93 & 0 & 0 & 1 & 3 & 3 & 0,82 & 1,00 \\
\hline \multicolumn{7}{|c|}{ Valor de la Aplicación: $A P S C$} & \multicolumn{8}{|c|}{0,89} \\
\hline
\end{tabular}




\begin{tabular}{|c|c|c|c|c|c|c|c|c|c|c|c|c|c|c|}
\hline $\begin{array}{l}\text { Criterio } \\
:\end{array}$ & \multicolumn{9}{|l|}{ 2. Estrategias } & \multicolumn{5}{|c|}{ Medición Aplicación } \\
\hline $\begin{array}{l}\text { Sub- } \\
\text { criterio: }\end{array}$ & \multicolumn{9}{|c|}{$\begin{array}{l}\text { 2.2. Evaluación de estrategias en base a información obtenida por } \\
\text { mediciones de los resultados y actividades relacionadas con la innovación } \\
\text { y creatividad. }\end{array}$} & $\begin{array}{l}\text { Pond } \\
\text { n [PA }\end{array}$ & $\begin{array}{l}\text { ació } \\
\text { ]: }\end{array}$ & \multicolumn{3}{|c|}{0,30} \\
\hline \multirow{2}{*}{ [i] } & \multirow{2}{*}{$\begin{array}{c}\text { Dim } \\
\text { [i] }\end{array}$} & \multicolumn{5}{|c|}{$\begin{array}{c}\text { Valoración Utilización } \\
\text { U [i] }\end{array}$} & \multirow{2}{*}{$\begin{array}{c}\text { Tota } \\
\mathbf{1} \\
\mathbf{U}[\mathbf{i}]\end{array}$} & \multicolumn{5}{|c|}{$\begin{array}{c}\text { Valoración Seguimiento } \\
\text { S [i] }\end{array}$} & \multirow{2}{*}{$\begin{array}{l}\text { Tota } \\
1 \\
\text { S [i] }\end{array}$} & \multirow{2}{*}{$\begin{array}{c}\text { Pes } \\
\text { o }\end{array}$} \\
\hline & & $\begin{array}{c}\mathbf{0 , 0} \\
\mathbf{0}\end{array}$ & $\begin{array}{c}0,2 \\
5\end{array}$ & $\begin{array}{c}0,5 \\
0\end{array}$ & $\begin{array}{c}\mathbf{0 , 7} \\
5\end{array}$ & $\begin{array}{c}1,0 \\
0\end{array}$ & & $\begin{array}{c}\mathbf{0 , 0} \\
\mathbf{0}\end{array}$ & $\begin{array}{c}0,2 \\
5\end{array}$ & $\mathbf{0 , 5 0}$ & 0,75 & $\begin{array}{c}1,0 \\
0\end{array}$ & & \\
\hline 1 & $\begin{array}{l}\text { 2.2a. Los líderes de } \\
\text { gobierno, ¿Garantizan } \\
\text { la definición de } \\
\text { criterios de evaluación } \\
\text { de estrategias de } \\
\text { inversión habilitadas } \\
\text { por TSI en base a } \\
\text { información r que } \\
\text { demuestre } \\
\text { alineamiento el } \\
\text { objetivos estratégicos } \\
\text { de la organización; } \\
\text { beneficios financieros } \\
\text { y no financieros y; el } \\
\text { riesgo?. }\end{array}$ & 0 & 1 & 3 & 3 & 0 & 0,57 & 0 & 0 & 3 & 4 & 0 & 0,64 & $\mathbf{1 , 0 0}$ \\
\hline 2 & $\begin{array}{lr}\text { 2.2b. Los líderes de } \\
\text { gobierno, ¿Garantizan } \\
\text { la existencia de } \\
\text { medidas } \\
\text { rendimiento r de } \\
\text { comportamiento } \\
\text { estratégico para uso del } \\
\text { gobierno en el contexto } \\
\text { de valor?. }\end{array}$ & 0 & 2 & 4 & 1 & 0 & 0,46 & 0 & 0 & 2 & 2 & 3 & 0,79 & 1,00 \\
\hline 3 & $\begin{array}{lr}\text { 2.2c. Los líderes } & \text { de } \\
\text { gobierno, ¿Garantizan } \\
\text { la existencia de un } \\
\text { proceso para ro la } \\
\text { asignación } & \text { de } \\
\text { responsabilidades } & \mathrm{y} \\
\text { delegación } & \mathrm{de} \\
\text { competencias } & \\
\text { relacionadas con } & \mathrm{el} \\
\text { establecimiento } & \mathrm{de} \\
\text { indicadores } & \mathrm{de} \\
\text { desempeño/rendimient } \\
\text { o de la organización?. }\end{array}$ & 0 & 0 & 2 & 5 & 0 & 0,68 & 0 & 0 & 3 & 3 & 1 & 0,68 & $\mathbf{1 , 0 0}$ \\
\hline \multicolumn{7}{|c|}{ Valor de la Aplicación: $A P S C$} & \multicolumn{8}{|c|}{0,70} \\
\hline
\end{tabular}




\begin{tabular}{|c|c|c|c|c|c|c|c|}
\hline Criterio: & \multicolumn{4}{|l|}{ 2. Estrategias } & \multicolumn{3}{|c|}{ Medición Efecto } \\
\hline Sub-criterio: & \multicolumn{4}{|l|}{ 2.1. Dirección de estrategias } & \multicolumn{2}{|c|}{$\begin{array}{l}\text { Ponderación } \\
\text { [PEF]: }\end{array}$} & 0,30 \\
\hline \multirow[t]{2}{*}{ [i] } & \multirow{2}{*}{$\begin{array}{c}\text { Dim } \\
{[i]}\end{array}$} & \multicolumn{5}{|c|}{$\begin{array}{c}\text { Valoración del Valor Percibido } \\
\text { V [i] }\end{array}$} & \multirow{2}{*}{$\begin{array}{l}\text { Total } \\
\text { V [i] }\end{array}$} \\
\hline & & $\mathbf{0 , 0 0}$ & 0,25 & $\mathbf{0 , 5 0}$ & 0,75 & 1,00 & \\
\hline 1 & $\begin{array}{l}\text { a. Aplicación del ejercicio de } \\
\text { dirección estratégica. }\end{array}$ & 0 & 0 & 0 & 0 & 3 & 1,00 \\
\hline \multicolumn{7}{|c|}{ Valor del Efecto: $E F S C$} & 1,00 \\
\hline
\end{tabular}

\begin{tabular}{|c|c|c|c|c|c|c|c|}
\hline Criterio: & \multicolumn{4}{|l|}{ 2. Estrategias } & \multicolumn{3}{|c|}{ Medición Efecto } \\
\hline Sub-criterio: & \multicolumn{4}{|c|}{$\begin{array}{l}\text { 2.2. Evaluación de estrategias en base a información obtenida por } \\
\text { mediciones de los resultados y actividades relacionadas con la } \\
\text { innovación y creatividad. }\end{array}$} & \multicolumn{2}{|c|}{$\begin{array}{l}\text { Ponderación } \\
{[\text { PEF }] \text { : }}\end{array}$} & 0,30 \\
\hline \multirow{2}{*}{ [i] } & \multirow{2}{*}{$\begin{array}{c}\text { Dim } \\
\text { [i] }\end{array}$} & \multicolumn{5}{|c|}{$\begin{array}{c}\text { Valoración del Valor Percibido } \\
\text { V [i] }\end{array}$} & \multirow{2}{*}{$\begin{array}{l}\text { Total } \\
\text { V [i] }\end{array}$} \\
\hline & & $\mathbf{0 , 0 0}$ & 0,25 & $\mathbf{0 , 5 0}$ & 0,75 & 1,00 & \\
\hline 1 & $\begin{array}{l}\text { a. Efectos de los resultados de } \\
\text { evaluación de estrategias en el } \\
\text { negocio. }\end{array}$ & 0 & 0 & 0 & 2 & 1 & 0,83 \\
\hline \multicolumn{7}{|c|}{ Valor del Efecto: $E F S C$} & 0,83 \\
\hline
\end{tabular}

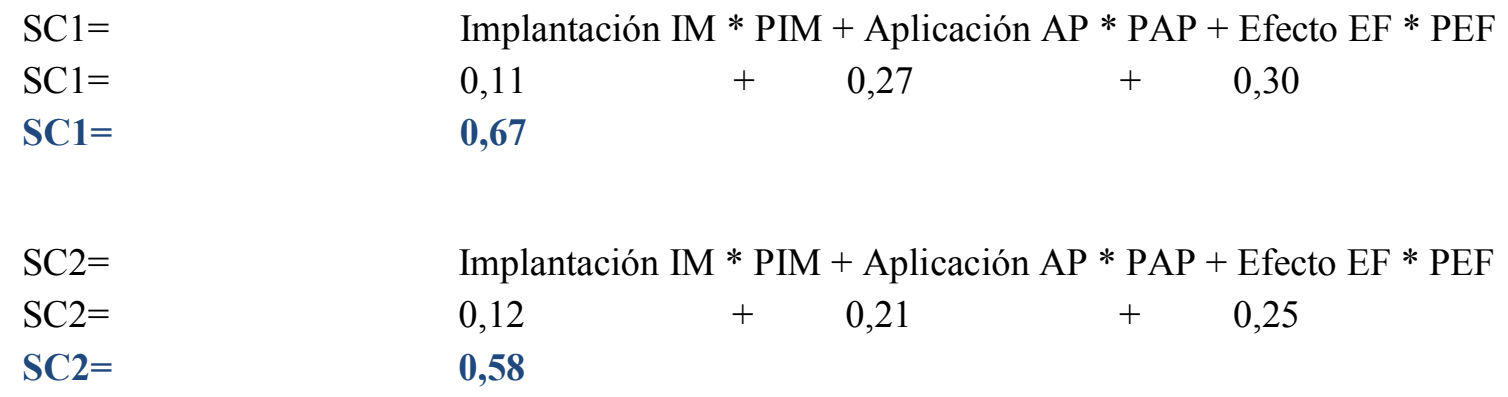

MEDIDA TOTAL DEL CRITERIO ESTRATEGIA $=\quad 0,62$ 


\section{Autoevaluación de Personas}

\section{CRITERIO: PERSONAS}

\begin{tabular}{|l|l|}
\hline \multicolumn{1}{|c|}{ Sub-criterios } & \multicolumn{1}{c|}{ Descripción } \\
\hline $\begin{array}{l}\text { 3.1. Roles y responsabilidades para } \\
\text { materializar y proteger el valor. }\end{array}$ & $\begin{array}{l}\text { Se evalúa cómo se define y comunica los roles y responsabilidades para todo } \\
\text { el personal que se relaciona con la cartera de proyectos de inversión del } \\
\text { negocio habilitados por las TSI, con el propósito de otorgar la autoridad } \\
\text { suficiente para desempenar con eficacia los roles y responsabilidades } \\
\text { asignadas. }\end{array}$ \\
\hline
\end{tabular}

\begin{tabular}{|c|c|}
\hline Criterio de Valor: & 3. Personas \\
\hline Sub-criterio & Dimensiones \\
\hline \multirow{5}{*}{$\begin{array}{l}\text { 3.1. Roles y responsabilidades para } \\
\text { materializar y proteger el valor. }\end{array}$} & $\begin{array}{l}\text { 3.1a. El gobierno de TSI, ¿Promueve el nivel de conciencia de los beneficios } \\
\text { de las TSI entre los tomadores de decisión de la organización?. }\end{array}$ \\
\hline & $\begin{array}{l}\text { 3.1b. El gobierno de TSI, ¿Promueve el nivel de conciencia de los beneficios } \\
\text { de las TSI entre el staff de usuarios de la organización que no pertenecen a la } \\
\text { función de TSI?. }\end{array}$ \\
\hline & $\begin{array}{l}\text { 3.1c. El gobierno de TSI, ¿Promueve talleres de concientización para } \\
\text { tomadores de decisiones y el staff de usuarios que no pertenecen a la función } \\
\text { de TSI?. }\end{array}$ \\
\hline & $\begin{array}{l}\text { 3.1d. La organización, ¿Promueve la formación y evaluación del gobierno de } \\
\text { valor de TSI en función de las responsabilidades asignadas en relación con la } \\
\text { definición de la cartera de programas de inversión de negocio habilitadas por } \\
\text { las TSI?. }\end{array}$ \\
\hline & $\begin{array}{l}\text { 3.1e. El gobierno de TSI, ¿Promueve la entrega al usuario del negocio de } \\
\text { procedimientos, técnicas y herramientas que les permitan responder a sus } \\
\text { responsabilidades relacionadas con las inversiones de negocio habilitadas por } \\
\text { las TSI?. }\end{array}$ \\
\hline
\end{tabular}

\section{Sub-criterio}

3.1. Roles y responsabilidades para materializar y proteger el valor.

\section{Valor percibido}

a. Mejora en la toma de decisiones como efecto del impulso a través de la concientización.

b. Participación del equipo rector de gobierno de TSI en la formación y evaluación.

c. Mejoras propuestas por las personas y aceptadas por el gobierno de TSI. 


\begin{tabular}{|c|c|c|c|c|c|c|c|c|c|c|c|c|c|c|}
\hline \multirow{4}{*}{$\begin{array}{c}\text { Criterio: } \\
\begin{array}{l}\text { Sub- } \\
\text { criterio: }\end{array} \\
{[i]}\end{array}$} & \multicolumn{9}{|l|}{ 3. Personas } & \multicolumn{5}{|c|}{ Medición Implantación } \\
\hline & \multicolumn{9}{|c|}{ 3.1. Roles y responsabilidades para materializar y proteger el valor. } & \multicolumn{2}{|c|}{$\begin{array}{l}\text { Ponderación } \\
\text { [PIM]: }\end{array}$} & \multicolumn{3}{|c|}{0,40} \\
\hline & \multirow{2}{*}{$\begin{array}{l}\text { Dim } \\
\text { [i] }\end{array}$} & \multicolumn{5}{|c|}{$\begin{array}{c}\text { Valoración Importancia } \\
\text { I [i] }\end{array}$} & \multirow{2}{*}{$\begin{array}{l}\text { Total } \\
\text { I [i] }\end{array}$} & \multicolumn{5}{|c|}{$\begin{array}{c}\text { Valoración Difusión } \\
\text { D [i] }\end{array}$} & \multirow{2}{*}{$\begin{array}{l}\text { Total } \\
\text { D [i] }\end{array}$} & \multirow{2}{*}{ Peso } \\
\hline & & $\mathbf{0 , 0 0}$ & 0,25 & 0,50 & 0,75 & 1,00 & & $\mathbf{0 , 0 0}$ & 0,25 & $\mathbf{0 , 5 0}$ & 0,75 & 1,00 & & \\
\hline 1 & $\begin{array}{lr}\text { 3.1a. El gobierno } \\
\text { de TSI, ¿Promueve } \\
\text { el nivel de } \\
\text { conciencia de los } \\
\text { beneficios de las } \\
\text { TSI entre los } \\
\text { tomadores } & \text { de } \\
\text { decisión de } & \text { la } \\
\text { organización?. } & \\
\end{array}$ & 0 & 0 & 5 & 2 & 0 & 0,57 & 2 & 5 & 0 & 0 & 0 & 0,18 & 1,00 \\
\hline 2 & $\begin{array}{l}\text { 3.1b. El gobierno } \\
\text { de TSI, ¿Promueve } \\
\text { el nivel de } \\
\text { conciencia de los } \\
\text { beneficios de las } \\
\text { TSI entre el staff de } \\
\text { usuarios de la } \\
\text { organización que } \\
\text { no pertenecen a la } \\
\text { función de TSI?. }\end{array}$ & 0 & 0 & 4 & 3 & 0 & 0,61 & 0 & 3 & 4 & 0 & 0 & 0,39 & 1,00 \\
\hline 3 & $\begin{array}{l}\text { 3.1c. El gobierno } \\
\text { de TSI, ¿Promueve } \\
\text { talleres de } \\
\text { concientización } \\
\text { para tomadores de } \\
\text { decisiones y el staff } \\
\text { de usuarios que no } \\
\text { pertenecen a la } \\
\text { función de TSI?. }\end{array}$ & 0 & 0 & 4 & 3 & 0 & 0,61 & 0 & 3 & 4 & 0 & 0 & 0,39 & 1,00 \\
\hline 4 & \begin{tabular}{lr} 
3.1d. & La \\
organización, & \\
¿Promueve & la \\
formación & y \\
evaluación & del \\
gobierno de valor \\
de TSI en función \\
de & \multicolumn{2}{l}{ las } \\
responsabilidades \\
asignadas & en \\
relación con & la \\
definición de & la \\
cartera & de \\
programas & de \\
inversión & de \\
negocio habilitadas \\
por las TSI?.
\end{tabular} & 0 & 0 & 2 & 5 & 0 & 0,68 & 3 & 4 & 0 & 0 & 0 & 0,14 & 1,00 \\
\hline 5 & $\begin{array}{l}\text { 3.1e. El gobierno } \\
\text { de TSI, ¿Promueve } \\
\text { la entrega al } \\
\text { usuario del negocio } \\
\text { de procedimientos, } \\
\text { técnicas y } \\
\text { herramientas que } \\
\text { les permitan } \\
\text { responder a sus } \\
\text { responsabilidades } \\
\text { relacionadas con } \\
\text { las inversiones de }\end{array}$ & 0 & 3 & 3 & 1 & 0 & 0,43 & 0 & 3 & 4 & 0 & 0 & 0,39 & 1,00 \\
\hline
\end{tabular}




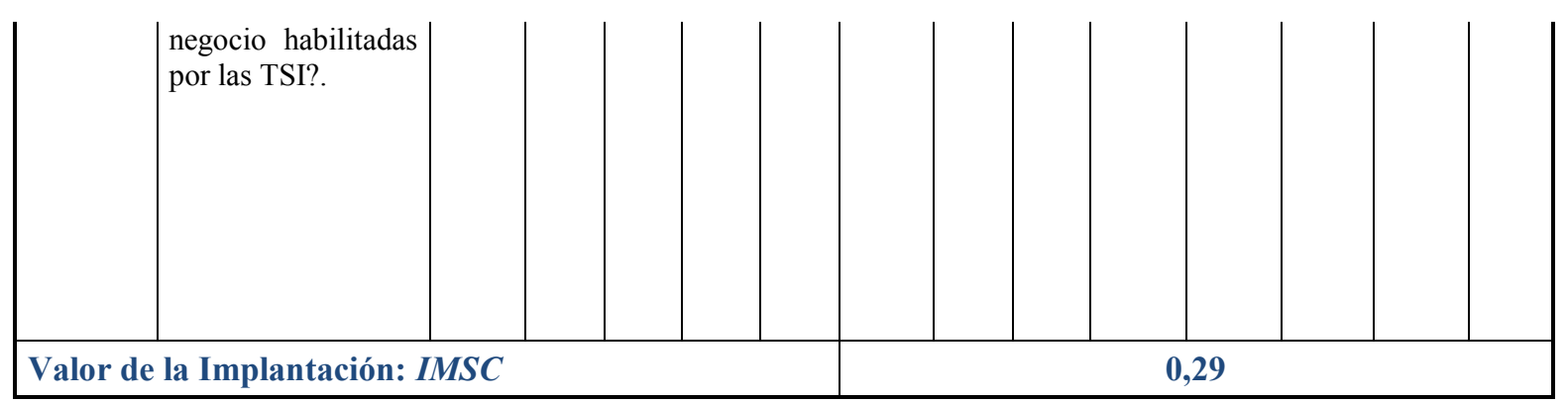




\begin{tabular}{|c|c|c|c|c|c|c|c|c|c|c|c|c|c|c|}
\hline \multirow{4}{*}{$\begin{array}{c}\text { Criterio: } \\
\begin{array}{l}\text { Sub- } \\
\text { criterio: }\end{array} \\
\text { [i] }\end{array}$} & \multicolumn{9}{|l|}{ 3. Personas } & \multicolumn{5}{|c|}{ Medición Aplicación } \\
\hline & \multicolumn{9}{|c|}{ 3.1. Roles y responsabilidades para materializar y proteger el valor. } & \multicolumn{2}{|c|}{$\begin{array}{l}\text { Ponderación } \\
\text { [PAP]: }\end{array}$} & \multicolumn{3}{|c|}{0,30} \\
\hline & \multirow{2}{*}{$\begin{array}{c}\text { Dim } \\
\text { [i] }\end{array}$} & \multicolumn{5}{|c|}{$\begin{array}{c}\text { Valoración Utilización } \\
\text { U [i] }\end{array}$} & \multirow{2}{*}{$\begin{array}{l}\text { Total } \\
\text { U [i] }\end{array}$} & \multicolumn{5}{|c|}{$\begin{array}{c}\text { Valoración Seguimiento } \\
\text { S [i] }\end{array}$} & \multirow{2}{*}{$\begin{array}{l}\text { Total } \\
\text { S [i] }\end{array}$} & \multirow{2}{*}{ Peso } \\
\hline & & $\mathbf{0 , 0 0}$ & 0,25 & $\mathbf{0 , 5 0}$ & 0,75 & 1,00 & & $\mathbf{0 , 0 0}$ & 0,25 & $\mathbf{0 , 5 0}$ & 0,75 & 1,00 & & \\
\hline 1 & $\begin{array}{lr}3.1 \text { a. El gobierno } \\
\text { de TSI, ¿Promueve } \\
\text { el nivel re } \\
\text { conciencia de los } \\
\text { beneficios de las } \\
\text { TSI entre r los } \\
\text { tomadores } & \text { de } \\
\text { decisión de } & \text { la } \\
\text { organización?. }\end{array}$ & 0 & 0 & 0 & 4 & 3 & 0,86 & 0 & 0 & 2 & 2 & 3 & 0,79 & 1,00 \\
\hline 2 & $\begin{array}{l}\text { 3.1b. El gobierno } \\
\text { de TSI, ¿Promueve } \\
\text { el nivel de } \\
\text { conciencia de los } \\
\text { beneficios de las } \\
\text { TSI entre el staff de } \\
\text { usuarios de la } \\
\text { organización que } \\
\text { no pertenecen a la } \\
\text { función de TSI?. }\end{array}$ & 0 & 0 & 0 & 4 & 3 & 0,86 & 0 & 0 & 2 & 2 & 3 & 0,79 & 1,00 \\
\hline 3 & $\begin{array}{l}\text { 3.1c. El gobierno } \\
\text { de TSI, ¿Promueve } \\
\text { talleres de } \\
\text { concientización } \\
\text { para tomadores de } \\
\text { decisiones y el staff } \\
\text { de usuarios que no } \\
\text { pertenecen a la } \\
\text { función de TSI?. }\end{array}$ & 0 & 0 & 0 & 4 & 3 & 0,86 & 0 & 0 & 3 & 3 & 1 & 0,68 & 1,00 \\
\hline 4 & $\begin{array}{lr}\text { 3.1d. } & \text { La } \\
\text { organización, } & \\
\text { ¿Promueve } & \text { la } \\
\text { formación } & \text { y } \\
\text { evaluación } & \text { del } \\
\text { gobierno de valor } \\
\text { de TSI en función } \\
\text { de } \\
\text { responsabilidades } \\
\text { asignadas las } \\
\text { relación con } \\
\text { definición de } \\
\text { cartera la } \\
\text { programas } & \text { le } \\
\text { inversión } & \text { de } \\
\text { negocio habilitadas } \\
\text { por las TSI?. }\end{array}$ & 0 & 0 & 0 & 3 & 4 & 0,89 & 0 & 0 & 4 & 3 & 0 & 0,61 & 1,00 \\
\hline 5 & $\begin{array}{l}\text { 3.1e. El gobierno } \\
\text { de TSI, ¿Promueve } \\
\text { la entrega al } \\
\text { usuario del negocio } \\
\text { de procedimientos, } \\
\text { técnicas y } \\
\text { herramientas que } \\
\text { les permitan } \\
\text { responder a sus } \\
\text { responsabilidades } \\
\text { relacionadas con las } \\
\text { inversiones de }\end{array}$ & 0 & 0 & 0 & 4 & 3 & 0,86 & 1 & 2 & 4 & 0 & 0 & 0,36 & 1,00 \\
\hline
\end{tabular}




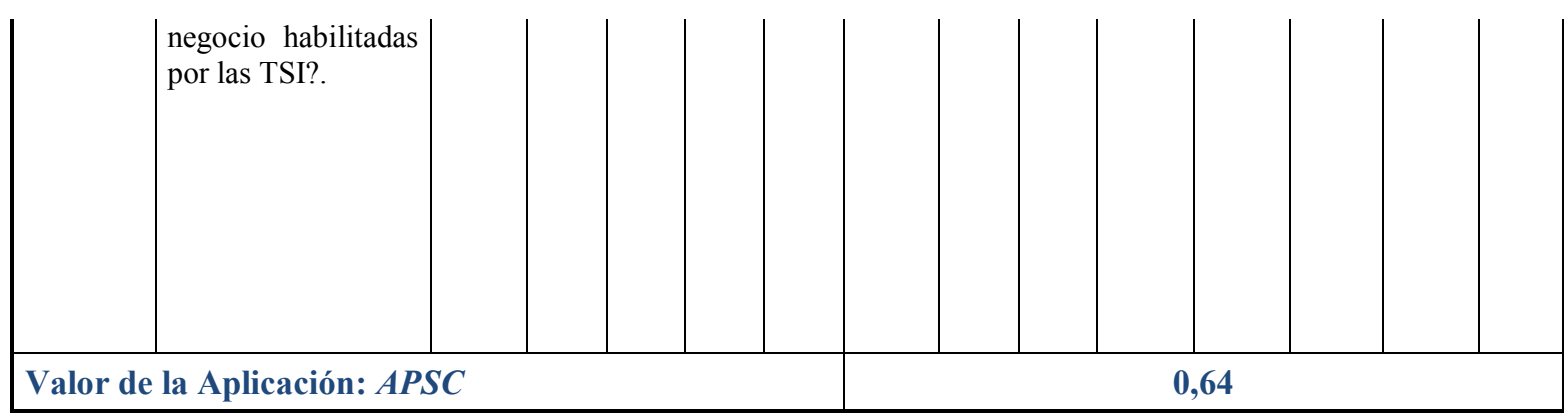

\begin{tabular}{|c|c|c|c|c|c|c|c|}
\hline Criterio: & \multicolumn{4}{|l|}{ 3. Personas } & \multicolumn{3}{|c|}{ Medición Efecto } \\
\hline Sub-criterio: & \multicolumn{4}{|c|}{ 3.1. Roles y responsabilidades para materializar y proteger el valor. } & \multicolumn{2}{|c|}{$\begin{array}{l}\text { Ponderación } \\
\text { [PEF]: }\end{array}$} & \multirow{3}{*}{$\begin{array}{r}0,30 \\
\text { Total } \\
\text { V [i] }\end{array}$} \\
\hline \multirow{2}{*}{ [i] } & \multirow{2}{*}{$\begin{array}{c}\text { Dim } \\
\text { [i] }\end{array}$} & \multicolumn{5}{|c|}{$\begin{array}{c}\text { Valoración del Valor Percibido } \\
\text { V [i] }\end{array}$} & \\
\hline & & $\mathbf{0 , 0 0}$ & 0,25 & $\mathbf{0 , 5 0}$ & $\mathbf{0 , 7 5}$ & $\mathbf{1 , 0 0}$ & \\
\hline 1 & $\begin{array}{l}\text { a. Mejora en la toma de decisiones } \\
\text { como efecto del impulso a través } \\
\text { de la concientización. }\end{array}$ & 0 & 0 & 2 & 1 & 0 & 0,58 \\
\hline 2 & $\begin{array}{l}\text { b. Participación del equipo rector } \\
\text { de gobierno de TSI en la } \\
\text { formación y evaluación. }\end{array}$ & 0 & 2 & 1 & 0 & 0 & 0,33 \\
\hline 3 & $\begin{array}{l}\text { c. Mejoras propuestas } \\
\text { personas y aceptadas } \\
\text { gobierno de TSI. }\end{array}$ & 0 & 3 & 0 & 0 & 0 & 0,25 \\
\hline \multicolumn{7}{|c|}{ Valor del Efecto: $E F S C$} & 0,36 \\
\hline
\end{tabular}

$\mathrm{SC} 1=$ Implantación IM * PIM + Aplicación AP * PAP + Efecto EF * PEF

$\mathrm{SC} 1=$

0,12

$+\quad 0,19$

$+\quad 0,11$

$\mathrm{SC} 1=$

0,42

MEDIDA TOTAL DEL CRITERIO PERSONAS = 


\section{Autoevaluación de Recursos}

CRITERIO: RECURSOS

\begin{tabular}{|c|c|c|c|}
\hline \multicolumn{3}{|c|}{ Sub-criterios } & Descripción \\
\hline $\begin{array}{l}\text { 4.1. Recursos } \\
\text { Materiales. }\end{array}$ & Financieros & $\mathbf{y}$ & $\begin{array}{l}\text { Se evalúa cómo se define y adecúan los recursos financieros y materiales con } \\
\text { los objetivos estratégicos, y prioridades. }\end{array}$ \\
\hline
\end{tabular}

\begin{tabular}{|l|l|}
\hline Criterio de Valor: & 4. Recursos \\
\hline \multicolumn{1}{|c|}{ Sub-criterio } & \multicolumn{1}{c|}{ Dimensiones } \\
\hline $\begin{array}{l}\text { 4.1. Recursos } \quad \text { Financieros } \\
\text { Materiales. }\end{array}$ & $\begin{array}{l}\text { y.1a. El gobierno de TSI, ¿Garantiza que se gestione de manera eficiente los } \\
\text { recursos financieros de acuerdo a las prioridades señaladas en el plan de } \\
\text { inversiones del negocio habilitadas por TSI?. }\end{array}$ \\
\cline { 2 - 2 } & $\begin{array}{l}\text { 4.1b. El gobierno de TSI, ¿Garantiza la disponibilidad de recursos materiales } \\
\text { para cubrir las necesidades prioritarias con criterio de calidad?. }\end{array}$ \\
\hline
\end{tabular}

\begin{tabular}{|c|c|c|c|}
\hline \multicolumn{3}{|c|}{ Sub-criterio } & Valor percibido \\
\hline $\begin{array}{l}\text { 4.1. Recursos } \\
\text { Materiales. }\end{array}$ & Financieros & & $\begin{array}{l}\text { a. Se percibe la eficiencia en la gestión de procesos: ahorro en tiempo, recursos } \\
\text { financieros y materiales. }\end{array}$ \\
\hline
\end{tabular}




\begin{tabular}{|c|c|c|c|c|c|c|c|c|c|c|c|c|c|c|}
\hline Criterio: & \multicolumn{9}{|l|}{ 4. Recursos } & \multicolumn{5}{|c|}{ Medición Implantación } \\
\hline $\begin{array}{l}\text { Sub- } \\
\text { criterio: }\end{array}$ & \multicolumn{9}{|c|}{ 4.1. Recursos Financieros y Materiales. } & $\begin{array}{l}\text { Pond } \\
{[\text { PIM }}\end{array}$ & ación & \multicolumn{3}{|c|}{0,40} \\
\hline \multirow{2}{*}{ [i] } & \multirow{2}{*}{$\begin{array}{l}\text { Dim } \\
\text { [i] }\end{array}$} & \multicolumn{5}{|c|}{$\begin{array}{l}\text { Valoración Importancia } \\
\text { I [i] }\end{array}$} & \multirow{2}{*}{$\begin{array}{c}\text { Total } \\
\text { I [i] }\end{array}$} & \multicolumn{5}{|c|}{$\begin{array}{c}\text { Valoración Difusión } \\
\text { D [i] }\end{array}$} & \multirow{2}{*}{$\begin{array}{l}\text { Total } \\
\text { D [i] }\end{array}$} & \multirow{2}{*}{ Peso } \\
\hline & & $\mathbf{0 , 0 0}$ & 0,25 & $\mathbf{0 , 5 0}$ & 0,75 & 1,00 & & $\mathbf{0 , 0 0}$ & 0,25 & $\mathbf{0 , 5 0}$ & 0,75 & 1,00 & & \\
\hline 1 & $\begin{array}{l}\text { 4.1a. El gobierno } \\
\text { de TSI, ¿Garantiza } \\
\text { que se gestione de } \\
\text { manera eficiente } \\
\text { los recursos } \\
\text { financieros de } \\
\text { acuerdo a las } \\
\text { prioridades } \\
\text { señaladas en el plan } \\
\text { de inversiones del } \\
\text { negocio habilitadas } \\
\text { por TSI?. }\end{array}$ & 0 & 2 & 5 & 0 & 0 & 0,43 & 0 & 2 & 5 & 0 & 0 & 0,43 & 1,00 \\
\hline 2 & $\begin{array}{l}\text { 4.1b. El gobierno } \\
\text { de TSI, ¿Garantiza } \\
\text { la disponibilidad de } \\
\text { recursos materiales } \\
\text { para cubrir las } \\
\text { necesidades } \\
\text { prioritarias con } \\
\text { criterio de calidad?. }\end{array}$ & 0 & 5 & 2 & 0 & 0 & 0,32 & 0 & 2 & 5 & 0 & 0 & 0,43 & 1,00 \\
\hline \multicolumn{7}{|c|}{ Valor de la Implantación: IMSC } & \multicolumn{8}{|c|}{$\mathbf{0 , 4 3}$} \\
\hline
\end{tabular}

\begin{tabular}{|c|c|c|c|c|c|c|c|c|c|c|c|c|c|c|}
\hline Criterio: & \multicolumn{9}{|l|}{ 4. Recursos } & \multicolumn{5}{|c|}{ Medición Aplicación } \\
\hline $\begin{array}{l}\text { Sub- } \\
\text { criterio: }\end{array}$ & \multicolumn{9}{|c|}{ 4.1. Recursos Financieros y Materiales. } & $\begin{array}{l}\text { Pond } \\
{[\text { PAP }}\end{array}$ & ación & \multicolumn{3}{|c|}{0,30} \\
\hline \multirow{2}{*}{ [i] } & \multirow{2}{*}{$\begin{array}{c}\text { Dim } \\
\text { [i] }\end{array}$} & \multicolumn{5}{|c|}{$\begin{array}{c}\text { Valoración Utilización } \\
\text { U [i] }\end{array}$} & \multirow{2}{*}{$\begin{array}{l}\text { Total } \\
\text { U [i] }\end{array}$} & \multicolumn{5}{|c|}{$\begin{array}{c}\text { Valoración Seguimiento } \\
\text { S [i] }\end{array}$} & \multirow{2}{*}{$\begin{array}{c}\text { Total } \\
\text { S [i] }\end{array}$} & \multirow[t]{2}{*}{ Peso } \\
\hline & & $\mathbf{0 , 0 0}$ & 0,25 & $\mathbf{0 , 5 0}$ & 0,75 & 1,00 & & $\mathbf{0 , 0 0}$ & 0,25 & $\mathbf{0 , 5 0}$ & 0,75 & 1,00 & & \\
\hline 1 & $\begin{array}{l}\text { 4.1a. El gobierno } \\
\text { de TSI, ¿Garantiza } \\
\text { que se gestione de } \\
\text { manera eficiente los } \\
\text { recursos financieros } \\
\text { de acuerdo a las } \\
\text { prioridades } \\
\text { señaladas en el plan } \\
\text { de inversiones del } \\
\text { negocio habilitadas } \\
\text { por TSI?. }\end{array}$ & 0 & 0 & 5 & 2 & 0 & 0,57 & 0 & 0 & 0 & 1 & 2 & 0,92 & 1,00 \\
\hline 2 & $\begin{array}{l}\text { 4.1b. El gobierno } \\
\text { de TSI, ¿Garantiza } \\
\text { la disponibilidad de } \\
\text { recursos materiales } \\
\text { para cubrir las } \\
\text { necesidades } \\
\text { prioritarias con } \\
\text { criterio de calidad?. }\end{array}$ & 0 & 0 & 2 & 5 & 0 & 0,68 & 0 & 0 & 1 & 1 & 1 & 0,75 & 1,00 \\
\hline \multicolumn{7}{|c|}{ Valor de la Aplicación: $A P S C$} & \multicolumn{8}{|c|}{0,83} \\
\hline
\end{tabular}




\begin{tabular}{|c|c|c|c|c|c|c|c|}
\hline Criterio: & \multicolumn{4}{|l|}{ 4. Recursos } & \multicolumn{3}{|c|}{ Medición Efecto } \\
\hline Sub-criterio: & \multicolumn{4}{|l|}{ 4.1. Recursos Financieros y Materiales. } & \multicolumn{2}{|c|}{$\begin{array}{l}\text { Ponderación } \\
{[\text { PEF]: }}\end{array}$} & 0,30 \\
\hline \multirow{2}{*}{ [i] } & \multirow{2}{*}{$\begin{array}{c}\text { Dim } \\
\text { [i] }\end{array}$} & \multicolumn{5}{|c|}{$\begin{array}{c}\text { Valoración del Valor Percibido } \\
\text { V [i] }\end{array}$} & \multirow{2}{*}{$\begin{array}{l}\text { Total } \\
\text { V [i] }\end{array}$} \\
\hline & & $\mathbf{0 , 0 0}$ & $\mathbf{0 , 2 5}$ & $\mathbf{0 , 5 0}$ & 0,75 & 1,00 & \\
\hline 1 & $\begin{array}{l}\text { a. Se percibe la eficiencia en la } \\
\text { gestión de procesos: ahorro en } \\
\text { tiempo, recursos financieros y } \\
\text { materiales. }\end{array}$ & 0 & 0 & 2 & 1 & 0 & 0,58 \\
\hline \multicolumn{7}{|c|}{ Valor del Efecto: $E F S C$} & 0,58 \\
\hline
\end{tabular}

$\begin{array}{llll}\mathrm{SC} 1= & \text { Implantación } \mathrm{IM} * \mathrm{PIM}+\text { Aplicación } \mathrm{AP} * \mathrm{PAP}+\text { Efecto EF * PEF } \\ \mathrm{SC} 1= & 0,17 & + & 0,25\end{array}$




\section{Autoevaluación de Procesos}

\section{CRITERIO: PROCESOS}

\begin{tabular}{|l|l|}
\hline \multicolumn{1}{|c|}{ Sub-criterios } & \multicolumn{1}{c|}{ Descripción } \\
\hline $\begin{array}{l}\text { 5.1. Diseño y mejora de procesos de } \\
\text { gobierno de valor. }\end{array}$ & $\begin{array}{l}\text { Se evalúa cómo se define y establece el sistema de gestión de procesos que } \\
\text { vinculen al gobierno con la gestión de las TSI, como soporte en el vínculo entre } \\
\text { la estrategia empresarial y el portafolio de proyectos de inversión habilitados } \\
\text { por TSI. Esto orientado a incrementar el valor percibido de los usuarios y partes } \\
\text { interesadas. }\end{array}$ \\
\hline 5.2. Necesidades de información. & $\begin{array}{l}\text { Se evalúa cómo la organización de TSI define, estructura y gestiona la } \\
\text { información para apoyar las políticas y estrategias de los interesados del } \\
\text { negocio. Además, cómo soporta de manera adecuada el proceso de toma de } \\
\text { decisiones, la ejecución de decisiones y el monitoreo para evidenciar el alcance } \\
\text { de resultados previstos. }\end{array}$ \\
\hline
\end{tabular}

\begin{tabular}{|c|c|}
\hline Criterio de Valor: & 5. Procesos \\
\hline Sub-criterio & Dimensiones \\
\hline \multirow{4}{*}{$\begin{array}{l}\text { 5.1. Diseño y mejora de procesos de } \\
\text { gobierno de valor. }\end{array}$} & $\begin{array}{l}\text { 5.1a. El gobierno de TSI, ¿Garantiza la definición, implementación y } \\
\text { seguimiento constante a los procesos que vinculan la estrategia con la cartera de } \\
\text { los proyectos de inversión habilitadas por las TSI?. }\end{array}$ \\
\hline & $\begin{array}{l}\text { 5.1b. El gobierno de TSI, ¿Garantiza la definición e impulso de la } \\
\text { implementación de un marco de gestión de programas de proyectos de } \\
\text { inversión habilitados por las TSI con el fin de aumentar el valor percibido por } \\
\text { el negocio e interesados?. }\end{array}$ \\
\hline & $\begin{array}{l}\text { 5.1c. El gobierno de TSI, ¿Garantiza la creación de valor a través del } \\
\text { incremento de la calidad en los procesos y la toma de decisiones?. }\end{array}$ \\
\hline & $\begin{array}{l}\text { 5.1d. El gobierno de TSI, ¿Garantiza un proceso para crear nuevo valor por el } \\
\text { uso de las TSI, que se alinee con la estrategia organizacional?. }\end{array}$ \\
\hline \multirow{4}{*}{ 5.2. Necesidades de información. } & $\begin{array}{l}\text { 5.2a. El gobierno de TSI, ¿Garantiza un conjunto de objetivos, mediciones, } \\
\text { metas y comparativas de rendimiento de interés para el negocio y otras partes } \\
\text { interesadas relevantes?. }\end{array}$ \\
\hline & $\begin{array}{l}\text { 5.2b. El gobierno de TSI, ¿Garantiza un proceso para recoger datos puntuales y } \\
\text { exactos para informar sobre el progreso frente a los objetivos estratégicos de la } \\
\text { organización?. }\end{array}$ \\
\hline & $\begin{array}{l}\text { 5.2c. El gobierno de TSI, ¿Garantiza un proceso de monitoreo que establezca } \\
\text { un método de Cuadro de Mando Integral que brinde una visión completa del } \\
\text { rendimiento del programa de proyectos de inversión habilitadas por las TSI?. }\end{array}$ \\
\hline & $\begin{array}{l}\text { 5.2d. El gobierno de TSI, ¿Garantiza un proceso de evaluación de la integridad } \\
\text { de la información y de la protección de la propiedad intelectual de las TSI?. }\end{array}$ \\
\hline Sub-criterio & Valor percibido \\
\hline \multirow{3}{*}{$\begin{array}{l}\text { 5.1. Diseño y mejora de procesos de } \\
\text { gobierno de valor. }\end{array}$} & $\begin{array}{l}\text { a. Buen funcionamiento de la estrategia apoyada en los proyectos de inversión } \\
\text { habilitadas por TSI. }\end{array}$ \\
\hline & $\begin{array}{l}\text { b. Buen desempeño de los programas de proyectos de inversión habilitadas por } \\
\text { TSI. }\end{array}$ \\
\hline & $\begin{array}{l}\text { c. Buen desempeño de procesos creadores de valor a través de documentos que } \\
\text { demuestren su actualización en el último año. }\end{array}$ \\
\hline \multirow{2}{*}{ 5.2. Necesidades de información. } & a. Recursos de información disponibles para toma de decisiones. \\
\hline & b. Uso de las TSI como medios para la toma de decisiones. \\
\hline
\end{tabular}




\begin{tabular}{|c|c|c|c|c|c|c|c|c|c|c|c|c|c|c|}
\hline \multirow{4}{*}{$\begin{array}{c}\text { Criterio: } \\
\begin{array}{l}\text { Sub- } \\
\text { criterio: }\end{array} \\
{[i]}\end{array}$} & \multicolumn{9}{|l|}{ 5. Procesos } & \multicolumn{5}{|c|}{ Medición Implantación } \\
\hline & \multicolumn{9}{|c|}{ 5.1. Diseño y mejora de procesos de gobierno de valor. } & \multicolumn{2}{|c|}{$\begin{array}{l}\text { Ponderación } \\
\text { [PIM]: }\end{array}$} & \multicolumn{3}{|c|}{0,40} \\
\hline & \multirow{2}{*}{$\begin{array}{l}\text { Dim } \\
\text { [i] }\end{array}$} & \multicolumn{5}{|c|}{$\begin{array}{l}\text { Valoración Importancia } \\
\text { I [i] }\end{array}$} & \multirow{2}{*}{$\begin{array}{l}\text { Total } \\
\text { I [i] }\end{array}$} & \multicolumn{5}{|c|}{$\begin{array}{c}\text { Valoración Difusión } \\
\text { D [i] }\end{array}$} & \multirow{2}{*}{$\begin{array}{l}\text { Total } \\
\text { D [i] }\end{array}$} & \multirow{2}{*}{ Peso } \\
\hline & & $\mathbf{0 , 0 0}$ & 0,25 & $\mathbf{0 , 5 0}$ & 0,75 & 1,00 & & $\mathbf{0 , 0 0}$ & 0,25 & $\mathbf{0 , 5 0}$ & $\mathbf{0 , 7 5}$ & 1,00 & & \\
\hline 1 & \begin{tabular}{llr} 
5.1a. El gobierno \\
de TSI, iGarantiza \\
la & \multicolumn{2}{r}{ definición, } \\
implementación & y \\
seguimiento & \\
constante a & los \\
procesos & & que \\
vinculan & & la \\
estrategia con & la \\
cartera de & los \\
proyectos & & de \\
inversión & & \\
habilitadas por las \\
TSI?.
\end{tabular} & 0 & 1 & 0 & 3 & 3 & 0,79 & 0 & 5 & 2 & 0 & 0 & 0,32 & 1,00 \\
\hline 2 & $\begin{array}{lr}\text { 5.1b. El gobierno } \\
\text { de TSI, ¿Garantiza } \\
\text { la definición } \\
\text { impulso de la } \\
\text { implementación de } \\
\text { un marco } & \text { de } \\
\text { gestión } & \text { de } \\
\text { programas } & \text { de } \\
\text { proyectos } & \text { de } \\
\text { inversión } & \\
\text { habilitados por las } \\
\text { TSI con el fin de } \\
\text { aumentar el valor } \\
\text { percibido por el } \\
\text { negocio } & \text { e } \\
\text { interesados?. }\end{array}$ & 0 & 0 & 2 & 3 & 4 & 0,81 & 0 & 0 & 2 & 2 & 3 & 0,79 & 1,00 \\
\hline 3 & $\begin{array}{l}\text { 5.1c. El gobierno } \\
\text { de TSI, ¿Garantiza } \\
\text { la creación de valor } \\
\text { a través del } \\
\text { incremento de la } \\
\text { calidad en los } \\
\text { procesos y la toma } \\
\text { de decisiones?. }\end{array}$ & 0 & 0 & 2 & 4 & 3 & 0,78 & 0 & 0 & 2 & 1 & 4 & 0,82 & 1,00 \\
\hline 4 & $\begin{array}{l}\text { 5.1d. El gobierno } \\
\text { de TSI, ¿Garantiza } \\
\text { un proceso para } \\
\text { crear nuevo valor } \\
\text { por el uso de las } \\
\text { TSI, que se alinee } \\
\text { con la estrategia } \\
\text { organizacional?. }\end{array}$ & 0 & 2 & 2 & 3 & 0 & 0,54 & 0 & 2 & 5 & 0 & 0 & 0,43 & 1,00 \\
\hline \multicolumn{7}{|c|}{ Valor de la Implantación: IMSC } & \multicolumn{8}{|c|}{0,60} \\
\hline
\end{tabular}




\begin{tabular}{|c|c|c|c|c|c|c|c|c|c|c|c|c|c|c|}
\hline \multirow{2}{*}{$\begin{array}{l}\text { Criterio: } \\
\begin{array}{l}\text { Sub- } \\
\text { criterio: }\end{array}\end{array}$} & \multicolumn{9}{|l|}{ 5. Procesos } & \multicolumn{5}{|c|}{ Medición Implantación } \\
\hline & \multicolumn{9}{|c|}{ 5.2. Necesidades de información. } & \multicolumn{2}{|c|}{$\begin{array}{l}\text { Ponderación } \\
\text { [PIM]: }\end{array}$} & \multicolumn{3}{|c|}{0,40} \\
\hline \multirow{2}{*}{ [i] } & \multirow{2}{*}{$\begin{array}{l}\text { Dim } \\
\text { [i] }\end{array}$} & \multicolumn{5}{|c|}{$\begin{array}{c}\text { Valoración Importancia } \\
\text { I [i] }\end{array}$} & \multirow{2}{*}{$\begin{array}{l}\text { Total } \\
\text { I [i] }\end{array}$} & \multicolumn{5}{|c|}{$\begin{array}{c}\text { Valoración Difusión } \\
\text { D [i] }\end{array}$} & \multirow{2}{*}{$\begin{array}{l}\text { Total } \\
\text { D [i] }\end{array}$} & \multirow{2}{*}{ Peso } \\
\hline & & $\mathbf{0 , 0 0}$ & 0,25 & $\mathbf{0 , 5 0}$ & 0,75 & 1,00 & & $\mathbf{0 , 0 0}$ & 0,25 & $\mathbf{0 , 5 0}$ & 0,75 & $\mathbf{1 , 0 0}$ & & \\
\hline 1 & $\begin{array}{ll}\text { 5.2a. El gobierno de } \\
\text { TSI, ¿Garantiza un } \\
\text { conjunto } \\
\text { objetivos, } \\
\text { mediciones, metas y } \\
\text { comparativas } \\
\text { rendimiento de } \\
\text { interés para el } \\
\text { negocio y otras } \\
\text { partes interesadas } \\
\text { relevantes?. }\end{array}$ & 0 & 1 & 2 & 4 & 0 & 0,61 & 0 & 1 & 3 & 3 & 0 & 0,57 & 1,00 \\
\hline 2 & $\begin{array}{l}\text { 5.2b. El gobierno de } \\
\text { TSI, ¿Garantiza un } \\
\text { proceso para } \\
\text { recoger datos } \\
\text { puntuales y exactos } \\
\text { para informar sobre } \\
\text { el progreso frente a } \\
\text { los objetivos } \\
\text { estratégicos de la } \\
\text { organización?. }\end{array}$ & 0 & 3 & 4 & 0 & 0 & 0,39 & 0 & 3 & 3 & 1 & 0 & 0,43 & 1,00 \\
\hline 3 & \begin{tabular}{lr}
\multicolumn{3}{l}{ 5.2c. El gobierno de } \\
TSI, ¿Garantiza \\
proceso & de \\
monitoreo & que \\
establezca & un \\
método de & Cuadro \\
de Mando Integral \\
que brinde una \\
visión completa del \\
rendimiento r del \\
programa & de \\
proyectos & de \\
inversión & \\
habilitadas por las \\
TSI?.
\end{tabular} & 0 & 3 & 4 & 0 & 0 & 0,39 & 0 & 1 & 2 & 4 & 0 & 0,61 & 1,00 \\
\hline 4 & $\begin{array}{lll}\text { 5.2d. El gobierno de } \\
\text { TSI, ¿Garantiza } \\
\text { proceso } & \text { de } \\
\text { evaluación de la } \\
\text { integridad de la } \\
\text { información y de la } \\
\text { protección de la } \\
\text { propiedad } & \\
\text { intelectual de las } \\
\text { TSI?. }\end{array}$ & 0 & 2 & 5 & 0 & 0 & 0,43 & 0 & 1 & 1 & 5 & 0 & 0,64 & 1,00 \\
\hline \multicolumn{7}{|c|}{ Valor de la Implantación: IMSC } & \multicolumn{8}{|c|}{$\mathbf{0 , 5 7}$} \\
\hline
\end{tabular}




\begin{tabular}{|c|c|c|c|c|c|c|c|c|c|c|c|c|c|c|}
\hline \multirow{2}{*}{$\begin{array}{l}\text { Criterio: } \\
\begin{array}{l}\text { Sub- } \\
\text { criterio: }\end{array}\end{array}$} & \multicolumn{9}{|l|}{ 5. Procesos } & \multicolumn{5}{|c|}{ Medición Aplicación } \\
\hline & \multicolumn{9}{|c|}{ 5.1. Diseño y mejora de procesos de gobierno de valor. } & \multicolumn{2}{|c|}{$\begin{array}{l}\text { Ponderación } \\
\text { [PAP]: }\end{array}$} & \multicolumn{3}{|c|}{0,30} \\
\hline \multirow[t]{2}{*}{ [i] } & \multirow{2}{*}{$\begin{array}{c}\text { Dim } \\
\text { [i] }\end{array}$} & \multicolumn{5}{|c|}{$\begin{array}{l}\text { Valoración Utilización } \\
\text { U [i] }\end{array}$} & \multirow{2}{*}{$\begin{array}{l}\text { Total } \\
\mathbf{U}[i]\end{array}$} & \multicolumn{5}{|c|}{$\begin{array}{l}\text { Valoración Seguimiento } \\
\qquad \mathrm{S}[\mathrm{i}]\end{array}$} & \multirow{2}{*}{$\begin{array}{c}\text { Total } \\
\text { S [i] }\end{array}$} & \multirow[t]{2}{*}{ Peso } \\
\hline & & $\mathbf{0 , 0 0}$ & 0,25 & $\mathbf{0 , 5 0}$ & 0,75 & 1,00 & & $\mathbf{0 , 0 0}$ & 0,25 & $\mathbf{0 , 5 0}$ & 0,75 & 1,00 & & \\
\hline 1 & 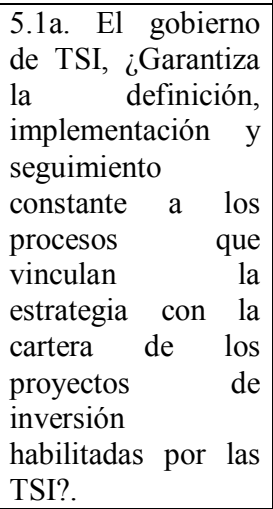 & 0 & 1 & 2 & 4 & 0 & 0,61 & 0 & 2 & 1 & 0 & 4 & 0,71 & 1,00 \\
\hline 2 & $\begin{array}{lr}\text { 5.1b. El gobierno } \\
\text { de TSI, ¿Garantiza } \\
\text { la definición e } \\
\text { impulso de la } \\
\text { implementación de } \\
\text { un marco } & \text { de } \\
\text { gestión } & \text { de } \\
\text { programas } & \text { de } \\
\text { proyectos } & \text { de } \\
\text { inversión } & \\
\text { habilitados por las } \\
\text { TSI con el fin de } \\
\text { aumentar el valor } \\
\text { percibido por el } \\
\text { negocio par? } \\
\text { interesados? }\end{array}$ & 0 & 0 & 3 & 3 & 1 & 0,68 & 0 & 0 & 0 & 3 & 4 & 0,89 & 1,00 \\
\hline 3 & $\begin{array}{l}\text { 5.1c. El gobierno } \\
\text { de TSI, ¿Garantiza } \\
\text { la creación de valor } \\
\text { a través del } \\
\text { incremento de la } \\
\text { calidad en los } \\
\text { procesos y la toma } \\
\text { de decisiones?. }\end{array}$ & 0 & 0 & 0 & 3 & 4 & 0,89 & 0 & 0 & 0 & 3 & 4 & 0,89 & $\mathbf{1 , 0 0}$ \\
\hline 4 & $\begin{array}{l}\text { 5.1d. El gobierno } \\
\text { de TSI, ¿Garantiza } \\
\text { un proceso para } \\
\text { crear nuevo valor } \\
\text { por el uso de las } \\
\text { TSI, que se alinee } \\
\text { con la estrategia } \\
\text { organizacional?. }\end{array}$ & 0 & 0 & 0 & 4 & 3 & 0,86 & 0 & 0 & 1 & 3 & 3 & 0,82 & $\mathbf{1 , 0 0}$ \\
\hline \multicolumn{7}{|c|}{ Valor de la Aplicación: $A P S C$} & \multicolumn{8}{|c|}{0,84} \\
\hline
\end{tabular}




\begin{tabular}{|c|c|c|c|c|c|c|c|c|c|c|c|c|c|c|}
\hline \multirow{4}{*}{$\begin{array}{c}\text { Criterio: } \\
\begin{array}{l}\text { Sub- } \\
\text { criterio: }\end{array} \\
{[i]}\end{array}$} & \multirow{2}{*}{\multicolumn{9}{|c|}{$\begin{array}{l}\text { 5. Procesos } \\
\text { 5.2. Necesidades de información. }\end{array}$}} & \multicolumn{5}{|c|}{ Medición Aplicación } \\
\hline & & & & & & & & & & \multicolumn{2}{|c|}{$\begin{array}{l}\text { Ponderación } \\
\text { [PAP]: }\end{array}$} & \multicolumn{3}{|c|}{0,30} \\
\hline & \multirow{2}{*}{$\begin{array}{c}\text { Dim } \\
\text { [i] }\end{array}$} & \multicolumn{5}{|c|}{$\begin{array}{c}\text { Valoración Utilización } \\
\text { U [i] }\end{array}$} & \multirow{2}{*}{$\begin{array}{l}\text { Total } \\
\text { U [i] }\end{array}$} & \multicolumn{5}{|c|}{$\begin{array}{c}\text { Valoración Seguimiento } \\
\text { S [i] }\end{array}$} & \multirow{2}{*}{$\begin{array}{l}\text { Total } \\
\text { S [i] }\end{array}$} & \multirow{2}{*}{ Peso } \\
\hline & & $\mathbf{0 , 0 0}$ & 0,25 & $\mathbf{0 , 5 0}$ & 0,75 & 1,00 & & $\mathbf{0 , 0 0}$ & 0,25 & $\mathbf{0 , 5 0}$ & 0,75 & $\mathbf{1 , 0 0}$ & & \\
\hline 1 & $\begin{array}{ll}\text { 5.2a. El gobierno de } \\
\text { TSI, ¿Garantiza un } \\
\text { conjunto } \\
\text { objetivos, } \\
\text { mediciones, metas y } \\
\text { comparativas } \\
\text { rendimiento de } \\
\text { interés para el } \\
\text { negocio y otras } \\
\text { partes interesadas } \\
\text { relevantes?. }\end{array}$ & 0 & 1 & 1 & 3 & 2 & 0,71 & 0 & 1 & 2 & 4 & 0 & 0,61 & 1,00 \\
\hline 2 & $\begin{array}{l}\text { 5.2b. El gobierno de } \\
\text { TSI, ¿Garantiza un } \\
\text { proceso para } \\
\text { recoger datos } \\
\text { puntuales y exactos } \\
\text { para informar sobre } \\
\text { el progreso frente a } \\
\text { los objetivos } \\
\text { estratégicos de la } \\
\text { organización?. } \\
\end{array}$ & 0 & 0 & 2 & 2 & 3 & 0,79 & 0 & 0 & 3 & 2 & 2 & 0,71 & 1,00 \\
\hline 3 & \begin{tabular}{lr}
\multicolumn{3}{l}{ 5.2c. El gobierno de } \\
TSI, ¿Garantiza \\
proceso & de \\
monitoreo & que \\
establezca & un \\
método de & Cuadro \\
de Mando Integral \\
que brinde r una \\
visión completa del \\
rendimiento r del \\
programa & de \\
proyectos & de \\
inversión & \\
habilitadas por las \\
TSI?.
\end{tabular} & 0 & 0 & 2 & 1 & 4 & 0,82 & 0 & 0 & 2 & 1 & 4 & 0,82 & 1,00 \\
\hline 4 & $\begin{array}{lll}\text { 5.2d. El gobierno de } \\
\text { TSI, ¿Garantiza } \\
\text { proceso } & \text { de } \\
\text { evaluación de } & \text { la } \\
\text { integridad de la } \\
\text { información y de la } \\
\text { protección de la } \\
\text { propiedad } & \\
\text { intelectual de las } \\
\text { TSI?. }\end{array}$ & 0 & 1 & 3 & 2 & 1 & 0,61 & 0 & 1 & 2 & 3 & 1 & 0,64 & 1,00 \\
\hline \multicolumn{7}{|c|}{ Valor de la Aplicación: $A P S C$} & \multicolumn{8}{|c|}{0,70} \\
\hline
\end{tabular}




\begin{tabular}{|c|c|c|c|c|c|c|c|}
\hline Criterio: & \multicolumn{4}{|l|}{ 5. Procesos } & \multicolumn{3}{|c|}{ Medición Efecto } \\
\hline Sub-criterio: & \multicolumn{4}{|c|}{ 5.1. Diseño y mejora de procesos de gobierno de valor. } & \multicolumn{2}{|c|}{$\begin{array}{l}\text { Ponderación } \\
\text { [PEF]: }\end{array}$} & \multirow{3}{*}{$\begin{array}{c}0,30 \\
\text { Total } \\
\text { V [i] }\end{array}$} \\
\hline \multirow[t]{2}{*}{ [i] } & \multirow{2}{*}{$\begin{array}{c}\text { Dim } \\
\text { [i] }\end{array}$} & \multicolumn{5}{|c|}{$\begin{array}{c}\text { Valoración del Valor Percibido } \\
\text { V [i] }\end{array}$} & \\
\hline & & $\mathbf{0 , 0 0}$ & $\mathbf{0 , 2 5}$ & $\mathbf{0 , 5 0}$ & 0,75 & 1,00 & \\
\hline 1 & $\begin{array}{l}\text { a. Buen funcionamiento de la } \\
\text { estrategia apoyada en los } \\
\text { proyectos de inversión habilitadas } \\
\text { por TSI. }\end{array}$ & 0 & 0 & 0 & 0 & 3 & 1,00 \\
\hline 2 & $\begin{array}{l}\text { b. Buen desempeño de los } \\
\text { programas de proyectos de } \\
\text { inversión habilitadas por TSI. }\end{array}$ & 0 & 0 & 0 & 1 & 2 & 0,92 \\
\hline 3 & $\begin{array}{l}\text { c. Buen desempeño de procesos } \\
\text { creadores de valor a través de } \\
\text { documentos que demuestren su } \\
\text { actualización en el último año. }\end{array}$ & 0 & 0 & 0 & 0 & 3 & 1,00 \\
\hline \multicolumn{7}{|c|}{ Valor del Efecto: $E F S C$} & 0,97 \\
\hline
\end{tabular}

\begin{tabular}{|c|c|c|c|c|c|c|c|}
\hline Criterio: & \multicolumn{4}{|l|}{ 5. Procesos } & \multicolumn{3}{|c|}{ Medición Efecto } \\
\hline Sub-criterio: & \multicolumn{4}{|l|}{ 5.2. Necesidades de información. } & \multicolumn{2}{|c|}{$\begin{array}{l}\text { Ponderación } \\
\text { [PEF]: }\end{array}$} & 0,30 \\
\hline \multirow{2}{*}{ [i] } & \multirow{2}{*}{$\begin{array}{c}\text { Dim } \\
\text { [i] }\end{array}$} & \multicolumn{5}{|c|}{$\begin{array}{l}\text { Valoración del Valor Percibido } \\
\text { V [i] }\end{array}$} & \multirow{2}{*}{$\begin{array}{l}\text { Total } \\
\text { V [i] }\end{array}$} \\
\hline & & $\mathbf{0 , 0 0}$ & $\mathbf{0 , 2 5}$ & $\mathbf{0 , 5 0}$ & 0,75 & 1,00 & \\
\hline 1 & $\begin{array}{l}\text { a. Recursos de información } \\
\text { disponibles para toma de } \\
\text { decisiones. }\end{array}$ & 0 & 0 & 0 & 0 & 3 & 1,00 \\
\hline 2 & $\begin{array}{l}\text { b. Uso de las TSI como medios } \\
\text { para la toma de decisiones. }\end{array}$ & 0 & 0 & 1 & 1 & 1 & 0,75 \\
\hline \multicolumn{7}{|c|}{ Valor del Efecto: $E F S C$} & 0,87 \\
\hline
\end{tabular}
$\mathrm{SC} 1=$
Implantación IM * PIM + Aplicación AP * PAP + Efecto EF * PEF
$\mathrm{SC} 1=$
0,24
$+\quad 0,25$
$+\quad 0,29$
$\mathrm{SC} 1=$
0,78
$\mathrm{SC} 2=$
Implantación IM * PIM + Aplicación AP * PAP + Efecto EF * PEF
$\mathrm{SC} 2=$
0,23
$+\quad 0,21$
$+\quad 0,26$
$\mathrm{SC2}=$
0,70

MEDIDA TOTAL DEL CRITERIO PROCESOS $=\quad \mathbf{0 , 7 4}$ 


\section{Autoevaluación de Proyectos}

CRITERIO: PROYECTOS

\begin{tabular}{|c|l|}
\hline Sub-criterios & \multicolumn{1}{|c|}{ Descripción } \\
\hline 6.1. Financieros y No financieros. & $\begin{array}{l}\text { Se evalúa cómo las direcciones de negocio administran y gestionan los } \\
\text { proyectos de inversión y no inversión habilitadas por las TSI, y que son } \\
\text { prioritarias por la generación de valor. }\end{array}$ \\
\hline
\end{tabular}

\begin{tabular}{|c|l|}
\hline Criterio de Valor: & 6. Proyectos \\
\hline Sub-criterio & \multicolumn{1}{c|}{ Dimensiones } \\
\hline \multirow{2}{*}{ 6.1. Financieros y No financieros. } & $\begin{array}{l}\text { 6.1a. El gobierno de TSI, ¿Garantiza la plena comprensión de la alta dirección } \\
\text { del negocio que hay varios tipos de portafolios de inversión que difieren en } \\
\text { complejidad y grado de libertad a la hora de recibir y asignar fondos?. }\end{array}$ \\
\cline { 2 - 2 } & $\begin{array}{l}\text { 6.1b. El gobierno de TSI, ¿Garantiza un modelo de categorización de proyectos } \\
\text { de inversión debido a la complejidad con que se gestionan?. }\end{array}$ \\
\hline
\end{tabular}

\begin{tabular}{|c|l|}
\hline Sub-criterio & \multicolumn{1}{c|}{ Valor percibido } \\
\hline \multirow{2}{*}{ 6.1. Financieros y No financieros. } & a. Valor desarrollado por los portafolios. \\
\cline { 2 - 2 } & b. Cumplimiento de la normativa legal. \\
\hline
\end{tabular}




\begin{tabular}{|c|c|c|c|c|c|c|c|c|c|c|c|c|c|c|}
\hline Criterio: & \multicolumn{9}{|l|}{ 6. Proyectos } & \multicolumn{5}{|c|}{ Medición Implantación } \\
\hline $\begin{array}{l}\text { Sub- } \\
\text { criterio: }\end{array}$ & \multicolumn{9}{|c|}{ 6.1. Financieros y No financieros. } & $\begin{array}{l}\text { Pond } \\
{[\text { PIM }}\end{array}$ & ación & \multicolumn{3}{|c|}{0,40} \\
\hline \multirow{2}{*}{ [i] } & \multirow{2}{*}{$\begin{array}{l}\text { Dim } \\
\text { [i] }\end{array}$} & \multicolumn{5}{|c|}{$\begin{array}{l}\text { Valoración Importancia } \\
\text { I [i] }\end{array}$} & \multirow{2}{*}{$\begin{array}{l}\text { Total } \\
\text { I [i] }\end{array}$} & \multicolumn{5}{|c|}{$\begin{array}{c}\text { Valoración Difusión } \\
\text { D [i] }\end{array}$} & \multirow{2}{*}{$\begin{array}{l}\text { Total } \\
\text { D [i] }\end{array}$} & \multirow{2}{*}{ Peso } \\
\hline & & $\mathbf{0 , 0 0}$ & 0,25 & $\mathbf{0 , 5 0}$ & 0,75 & 1,00 & & $\mathbf{0 , 0 0}$ & 0,25 & $\mathbf{0 , 5 0}$ & 0,75 & 1,00 & & \\
\hline 1 & $\begin{array}{lr}\text { 6.1a. El gobierno } \\
\text { de TSI, ¿Garantiza } \\
\text { la } & \text { plena } \\
\text { comprensión de la } \\
\text { alta dirección del } \\
\text { negocio que hay } \\
\text { varios tipos } \\
\text { portafolios } \\
\text { inversión de } \\
\text { difieren que } \\
\text { complejidad r en } \\
\text { grado de libertad a } \\
\text { la hora de recibir y } \\
\text { asignar fondos?. }\end{array}$ & 1 & 2 & 0 & 4 & 0 & 0,50 & 0 & 2 & 1 & 4 & 0 & 0,57 & 1,00 \\
\hline 2 & $\begin{array}{lr}\text { 6.1b. El gobierno } \\
\text { de TSI, ¿Garantiza } \\
\text { un modelo de } \\
\text { categorización de } \\
\text { proyectos de } \\
\text { inversión debido a } \\
\text { la complejidad con } \\
\text { que se gestionan?. }\end{array}$ & 0 & 0 & 3 & 2 & 2 & 0,71 & 0 & 1 & 1 & 5 & 0 & 0,64 & 1,00 \\
\hline \multicolumn{7}{|c|}{ Valor de la Implantación: IMSC } & \multicolumn{8}{|c|}{0,61} \\
\hline
\end{tabular}




\begin{tabular}{|c|c|c|c|c|c|c|c|c|c|c|c|c|c|c|}
\hline Criterio: & \multicolumn{9}{|l|}{ 6. Proyectos } & \multicolumn{5}{|c|}{ Medición Aplicación } \\
\hline $\begin{array}{l}\text { Sub- } \\
\text { criterio: }\end{array}$ & \multicolumn{9}{|c|}{ 6.1. Financieros y No financieros. } & $\begin{array}{l}\text { Ponde } \\
\text { [PAP] }\end{array}$ & ación & \multicolumn{3}{|c|}{0,30} \\
\hline \multirow{2}{*}{ [i] } & \multirow{2}{*}{$\begin{array}{c}\text { Dim } \\
\text { [i] }\end{array}$} & \multicolumn{5}{|c|}{$\begin{array}{c}\text { Valoración Utilización } \\
\text { U [i] }\end{array}$} & \multirow{2}{*}{$\begin{array}{l}\text { Total } \\
\text { U [i] }\end{array}$} & \multicolumn{5}{|c|}{$\begin{array}{c}\text { Valoración Seguimiento } \\
\text { S [i] }\end{array}$} & \multirow{2}{*}{$\begin{array}{l}\text { Total } \\
\text { S [i] }\end{array}$} & \multirow{2}{*}{ Peso } \\
\hline & & $\mathbf{0 , 0 0}$ & $\mathbf{0 , 2 5}$ & $\mathbf{0 , 5 0}$ & 0,75 & $\mathbf{1 , 0 0}$ & & $\mathbf{0 , 0 0}$ & 0,25 & $\mathbf{0 , 5 0}$ & 0,75 & $\mathbf{1 , 0 0}$ & & \\
\hline 1 & $\begin{array}{lr}\text { 6.1a. El gobierno } \\
\text { de TSI, ¿Garantiza } \\
\text { la } & \text { plena } \\
\text { comprensión de la } \\
\text { alta dirección del } \\
\text { negocio que hay } \\
\text { varios tipos } \\
\text { portafolios } \\
\text { inversión de } \\
\text { difieren que } \\
\text { complejidad } \\
\text { grado de libertad a } \\
\text { la hora de recibir y } \\
\text { asignar fondos?. }\end{array}$ & 1 & 1 & 3 & 2 & 0 & 0,46 & 0 & 0 & 1 & 3 & 3 & 0,82 & 1,00 \\
\hline 2 & $\begin{array}{l}\text { 6.1b. El gobierno } \\
\text { de TSI, ¿Garantiza } \\
\text { un modelo de } \\
\text { categorización de } \\
\text { proyectos de } \\
\text { inversión debido a } \\
\text { la complejidad con } \\
\text { que se gestionan?. }\end{array}$ & 1 & 1 & 0 & 2 & 3 & 0,68 & 0 & 0 & 2 & 2 & 3 & 0,79 & 1,00 \\
\hline \multicolumn{7}{|c|}{ Valor de la Aplicación: $A P S C$} & \multicolumn{8}{|c|}{0,80} \\
\hline
\end{tabular}

\begin{tabular}{|c|c|c|c|c|c|c|c|}
\hline Criterio: & \multicolumn{4}{|l|}{ 6. Proyectos } & \multicolumn{3}{|c|}{ Medición Efecto } \\
\hline Sub-criterio: & \multicolumn{4}{|l|}{ 6.1. Financieros y No financieros. } & \multicolumn{2}{|c|}{$\begin{array}{l}\text { Ponderación } \\
\text { [PEF]: }\end{array}$} & 0,30 \\
\hline \multirow[t]{2}{*}{ [i] } & \multirow{2}{*}{$\begin{array}{c}\text { Dim } \\
\text { [i] }\end{array}$} & \multicolumn{5}{|c|}{$\begin{array}{c}\text { Valoración del Valor Percibido } \\
\text { V [i] }\end{array}$} & \multirow{2}{*}{$\begin{array}{l}\text { Total } \\
\text { V [i] }\end{array}$} \\
\hline & & $\mathbf{0 , 0 0}$ & 0,25 & $\mathbf{0 , 5 0}$ & 0,75 & 1,00 & \\
\hline 1 & $\begin{array}{l}\text { a. Valor desarrollado por los } \\
\text { portafolios. }\end{array}$ & 0 & 0 & 1 & 1 & 5 & 0,89 \\
\hline 2 & $\begin{array}{l}\text { b. Cumplimiento de la normativa } \\
\text { legal. }\end{array}$ & 0 & 1 & 2 & 0 & 4 & 0,75 \\
\hline \multicolumn{7}{|c|}{ Valor del Efecto: $E F S C$} & $\mathbf{0 , 8 2}$ \\
\hline
\end{tabular}

$\mathrm{SC} 1=$

$\mathrm{SC} 1=$

$\mathrm{SC} 1=$
Implantación IM * PIM + Aplicación AP * PAP + Efecto EF * PEF
0,25
$+\quad 0,23$
$+\quad 0,25$

0,73

MEDIDA TOTAL DEL CRITERIO PROYECTOS $=\quad 0,73$ 


\section{Modelo de Evaluación de Calidad Gobierno de Tecnologías y Sistemas de Información Basada en Valor}

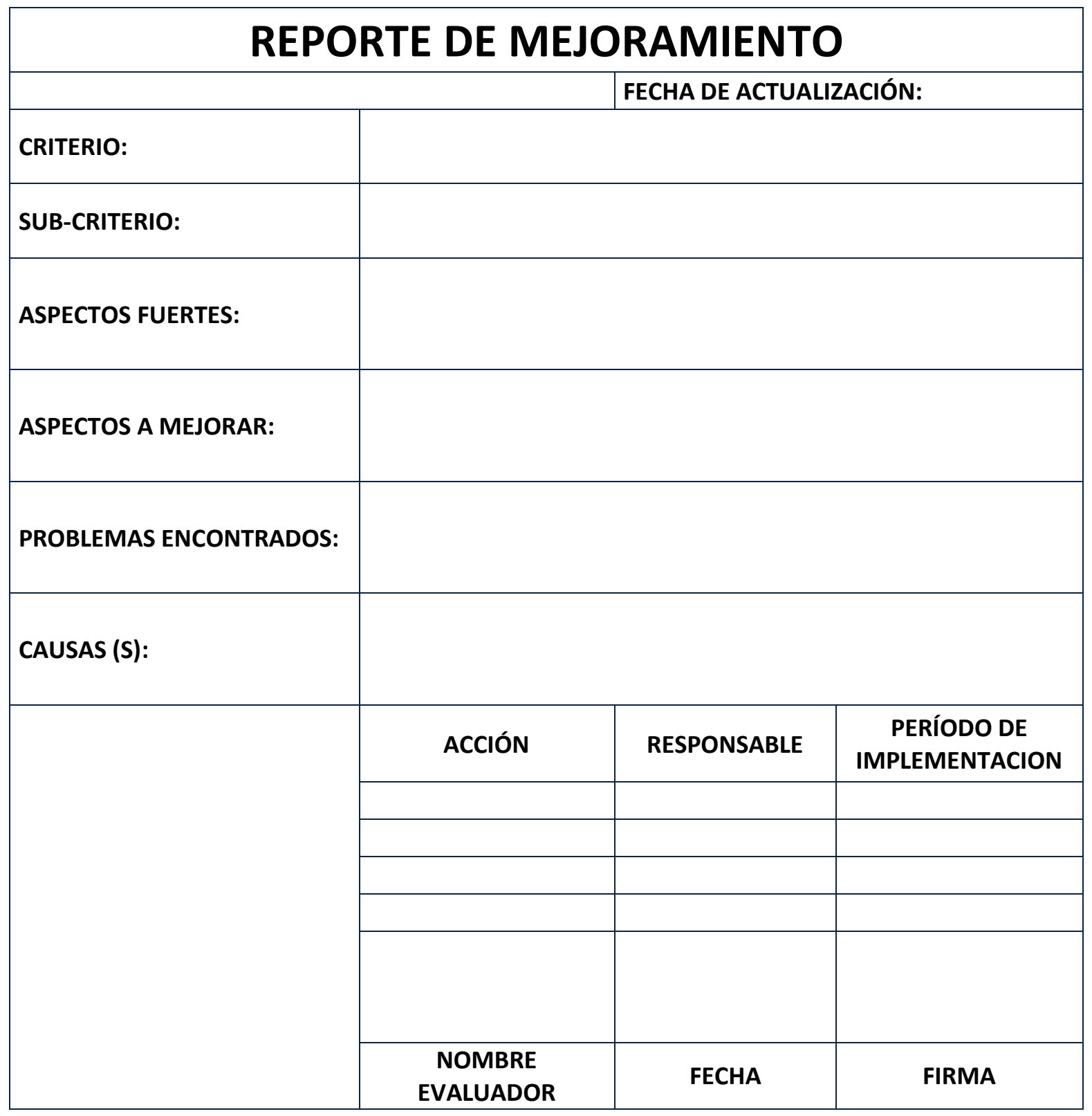

